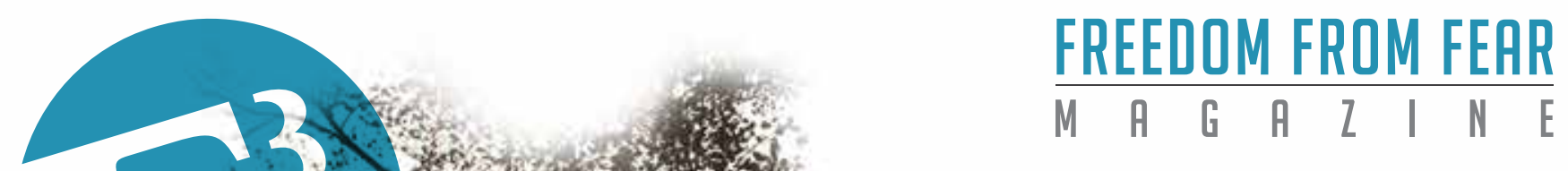

PLANNING RESILIENCY SHAPING THE FUTURE
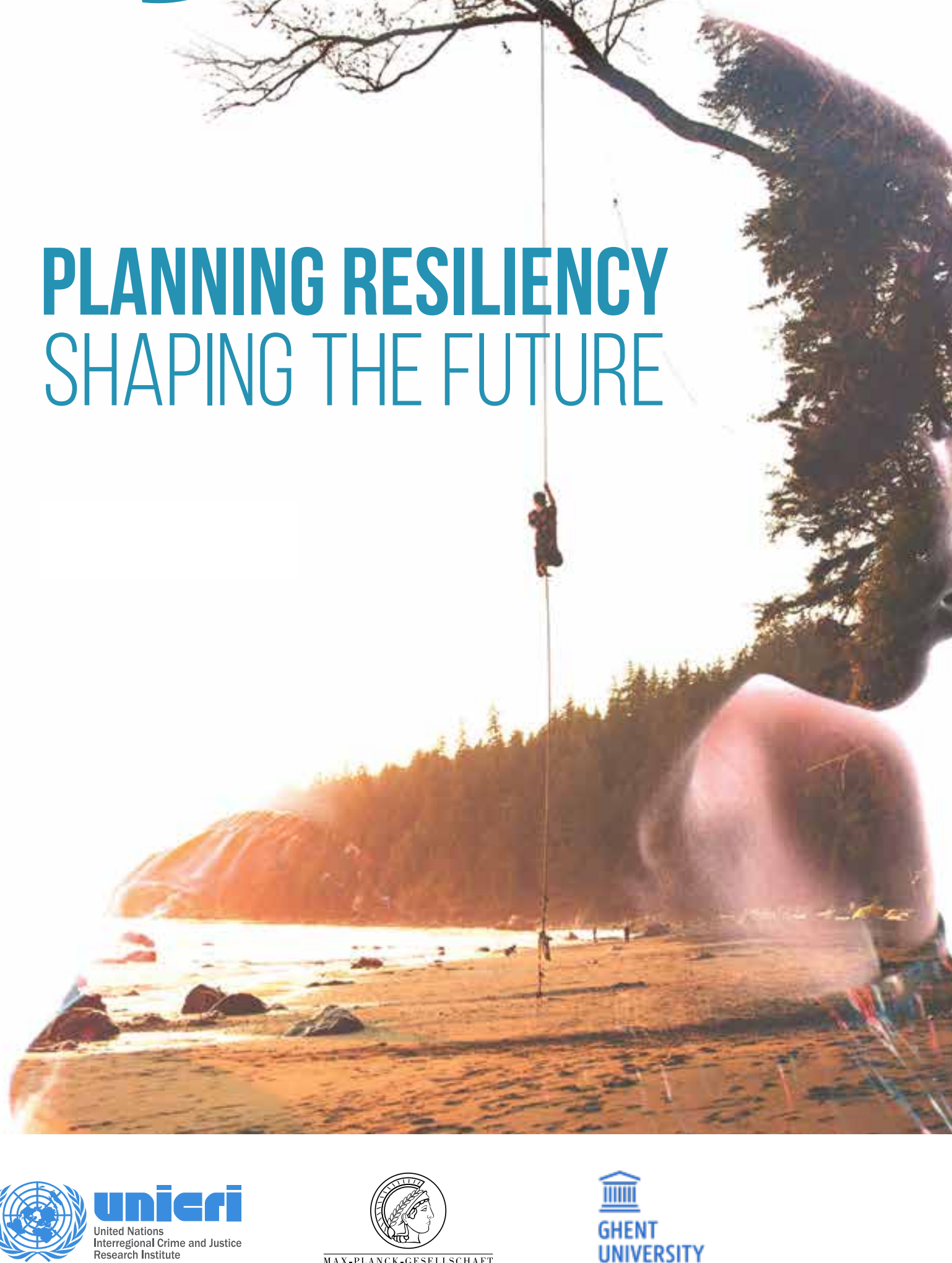

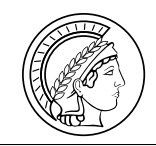

MAX-PLANCK-GESELLSCHAF
시III

GHENT

UNIVERSITY 


\section{I am}

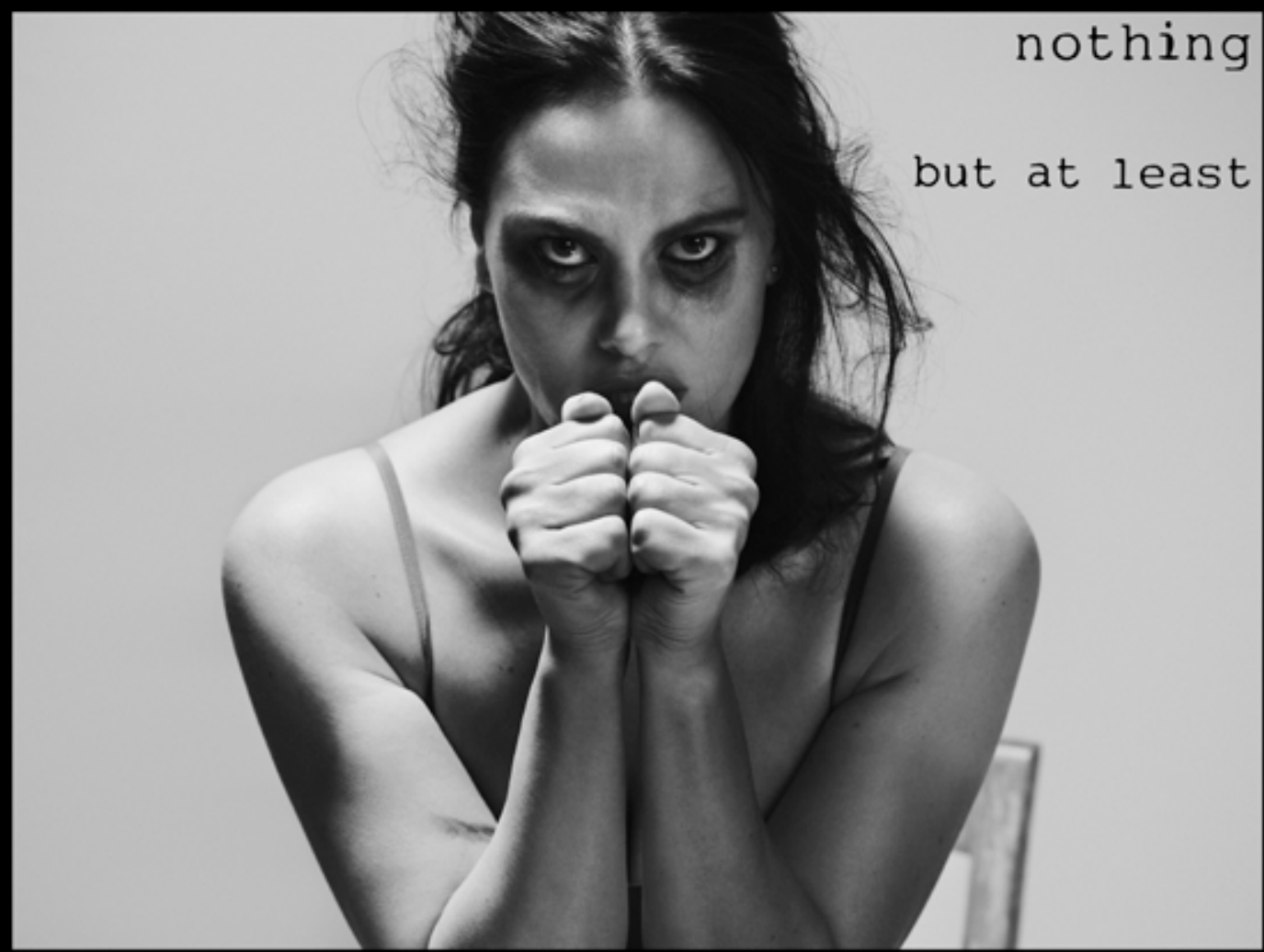

nOW

I am not you

even if you pummel me to the floor once again in my nightmares
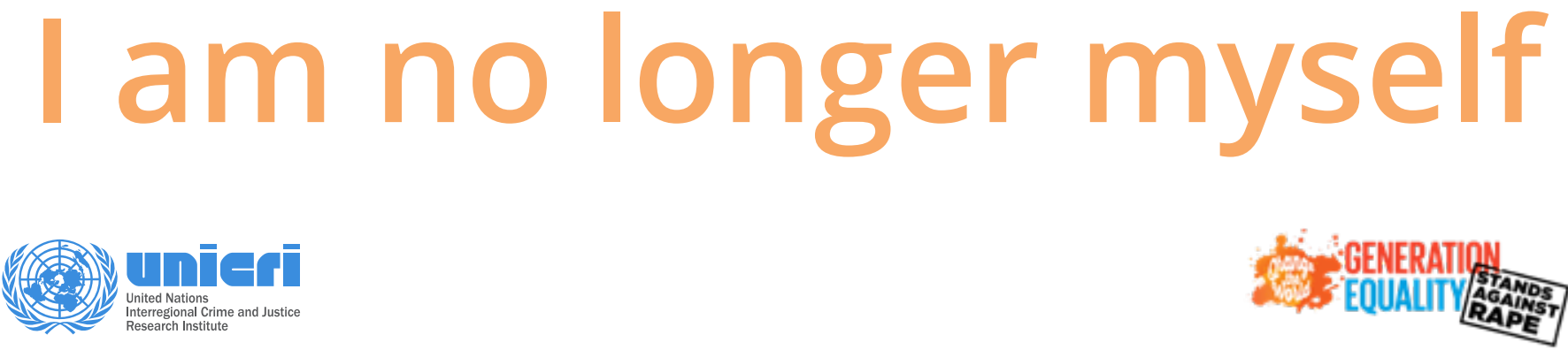

\section{INTERNATIONAL DAY FOR THE ELIMINATIONOF VIOLENCE AGAINST WOMEN 25 NOVEMBER 2019}

The actress Melania Dalla Costa and the photographer Dimitri Dimitracacos joined UNICRI in the development of the campaign for the elimination of violence against women. The campaign is a tribute to the victims and it describes the painful process that leads to the destruction of an identity. An identity that can reborn through the strength that only solidarity and help can generate. The campaign is also launching a strong message to violent people: their abuses are a form of weakness, a denial of our human nature. 

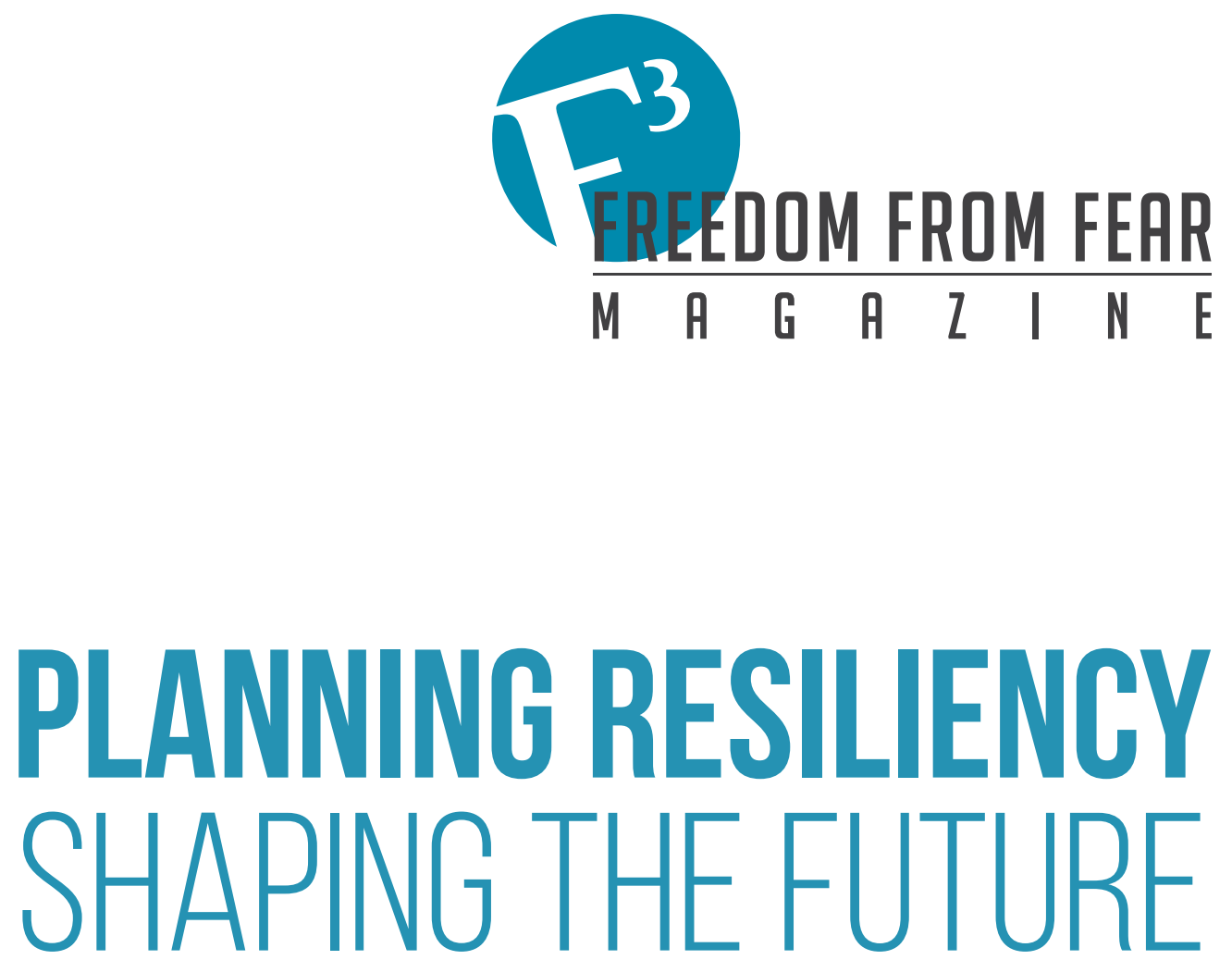

G9

Confusion of goals and perfection of means seems, in my opinion, to characterize our age 
Editorial Board

UNICRI

Bettina Tucci Bartsiotas

Marina Mazzini

Leif Villadsen

Max-Planck Institute

Hans-Jörg Albrecht

Ulrike Auerbach

Michael Kilchling

Ghent University

Tom Vander Beken

Jelle Janssens

Noel Klima
Editor in Chief

Marina Mazzini

Editorial Team

Merwan Benamor

Fabrizio De Rosa

Robin Hughes

Jinyi Li

Marina Mazzini
Graphic and layout

Antonella Bologna

Cover design

Beniamino Garrone

Website designer

Davide Dal Farra

\section{Disclaimer}

The views expressed are those of the authors and do not necessarily reflect the views and positions of the United Nations. Authors are not responsible for the use that might be made of the information contained in this publication.

Contents of the publication may be quoted or reproduced, provided that the source of information is acknowledged.

The designations employed and the presentation of the material in this publication do not imply the expression of any opinion whatsoever on the part of the Secretariat of the United Nations and UNICRI, concerning the legal status of any country, territory, city or area or of its authorities, or concerning the delimitation of its frontiers or boundaries.

The mention of specific institutions, companies or of certain manufacturers' products does not imply that they are endorsed or recommended by the Secretariat of the United Nations or UNICRI in preference to others of a similar nature that are not mentioned. 


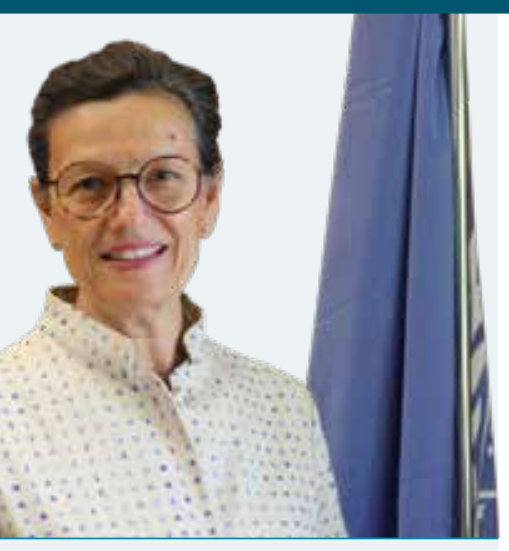

by Bettina Tucci Bartsiotas Director a.i. of UNICRI

The development of modern technologies along with the acceleration of globalization and increasing inequalities are generating new paradigms and unpredictable risks. This has huge impact on populations all over the world. Today, millions of people are coping with crises stemming from climate change, violent extremism, organized crime, and a general lack of vision on how to develop sustainable responses. Threats, uncertainties and socioeconomic disparities, and the need for new effective and innovative approaches are symbiotic in every corner of the world.

Over the recent years, the word "resilience" is occupying the vocabulary of the global community. Why? It appears that we have entered a phase where we must cope with problems and adversities that we failed to anticipate and address from the very beginning. The word resiliency per se represents an admission of the need to survive and adapt to a variety of exponential changes that find us unprepared. "Resilience is an individual's ability to generate biological, psychological and social factors to resist, adapt and strengthen itself, when faced with an environment of risk, generating individual, social and moral success." ${ }^{\text {"1 }}$ Resilience expresses the abilities of people, communities and systems to deal with challenges or crises.

In the field of crime and justice, developing resilience within and among institutions, social systems, communities and individuals requires a thorough knowledge of its causes and the possible ways to prevent escalation.

This issue of F3 includes articles describing different areas where resilience should be built. They offer a variety of perspectives, illustrating the necessity of enhancing resilience in institutions, systems and societies to achieve human rights for all, prevent and counter violent extremism and mitigate risks and respond to threats. The articles of this issue are closely connected to the Sustainable Development Goal 16 of the United Nations 2030 Agenda, which aims to promote peaceful and inclusive societies, provide access to justice and strength-

1 Colchado, Oscar Chapital. (2018). "Resiliencia: Una propuesta de concepto y de etapas de desarrollo." Instituto Nacional para la Evaluación de la Educación. https://www.academia.edu/38119923/ Resiliencia Una propuesta de concepto y de etapas de desarrollo 
en institutions and accountability. In addition, Goals 4, 5, 9, 10, 11, 12, 14 are also referred in these articles, embodying the connections between resilience and education, gender equality, online security, youth empowerment, community policies, environmental crimes and so on.

The importance of building collective resilience cannot be ignored. For example, once a crime is committed, a criminal justice institution focusing on both the processes of desistance and recovery, and the harm endured by both victims and perpetrators, helps ensure true justice. When confronted with challenges and crises, countries with enhanced international cooperation and harmonized legal frameworks to the relevant conventions and treaties have shown to be more resilient. Enhancing community resilience facilitates the promotion of social justice, development and the protection of vulnerable groups. Collaborative communities can play a significant role in shaping the future of young people, their ability to find a role in the society through education and skills development. Building resilience at the individual level helps people better tackle current and potential crises, for instance, taking personal actions to guarantee their online privacy as well as recognizing sensitive and violent information in social media and the Internet to deal with cybercrime or cyber violence.

We are standing at a crossroad, and resilience helps guide us to a positive direction. To achieve a world of respect for dignity and diversity, the rule of law, justice and development, all sides must act together and make collaborative efforts to implement comprehensive responses.

Building resilient societies give us the possibility of reshaping a resilient world.

As a central and transformative guide of the 2030 Agenda and its SDGs, the promise "Leaving no one behind" still faces challenges and threats stemming from inequalities and vulnerabilities. Recent days have witnessed a wave of demonstrations around the world, from the Middle East to Latin America and the Caribbean... from Europe to Africa and Asia. Behind those protests in cities across the world, there are economic issues relating to systems and political demands coming from people. António Guterres, Secretary-General of the United Nations said: "The global wave of demonstrations we are witnessing shows a growing lack of trust between people and political establishments. People are hurting and want to be heard. We must listen to the real problems of real people, and work to restore the social contract." 2

2 https://twitter.com/antonioguterres/status/1187794920846876672?lang=en 
Researchers identified resilience as a process, not a trait. From the lessons learned all along this adaptation process, we may extrapolate the answers we need to use the governance tools, knowledge and cooperation mechanisms to eradicate the problems we are facing. Instead of limits itself to building resilience, a real advanced society should be able to prevent crises before it is too late and before an adaptation is needed. A real advanced society requires focus pertaining to the commitment of doing what is possible before a situation gets to the point of crisis and should be able to expand its advances.

One day we will achieve a world where no one is left behind; the hope is that this world will have created the conditions for true sustainability. Charles Darwin said that "It is not the most intellectual or the strongest of species that survives; but the species that survives is the one that is able to adapt to and adjust best to the changing environment in which it finds itself." Compared to the past, changes are occurring at an exponential rate that obliges us to develop the capacity to anticipate and mitigate negative consequences. We want the change to continue for the best of humankind, minimizing uncertainty, fear, pressure and lack of vision. We need to develop the tools and resources to build resilience.

The only vision that can lead humankind is the one the United Nations has offered since its very creation, almost 75 years ago. The Charter of the United Nations includes the antidotes to address our current problems. We just need the political will to implement a concept of global solidarity. I hope we will reach the day when we replace resiliency with global solidarity to be one step ahead of the challenges of our global village. 


\section{CONTENTS}

1 Women and prevention of violent extremism: does it work - and if so, how?

by Edit Schlaffer

8 Community resilience: insights from UNICRI experience in the Sahel-Maghreb

by Danielle Hull, Tamara Nešković, Manuela Brunero

12 No one is left behind in the fight of the EU against violent extremism

by Deborah Phares

18 Youth engagement and resilience against violent extremism in the Sahel

22 How to train professionals for managing the contradictions of a multiethnic society? by Loretta Fabbri and Claudio Melacarne

InFocus

Who is susceptible to the call of political violence? A study of differential susceptibility and situational resistance to exposure to online violent extremism

by Lieven J.R. Pauwels and Wim Hardyns

Youth

The phenomenon of returning foreign terrorist fighters and its challenges by Barbara Stadlbauer
Lived-experience-and-strengths-based strategies for persons with mental illness who offended and their family members

by Ciska Wittouck, Freya Vander Laenen, Stijn Vandevelde, Sara Rowaert, Natalie Aga, Sofie Van Roeyen, Kurt Audenaert, Wouter Vanderplasschen, Tom Vander Beken

58 A more humane approach to addressing the harm of criminal behaviour

by Tim Chapman and Annemieke Wolthuis 
64 When Sport Breaks Down Walls

by Massimiliano Montanari

68

Sapere Aude: a social mentorship project which uses education to promote social justice for children and young people living in the public care system

by Milena Westermann

74 SDG 14: stepping up international efforts to tackle ocean plastic pollution

by Jivan Dasgupta

InFocus

Obligation to Investigate , Minimum Investigative Standards under Article 2 of the ECHR, and Their

Applicability to Post-conflict Situations

by Andrey Antonov

88 Collective Human Action against Deepfakes by Pierluigi Casale, Vladimir Osin, Grazina Raguckaja and Giulia Violatto

929 Online Privacy Myths Keeping You from Maximum Online Privacy

by Harold Kilpatrick

InFocus

The Companion to International Humanitarian

Law. A practical approach to the dissemination

98

of International Humanitarian Law

by Drazan Djukić and Niccolò Pons

Youth

Why collaborative communities are the future of youth empowerment and education

106

by Rudradeb Mitra

Youth

International law on the recruitment

114

by Mira Luoma

Interview

The legacy of Giovanni Falcone: never lower your head, be brave and always fulfil your commitments until the end

Interview with Maria Falcone

134 The Resiliency of the UN staff member's Oath of Office

by Andrea Angeli

vii 


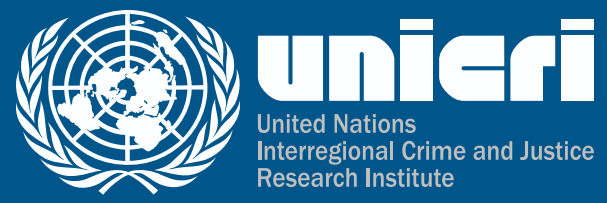

\section{THE NEXUS BETWEEN TRANSNATIONAL ORGANIZED CRIME AND TERRORISM}

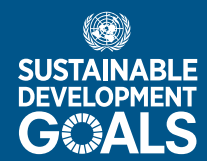

The convergence of criminal and terrorist groups undermines peace, security and economic development.

Their illicit activities span from the trafficking of arms, persons, drugs, artefacts and natural resources to corruption, kidnapping, extortion and bank robbery. UNICRI, with the support of the Netherlands and under the auspices of the

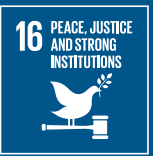

Global Counterterrorism Forum, developed The Hague Good Practices on the Nexus between Transnational Organized Crime and Terrorism to support Member States policies.

The Nexus Policy Toolkit provides practical examples on how to better understand the Nexus and formulate effective responses.

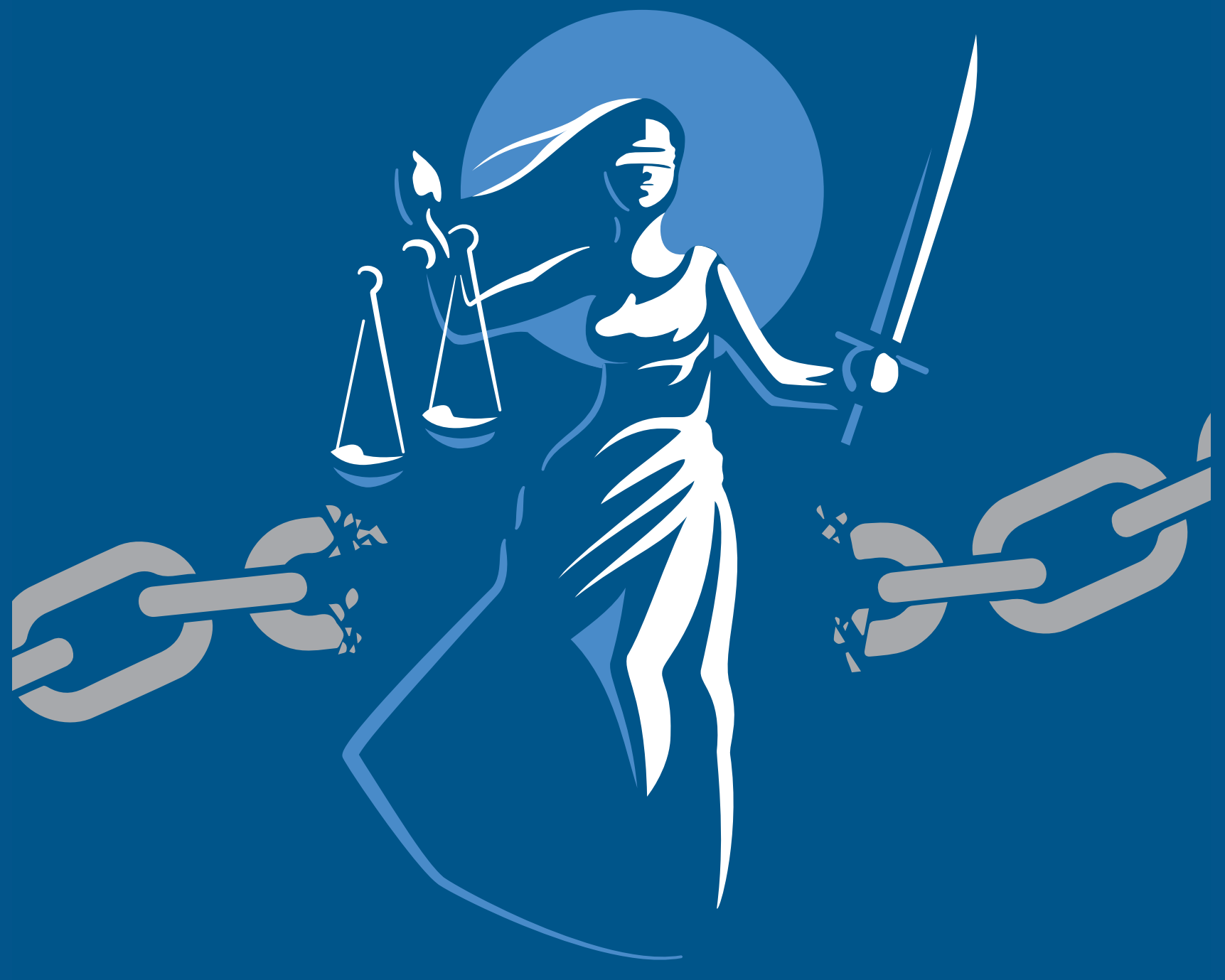




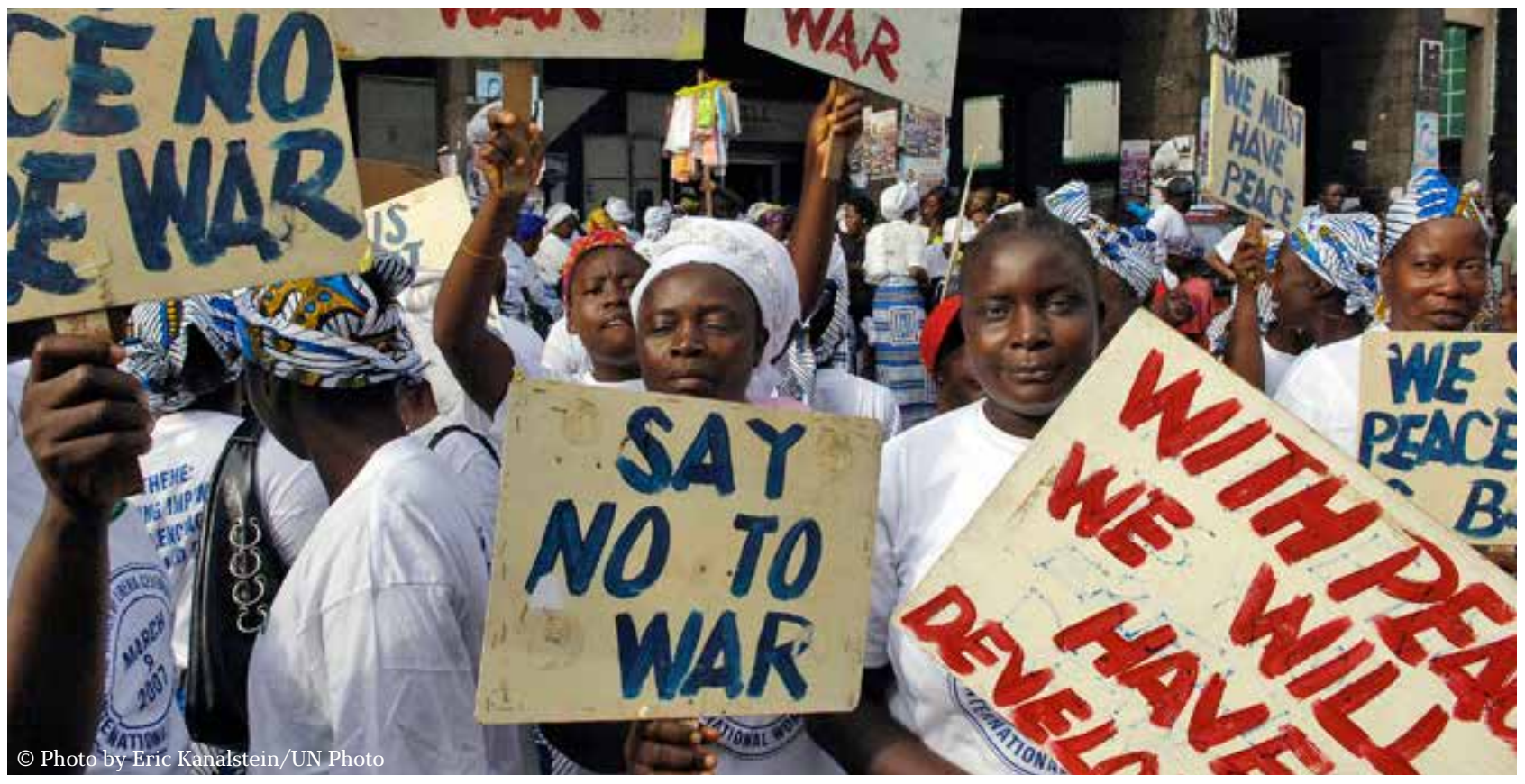

Security is a human right which requires the cooperation of governmental and nongovernmental actors. The global investment must focus on an integrated bottom-up security architecture. A wide-ranging dialogue around security should have one common goal: not only to recognise democratic and legal structures, but also to exploit the opportunities that they present.

Freedom and democracy are the cornerstones of an open society. Nevertheless, freedom can engender fear and resistance, and we must continue to fight for and defend it with the tools of critical thinking, targeted education and continuous encouragement. This is a clear mandate.

Paul Kirchhof, an expert in German constitutional law, speaks of courageous freedom. Only when we find the courage and convic- tion to take new approaches, undaunted by the risks, will we succeed in rooting people - young people in particular - in the place where they belong: in their families and in our society. Only then will we succeed in retrieving those who have already succumbed to extremist ideologies.

How can we achieve this? Civil society composed of women and men is key.

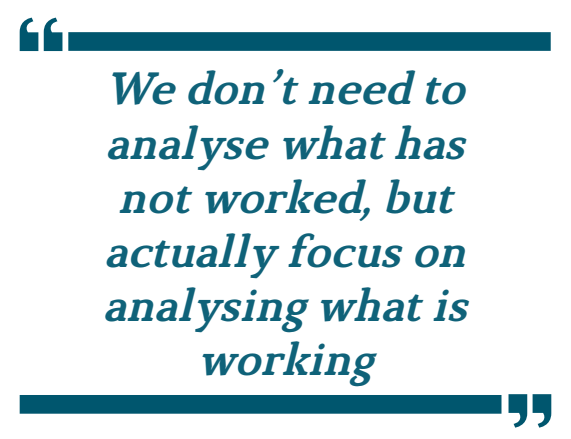

It is in the local contexts of the family, educational institutions, social services and leisure-time education that exclusion and discrimination first become apparent. Two significant groups are on the frontlines when it comes to these individual frustrations: those who seduce and recruit and those who protect and safeguard. It is a competition between ideologies and emotions which we must address in a timely fashion with expertise and empathy.

This challenge can only be met if we employ the right set of tools: educational opportunities, access to the job market and enforcing psychological resilience at all levels of society. The overarching aim of all extremist groups and ideologies is to undermine democracy and social cohesion. It is therefore necessary to take an approach which encompasses an all of society approach in this highly sensitive and complex arena. 


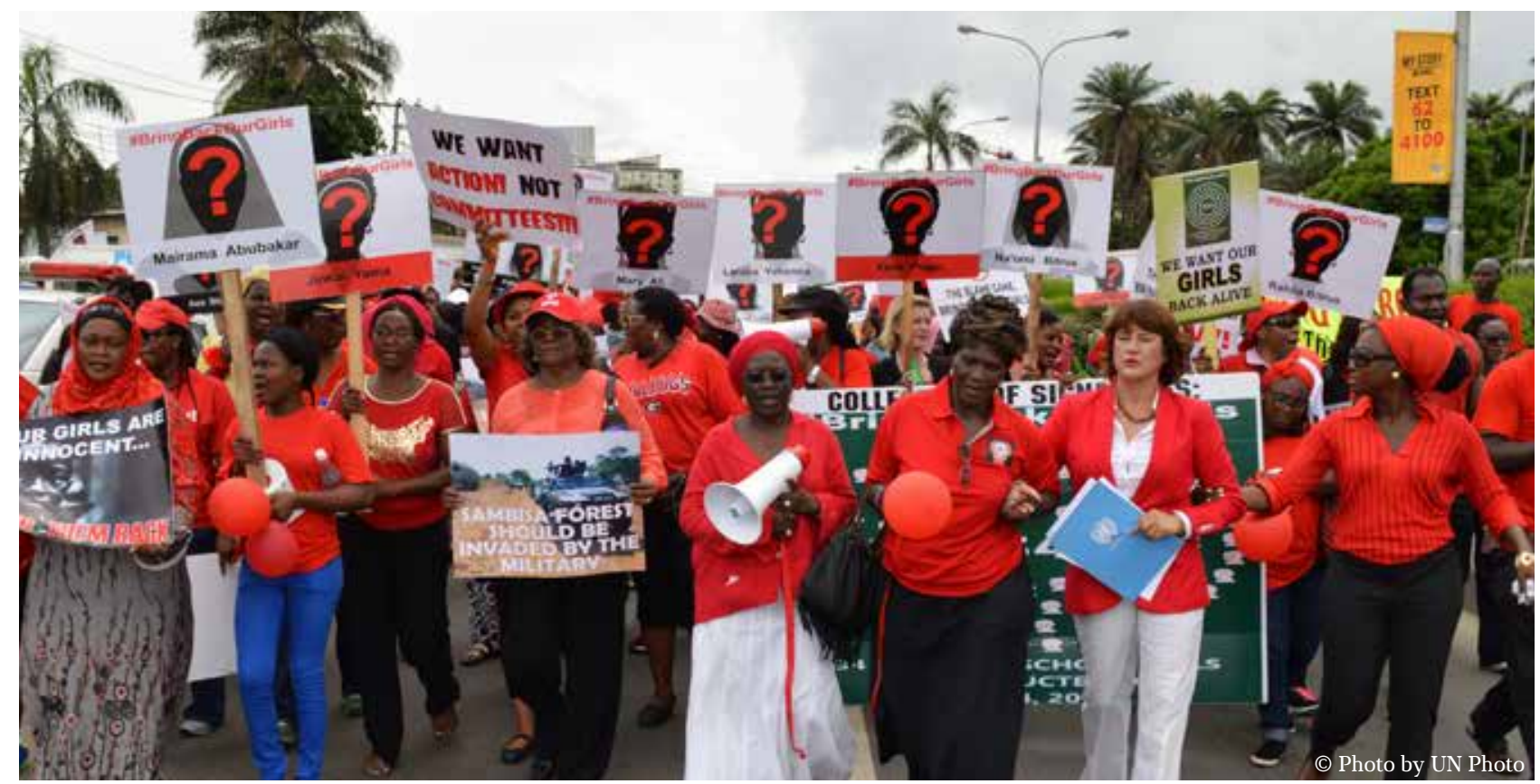

G4

Securitizing
approaches
without involving
safeguarding
mechanisms have
not shown the
results we hoped for

Doing so requires much of us: we must strengthen our common identity; and we must reinforce a sense of belonging, bolstering solidarity across all demographics.

And so, where do we begin? We look at the foundations of the political fabric: in families and in schools moving up to the political level starting from the municipal level and finally to the top layer, the parliaments and high-level decision-making fora.
The representatives of these entities need to form a protective layer, particularly in situations of crisis and uncertainty. They have to connect with the youth and deal with their volatile economic and emotional conditions, guiding them into the right direction while they are exploring themselves and the world. The personal, after all, is political. In order to construct a 'private' security architecture, we must educate the educators and start with the mothers as the first teachers in the lives of their children as a potential first line of defence strategy. They, thanks to their emotional connection with their children and their readiness to act, are well positioned to be placed as key security allies.
They need the confidence and the competence to recognise warning signs such as anger, restlessness and isolation and address it in due time.

\section{G6 \\ Security is a human right which requires the cooperation of governmental and nongovernmental actors}

We must strengthen, educate and encourage mothers so that they are capable of creating a barrier between radical influences and young people, targeted by the toxic and polarizing ideologies of religious and right-wing extremism. 
However, mothers in this role are not without controversy and do encounter certain obstacles. While they may have emotional access and physical proximity to their children, radicalisation remains taboo. Like other groups working with young people, mothers need an efficient support system and network which provides a safe space in which to discuss their fears and observations regarding the many dangers faced by their children from drugs and gang violence to violent extremism, and to take decisive action. Here, a support system outside the traditional institutions plays a key role.

The tools of the ideologists and recruiters - both online and offline - are exactly the tools the mothers of adolescents and young adults must reclaim: making time, listening, building trust, showing empathy. These techniques are also crucial to preventative youth work and within the challenges of rehabilitation.

\section{Gq \\ It is in the local contexts of the family, educational institutions, social services and leisure-time education that exclusion and discrimination first become apparent}

But how do we mobilize and prepare this critical group for potential frontline intervention?

Against the background of a growing frustration with male-dominated and hard power-oriented security strategies, Women without Borders (WwB) in 2008 launched its Sisters Against Violent Extremism (SAVE) network. It is the world's first female counter-extremism platform including women from 21 countries, from Columbia to Kosovo, from Pakistan to Palestine, promoting women's voices in the international security, counter-terrorism, and peacebuilding debates.

The outcome of the ongoing SAVE consultations was the understanding that mothers, in particular, have for too long been excluded from prevention strategies. Women without Borders conducted the first indepth applied research study centred on mothers and security, entitled "Can mothers challenge extremism?" The survey explored over one thousand concerned mothers' attitudes towards, perceptions of, and experiences with radicalisation and violent extremism in their families and communities

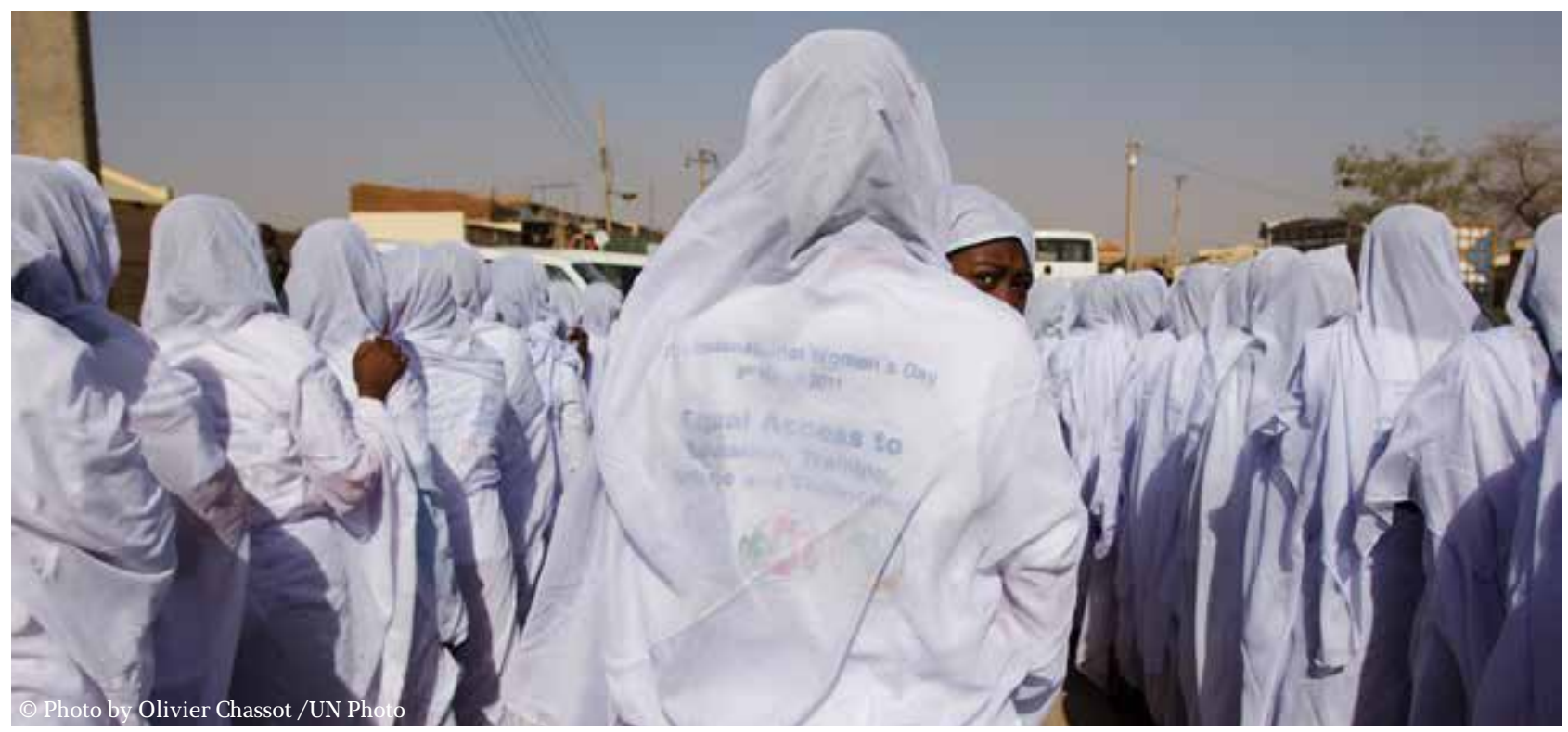


in Pakistan, Palestine, Israel, Nigeria, and Northern Ireland. The research revealed that although mothers are well suited and situated to recognise and react to early warning signs of radicalisation due to their place at the heart of the family, often they lack the appropriate space, structures, and training to develop the necessary competence and confidence to assume their prevention role.

On the basis of these study findings, Women without Borders conceptualised and developed the pioneering "MotherSchools: Parenting for Peace Model" which has so far been piloted and implemented in 12 countries, involving around 3,000 mothers until now.

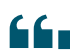

\section{Women without} Borders conducted the first in-depth applied research study centred on mothers and security, entitled "Can mothers challenge extremism?"

The MotherSchools Model creates a formalized space for mothers to deconstruct individual and social barriers to address the taboo issue of extremism while improving their knowledge of early warning signs. MotherSchools facilitate collec- tive strategizing to effectively counter radical influences in adolescent children, families and communities at large. $\mathrm{WwB}$ trains local individual drawn from local professional pools including social workers, teachers, psychologists, community leaders to become MotherSchools teachers. These teachers implement the MotherSchools curriculum in regular meetings over several months. The Curriculum uses developmental psychology, self-confidence training and exercises and theoretical sessions to define radicalisation and prevention at the individual level. The Model has been designed to strengthen individual capability, emotional literacy and awareness of extremist influences to both empower and enable mothers to effectively prevent and confront the threat of violent extremism in their communities.

And that's exactly the philosophy of the prevention model "MotherSchools: Parenting for Peace". It is a space to educate the educators, to create a community of women who realize that they are key in building up their children's strength and social immune systems. The MotherSchools do not require physical buildings, but committed and trusted local partners in their communities.

Based on the programme's rigorous monitoring and evaluation process, $\mathrm{WwB}$ seeks to advance the knowledge of con- text-specific radicalisation dynamics over time; deepen the understanding of why and how mothers represent the missing link in prevention strategies in vulnerable and affected communities; and ensure that MotherSchools continue to effect positive and sustained impact.

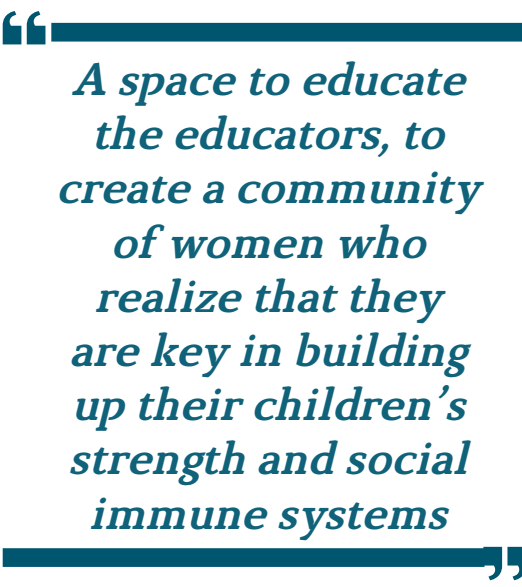

The MotherSchools implementation has started in Tajikistan in 2012 followed by Indonesia, Pakistan, India (including Indian-Administered and Pakistan-Administered Kashmir), Bangladesh, Zanzibar, Jordan and later travelling to Europe with current roll-outs in Austria, Germany, Belgium, England and the Western Balkans.

This approach works because is it based on a methodology which provides a framework, a targeted community, a monitored call to action and support to respond to situations of urgency. This model of local leadership in action is providing constructive engagement based on critical reflection and introspection. 


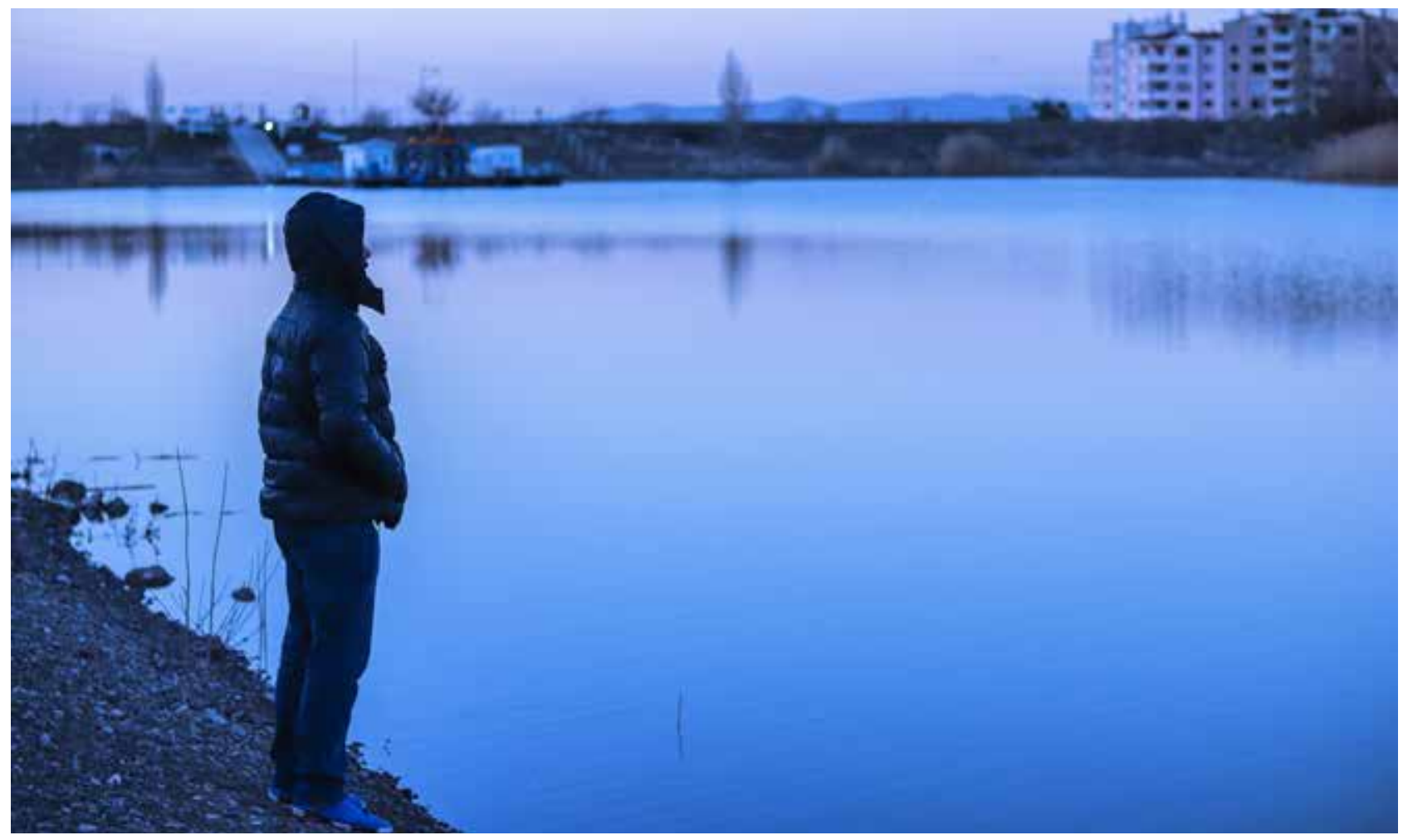

The insights and impact of the achievements need to arrive at the community level and need to be shared with the respective stakeholders. The MotherSchools graduation ceremony finally provides an important outreach opportunity to engage the participating family members as well as local stakeholders in the community and policy level: particularly mayors and the media. Providing the participants and teachers with this formal recognition is an important step for embedding the model into the community and mobilizing future participants and teachers. The graduation ceremony is also a point of departure for the participants enabling them to assume a public role and become authority figures.
The engagement of mothers in this arena is not unquestioned. The criticism touches upon instrumentalization of women and focuses on the stereotyped gendered roles of women as mothers and wives and potential peace makers instead of addressing the specific social and economic exclusion, injustices and inequalities in their societies.

On the contrary: the mobilisation of mothers as key witnesses and potential agents of change enhances an empowerment process that can have a ripple effect in their immediate and extended families as well as in their communities.

Gender has a symbolic significance for diversity and inclusion. It is absolutely necessary to take a nuanced approach to gender roles when it comes to the discussion and prevention of extremism. Confinement to stereotypical roles is a fixed part of an extremist world view and leaves little room for the exploration of desired and alternative life models.

The development of an effective individual immune system against all forms of violence and extremism can be best achieved in an environment which provides both physical and emotional security. This applies to both the private and public spheres, from families and schools to prisons.

Resilience-oriented gender politics also rely on the leadership of mothers and fathers in the 
family, and men and women in the community. Gender politics also means that female voices must be heard in equal measure to male voices at all levels of the security build-up.

Prevention strategies can be most punctually and effectively implemented when women's potential is promoted and encouraged systematically. Women must be recognised as part of an innovative strategy and engaged as such. Not least, it is of categorical importance that a gender sensitive approach also includes the complimentary role men have to play in their families and in public.

The inclusion of fathers in preventing violent extremism is WwB's strategic next step towards the whole of community approach. Many fathers present challenges to family cohesion due to poor communication skills, physical and mental absence. Domestic violence as an experience of normalized violence often is an opening moment for violent extremism. The connection between domestic violence and subsequent radicalization is a challenge that needs to be targeted.

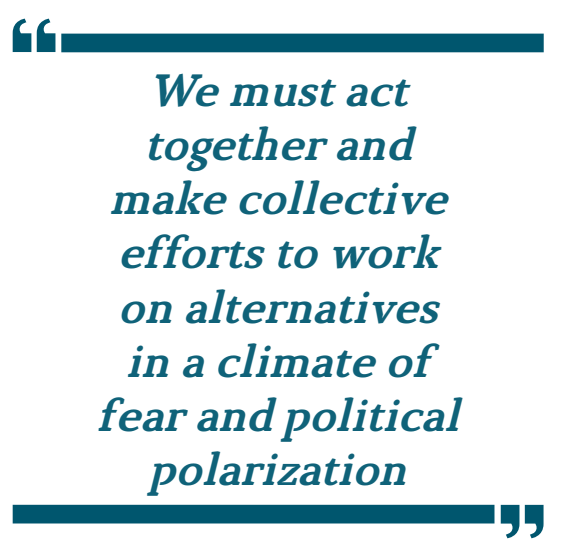

Pilot FatherSchools workshops have taken place in Austria and will be rolled out in Germany this year. FatherSchools promise to be more than just a mitigating measure. In communities at risk where notions of hyper masculinity often are linked to violence, fathers must be viewed as the missing piece of the puzzle in a family-based and whole-of community security approach.

The processes of radicalisation take hold extremely quickly. The window of opportunity for intervention closes when we do not react.

This is a clear mandate for our societies: we must act together and make collective efforts to work on alternatives in a climate of fear and political polarization. What it takes is a strategy which demands courage and optimism.

\section{The Author}

Edit Schlaffer, an internationally recognised social scientist, founded Women without Borders (WwB) in 2001 with a view to building up the competence and confidence of women to effect social change in marginalised communities across the world. Schlaffer focuses on gender-based peacebuilding strategies that harness the strength of civil society in building a new women led security architecture.

Responding to the growing threat of violent extremism, Schlaffer launched Sisters Against Violent Extremism (SAVE), the world's first female counter-extremism platform. Over the past decade, WwB has been strengthening local and global security through its pioneering MotherSchools: Parenting for Peace Model addressing three thousand concerned mothers in 15 countries across Europe, Asia, the Middle East, and East Africa. In developing and implementing this internationally recognized strategy, Schlaffer's preventing violent extremism research introduced and has since normalised the concept of mothers as the first line of defence against extremism.

Schlaffer is Ashoka Fellow and recipient of numerous awards: Reader's Digest 'European of the Year', Foreign Policy's '100 Global Thinkers', Grand Decoration of Honour in Gold for Services to the Republic of Austria, Soroptimist International Peace Prize, Aenne Burda Award for Creative Leadership, Newsweek's '150 Movers and Shakers', and Women's eNews 21 Leaders of the $21^{\text {st }}$ Century. 


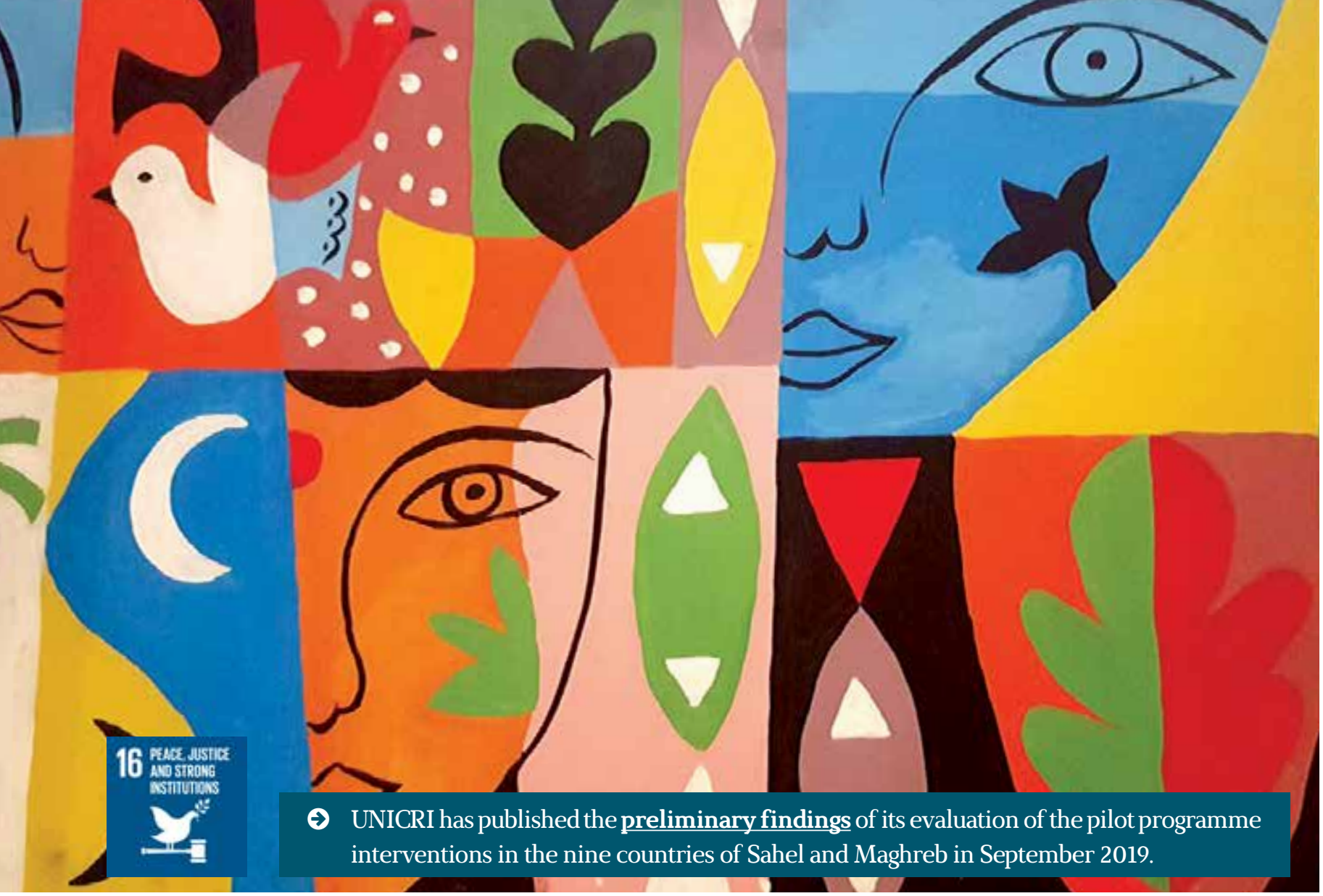

\section{Community resilience: insights from UNICRI experience in the Sahel-Maghreb}

\section{To adapt, bend, and change - but not to break}

by Danielle Hull, Tamara Nešković, Manuela Brunero

In physics, "resilience" is a measure of how well a material, such as rubber or metal, responds to pressure by bending, adapting, and changing, without breaking. However, this concept is more than a scientific term. Resiliency can also describe a community's ability to bounce back from pressures, including natural disasters, economic downturns, and - in the case of UNICRI's Pilot Project on Countering Radicalisation and Violent Extremism in the Sahel-Maghreb - violence and terrorism. In the Sahel and Maghreb, the pressure on communities is certainly intense, and ever-growing. Conflicts in Libya and Mali threaten to spill over porous borders, while drought and desertification have increased food insecurity and heightened intercommunal tensions. Increasingly active extremist militant groups have brought violence and chased out tourists, which once had been an importance source of income. Now, more than ever, an 
approach aimed at building the resilience at a community level is needed - one that can empower communities to respond to these pressures by adapting and changing, without "breaking" and entering into conflict.

As the security situation deteriorates across the regions, it can be tempting to come to the logical, yet oversimplified, conclusion that a security problem requires a security solution. After all, much of the area has had limited state presence over the past decade, allowing armed groups to grow in strength, and smuggling and illicit trafficking to increase in profitability.

GG

$$
\begin{gathered}
\text { In physics, } \\
\text { "resilience" is a } \\
\text { measure of how } \\
\text { well a material, } \\
\text { such as rubber or } \\
\text { metal, responds } \\
\text { to pressure by } \\
\text { bending, adapting, } \\
\text { and changing, } \\
\text { without breaking }
\end{gathered}
$$

Often, when the government has been present, it has been weak, or viewed as biased and corrupt. Therefore, one might conclude, the focus should be put on improving the ability of the state to police the areas of insecurity, and relying on the army to impose security. Certainly, these are important elements of a counterterrorism strategy, and form a key part of the international efforts in the regions.

However, a community-resilience approach recognizes that the issues of violent extremism and radicalization have their roots in local conflicts - and likewise that the solutions lie in a dynamic and inclusive, community-wide approach. In the words of the Nigerien diplomat Abdallah Wafy, «la réponse au terrorisme n'est pas que 'le tout sécuritaire. » (The response to terrorism is not 'only security). ${ }^{1}$ UNICRI's pilot programme (envisaging many projects) seeks to implement and evaluate efforts to improve the capacity of the communities in the Maghreb and Sahel to cope with the pressure they face and resist to violent radicalization. Rather than confronting threats with a purely military response, it strives to identify ways for communities to harness their own assets to undermine and control violent radicalization. While the individual projects differ in their activities, focus, and geographic locations, they all demonstrate some key elements of resil- iency - to begin with, they are community-driven.

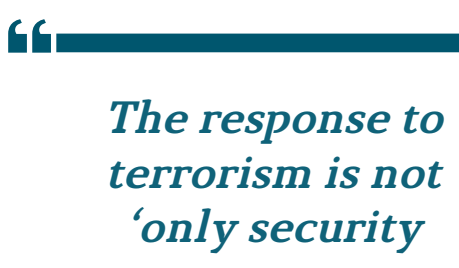

5

\section{The power to envision the future}

As the name might suggest, efforts to build community resilience must be based precisely there - in the community itself. Resilience cannot be built on behalf of the communities, it cannot come from external actors imposing ideas and programs from afar. Rather, it requires critical reflection on and coming to terms with the issues, needs, and problems driving some members of the community to engage with violent extremism. This means that projects must be locally-defined and driven. That is, "the power to envision the future of the community and build its resilience resides with the community members." 2

The local level is an essential staging ground for efforts to build resiliency, as communities resilient to violent extremism require strong social ties

1 Rolley, Sonia. «Invité Afrique - Abdallah Wafy: «En Réponse Au Terrorisme, Il N’y a Pas Que Le ‘tout Sécuritaire’». RFI. June 08, 2019. Accessed July 09, 2019. http://www.rfi.fr/emission/20190608-reponse-terrorisme-il-y-pas-le-tout-securitaire-abdallah-wafy.

2 Lerch, Daniel. Six Foundations for Building Community Resilience. Post Carbon Institute. Edited by Asher Miller, Ken White, and Richard Heinberg. November 2015. Accessed July 9, 2019. http://www.postcarbon.org/wp-content/uploads/2015/11/Six-Foundations-for-Building-Community-Resilience.pdf. 
as well as trust and dialogue among diverse - and potentially conflicting - groups. Research in fact confirms that the lack of a sense of belonging or strong social identity can be important risk factors for violence. ${ }^{3}$ Attempts to construct strong social bonds, foster inclusion, and address local grievances make community engagement and ownership of the project vital.

G6

Resilience cannot be built on behalf of the communities, it cannot come from external actors imposing ideas and programs from afar

UNICRI's pilot programme began with each community having the freedom - and responsibility - to define its own problems and propose appropriate solutions. Based on the belief that those most directly affected by violent extremism can design the most innovative and successful efforts to counter it, the project was, from its very inception, community-led. As a consequence, several and different grievances have been identified by local partners, encompassing political, social, educational, economic and security issues. Interestingly enough, even though all of them have been reported as critical for the local communities, not all of them have been addressed by the interventions. Main emphasis and attention have been devoted to inclusive governance and citizens' participations, equal access to services, accountability of security forces, social justice, access to education, (including religious education) and social inclusion.

\section{Resilience for whom?}

Who should be included in resiliency-building projects?
Who should benefit from them? The answer to these questions is deceptively straightforward: everyone. Inclusivity goes to the very heart of resiliency. In order to truly be resilient - to be able to weather the pressures that these communities face it is important to include those who often have been excluded in traditionally gerontocratic, male-dominated communities: women, youth, and ethnic minorities. The pilot project did just that. The reason for focusing on these groups is two-fold. First, exclusion can be a powerful driver of violence.

Violent extremist groups may draw on youth's frustration with their lack of employment and role in their communities through offering prestige and pay for joining. Excluded minority groups may turn to violent groups out of desperation, fear, or anger; while women - research has suggested - can play both a motivat-

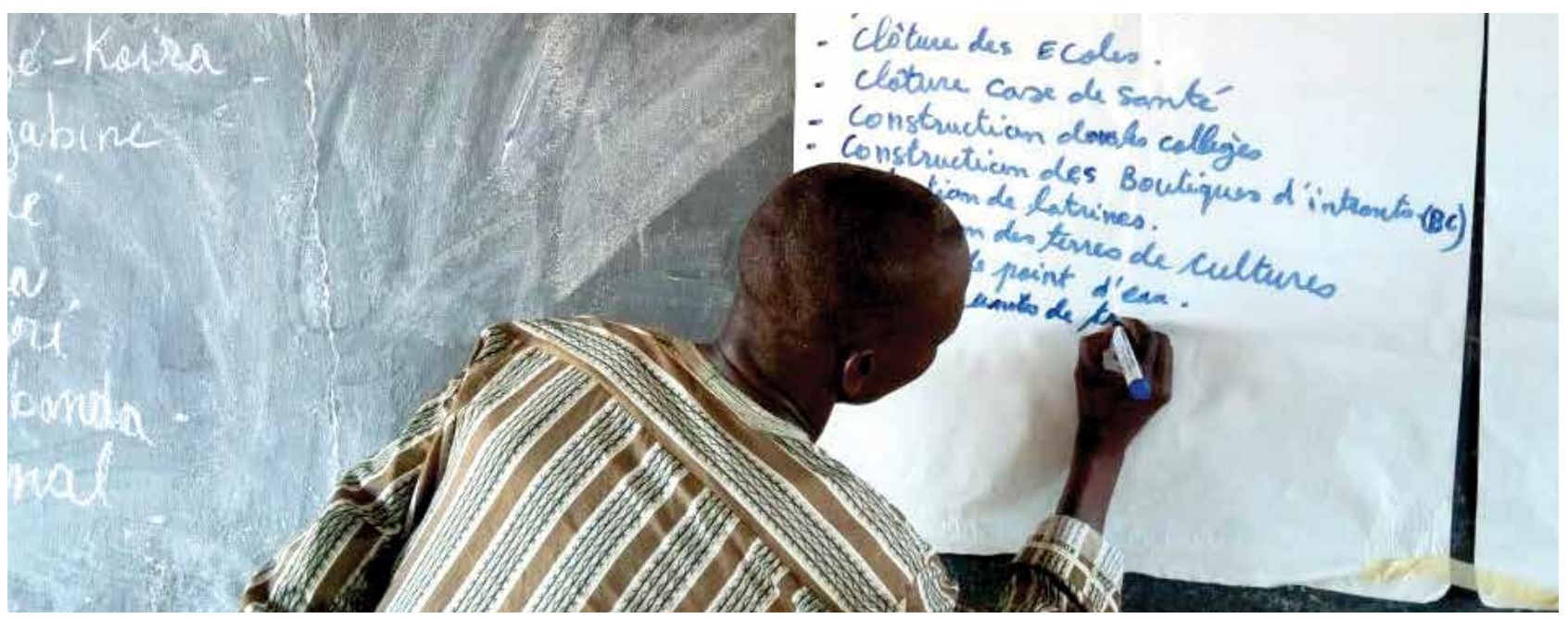

3 Ellis, B. Heidi, and Saida Abdi. "Building Community Resilience to Violent Extremism through Genuine Partnerships." American Psychologist 72, no. 3 (2017): 289-300. doi:10.1037/amp0000065. 
ing part in encouraging violence, as well as an indispensable role in peace-making. Thus, from an efficacy point of view, successful efforts to counter violent extremism must address those most atrisk of being drawn into violent groups along with those with the power to build a lasting peace.

\section{G9 \\ Inclusivity goes to the very heart of resiliency}

Yet, it is not simply a matter of effective programming: women, youth, and minorities cannot be shut out of the system. A system that works only for a select group or groups is brittle. In order to exhibit the dynamism inherent in resiliency, communities must embrace diverse perspectives and inputs, and strive to respond to the needs of all community members.

\section{Try, and try again}

Even with an inclusive and community-driven approach, resiliency is not something that, once achieved, can remain static and in place. Nor can it be achieved through a one-size-fits-all initiative. Building resiliency requires being open to failure and learning what methods work well and what do not. It demands an iterative process of trial, error, and learning.

Indeed, a final ingredient in building community resilience

to violent extremism is a healthy dose of courage. Undoubtedly, it takes a great deal of courage to face up to violent actors in one's own community and country. It takes another, equally important, form of courage to be willing to accept failures, at least in the short-term, to battle the seemingly insurmountable one step at a time, and to commit time, energy, and resources to the long and ongoing process that is resilience-building.

This has been the foundation of UNICRI's pilot programme, which, from the beginning, has sought to implement, test, and evaluate a diverse range of interventions, in different locations, and with varying organisations in order to identify the most successful projects, and determine why they were successful.

Though an admittedly difficult task in and of itself, identifying successes alone is not sufficient to build a robust and resilient base against violent extremism. Despite the human toll that violent extremism has taken in these regions and around the world, our understanding of what drives and prevents violence is still improving. Thus, sharing and disseminating the various projects' strategies, challenges, materials, and important findings is crucial.

\section{The Author}

Danielle Hull is a Master in Public Affairs (MPA) student at Princeton University. She received her undergraduate degree from Harvard in 2013 and has worked in Bamako, Mali, and Jefferson Parish, Louisiana. In summer 2019, she interned with UNICRI as part of the Pilot Project on CVE in the Sahel-Maghreb.

Tamara Neskovic is a Monitoring and Evaluation Analyst (Fellow) at UNICRI. She has honed her skills working for the European Commission and the Organisation for Security and Cooperation in Europe (OSCE) in Belgrade, Vienna and Warsaw. She has experience in all steps of the project management cycle: design, review, approval, management, administration, monitoring and evaluation. Her passion are logical frameworks.

Manuela Brunero works as Programme Officer in the Counter-Terrorism Unit at UNICRI, where she is responsible for developing and managing projects related to countering violent extremism, rehabilitation and reintegration of violent extremist offenders and rule of law-based approaches to counterterrorism. Before joining UNICRI, she has worked in the field of social and economic inclusion at UNDP in Albania and at ILO in Geneva. She holds a MA in International Relations and Human Rights. 
With the support of the European Commission (EC) and DG NEAR, forty-eight small grants were carried out within the framework of the Pilot Project in the Maghreb region.

\section{Preventing and countering violent extremism}

As we all know, violent extremism is on the rise since the Syria war and Daesh's propaganda. It is generally referred to as accepting the use of violence in line with an ideological commitment to achieve political, religious or social goals. It is not just about embracing the ideology but also acting upon it.

G9

The complete structure of the project goes from studying the actual context of each community, to piloting grass-root initiatives and then monitoring their impact

The UNICRI programme on preventing and countering violent extremism (P/CVE) understood the complexity of the subject. With funds from the $\mathrm{EU}$, the answer to tackle the problem has been a wide vari- ety of on-the-ground projects in carefully elected vulnerable parts of a selection of countries, in both the Maghreb and Sahel regions. In the Maghreb region, Morocco, Algeria, Tunisia and Libya were the centre of attention. The $\mathrm{P} / \mathrm{CVE}$ programme tailored itself to cultural contexts, with focused local interventions and a longterm involvement with trusted community actors.

The complete structure of the project goes from studying the actual context of each community, to piloting grass-root initiatives and then monitoring their impact. The main objective is to understand mechanisms enhancing community resilience towards radical and violent extremist tendencies.

\section{No one is left behind}

In order to touch every vulnerable individual, diverse topics have been developed into real actions: from environment, art and cultural activities, religious tolerance, women's rights, debate skills and critical thinking, to sports, media and radio, advocacy and leadership.

No one was left behind. The audience targeted was broad: $27 \%$ youth, $13 \%$ civil society activists, $11 \%$ women, $11 \%$ journalists, $11 \%$ imams and religious leaders, $8 \%$ of teachers in koranic and state schools, 6\% lo- cal administration, 5\% minority groups, 3\% tribal leaders, $3 \%$ refugees and returnees and $3 \%$ former slaves.

Even though the EU-funded pilot programme has been extended to 2020, the first phase of the qualitative evaluation has been completed and a report on preliminary findings has been issued. While the evaluation is still preliminary, it is vital and is already helping UNICRI to identify good practices and formulate early conclusions on what works and what does not in making the communities more resilient to radicalisation and violent $\mathrm{ex}^{-}$ tremism. Outcomes will then be used to make future actions even more impactful and effective.

Meanwhile, monthly newsletters reviewing key information and offering latest updates with concrete examples of the activities implemented on the ground are being disseminated.

\section{GC. \\ Unemployment, lack of public services, access to health care, distrust towards the political establishment and corruption are just a few of the problems being faced by them}




\section{Far-reaching array of projects}

Prolific initiatives by local organisations were supported by UNICRI. The youth being the largest majority of the population in the Maghreb region, most of the actions were devoted to them specially considering the challenges they face. Unemployment, lack of public services, access to health care, distrust towards the political establishment and corruption are just a few of the problems being faced by them.

Among the successful initiatives let's cite one in Morocco: the "Jeunes unis contre le radicalisme" implemented by the «Comité Européen pour la Formation et l'Agriculture» (CEFA); one in Tunisia: "Hope: Support for democratic citizenship through artistic innovation" by Fanny Raghman Anni (FRA) one in Libya: "Active Citizen" by $\mathrm{H} 2 \mathrm{O}$ Association for supporting democratic transition and youth engagement; and one regional one: "Media for Democracy in North Africa" by International Federation of Journalists (IFJ).

\section{Mazen Smeti}

"With our art, we were able to decorate institutes, rural schools and streets"

Twenty-one-year-old Mazen Smeti, a Tunisian passionate dancer participated in one of the biggest projects implemented by the COOPERA organisation "Jovenes para la cooperacion internacional al Desarrollo". It was an Interdisciplinary Mobile Cultural Activity (IMCA) for youth vulnerable to socioeconomic exclusion and violent extremism, radicalization and terrorist recruitment. The activities took place in the Tunisian mountains near the Algerian border, an area sadly considered as a smuggler and terrorists' hotspot, a kind of jihadist groups' "informal headquarters."

Mazen discloses that he was engaged in two different "cultural caravans" organised by the project. "I was already practicing dancing before the cara-

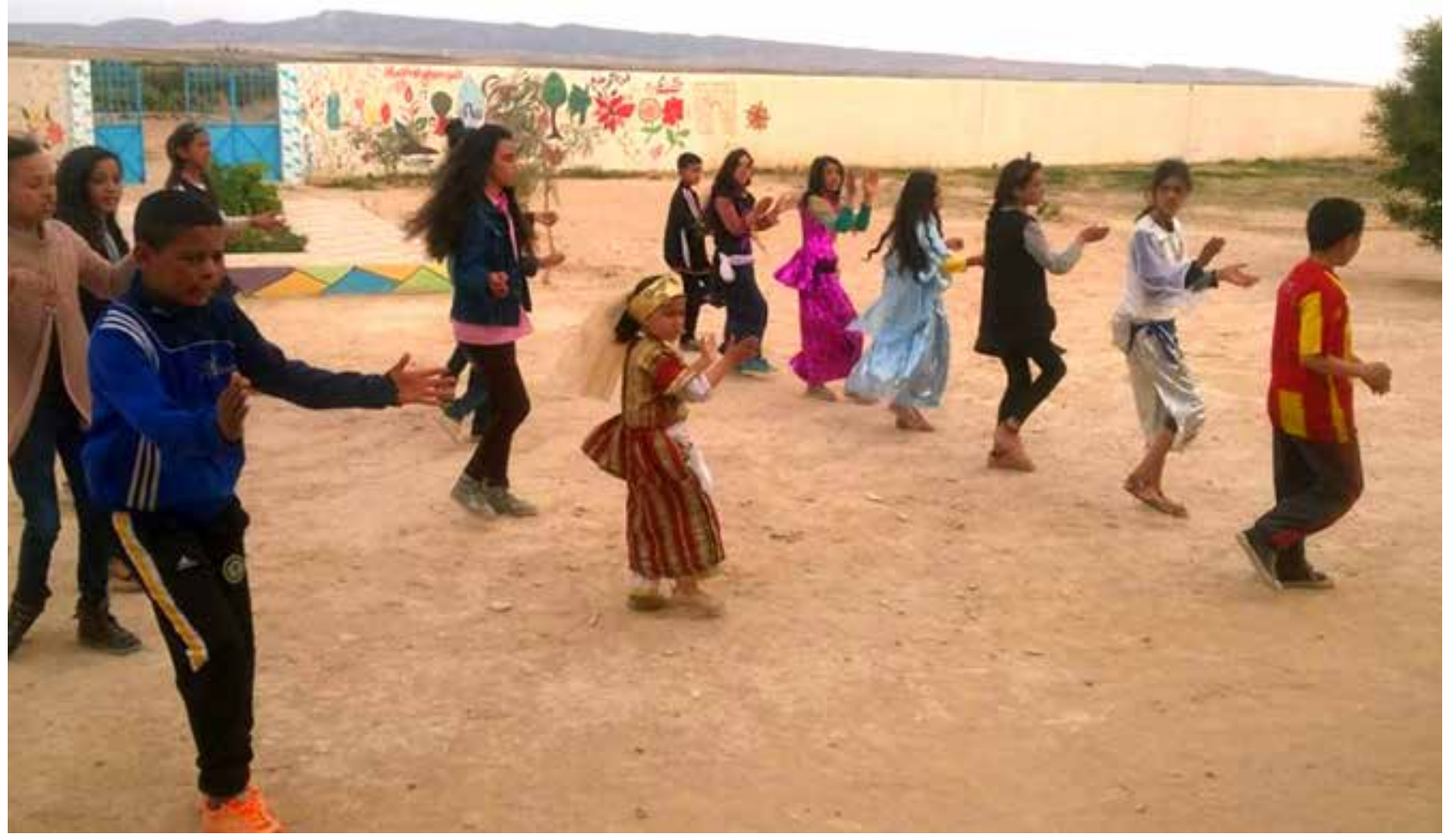


van and when I participated in the event, I was able to develop my talent and technique in dance. At the end, we were able to present a nice show."

\section{G4 \\ With this initiative, the walls became bearers of the young generation's voices

Mazen did not just dance, he also embraced a new form of expression. "Besides, I learned something new and it is graffiti. I liked it to the point that when the cultural caravan was over, with a group of friends, we created "The Junks."' The latter is a small group engaged in painting spaces in the cities to give them a different image and a new look to encourage opening youth perspectives. Mazen adds that thanks to the caravan he made new friends and that: "With our art, we were able to decorate institutes, rural schools and streets." With this initiative, the walls became bearers of the young generation's voices. COOPERA encouraged them by purchasing diverse painting materials.

The project's activities were diverse. With the cooperation of local leaders and village chiefs, the caravan travelled to Kasserine, Sousse, Tunis, Le Kef, Sbeitla, Thala and Karouan, accompanied by music performances and conducting various workshops.
The workshops were held in seven locations over thirty-six days and on eleven training topics. From break-dance to mural painting, photography, hairdressing, henna tattoo, rosemary oil distilling and diverse handicrafts, there was an interest for everyone. Not less than 608 youths, girls and boys participated in the workshops.

\section{Omayma Derwichi}

A charismatic twenty-twoyear-old lady with a fashion designer background, shared joyfully her experience with us. She took part in one of the cultural caravans implemented by the COOPERA organisation and she says it was a beautiful

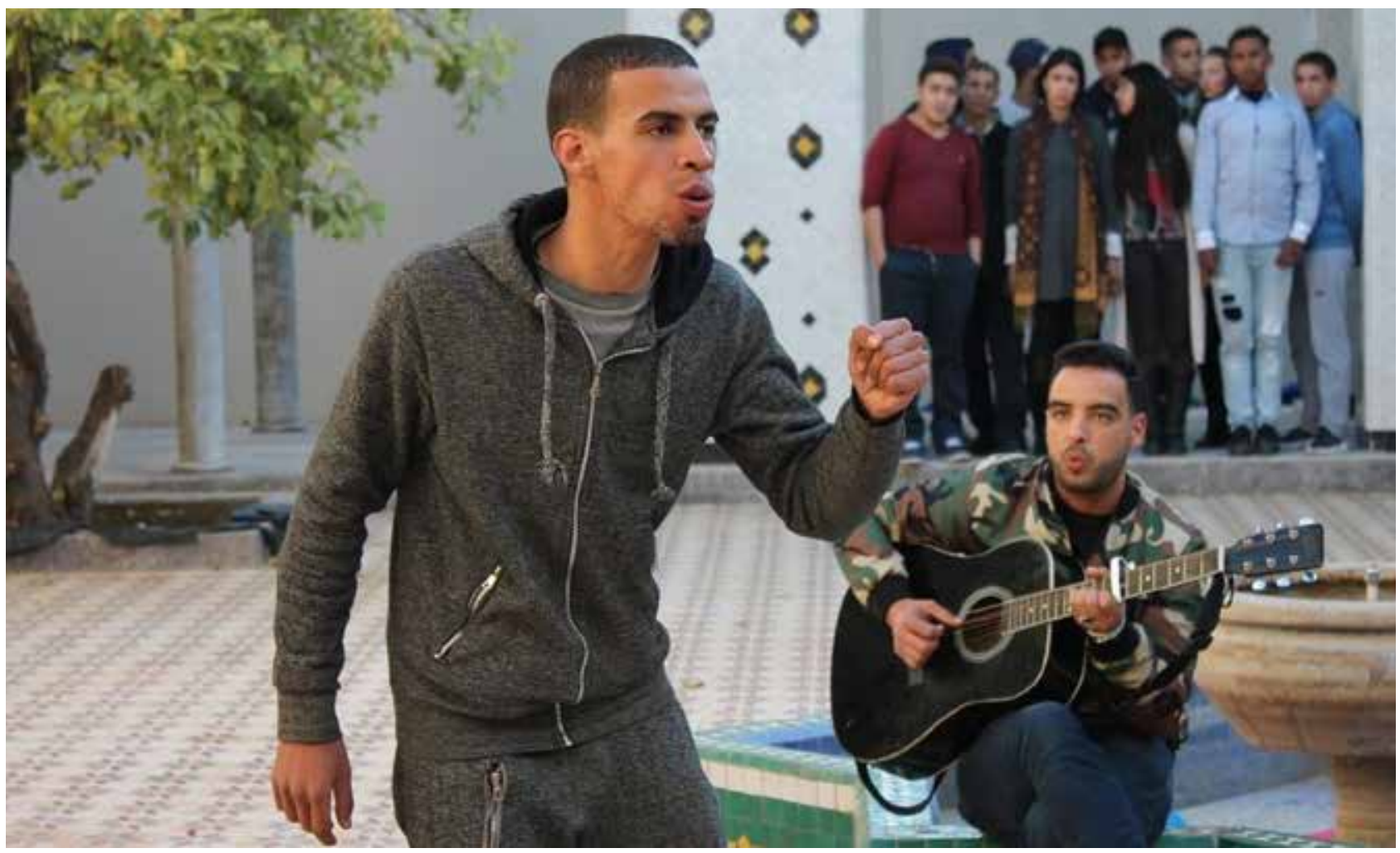




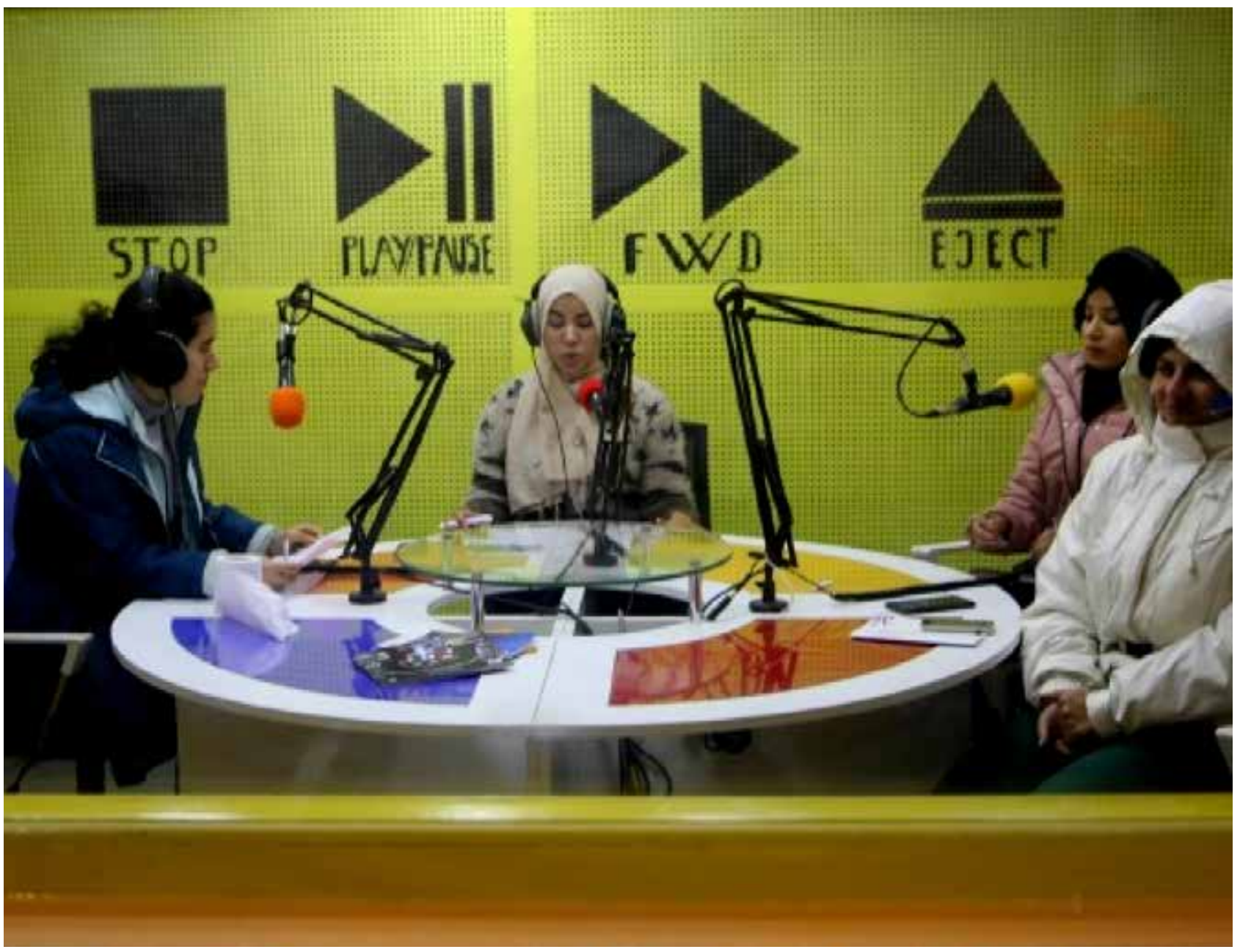

experience, she enjoyed it a lot and learned new things especially in the field of dance and theatre.

\section{G4}

\section{Talking about improving self- esteem and giving tools, hope and a purpose in life, isn't that the best way to fight extremism and violence?}

Omayma experienced coaching in physical expression, an approach to movement for dancers and actors. The technique maximises body capacities for enhanced and more sophisticated performances. Exercising within a group has encouraged her to surpass herself even though she is a medal winner. Actually, Omayma has won first place in basketball, football and gymnastics. Nonetheless, this experience boosted her self-esteem and encouraged her to stay in contact with the new friends she made and maybe, who knows, build new projects for the future.

Talking about improving self-esteem and giving tools, hope and a purpose in life, isn't that the best way to fight extremism and violence?

All and all, these EU-funded activities offered a listening ear, gave a push to participants to challenge themselves to be creative and produce something while being backed up 
by a group of trustworthy people and being congratulated for the accomplished work. Having the opportunity to be listened to, share personal experiences with others, and learn about someone else's life challenges helps somehow find more internal peace and harmony.

\section{GG \\ Experts say that disinformation, the desire for meaning and order, and the need for change are the main reasons for religious extremism}

\section{The best is yet to come}

Experts say that disinformation, the desire for meaning and order, and the need for change are the main reasons for religious extremism. Nonetheless, lack of culture, education and social inclusion are as well fundamental motives. Over 80 civil society organisations in the Sahel and Maghreb regions worked with community groups on these aspects, trying to erase the sense of victimhood and pushing for critical thinking, human rights, gender equality and artistic creation.

This EU-funded regional programme is doing a lot of good to the communities. Amazingly diverse and well thought it educates a careful selection of youth that will, in a domino ef- fect, instruct others and so one. By respecting the history, cultural and religious traditions, the local initiatives have boosted social cohesion and inclusion, making the communities more resilient to the spread of violent extremist ideologies. The best is yet to come: the approach to the implementation of those small-scale interventions is ultimately applicable to other regions that are affected by similar phenomena.

\section{G4 \\ By respecting the history, cultural and religious traditions, the local initiatives have boosted social cohesion and inclusion}

\section{The Author}

Deborah Phares: a many years of working as a university teacher, an artist and a creative director in the advertising field in Lebanon, she graduated with a second master in political communication and lobbying from the ULB university and has been the information and communication manager of the EU Neighbours South project. Based in Brussels, she is now pursuing her $\mathrm{PhD}$ on counter-discourses to islamist and jihadist online propaganda in English, French and Arabic. 


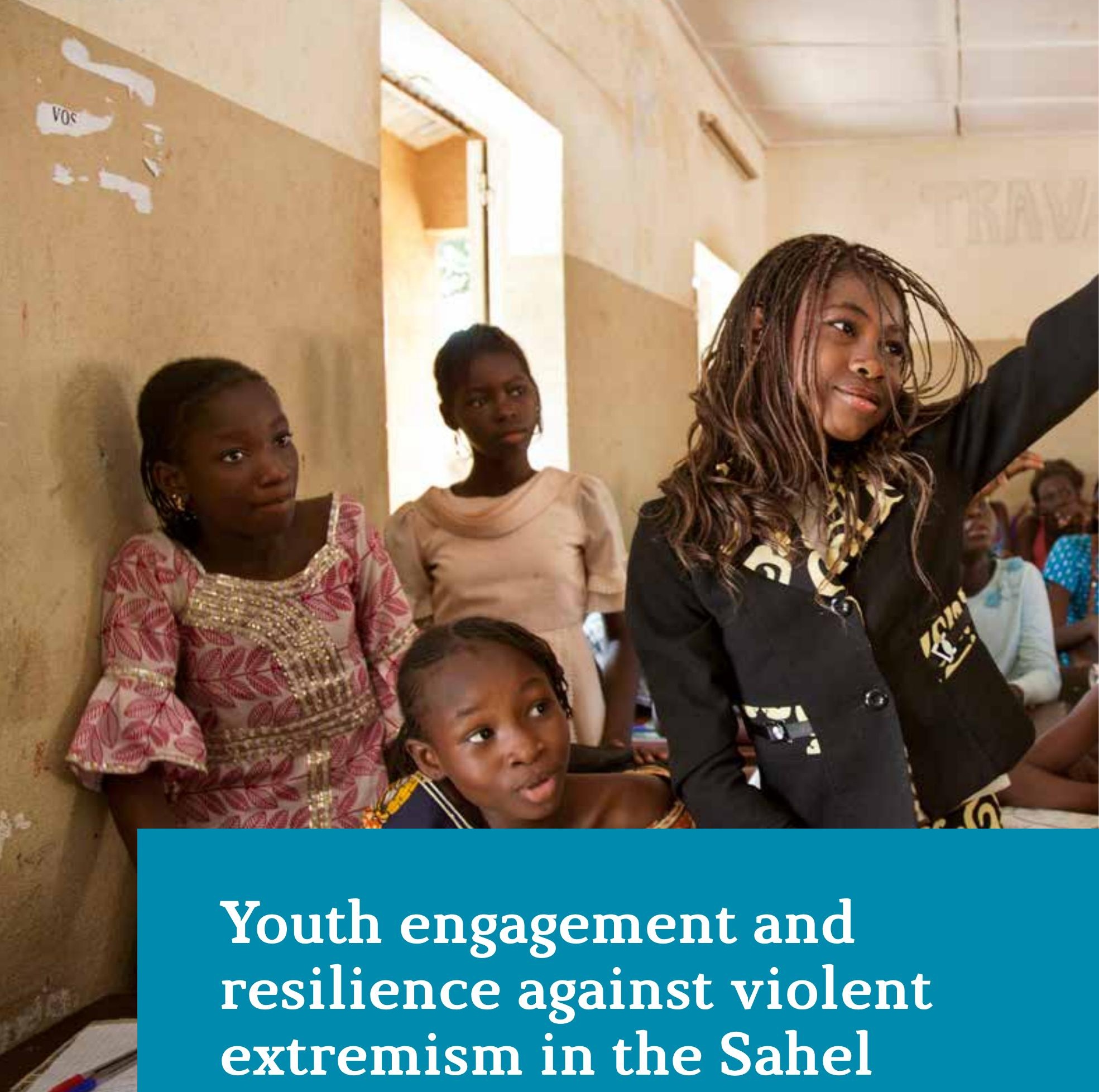

16 pace vustice

6 MD SiRang

NSHIUID:

$\sum_{1}^{2}$
- Organised by the International Centre for Counter-Terrorism (ICCT),

the Global Center on Cooperative Security (Global Center), and the

United Nations Interregional Crime and Justice Research Institute (UNICRI) 

The panelists called for youth to be recognised as key actors that should be involved from the outset in program design, implementation, and evaluation. Furthermore, they stressed that engagement should reach beyond urban youth to incorporate perspectives of young people in more remote areas.

\section{Key Takeaways}

In their opening remarks, Ambassador Julie Pruzan-Jørgensen (Special Envoy to the Sahel and Maghreb, Ministry of Foreign Affairs of Denmark) and
Coumba Gaye (First Counselor, Permanent Mission of the Republic of Senegal to the United Nations), expressed their concern regarding the rapidly deteriorating security situation in the Sahel and the impact of the spill-over effects on the larger West African region. They advocated for strong partnerships and cooperation among international actors, including the Global Counter-Terrorism Forum's Capacity-Building in the West Africa Region Working Group, as well as the promotion of youth as actors of change to address the challenges faced by Sahelian countries.
Julie Pruzan-Jørgensen: "An effective approach requires even closer partnerships with the countries in the Sahel as well as regional organisations"

Coumba Gaye: "Young people should be at the forefront of this fight"

\section{Youth as the drivers of change}

The overwhelming majority of Sahelian youth have no interest in joining or engaging with terrorist or violent groups and do not view themselves as 'poten-

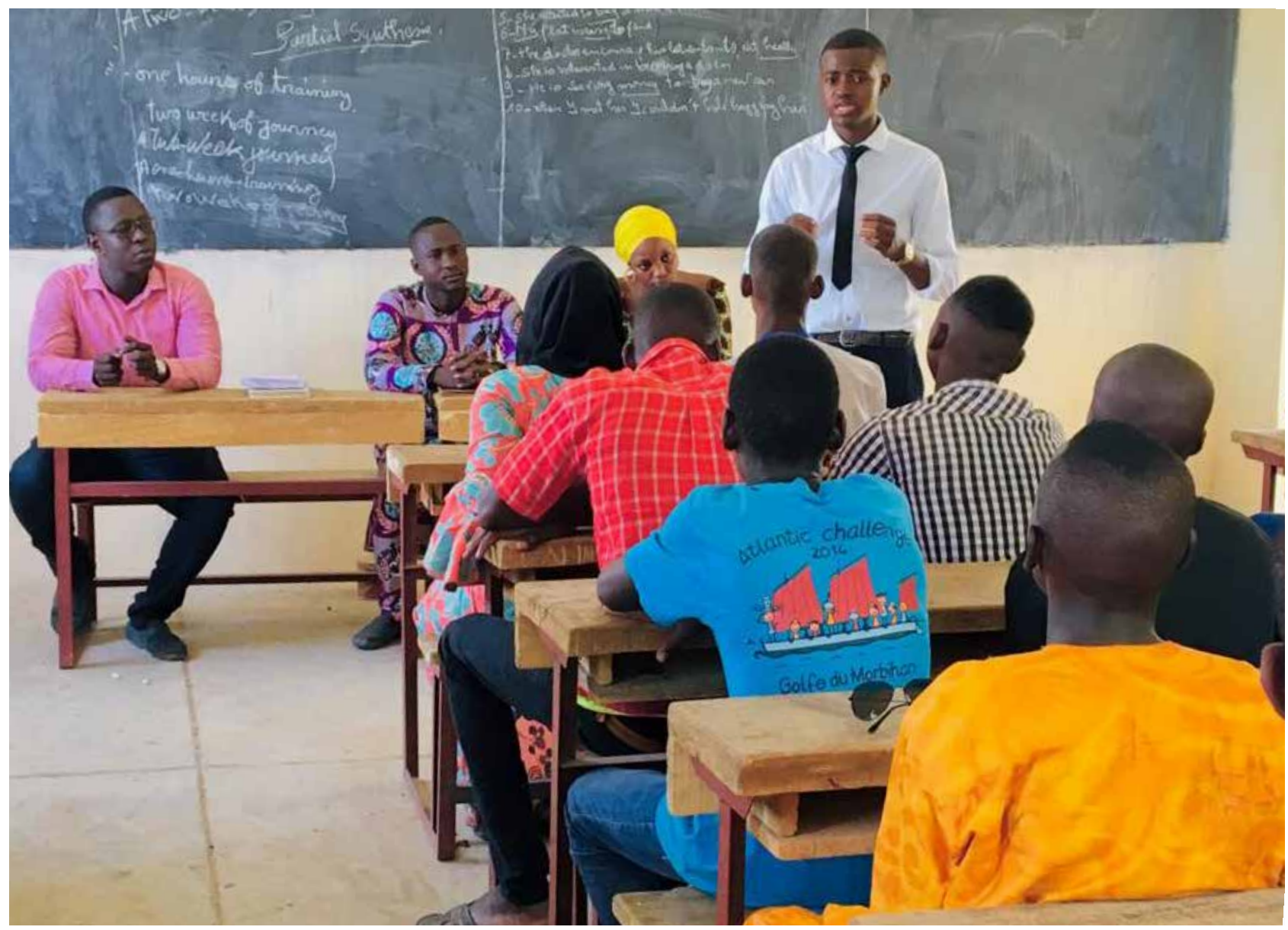


tial extremists.' Instead, they want to address the structural issues that often affect communities in the Sahel such as scarce educational and employment opportunities, the fragile security situation, and the lack of inclusivity at the governmental level. The international community should be careful with the words used to label their programs and put youth at the centre of their actions. Indeed, making youth resilient against terrorism and raising awareness on the narratives and recruitment techniques of terrorist groups should start from a positive focus on youth as drivers of change.

Rahama Nantoumé: "Youth are not the future; they are the present, the future needs to be prepared today"

\section{The need to engage youth before, during and after program implementation}

Youth should be involved in every stage of programming. They should not solely be beneficiaries of programs and pro- jects, they should be engaged in the design, monitoring and evaluation process. This requires their involvement from the very beginning of each initiative in order to incorporate their views and perspectives to better prioritize issues and present tailor-made responses. The input from youth should not be limited to identification of areas to be addressed, but should also concern the approaches and manners to address those issues. Youth should be engaged and recognized as pivotal partners in building resilience and fostering more inclusive societies.

Maji Peterx: "Young people are (portrayed as) the face of violent extremism... they are also the solution"

\section{The need to reach}

\section{beyond urban youth}

The international community tends to work with English and French-speaking, urban elite youth who already have resources and leadership capabilities. There is a distinct need to come up with strategies to reach beyond that group. Exist- ing counterparts could represent a gateway to local communities and should be consulted on how to best engage hard-toreach groups.

Yehiya Boré: "I hear everywhere that the Sahel is about terrorism, radicalisation, and extremism... that is not true. In the Sahel, you find culture everywhere. People sing together, people dance together, people laugh together"

\section{Conclusions}

The Sahel region is primarily home to thousands of youth who work every day to build a more peaceful society. The international community can facilitate this process by supporting them to unite against violent extremism, to weaken the appeal of terrorism, and to be the drivers of change. Culture, education, employment and social networks should be at the forefront of the strategy to counter violent extremism. Cross-cultural youth dialogues and initiatives can enable young people to mobilize and effectively counter radicalization, recruitment, and thus violent extremism in the region.

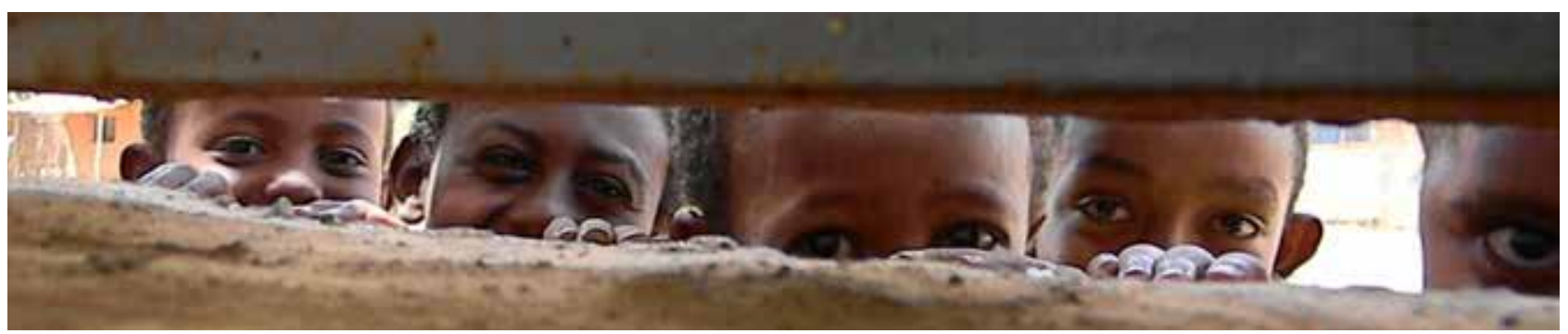




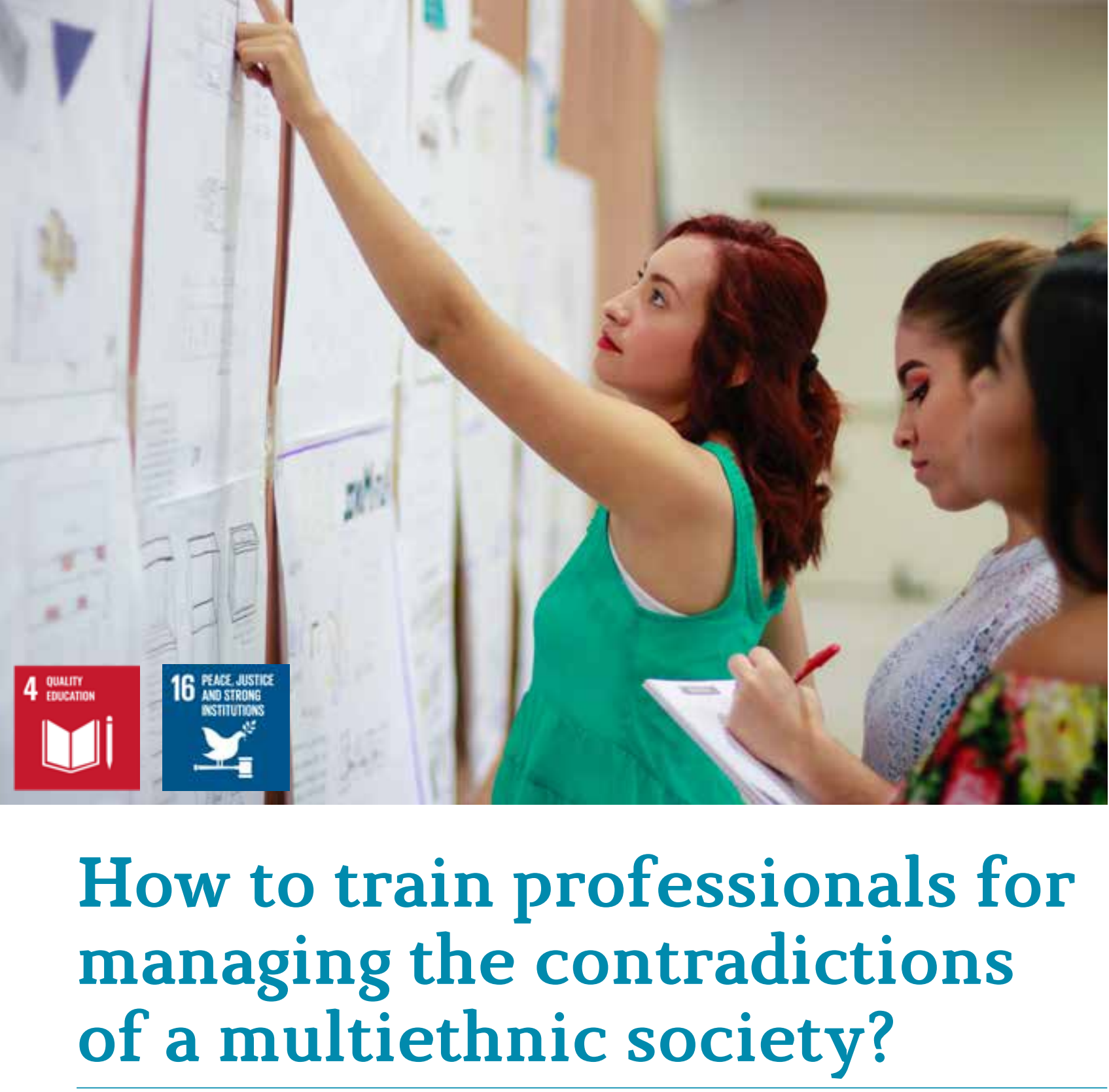

by Loretta Fabbri and Claudio Melacarne

The society we live in is so diverse and mixed that we are no longer able to understand it only through traditional research perspectives. It is multiethnic and we often see that the stories shared in the public arena do not reflect what happens in everyday life.

People are living a fragmentation of cultures and traditions due to the contact between persons and groups who have different life perspectives, which generates a form of "situated translation" of principles, rules of conduct and socially acquired beliefs. For example, young people are learning from peer-mixing practices and lifestyles that often generate cultural confusion or estrangement from their parents or the community where they have grown up.

Therefore, the different contexts of modern life cannot be defined only as multiethnic or multicultural. It is not only a new conversational area, but a learning arena. To be able to understand why people close their minds from different points of view or develop violent 
behaviors, we need to produce more "situated knowledge". How are students defining their identity at school or how are professionals developing informal ways to work beyond cultural, religious and ideological perspectives?

GG

To be able to
understand why
people close
their minds from
different points of
view or develop
violent behaviors,
we need to produce
more "situated
knowledge"

Traditional macro categories are not enough when we want to deeply understand the possibility of generating inclusive communities, when we want to manage contexts with a high multicultural density and we try to prevent phenomena of radicalization.

Many phenomena are changing faster than our static model of interpretation in theory. Therefore, we need to engage the knowledge generated through informal learning processes. For example: we could use the signs of aesthetics - or the symbols of a culture - to understand the levels of integration or exclusion of a person or group in our community. Or we could use them to understand the lev- el of radicalization. In many cases we may need a deeper level of enquiry to understand what those signs or symbols mean for the specific, local community.

Multiethnic communities encourage the localization of broader processes of socialization. Let's think about informal peer education at school. Students learn elements from very different cultures, sometimes generating misalignments in the families they belong to.

\section{G4 \\ Traditional macro categories are not enough when we want to deeply understand the possibility of generating inclusive communities}

Another informal learning process is created by the dialectical relationship between generations. People of different ages create a proximal development area that does not depend on the multicultural density of the context but on different learning experiences. What are the perspectives of a young person who has studied and lived, since childhood, in multicultural classes and an adult who has experienced mono-cultural walks of life?
So, what knowledge is useful for us to manage these contexts and support inclusive informal learning?

To understand the outcomes of these processes, it is necessary to be able to enter into the contradictions of everyday life and grasp the meanings generated by contingent situations. Sometimes this is how we discover that some signs of belonging are no evidences and testimonies of a monolithic and sometimes radical adherence to an ideology, a culture or a religion. The signs that were manifested and exhibited do not necessarily correspond to the meanings attributed to them by society or by communities.

Apparently, the distinctive trait in terms of today's life contexts is that people have greater margins of freedom in regards to the translation of the cultures of belonging. So, what knowledge is useful for us to manage these contexts and support inclusive informal learning? How can we use this informal learning to generate the setting for emancipatory learning into schools or workplaces? How do we train professionals to become able to do this? 


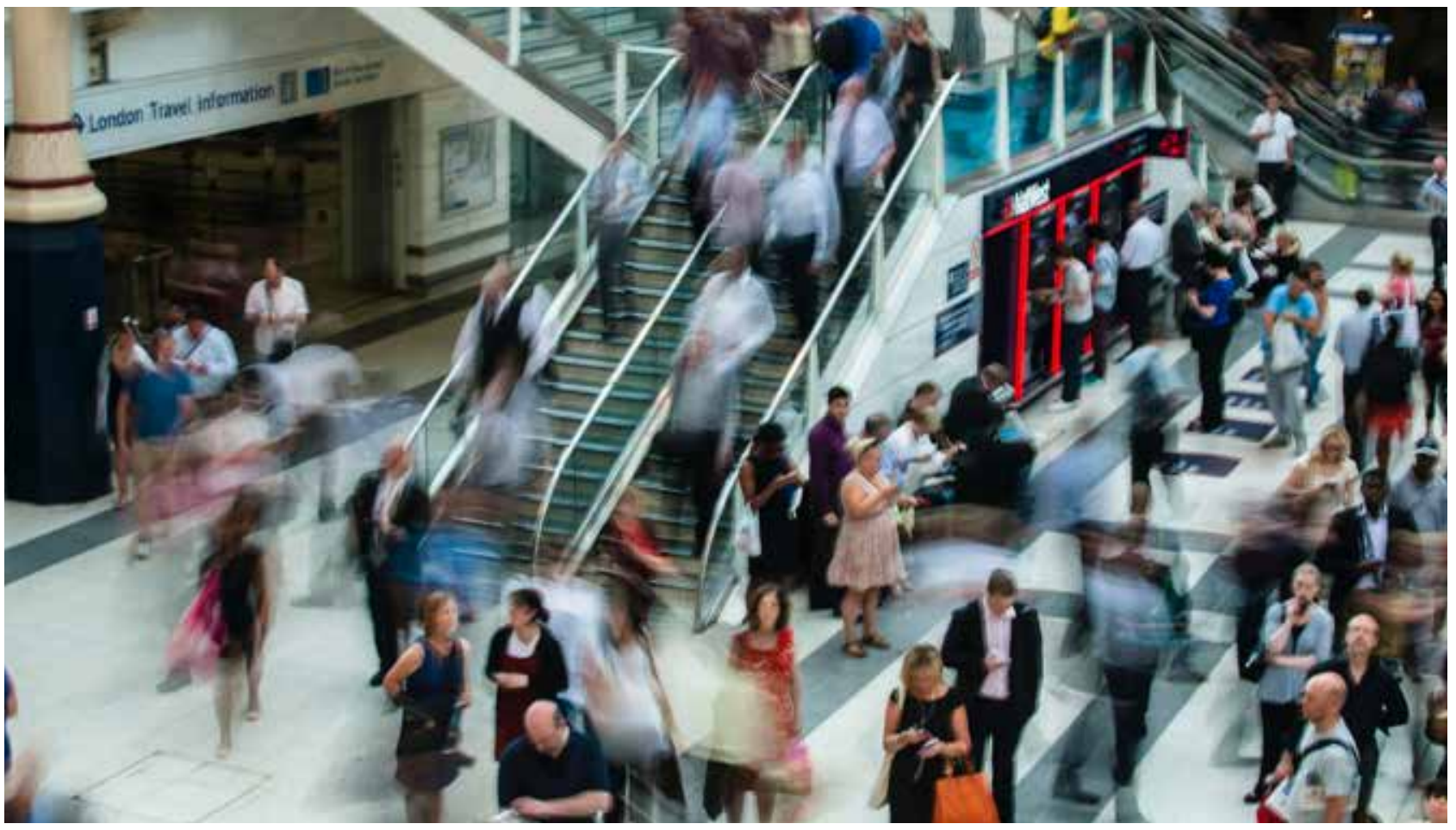

\section{Are we forgetting to study everyday life?}

Despite the wealth of studies on the theme of human rights, on the creation of an inclusive society and on phenomena of radicalization, we cannot assume that we have generated all the knowledge useful for understanding and planning actions for contrasting opinions, stereotypes and for the promotion of dialogue between peoples and cultures.

Professionals can take advantage of scientific knowledge and case studies that illustrate the reasons and causes of certain phenomena in detail. But, despite this, the application of models and grids of analysis only partially facilitate the solution or management of emerging problems in multiethnic societies.

\section{G6 \\ The outcomes of these actions ended up "educating" prisoners to hide the signs used to identify the affiliation to a group, ideology or religion}

Some examples taken from empirical research are symbolic. There is a broad convergence of studies showing that inmates, over the span of their detention, develop even more radical perspectives of thought than they had previously. Therefore, it is difficult to balance certainty and proportionality of the sentence with effective rehabilitative action. Moreover, professionals often use assessment scales to try and define or understand the level of a prisoner's radicalization, usually focusing only on religious radicalization. After a few years, the outcomes of these actions ended up "educating" prisoners to hide the signs used to identify the affiliation to a group, ideology or religion. Now, they often exhibit neutral behaviors. Or, inversely, professionals are no longer able to read the new signs of adherence to a path of thought radicalization. A similar outcome can occur in everyday life. What are the religious symbols, what are the 
evidences that can be accepted as certain elements to understand the sense of belonging to an ideology, to a tradition or to a culture?

While it may seem like a paradox, increasing the general knowledge about something does not necessarily mean that we are increasing the quality of professional actions.

There is a risk that we end up adopting approaches that are only diagnostic and oriented to develop standards and general theory. We are losing the educational approach, and above all we are missing the opportunity of enhancing what, even in an informal way, is happening in terms of inclusion and coexistence.

\section{Supporting professional development to produce a "situated knowledge"}

The critical point in professional practices is that problems do not emerge to professionals as well-formulated structures. This element is further stressed by multicultural professional practices. Problems tend to present themselves as chaotic, uncertain and undetermined. Those who are involved in professional practices need to produce a "situated" and unique knowledge because general criteria cannot inform experts on the right decision to make. Conflicts of values, personal and organizational implications, and complexity of situations are not understandable by stoic knowledge.

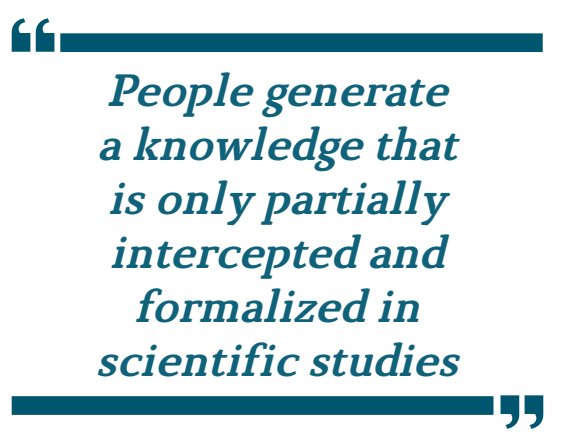

When different cultures, traditions or expectations are in concert, they produce learning phenomena that arises spontaneously in everyday life or in the workplace. People generate a knowledge that is only partially intercepted and formalized in scientific studies.

Professionals working in contexts with a high multicultural density often declare that there are no appropriate categories of analysis to resolve problematic situations, or they have not been suitably trained in a professional sense for these situations. Real-life is ways ahead of the current status of research. The gap between theory and practice, encourages professionals to use standards, schedules and theories with no connections with the situations in which they operate. We are providing below an example where a professional, a teacher, relied on procedures uncritically.

A few months ago at the University of Siena we inaugu- rated a series of seminars that focused on leadership and management of contexts with high multicultural density, where primary attention was given to methods of intervention that were useful for preventing the phenomenon of radicalization. This series of seminars was part of F.O.R.w.A.R.D, an international project funded by the Italian Ministry of Education, University and Research (MIUR). During one of these seminars, a colleague reported the example of how a teacher in North America had made decisions guided by procedures rather than by understanding the situation. The teacher was certainly competent in her discipline, she was much loved by her students and she had studied a lot in regards to methods of radicalization prevention. She never thought she would find herself in the following professional situation.

Following the attack of November $13^{\text {th }}, 2015$ at the Bataclan, she asked her students to compose an essay on the tragic event. Her intent was to support reflections on the phenomenon of terrorism in the classroom. She was expecting a unanimous condemnation of the attack.

At the time of the correction of the texts, she had to acknowledge that a large part of the students was reflecting on the reasons for the violent act. Many students had written a text where they explained their 
surprise that there was still someone ready to die for a political ideal. Some students had framed the event in a more general story, quoting the theme of oppression of the poor people or the decline of the values as the main motivational factor. The teacher found herself in what is metaphorically described by Schön as "the swamp of professional practice”. The teacher did not correct the papers that expressed arguments, not condemnation.

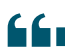

The gap between theory and practice, encourages

professionals to use standards, schedules and theories with no connections with the situations in which they operate.

Worried of the contents of these written tests, she left no scope for further reflection on what those texts meant to some of her students. This inevitably implied a loss of trust, contact and relationships within the class. Parents were obviously involved and monitoring procedures were activated. The first effect on the class was the generation of distance and distrust. Some of the students felt attacked and blamed the teacher for not being able to handle the situation, for misrepresenting the texts and for not understanding their need for further discussion. After a few days, the news was on the local newspaper and the students had been labeled. A part of the classroom came out of this story with the idea that at school, in that class, they could not be trusted nor could they argue. Some teachers inside the institute were implicitly led to take a position publicly. Ultimately, we do not know whether that teacher had a preventive effect or fed further forms of radicalization, but her action certainly reflected many of the theories she had learned. The teacher did not seek a comparison with colleagues or professionals to validate her didactic decision. She did not address the problem, which would have been the best way to intervene in that particular situation, but instead she used the procedures as the best way to take charge of the problem.

This experience shows that sometimes, professionals adopt perspectives with a limited space for situational management of the problem. The teacher used her representations and scientific knowledge, believing that she could not do otherwise, because she had been taught to manage the problem this way.

So, how can we keep contact with adolescents who express clear positions that are in contrast with the values shared by their socio-cultural context? How can the school remain an open environment for comparison and management of the complexities that are also reflected in everyday life? How can we train professionals to make them capable of managing the contradictions generated by multiculturalism without generating further tears and cultural divisions?

\section{The professionals as researchers. The case at University of Siena}

The project F.O.R.w.A.R.D, a year-long experimentation conducted by the University of Siena aims at developing methodologies to support inclusive societies and prevent the radicalization processes. One action of this project is focused on developing a training program for social educators. The core idea of this program is: an educator needs necessary multicultural skills to mange educational and learning processes, one of these skills is the ability to produce "situated knowledge". Some of these skills could be useful in preventing and understanding the phenomenon of radicalization in its various forms: religious, political and cultural. The objective of this action is to support future educators in learning cultural skills and functional methodological devices to respond to the challenges of multiethnic environments. The idea is not to build an ad-hoc degree course to train experts in de-radicalization, but to 
make educators able to manage the complexity of multicultural practices.

GG

An educator
needs necessary
multicultural
skills to mange
educational and
learning processes,
one of these skills
is the ability to
produce "situated
knowledge"

Following this hypothesis, we have included optional teaching modules within the three-year degree in Education Sciences at the University of Siena: Pedagogy of de-radicalization, Psychology of radicalism, Soci- ology of migration, Philosophical practices for the prevention of new radicalisms, Psychology of multicultural processes, European immigration law, Trans-cultural pedagogy, Philosophy of intercultural education, and Intervention methodologies and tools for inclusion in jail, in institutional settings and related welfare services.

Currently, in the first year of experimentation, about 25 students have enrolled in these courses, a portion of which are from other countries. Some students have been involved in research on the territory, aimed at producing data on the phenomena of "micro-radicalization". In some cases active development methodologies have been used to support the critical analysis of the most contradictory situa- tions that we analyzed in everyday life. We created a mixed community composed of academics, professionals and students where we could study the inclusion process generated by informal learning. Sometimes we found stories of micro-radicalization in daily life.

Ultimately, the initial question addressed by this article came up while facing a case study about a youth who was showing the initial signs of a radicalization process. We knew the cultural origin of this young man and we knew about his community. We also had a scale of the classification of radicalization processes to use, we must therefore ask: how could we act in terms of real professional practices where the first objective is not to generate further

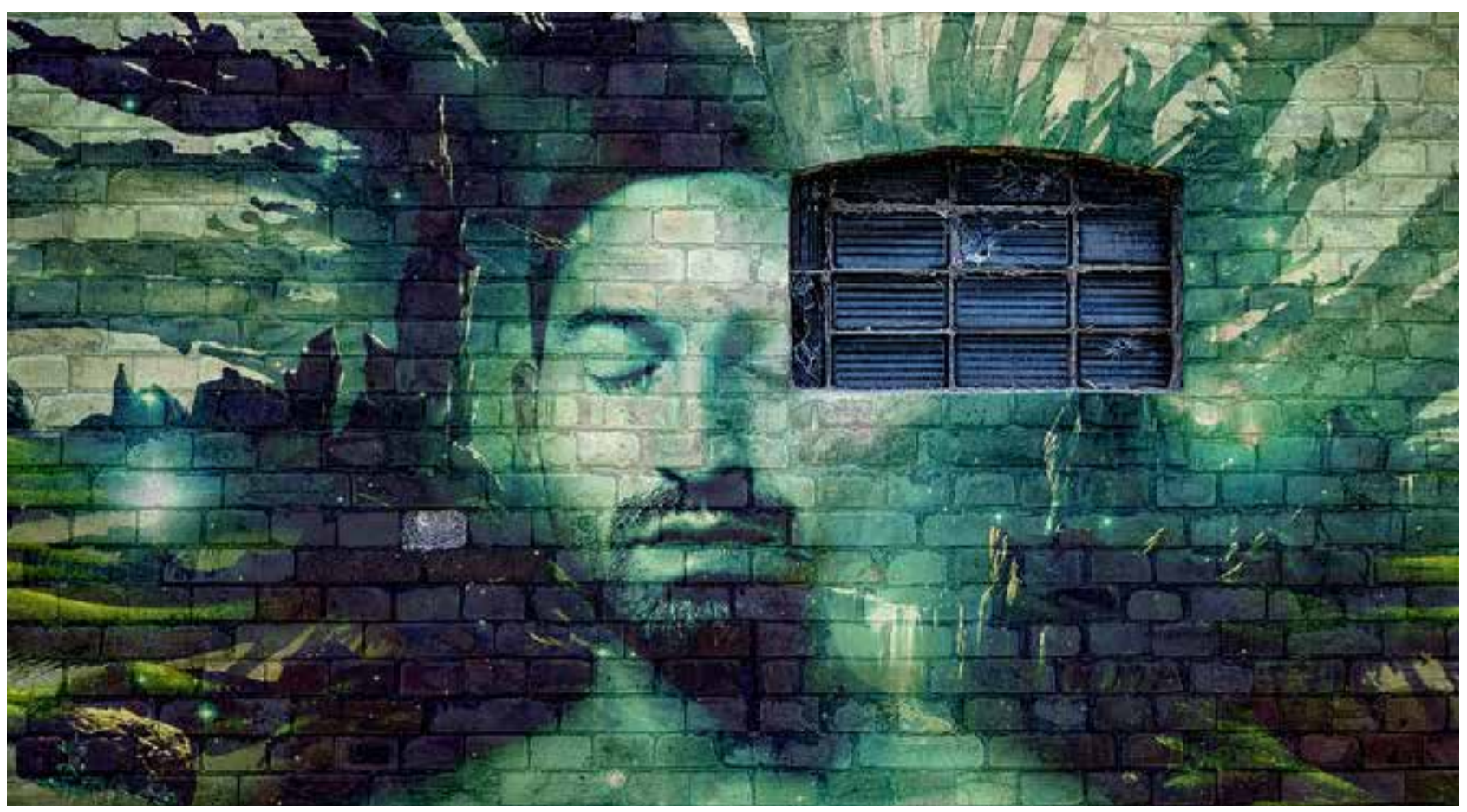




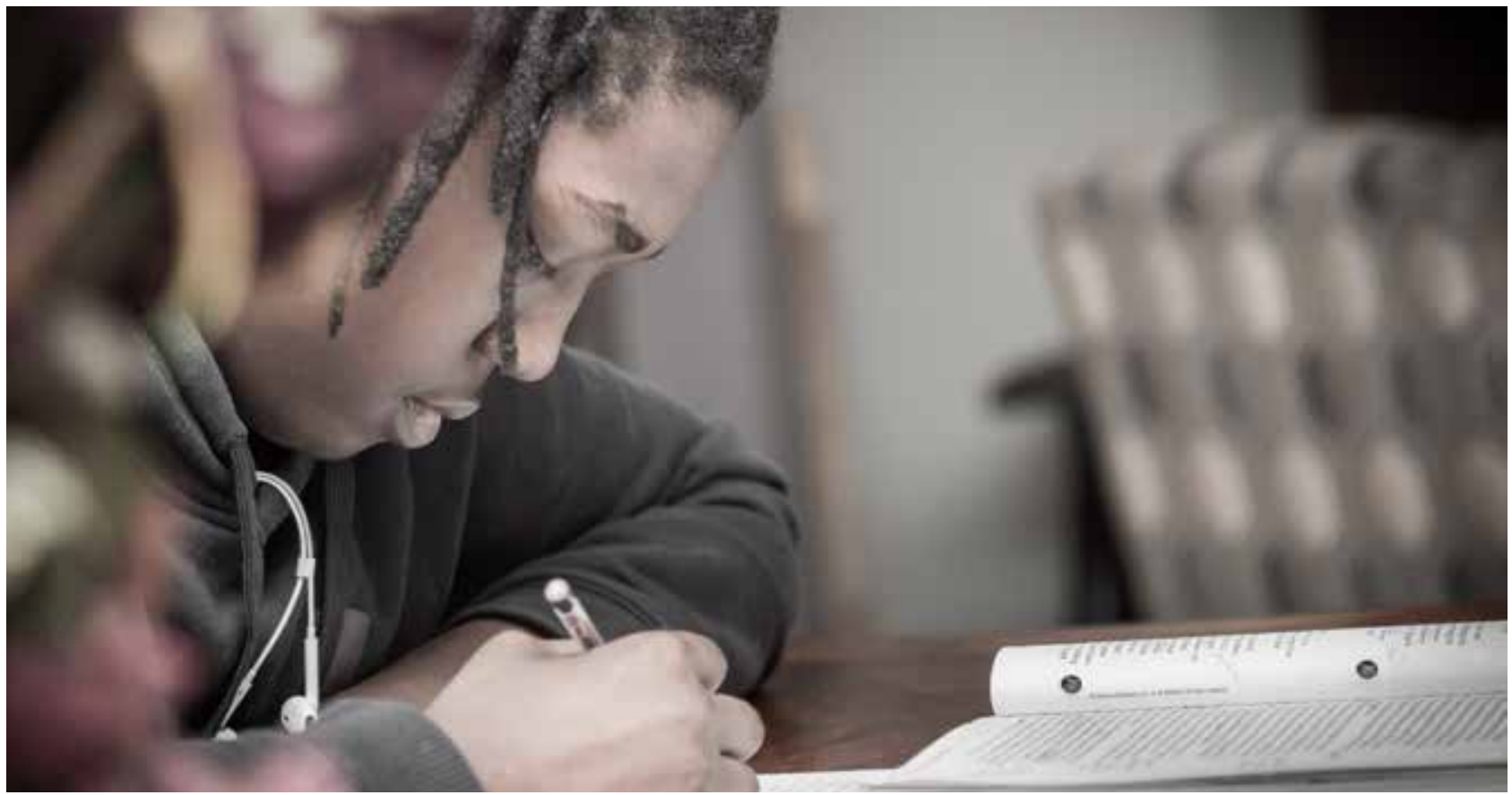

fractures between people and communities? We have been challenged as researchers. How can we reconcile the need to remain adherent to our institutional mandate and not lose contact, relationships and trust with people who risk moving from the stage of radical thought to that of transforming this thought into violent actions?

We need to stick with meanings and actions made by people in everyday life because the general categories risk to generate new forms of stereotypes and misunderstandings. The informal learning generated within families, workplaces, communities could be the new opponent while working towards a more inclusive and open society.

\section{The Authors}

Loretta Fabbri, Ph.D, is Full professor of Didactics and Transformative Methodologies and Vice-head of the Department of Education, Human Sciences and Intercultural Communication, and delegate of the Rector for the soft-skills programs within the Teaching \& Learning Center at the University of Siena. Her research is focused on Theory and Methods of Transformative Learning, Community of Practices and post-qualitative research.

She is co-founder of the Italian Transformative Learning Network and works with private and public institutions for continuing education programs.

Claudio Melacarne, Ph.D, is Associate Professor of Social Pedagogy at University of Siena. He is interested in studying professional development processes in organizations using educational and training research methodologies. He is Codirector of the international journal Educational Reflective Practices. He works as a consultant in public and private companies. He currently teaches Foundation of Social Pedagogy and Methodologies of Educational Research and Training. He is the coordinator of the Educational Sciences and Organizational Consulting program (MSc) at the University of Siena. 


\section{MASTER OF LAWS IN TRANSNATIONAL CRIME AND JUSTICE}

The Master of Laws (LL.M.) in Transnational Crime and

Justice is designed for young professionals and university graduates wishing to specialize in the fields of international law dimensions of peace and conflicts, transnational crimes and transitional justice, humanitarian law, international criminal law and procedure, and international human rights law.

\section{LL.M. OFFICE CONTACTS}

E-mail: unicri.Im@un.org

Tel.: (+39) $0116537157-154--$ - (+39) 011653711

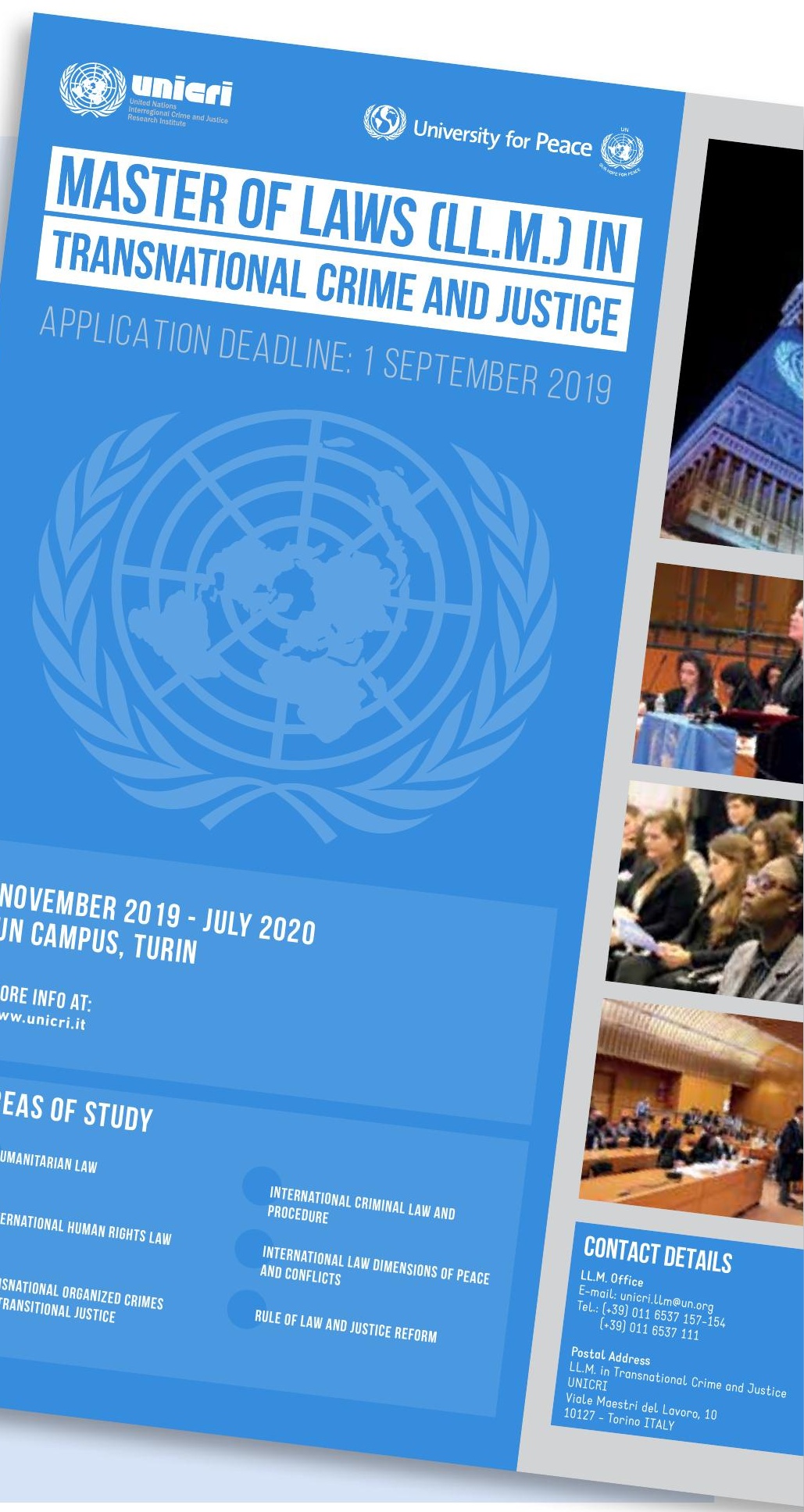


Who is susceptible to the call of political violence?

A study of differential susceptibility and situational resistance to exposure to online violent extremism

by Lieven J.R. Pauwels and Wim Hardyns (Ghent University)

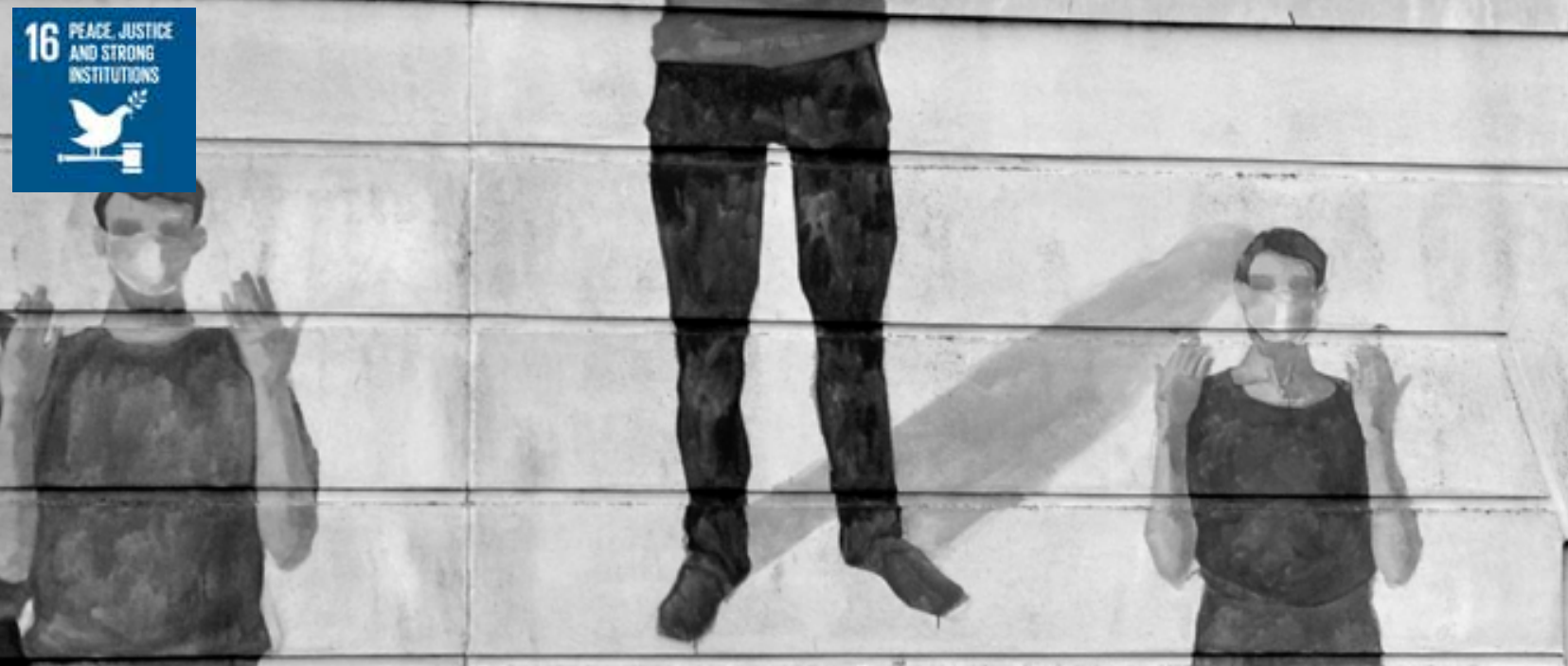




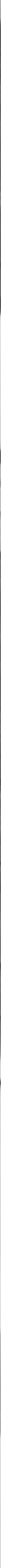




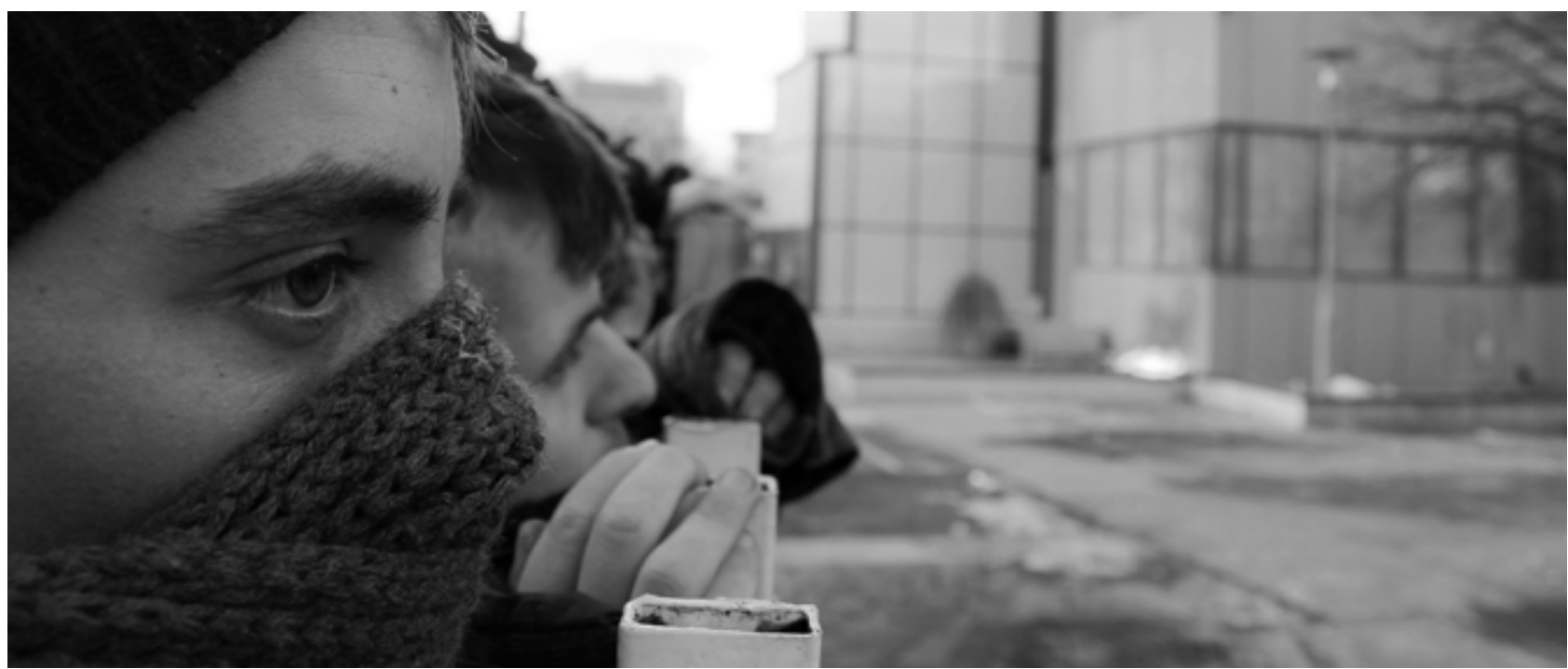

\section{Exposure to violent} extremism

One hotly debated issue in contemporary research on politically and/or religiously motivated violence is the issue of 'differential susceptibility' versus 'situational resistance of exposure to extremism', both in real life and through social media., ${ }^{1,2}$ The basic idea is that individuals who are susceptible will be influenced differentially to commit politically or religiously motivated violence, depending on their level of exposure to extremist content. Situationally immune individuals are sufficiently protected against negative influences such as exposure to extremist content via social media or online exposure to vio- lent extremism. In criminology, the idea of differential susceptibility is acknowledged in different frameworks (see Wikström \& Bouhana, 2016). The issue of differential susceptibility has a long tradition in developmental and social psychology.

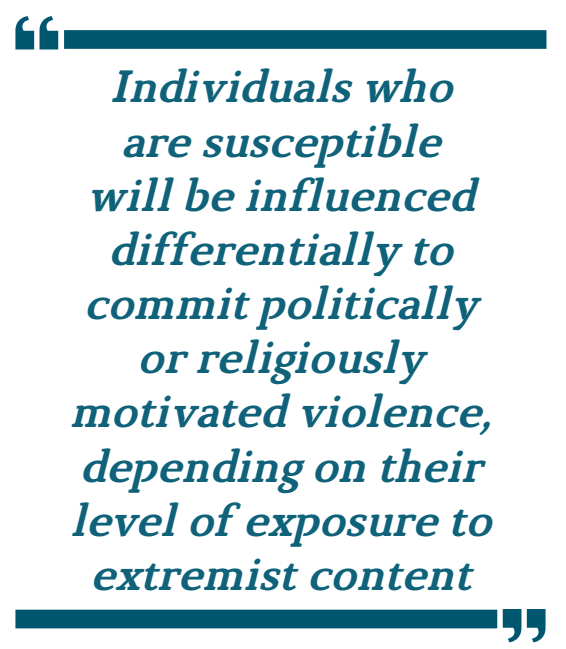

The study of politically motivated violent crimes is interdisciplinary and has a long tradition in political sciences (for overviews see Koehler, 2017), criminology (e.g. LaFree \& Freilich, 2017) and psychology (e.g. Bandura, 1990; Borum, 2004; Davis \& Cragin, 2009). Contemporary scholars of political/religious violence discuss the importance of exposure to extremist content online (e.g. using social media). Akin to the heated debate on the relation between exposure to aggression in playing (video) games and aggressive behavior, the discussion on the impact of exposure to online extremist content takes different forms. Several learning theories are often used to explain the ef-

1 This article is a summary of our study that is published in the thematic issue "Developmental Pathways Towards Violent Left-, Right-Wing, Islamist Extremism and Radicalization" of the International Journal of Developmental Science. For the full-text of our study, see: Pauwels, L. \& Hardyns, W. (2018). Endorsement of extremism, exposure to extremism via social media and self-reported political/religious aggression. International Journal of Developmental Science, 12, 51-69. https://content.iospress.com/articles/international-journal-of-developmental-science/dev170229

2 We would like to thank Belgian Science Policy (BSP) and the Belgian Ministry of the Interior (IBZ), who co-financed this research project to get insight in the relationship between exposure to extremist content and politically/religiously motivated aggression. A first research report was published as (Pauwels et al., 2014). We have complied with Helsinki Ethical Declaration in the treatment of our data. 
fects of exposure to aggression. One of the first influential models was the Social-Cognitive Model of Albert Bandura, who also stressed the importance of attitudes and extremist beliefs on the commitment of atrocities like acts of terrorism (Bandura, 1990). Some scholars hypothesize that there is a strong causal relationship between an individual's exposure to extremist content and the individual committing political/religious violent crimes (Akers \& Silverman, 2004), while other scholars argue that online exposure is a matter of selection effects (King $\varepsilon$ Taylor, 2011; Klausen, 2015). Selection effects occur when people self-select (or choose) to build their own niches. Few studies have examined interaction (i.e. amplification) effects as a viable explanation for the moderate-sized main effects of measures of exposure to extremist content through social media and self-reported acts of crime, committed to obtaining political or religious goals (Schils \& Pauwels, 2016). As crime is a legal construct (i.e. a summary of what is prohibited by law in a given jurisdiction in a certain time window), we have decided not to focus on this heterogeneous phenome- non of crime ${ }^{3}$ and to connect with the social-psychological research tradition focusing on aggression, namely political aggression (Allen \& Anderson, 2017). After all it is aggression, and the most severe forms of, namely seriously violent acts which affect our (biased) perceptions of fear of crime.

\section{Gf \\ The internet and social media can function as an echo room and that social media and the internet play an important role in recruiting members of extremist groups}

Aggression and violence are often used synonymously in the fields of political science and criminology, but in social psychology, violence refers to the most serious acts of aggression, i.e. behavior intended to cause harm (whether or not attempted or succeeded). Intentionality, harm and the avoidance of harm by the target are what distinguishes aggression from other behaviors that may be antisocial or may involve the breaking of conventional norms. Most scholars in the 'political violence and illegal political protest' research tradition as well as scholars in the 'violent extremism' and 'terrorism' literature seem to agree on the fact that the internet and social media can function as an echo room and that social media and the internet play an important role in recruiting members of extremist groups (Amble, 2012; Awan, Hoskins, \& O'Loughlin, 2011; Klausen, 2015; Roversi, 2008). ${ }^{4}$ Much of the debate is however not based on large-scale empirical studies but either on in-depth analyses of narratives of terrorists (Moghaddam, 2006; Speckhard, 2012) and case studies of suicide bombers (e.g. Pape, 2005). We encourage these kinds of indepth studies as they provide very valuable information on terrorists' motives and help to reconstruct the life histories of these individuals. However, large scale studies in general populations are somewhat lacking, although both quantitative and qualitative studies of political aggression are needed to enhance our understanding of the mechanisms that affect the commitment of politically violent acts.

3 Leading contemporary criminologists argue that the study of causes of crime is hampered by the heterogeneity of definitions, and suggest as a solution to this problem that it is more worthwhile to try to explain why people break rules, stated in law, knowing the sanction is possible. The rule-breaking element is what all crimes have in common, according to some criminological research traditions (Wikström \& Bouhana, 2017). Definitional problems have challenged criminology for a long time (Agnew, 2011).

4 In this contribution we do not pay attention in separate paragraphs to the problems of defining violent extremism and terrorism, as a myriad of definitions exist. Radicalization is a complex process of incrementally experienced commitment to extremist political or religious ideology. For an overview of definitions of radicalization processes we refer to Horgan (2005) and Koehler (2017). For an overview of the relationships between extremism and terrorism we refer to Schmid (2011). 
A large-scale web survey of young adults in Belgium

Recently, we studied the interaction between specific measures of endorsement of extremism (e.g. endorsement of religious, left-wing or far-right extremism), thrill-seeking, and active online exposure to extremism via social media with regard to the explanation of politically and/or religiously motivated aggression (see also Schils \& Pauwels, 2016; Pauwels \& Schils, 2016). While the relationship between exposure to crimeprone contexts and aggression has been studied widely, no previous study has explicitly demonstrated the conditional effects of these factors in a survey of young adults and with regard to political aggression. Our study is inspired by the General Aggression Model, a well-established theory of aggression and the Situational Action Theory, a recently developed theory of crime causation. The unique contribution of our study is that it is based on distinctive measures of endorsement for extremism (left-wing nationalist/ separatist and religious extremism) and that it focuses on the differential effect of exposure to extremist content online. We made use of a large-scale web survey of young adults in Belgium where 6,020 respondents completed the online questionnaire. The mean age (range, 1531 years) was 20.19 years, and
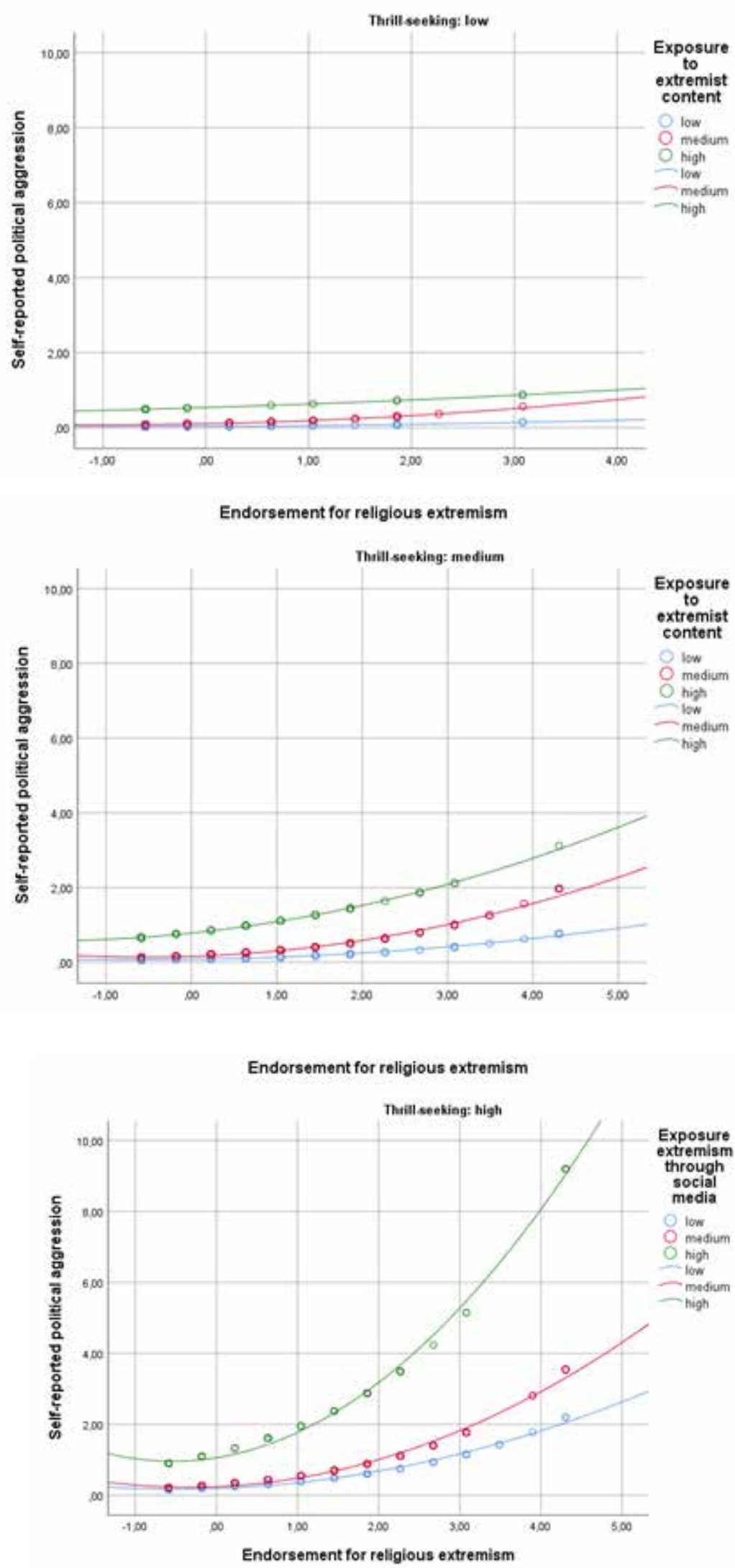
$35.3 \%$ of the sample were males. The results support an amplification effect: endorsement of extremism is related to self-reported political aggression but its effect increases by levels of active social media exposure. The results additionally showed that (1) there is no relationship between endorsement of leftwing, right-wing and religious extremism in individuals scoring low on thrill-seeking, (2) there is a moderate relationship positive between endorsement of left-wing, right-wing and religious extremism in individuals scoring averaged on thrill-seeking, (3) there is a strong positive relationship positive between endorsement of left-wing, rightwing and religious extremism in individuals scoring high on thrill-seeking. We illustrate these findings for the relation- ship between endorsement for religious extremism, political aggression and thrill-seeking.

The unique
contribution of our
study is that it is
based on distinctive
measures of
endorsement for
extremism (left-
wing nationalist/
separatist
and religious
extremism) and that
it focuses on the
differential effect
of exposure to
extremist content
online

These findings are rather stable across extremism-specific measures of endorsement of extremism. This study adds to the growing body of literature demonstrating a statistical interaction between the endorsement of extremism and the online exposure to its narrative. The relationship between exposure to extremist content and self-reported aggression remains however controversial, not only from theoretical and empirical perspectives but also from a policy perspective. We are limited in deepening this discussion here but we can refer to the debates regarding the effect(s) of exposure to violent video games. In short, such studies have shown mixed results, and those studies that do show significant effects of exposure reveal small statisti-

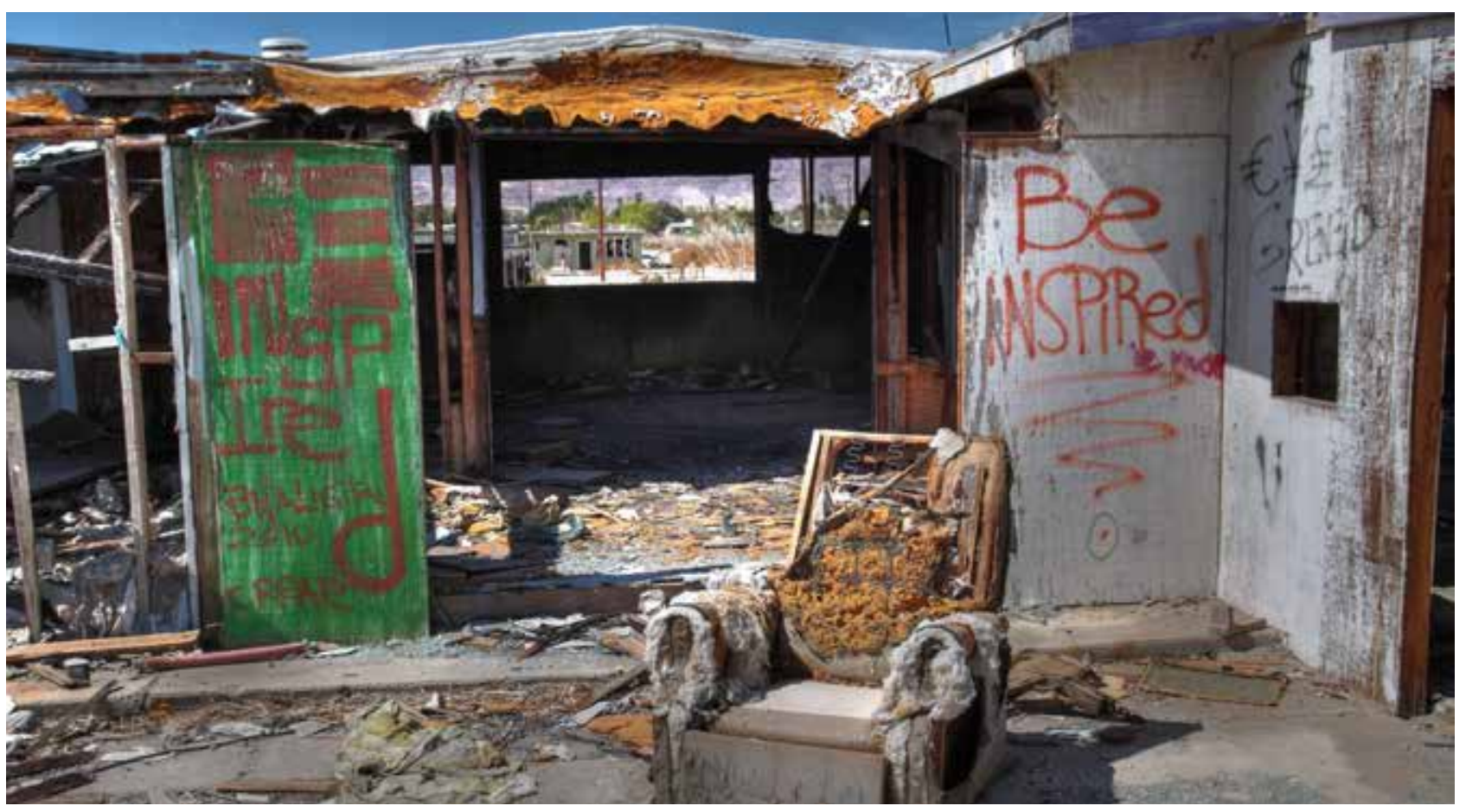


cal effects. This study shares a similarity with the more conventional studies of exposure to criminogenic 'violent' contexts. We studied the effect of exposure to extremism, albeit from a completely different angle consisting of exposure to extremist content (online). The basic idea was to discover similarities or differences in the processes leading to the act of political violence. Our study contributes to the literature by showing that exposure to extremist content is not related to political violence when individuals are sufficiently protected by both their morals and their level of thrill-seeking. But when self-control decreases, the effect of exposure to extremist content on the relation between endorsement of rightwing, left-wing or religious violent extremism and political violence becomes stronger.

\section{Key questions and future studies}

There are several key questions that remain under-researched thereby deserving further inquiry. They are (1) how do individuals acquire their endorsement to extremism?, (2) how stable are these attitudes through the life course?, and (3) how stable are these interactive patterns across different phases of development? We have studied a large sample of young adults, but the research should cover the course of an individual's life. Sometimes individuals radicalize much later in life and some have a history of deviance. However, sometimes adults radicalize without any developmental history of externalizing behavior. If we really want to take developmental tests of the processes of radicalization (and disengagement) seriously, panel data can be of high value. Young adolescents and even children have been drawn to areas of conflict because of a fast process of radicalization, thus, we need to increase our understanding of the differential susceptibility of several age groups to different kinds of exposure. The power of radical messages online and offline and the powerful discourses brought about by recruiters should neither be overestimated or underestimated. Small effect sizes in studies often lead to underestimating, but we argue that overall small effect sizes are related to differential susceptibility. Different age groups represent different phases in the lifecourse and thrill-seeking is especially higher in adolescents than in older populations. This suggests a plausible explanation for the vulnerability of adolescents. However, what makes adults suddenly develop attitudes favorable to extremism? And how is the process of disengagement, i.e. the process of desistance brought about?

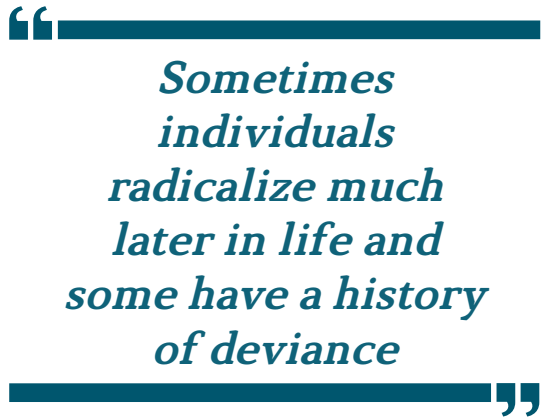

Future studies should try to improve sound integrative theories analyzing all mechanisms involved in the explanation of political aggression as well as the processes that lead to the development of endorsement of extremism. They should also address the factors leading to exposure to extremist content, which is likely caused by a combination of social influence (peer influence of members of extremist groups), social selection (i.e. urban segregation, which causes recruiters to target some areas more than others), and self-selection (i.e. processes of perception and choice, caused by a sense of belonging or similar human motives). In other words, it is of major importance in terms of theory and policy to disentangle the so-called 'causes of the causes' of political aggression to further enhance our understanding of how grievances and weak social integration gives rise to political powerlessness, alienation from wider society and the development of endorsements of nationalist-separatist, religious or left-wing extremism. While these atti- 


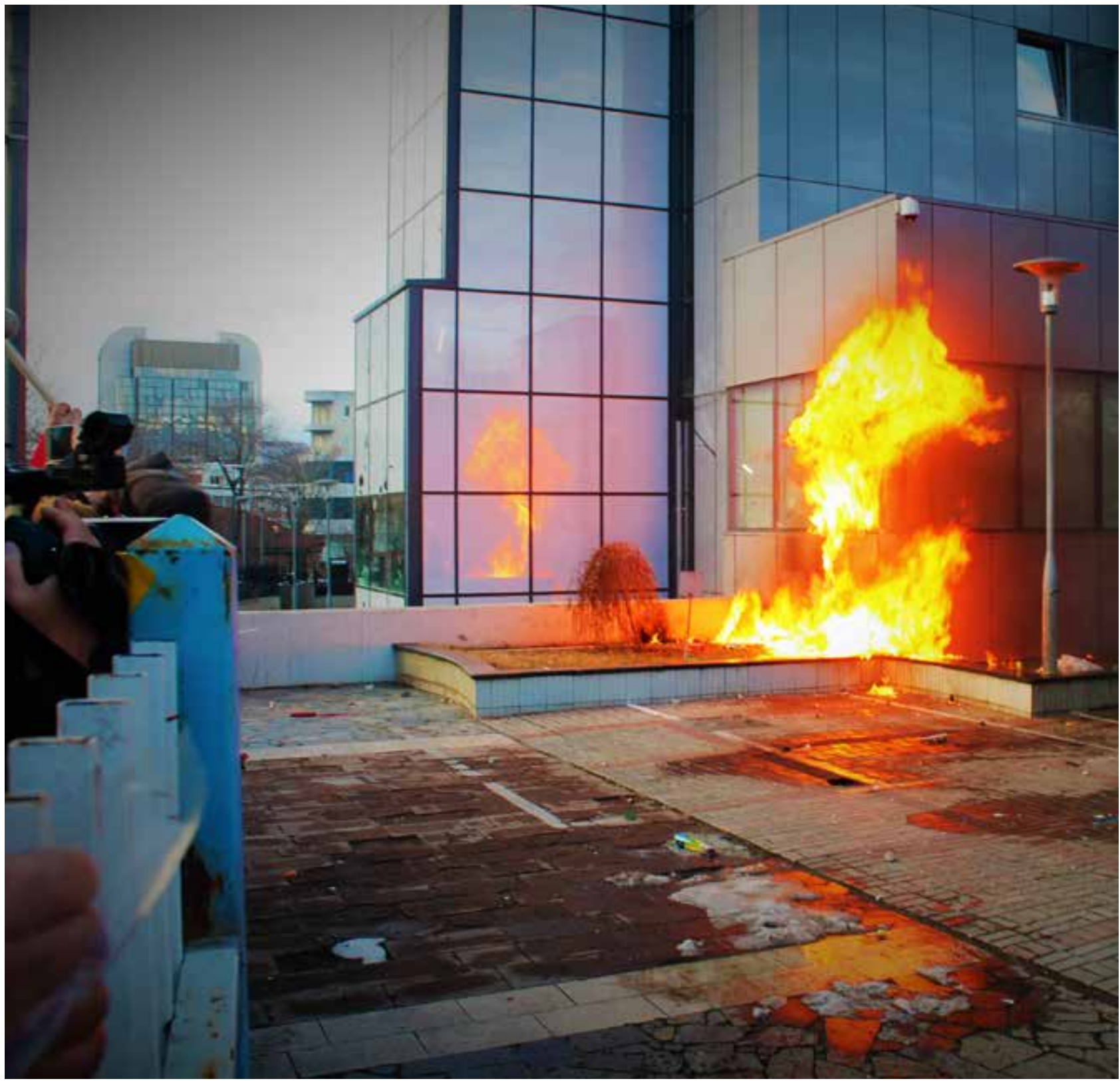

tudes and beliefs are different, the interactive processes that produce political aggression, as an outcome, seem to be highly similar. There is an urgent need to develop a critical test of propositions derived from truly interdisciplinary integrative theories that incorporate elements of cognitive neurosciences, cognitive psychology (beliefs), sociology and geography (exposure to settings). Some disciplines will be more useful in explaining some of the 'causes of the causes' of violent extremism, while others will be more useful in explain- ing direct and situational causes of violent extremism. Our personal experience is that this kind of theoretical integration will require scholars to learn each other's language, but once this barrier has been overcome, challenging new research strategies can be facilitated. 


\section{Policy implications for the prevention of political aggression}

What do these results suggest with regard to the prevention of online radicalization into extremism? This study suggests that exposure to extremist content strongly triggers the endorsement of extremism for individuals, while the magnitude of the effect of exposure to extremist content on self-reported political violence is further amplified by levels of thrill-seeking. This means that of primary concern are complex interactions between individual and circumstantial characteristics. Websites and social media platforms visited by adolescents differ in nature as well as in persuasiveness of extremist content. Their content is sometimes very provocative and tempting which, triggers an emotional reaction and affects attitudes, as well as norms (Ramsay, 2013; Roversi, 2008). Some virtual settings give very easy access to extremist content and pose a dangerously real potential for further recruitment into extremist groups or for preparing attacks in the form of "home-grown violent radicalization.' Although extremists might be trying to spread hate and induce polarization in mainstream virtual settings (such as chat rooms and web fora for a general audience), these mainstream settings are not extremist in nature. While closing down these general fora is not very effective in the prevention of violent extremism, extremist content which is polarizing should be removed to avoid further escalation. Governments should support the removal of extremist content on mainstream social media and fora.

\section{G4 \\ This study suggests that exposure to extremist content strongly triggers the endorsement of extremism for individuals}

Adolescents in an early stage of radicalization may also visit websites or YouTube channels containing explicitly extreme content or join extremist groups on social media in search of plain answers to complex problems related to

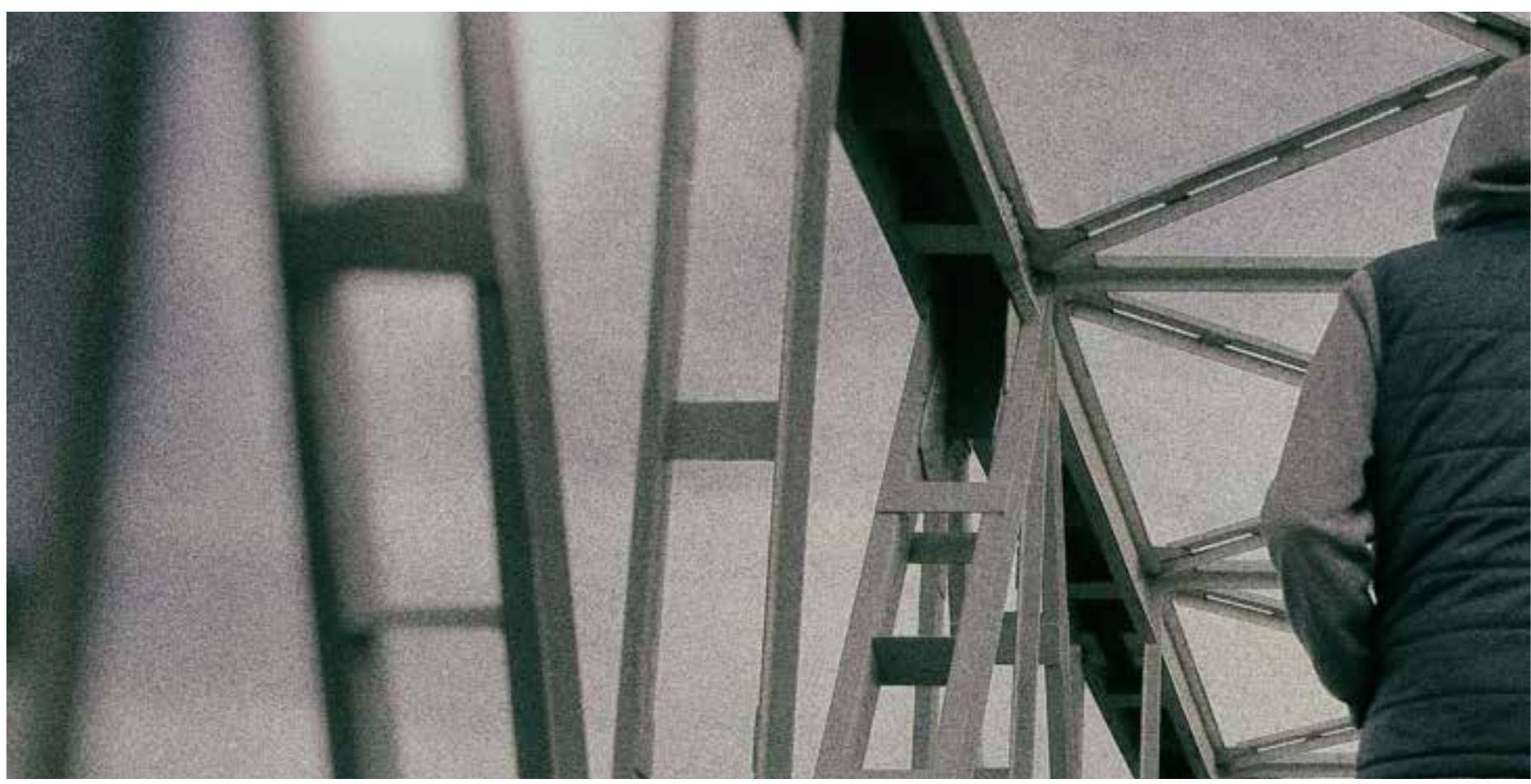


political aggression. Individuals who score high on thrill-seeking measurement caliber experience an amplification effect: In this group, the effect of endorsing extremism is triggered by levels of exposure. Thrill-seeking pulls some individuals towards extremist groups.

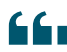

The focus should move from counter-narratives to alternative narratives which provide strong and positive arguments

Consequently, these highly susceptible individuals may be especially difficult to convince to abide by the law with (online or offline) rational narratives alone. Online narratives will have lesser impact if the real-life circumstantial characteristics are not addressed simultaneously. The prevention of endorsing extremism, be it on the left-wing, rightwing or religious wing, will be easier to facilitate by developing interventions that reorient moral endorsement (e.g. through education and cognitive behavioral therapy) and cognitive nurturing (e.g. learning to overcome proneness to thrill-seeking), akin to that in developmental crime prevention. In this study we have not addressed the problem of the causes of the causes, i.e. why and how (events and processes) some individuals develop their grievances. However, several empirical studies have pointed to the role of grievances, group processes and alienation (e.g. Doosje et al., 2013).

Some individuals may engage in aggression habitually because behaving violently may have provided rewards to the actor as a means to solve problems encountered in life, or because they have been raised in disadvantageous ecological contexts. Here, social prevention is important and this prevention can be achieved by removing at-risk individuals from certain ecological contexts where they are repeatedly provoked or tempted. It is important that the prevention of political aggression has a profound knowledge-base and that it takes an analytical approach to prevent problems of the day being from being solved with 'measures of the day' (Wikström \& Treiber, 2016). We hope that this study, which demonstrates the complexity of political aggression, may set a paradigm for interventions by analytically looking at the problem of political aggression.

\section{The Authors}

Lieven J.R. Pauwels is a professor of criminology at the Department of Criminology, Criminal Law and Social Law at Ghent University, Belgium. He is Director of the Institute of International Research on Criminal Policy (IRCP). He is interested in a developmental-ecological approach to juvenile delinquency, violent extremism, and knowledge-based (crime) prevention.

Wim Hardyns is a professor of criminology at the Department of Criminology, Criminal Law and Social Law at Ghent University, Belgium. He is a member of the Institute of International Research on Criminal Policy (IRCP). His current interests are crime mapping and statistics, environmental criminology, crime prevention, new security technologies, big data, radicalization, and terrorism. 


\section{References}

Akers, R. L., \& Silverman, A. (2004). Toward a social learning model of violence and terrorism. In M.A. Zahn, H.H. Brownstein, \& S.L. Jackson (Eds), Violence: From theory to research (pp.19-30). London: Matthew Bender/LexisNexis.

Allen, J. J., \& Anderson, C. A. (2017). Aggression and violence: Definitions and distinctions. In P. Sturmey (Ed.), The Wiley Handbook of Aggression and Violence.

Amble, J. C. (2012). Combating terrorism in the new media environment. Studies in Conflict \& Terrorism, 35, 339-353.

Bandura, A. (1990). Mechanisms of moral disengagement in terrorism. In W. Reich (Ed.) Origins of terrorism: Psychologies, ideologies, states of mind (Pp161-191). Cambridge: Cambridge University Press.

Borum, R. (2004). Psychology of terrorism. Tampa: University of South Florida.

Davis, P. K., \& Cragin, K. (Eds) (2009). Social science for counterterrorism: Putting the pieces together. Santa Monica: Rand Corporation. DOI: 10.7249/MG849

Doosje, B., Loseman, A., \& Bos, K. (2013). Determinants of radicalization of Islamic youth in the Netherlands: Personal uncertainty, perceived injustice, and perceived group threat. Journal of Social Issues, 69, 586-604.

Horgan, J. (2005). The psychology of terrorism. New York: Routledge.

King, M., \& Taylor, D. M. (2011). The radicalization of homegrown jihadists: A review of theoretical models and social psychological evidence. Terrorism and Political Violence, 23, 602-622.
Klausen, J. (2015). Tweeting the Jihad: Social media networks of Western foreign fighters in Syria and Iraq. Studies in Conflict \& Terrorism, 38, 1-22.

Koehler, D. (2017). Understanding Deradicalization: Methods, tools and programs for countering violent extremism. London: Routledge.

LaFree, G., \& Freilich, J. D. (Eds.). (2017). The Handbook of the Criminology of Terrorism. Sussex (UK): Wiley Blackwell.

Leuprecht, C., Hataley, T., Moskalenko, S., \& McCauley, C. (2010). Containing the narrative: Strategy and tactics in countering the storyline of global jihad. Journal of Policing, Intelligence and Counter Terrorism, 5, 42-57. DOI: $10.1080 / 18335300.2010 .9686940$

Moghaddam, F. M. (2006). From the terrorists' point of view: What they experience and why they come to destroy. Westport, CT : Praeger Security International.

Pape, R. A. (2005). Dying to win: Why suicide terrorists do it. Gibson Square.

Pauwels, L., Brion, F., Schils, N., Lafinneur, J., Verhage, A., De Ruyver, B., Easton, M. (2014). Explaining and Understanding the Role of Exposure to New Social Media on Violent Extremism - An Integrative Quantitative and Qualitative Approach-, Gent: Academia Press

Pauwels, L., \& Schils, N. (2016). Differential Online Exposure to Radical Content and Political Violence: Testing the Relative Strength of Social Learning and Competing Perspectives, Terrorism and Political Violence, 28, 1-29.

Ramsay, G. (2013). Jihadi Culture on the World Wide Web. New York: Bloomsbury Publishing.
Roversi, A. (2008). Hate on the net: Extremist sites, neo-fascism on-line, electronic Jihad. Hampshire: Ashgate.

Schils, N., \& Pauwels, L. (2016). Political/ religious violence and the mediating role of extremist propensities. Testing a theoretical elaboration of situational action theory. Journal of Strategic Security 9, 70-91

Schmid, A. P. (Ed.). (2011). The Routledge handbook of terrorism research. New York: Taylor \& Francis.

Speckhard, A. (2012). Talking to Terrorists. Understanding the Psycho-Social Motivations of Militant Jihadi Terrorists, Mass Hostage Takers, Suicide Bombers \&' Martyrs'. McLean (VA): Advances Press.

Weilnböck, H. (2013). Das narrative Prinzip: Good Practice-Interventionen im Kontext des Radicalisation Awareness Network (RAN). In R. Melzer, \& S. Serafin (Eds), Rechtsextremismus in Europa Länderanalysen, Gegenstrategien und arbeitsmarktorientierte Ausstiegsarbeit (pp. 397-428). Frankfurt am Main: Zarbock GmbH \& Co.

Wikström, P.-O. H., \& Bouhana, N. (2017). Analyzing radicalization and terrorism: A situational action theory. In Lafree, G. \& Freilich, J. (Eds.) The handbook of the criminology of terrorism (pp175-186). Sussex (UK): Wiley Blackwell

Wikström, P.-O., \& Treiber, H. (2016). Beyond risk factors: An analytical approach to crime prevention. In: Teasdale, B., Bradley, M.S. Preventing Crime and Violence. Advances in prevention science (pp 73-87), Cham (Switzerland): Springer International Publishing. 
According to the Security Council, over 30,000 FTFs from over 100 Member States were attracted by terrorist organizations such as Al-Qaida, the Islamic State in Iraq and the Levant (ISIL, also known as Da'esh). "Because the related challenges are by their nature international, the Council has called on Member States to enhance their international cooperation in preventing their travel. Attempts to combat the threat through a purely domestic approach will not work." 2

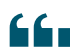

\section{Some countries remain more vulnerable to this phenomenon than others, but overall it is an international problem that requires new approaches}

It is difficult to estimate the number of FTFs killed, as well as the number of those who have returned to their countries of origin or have relocated to third countries. ${ }^{3}$ The reasons for the return of FTFs to their home countries vary: it can be due to disillusionment, remorse, capture or simply the unfulfilled dream of receiving benefits which were promised during radicalization. Handling this sit- uation is a major challenge for many countries. While foreign terrorist fighters are a serious problem in the countries to which they travel, they arguably pose a greater risk when they are in their home countries. Some countries remain more vulnerable to this phenomenon than others, but overall it is an international problem that requires new approaches.

In 2014, the United Nations Security Council passed resolution 2178 to address the threat posed by foreign terrorist fighters. It called on Member States to adopt legislation that prevents the transit of FTFs. Recalling this resolution, the Council further passed resolution 2396 at the end of 2017 and urged the strengthening of measures to counter the threats posed by returning foreign terrorist fighters. The main concern was that the intention of returning terrorist fighters was not to rehabilitate themselves, but to foster radicalization. In many cases, their return yielded new threats and gained skills, but also traumas. Many of the returning fighters were trained to carry out attacks in their countries of origin and therefore pose a serious threat to the community.

The Hague-Marrakech Memorandum, recognizing the major challenge the phenomenon of foreign terrorist fighters represents for the international community (countries of origin as well as transit and destination countries), brought together a list of good practices that should help States to better handle the risks they are facing. These good practices are meant to provide guidance and support to States by helping to adapt the required and improved legislation. The challenge that exists regarding returning foreign fighters involves important considerations: should these people be treated as victims that are to be reintegrated into society or as criminals to be put on trial? How can they establish the truth about the atrocities that foreign terrorist fighters may have committed and support the global fight against impunity?

\section{GG \\ Should these people be treated as victims that are to be reintegrated into society or as criminals to be put on trial?}

In the process of seeking justice and fighting impunity, the international community has a responsibility to ensure cooperation and, more importantly, to challenge incorrect preju-

https://www.un.org/sc/ctc/focus-areas/foreign-terrorist-fighters/

https://www.un.org/sc/ctc/wp-content/uploads/2018/04/CTED-Trends-Report-March-2018.pdf 


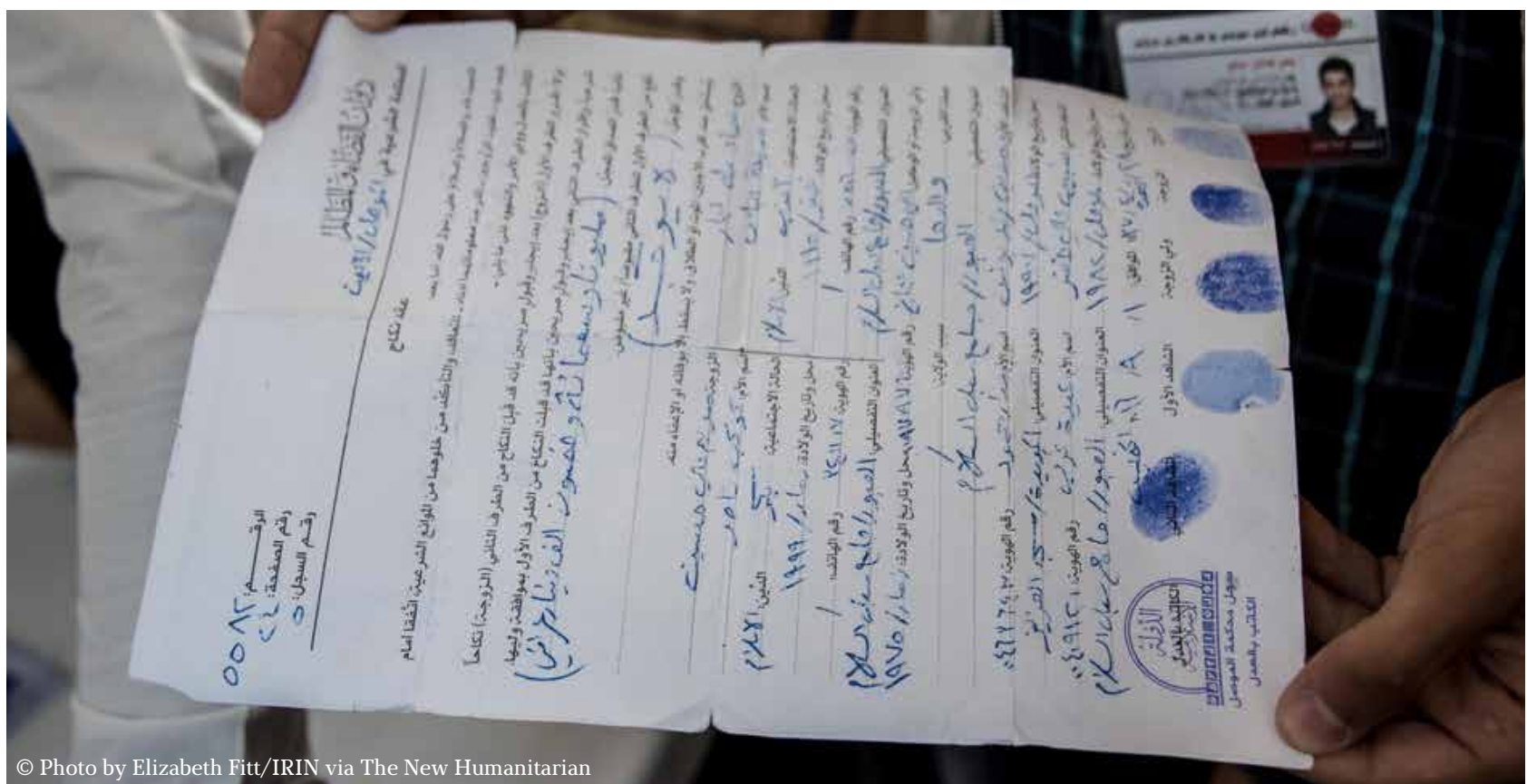

dices in order to prevent polarization of opinions between States. What approach is best in striking a balance between the need to seek justice and the need to rehabilitate in order to avoid stigmatization (which provides further fuel for radicalization)?

The legal status of foreign terrorist fighters varies according to the domestic legal system but overall seems to be rather unclear. The approaches that States have taken to address the return of foreign fighters have up to now been rather stringent at both the liberal and conservative ends of the spectrum.

The conservative way of dealing with returning foreign fighters includes the criminalization of acts committed abroad in the context of "foreign fighting" and follows conservative ideas of criminal justice. This approach chooses to conduct rehabilitation during time served in prison. Of course, this requires the prison and its staff to be specially trained and equipped with the skills necessary to eliminate the risk of relapse.

The liberal approach prioritizes rehabilitation and reintegration, focusing more on the ordeal that foreign terrorist fighters might have gone through. Also, returning fighters who have already served jail sentences or have not been found guilty of any charges must somehow be rehabilitated and reintegrated. This helps to prevent them from spreading further radicalization or re-succumbing to extremism, thereby harming national and international communities. The process of reintegration and rehabilitation is very individual and varies from person to per- son, effectively placing an even greater burden on the affected countries. It includes mental support for the returning fighters - many of whom suffer from post-traumatic mental diseases - and support for their families, which is one aspect that seems to be forgotten quite often in the discourse. The families of returning foreign fighters pose an especially sensitive challenge to countries. Global expertise on working with children associated with foreign terrorist fighters or children who are born into a family of foreign terrorist fighters is still very limited. Despite this, it should be a priority for institutions to work with children so that radicalization can still be prevented. To implement this approach, States will have to guarantee that they possess the necessary prerequisites for these institutions to be put in place. 


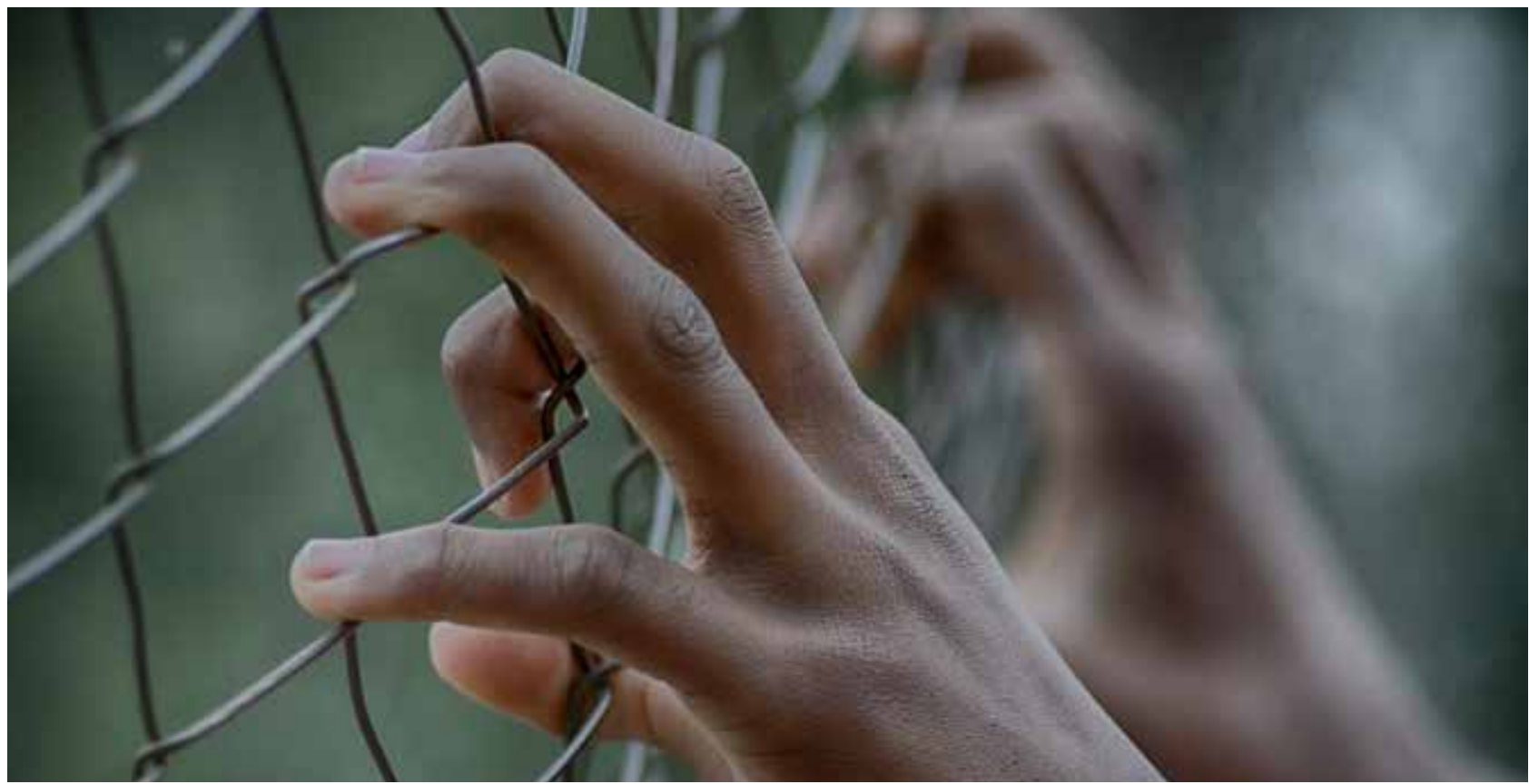

G4

\section{The legal status of foreign terrorist fighters varies according to the domestic legal system but overall seems to be rather unclear}

Another approach that States take is the view that foreign terrorist fighters are "victims of human trafficking". The United Nations Protocol to Prevent, Suppress, and Punish Trafficking in Persons, especially Women and Children, defines trafficking in persons as "the recruitment, transportation, transfer, harbouring or receipt of persons, by means of the threat or use of force or other forms of coercion, of abduction, of fraud, of deception, of the abuse of power or of a position of vulnerability or of the giving or receiving of payments or benefits to achieve the consent of a person having control over another person, for the purpose of exploitation." ${ }^{*}$ By kidnapping and brainwashing young women and young men who are sometimes not even 18 years of age, the Islamic State effectively takes advantage of them. The meeting of the required facets of deception, transport and exploitation, or in some of the cases of young women travelling to Syria or Iraq for the purpose of joining the Islamic State can surely amount to human trafficking. A typical situation by which terrorist organizations gain the consent of these young women is entrapping them with the promise of being jiha- di wives. Their age makes them vulnerable to exploitation. This, of course, influences the way domestic law must regard the actions taken by these young foreign terrorist fighters. The consent of the victim is irrelevant if achieved by fraud or coercion. If the consent is given by a minor, it is also considered invalid. Therefore, once they return home, they require special attention regarding their reintegration as well as their legal responsibility needing to to be guaranteed.

"Returning foreign terrorist fighters pose an enormous challenge with no easy solution," Vladimir Ivanovich Voronkov, Under-Secretary-General of the United Nations Counter-Terrorism Office, stated in November 2017. "This is a truly

4 https://www.unodc.org/documents/treaties/UNTOC/Publications/TOC\%20Convention/TOCebook-e.pdf 


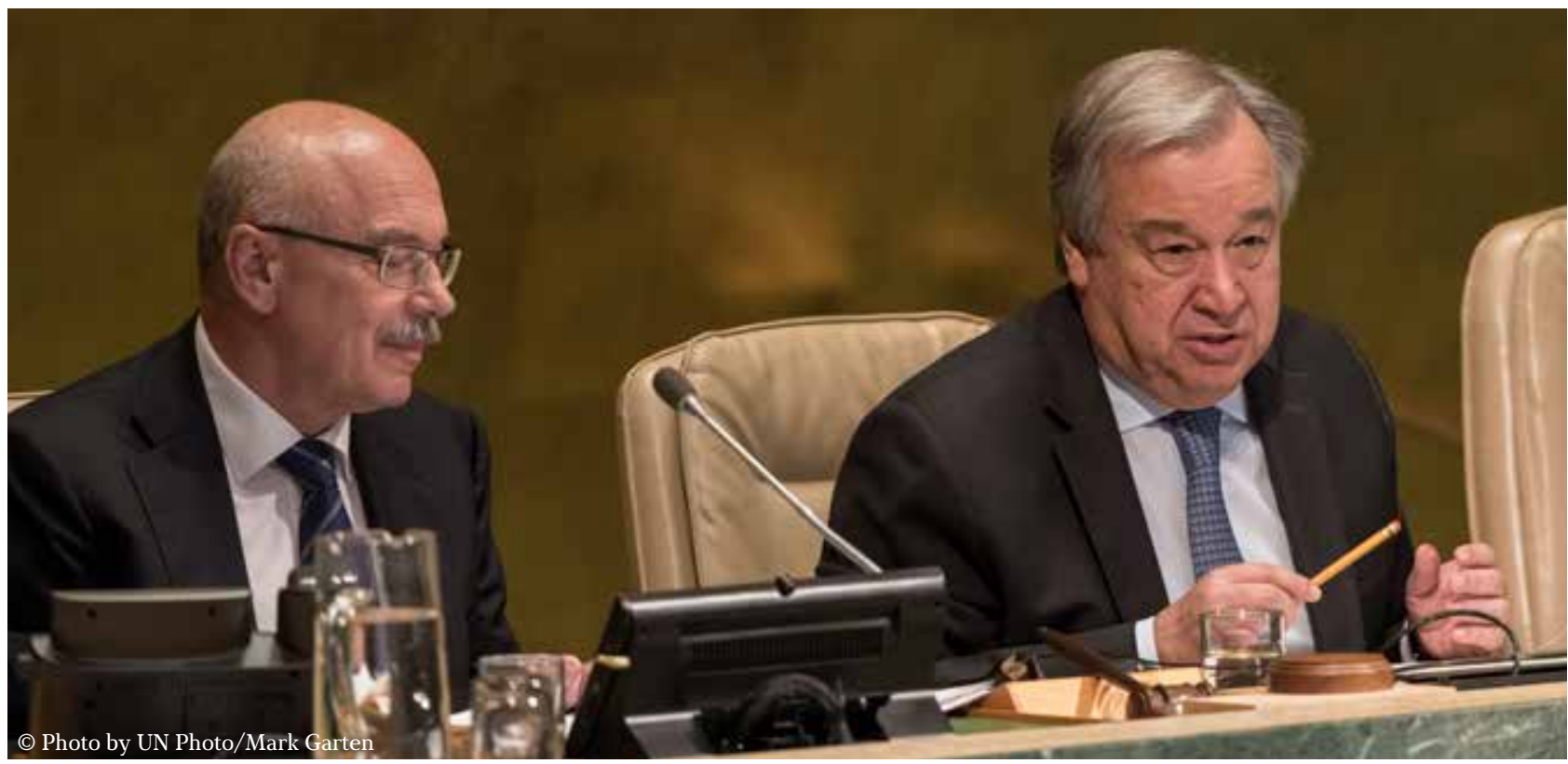

global challenge that demands an urgent and concerted multilateral response. ${ }^{\prime 5}$ In any case, the thing that is needed the most but at the same time presents one of the greatest challenges, is international cooperation. INTERPOL holds a database that is meant to support countries in identifying those who are considered "returning terrorist fighters." Border control is more crucial than ever because of another problem which concerns how returning terrorist fighters might use the refugee system of their home countries to illegally smuggle themselves back in.

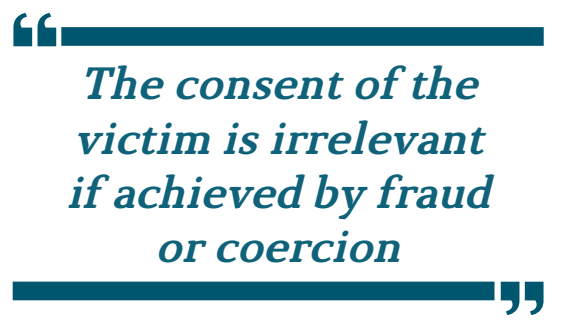

The affected countries are in serious need of international support. Besides cooperation in border control, this includes the general improvement of transnational data exchange. Resolution 2178 also called for a more holistic approach on countering terrorism in general. Recalling and reaffirming earlier resolutions, it states that "... terrorism in all forms and manifestations constitutes one of the most serious threats to international peace and security and that any acts of terrorism are criminal and unjustifiable regardless of their motivations, whenever and by whomsoever committed, and [that we remain] determined to contribute further to enhancing the effectiveness of the overall effort to fight this scourge on a global level."6

\section{The Author}

Barbara Stadlbauer. Having grown up in Germany, Austria and the United States, she studied Law in Vienna and Transnational Crime and Justice in Turin. After graduation from the LL.M. programme she moved to Tunisia, where she is currently working in the development of the educational sector.

5 https://www.un.org/counterterrorism/ctitf/sites/www.un.org.counterterrorism.ctitf/files/20171128USGVoronkov statement SCFTFbriefing Asdelivered.pdf

6 https://undocs.org/S/RES/2178(2014) 

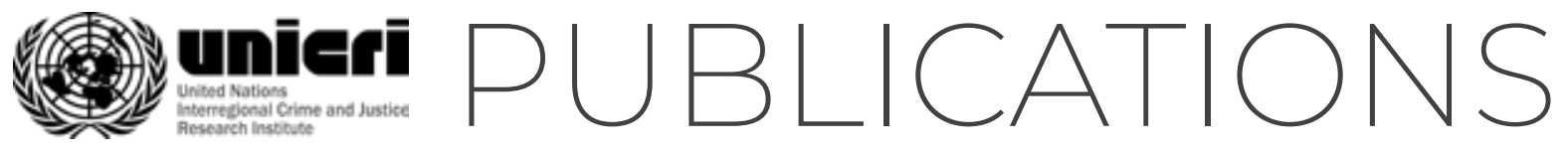

Enhancing knowledge and raising awareness to find innovative solutions and drive change
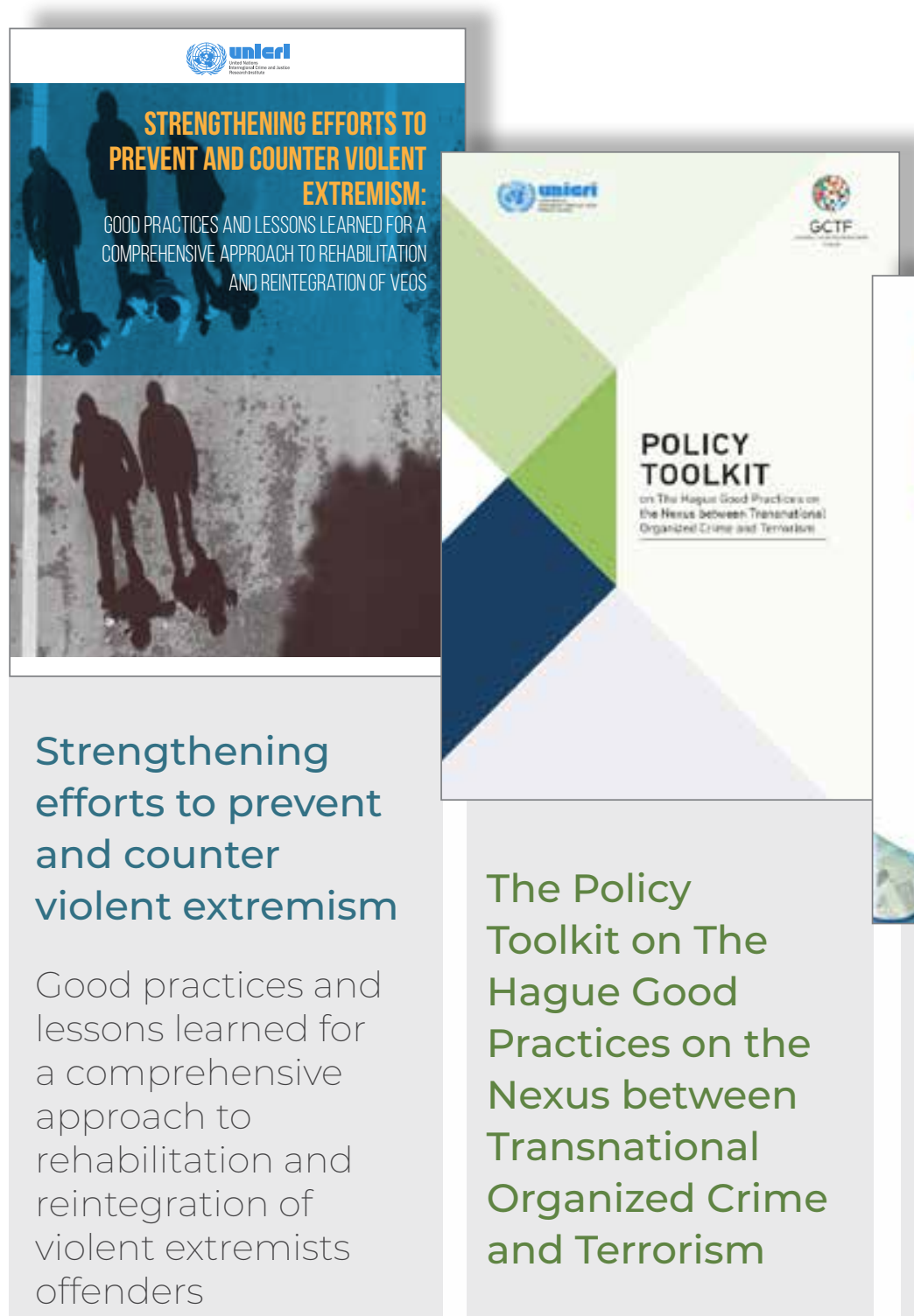

(9) unieri

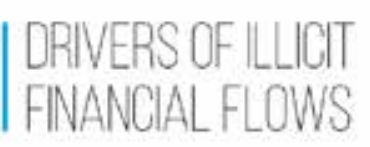

Drivers of Illicit

Financial Flows 
Diversion of persons with mental illness who offended

There is a plurality of criminal justice responses to PMIO across countries and continents. One way of responding to PMIO is subjecting them to court-mandated treatment which is typically combined with ongoing judicial supervision. $^{3}$ Court-mandated treatment programs for PMIO aim at reducing recidivism and improving mental health outcomes in PMIO by referring them to judicially supervised treatment and services instead of imposing traditional criminal justice responses, such as prison or jail sentences. ${ }^{4} \quad$ Judicially supervised treatment for PMIO may involve residential treatment such as detainment in or admission to a forensic psychiatric hospital and/or community programs such as specialized probation services and forensic assertive community treatment. The goal of court-mandated treatment is therefore twofold: the protection of society, and the provision of treatment as well as support for the individual. While both care and control are necessary to attain the goal of court-mandated treatment programs, their focus, as well as the focus of inter-agency collaboration between the criminal justice system and the mental health system has traditionally been primarily on controlling risk. $^{5}$

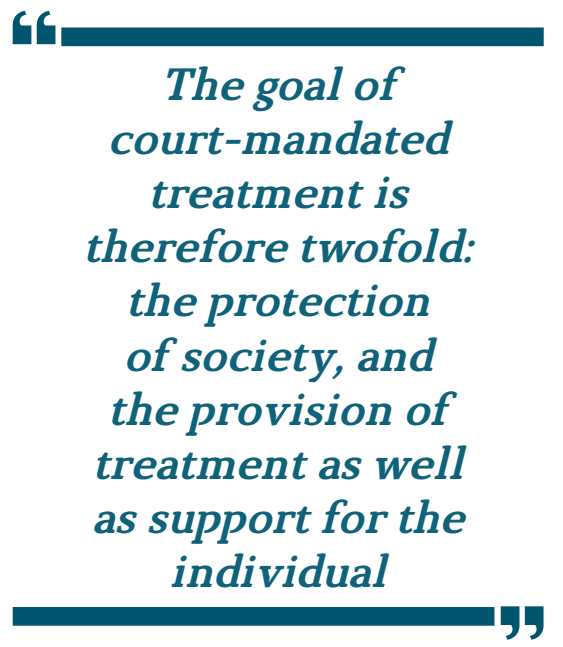

\section{Strength-based approaches gather momentum in forensic mental health care}

As a supplementary counterbalance to risk-based approaches, strengths-based approaches gather much more momentum in the broad field of forensic mental health care. Strengthsbased approaches are characterized by the following six principles: 1) people with mental illness (and other issues) and their social network (such as partners, family and friends) can learn, grow and change, 2) the focus is on the individual and contextual strengths rather than (exclusively) on deficits, 3 ) the community is viewed as an oasis of (natural) resources, 4) the client directs the change process and defines (personally meaningful) goals, 5) the relationship between the recipient and the professional is essential and hope-inducing, and 6) the primary setting for strengths- based practice is the community or the natural environment of the recipient instead of the office. ${ }^{6}$ Examples of strengthbased approaches in forensic mental health care are the desistance, the recovery, and the human rights paradigms. These paradigms differ regarding their substantive focus but share the value they attach to strengths, capabilities, human dignity, participation, connectedness, and inclusion. ${ }^{7}$

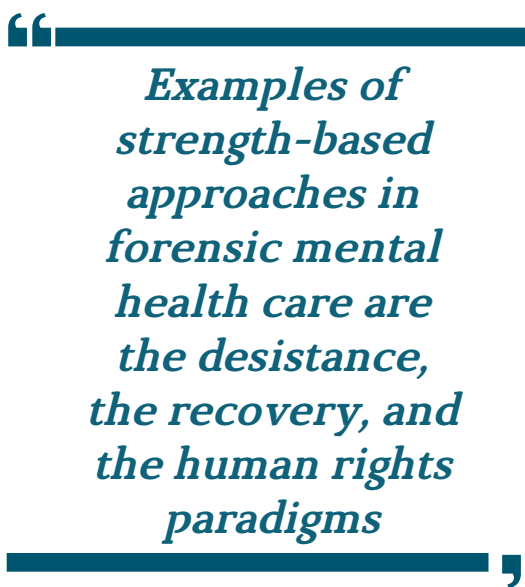

\section{A lack of attention to the voices of persons with mental illness who offended and their family members}

In general, the voices of PMIO and their families are lacking in terms of debates about 'what works' and how in court-mandated treatment. Yet, contextually, this lived-experience or real-life evidence is important for the development of relevant practice and policy. ${ }^{8,9}$ In re- 


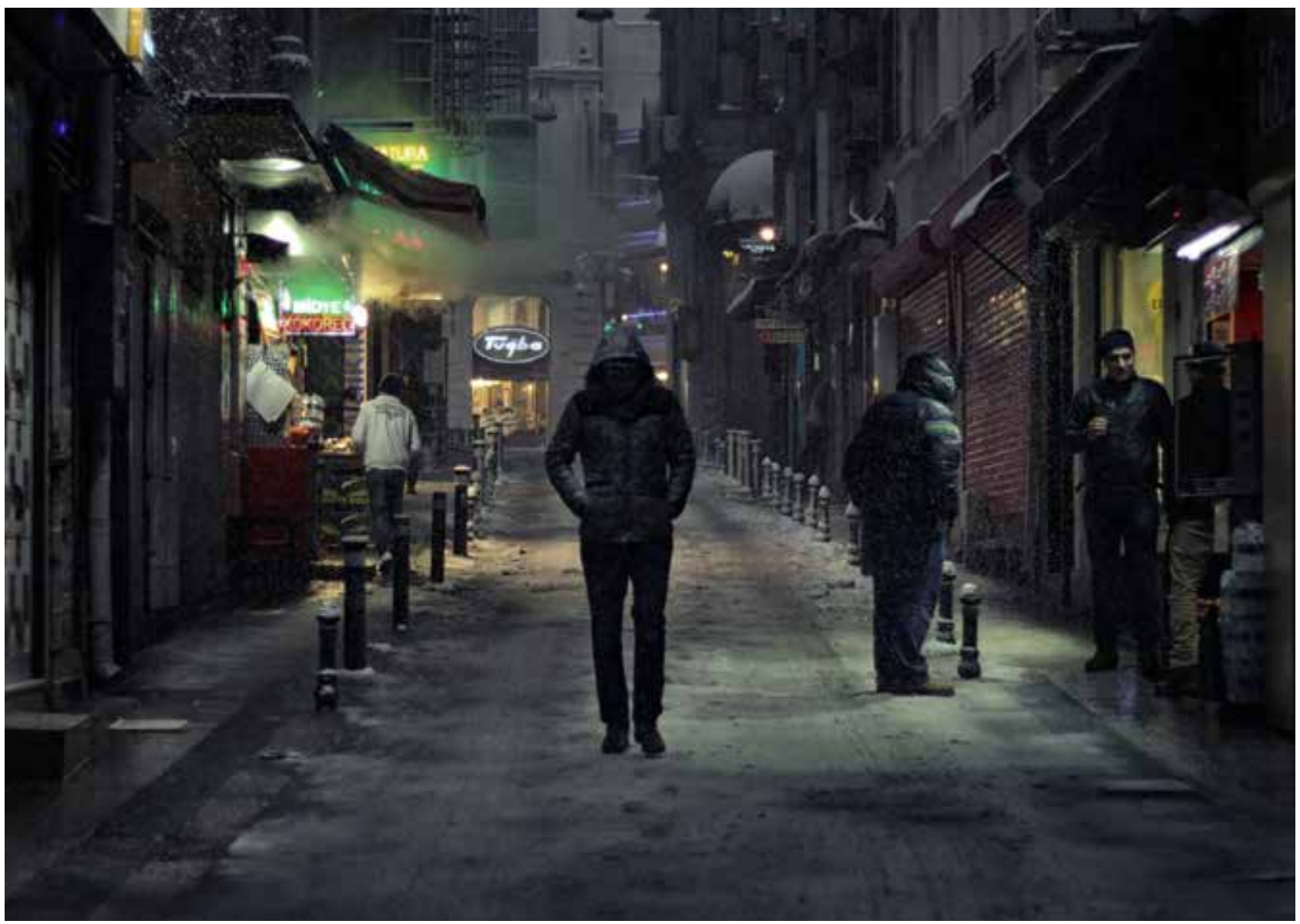

search, the strengths and capacities of PMIO and their family members can be acknowledged by centralizing their lived experiences during the research process. Thereby the scientific, outsider approach to care is fused with a subjective, insider approach to care, which has also been recommended by the World Health Organization. ${ }^{10,11}$ Qualitative research, which focuses on subjective experiences and meaning making of individuals, is well suited to gaining insight into how outcomes and processes can be explained. ${ }^{12}$
Lived-experienceand-strengths-based recommendations of persons with mental illness who offended and their family members

The current multidisciplinary study is connected with strengthsbased approaches across different disciplines, namely procedural justice, desistance, recovery and family support.' The study was carried out in Flanders, the Flemish-speaking part of Belgium.
Thirty-three family members, ${ }^{1}$ i.e. mothers, fathers, brothers, sisters, uncles, antes, and daughters of PMIO, participated in the study in terms of family support. This study consisted of semi-structured interviews and family support groups.

In total, 286 PMIO who were subjected to court-mandated treatment with an indefinite duration participated in focus groups and semi-structured interviews as part of the studies on procedural justice, desistance, and recovery. At the time 
of the study, these participants were incarcerated, were admitted to forensic or general inpatient psychiatric services, were supported by forensic or general outpatient psychiatric or social services, were supported by in- and outpatient services for persons with a mental disability, or were already definitely released into the community.

The following lived-experienced-and-strengths-based recommendations are based on the results of these four qualitative studies. These recommendations can serve as inspiration for professionals in the mental health system as well as for professionals in the criminal justice system.

\section{A humane and high-quality approach}

PMIO and their family members want to be approached as human beings, and not as 'criminals' or 'numbers'. Professionals who treat them with respect, have faith in them and trust them are important. Someone who believes in them would also support them in believing in themselves. Being approached in a humane and high-quality manner can offer an antidote to (self) stigma. A negative approach by professionals can echo previous experiences of stigma and exclusion. PMIO and their family members appreciate professionals who listen actively, show gen- uine care, make time for them, and are 'really there' for them.

In order to fully comprehend PMIO and their family members, formal interactions - such as treatment sessions, appointments with probation officers, and judicial hearings -, should be accompanied by informal and spontaneous interactions. Examples of informal and spontaneous interactions can consist of: going on an excursion together or completing household chores together. Professionals should be present around PMIO and their family members. Recovery and desistance-oriented practices recognize that daily life offers real-life opportunities for learning and positive experiences.

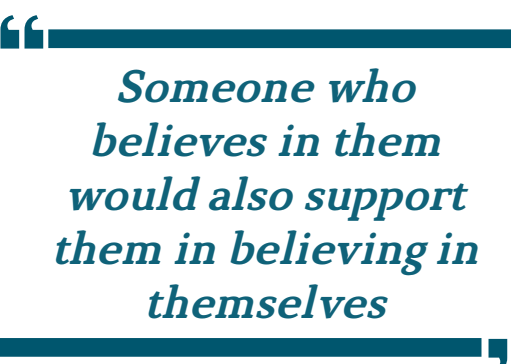

\section{Active involvement}

PMIO and their family members want to be actively involved with court-mandated treatment. They are often not involved in the decision-making processes. It is important to listen actively to what they have to say and initiate true dialogues instead of alternating monologues, and by asking indepth questions. Family mem- bers are often searching for a shared partnership with the providers of treatment so they can jointly share information and advice.

\section{Ge \\ A negative approach by professionals can echo previous experiences of stigma and exclusion}

Listening is important but of equal importance are their needs, desires, concerns, and insights being taken into account. Consequently, (mental health) care and support programs and conditional release conditions can be individually tailored. Participation is important on a substantive level (e.g. the content of a daily schedule, treatment sessions, conditional release conditions) as well as on a formal level (e.g. the different stages and goals of treatment over time).

\section{Transparent communication}

Transparency and information sharing are preconditions for active involvement. PMIO and their family members are often not informed about the different aspects of court-mandated treatment. Written information is necessary and useful, however it is insufficient. Oral communication and the possibility to ask questions as well as ex- 


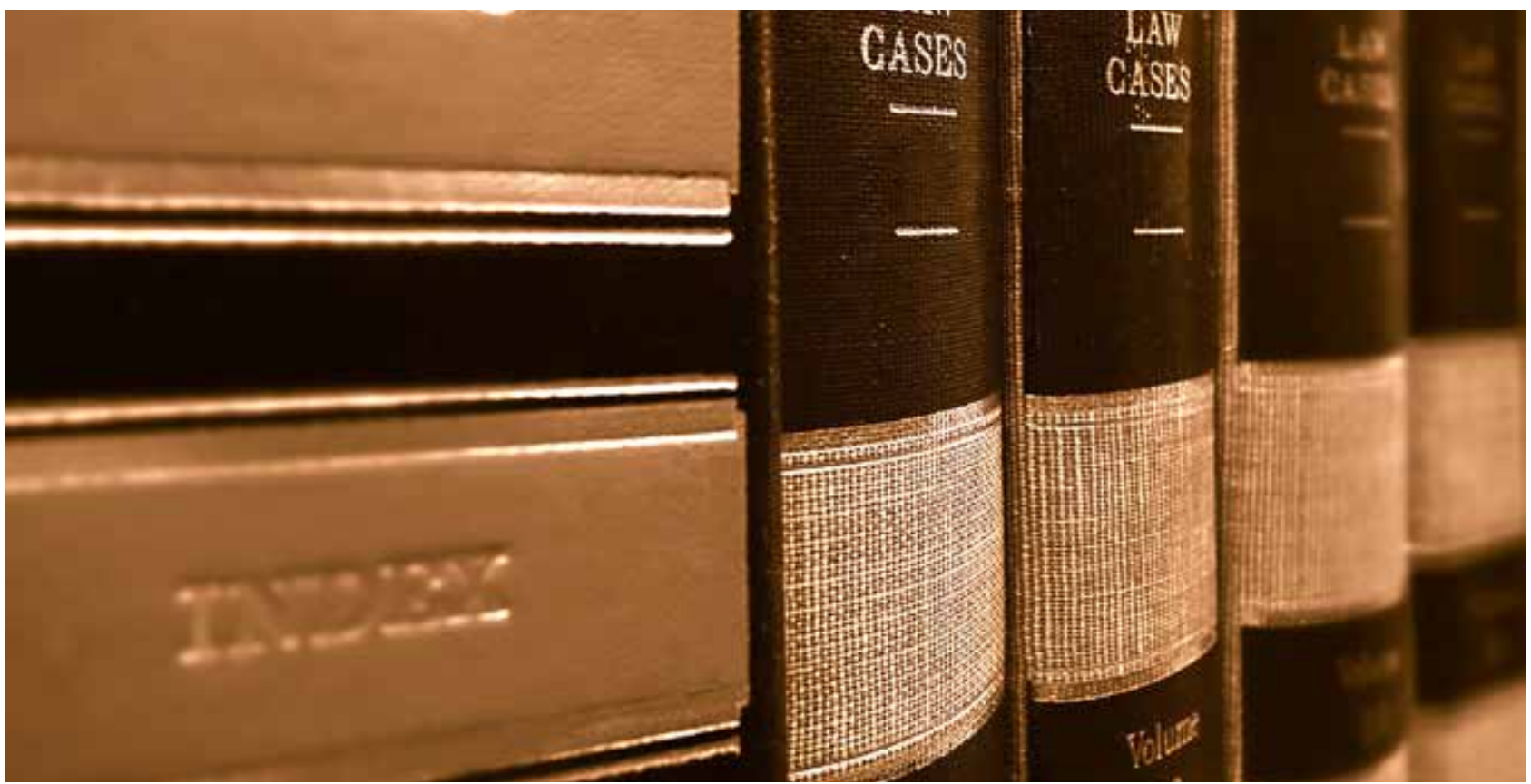

press concerns are vital. Oral and written communication should focus on both general and personalised information.

In the beginning as well throughout the court-mandated treatment trajectories understandable information should be continuously provided to PMIO and their families. This information should consist of the significance, meaningfulness, usefulness, and continuity of treatment, of conditional release conditions, of ward rules, of treatment agreements, or of any other relevant aspect considered important to PMIO and their families.

Decision-making processes should be transparent, and decisions of professionals should be explicitly motivated. Expectations and concerns of pro- fessionals should be clearly communicated so that PMIO and their family members are aware of the requirements for successful completion of court-mandated treatment.

\section{GG \\ Transparency and information sharing are preconditions for active involvement}

\section{Individualized care and support}

A balance should be maintained between giving attention to the individual needs of PMIO and to the societal needs, as well as between care and control. Treatment goals and conditional release conditions should be tailored to the needs of the individual instead of relying on one-size-fits-all goals and conditions. Treatment should cover more subjects than merely criminal offenses and past issues. Themes such as self-reliance and trauma are examples of important topics for PMIO.

The treatment method should also be a meaningful experience for PMIO. First, an appropriated balance between individual and group treatment opportunities should be provided. Second, periods of rest and tranquility should be provided during court-mandated treatment trajectories. During these periods, PMIO can strengthen and perpetuate their recovery. Third, (obligatory) living in shared residencies can be a stressful experience. Living together in smaller groups can bring some relief. 


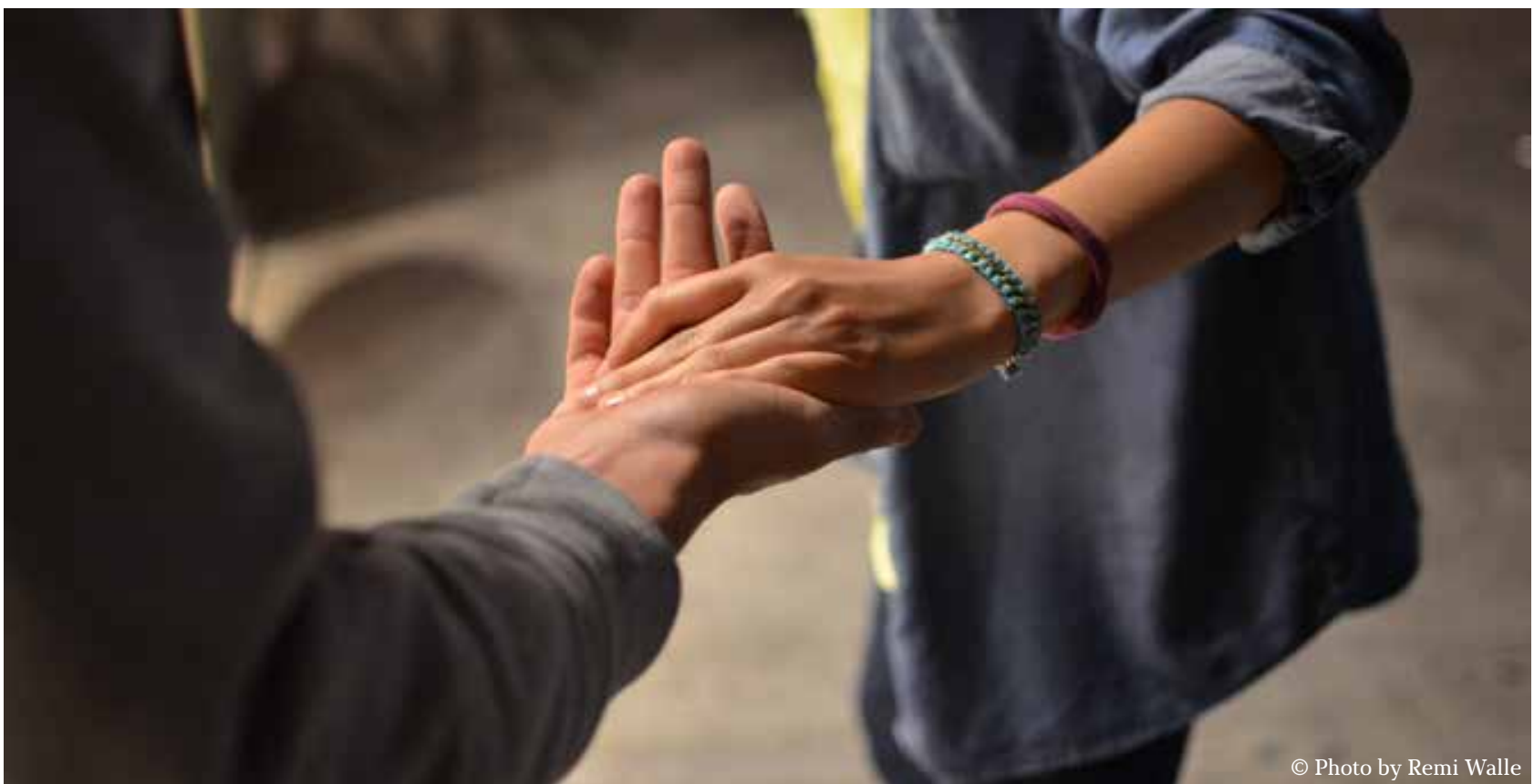

G6

\section{Treatment should cover more subjects than merely criminal offenses and past issues}

Control does not have to disappear. Some types of control can be helpful for PMIO, as long as control does not become coercion. Examples of 'helpful control' are personalized conditions and shared decision making. Examples of 'coercive control' are high levels of pressure to perform and forced admission to treatment services.

\section{Gradual reintegration}

Societal exclusion processes can be repeated on the level of mental health care when all care and support is provided within one facility. This thereby precludes social and professional interactions with persons not affiliated with the facility. Existing social contacts outside of the facility should be retained as much as possible. For instance, by allowing PMIO employment in the community even if they are admitted to a (forensic) psychiatric hospital, or by cooperating with the neighbourhood or community in order to initiate, stimulate or reinforce contacts between neighbourhoods or the community and PMIO.

Working towards re-integration into the community should start as soon as possible during a court-mandated treatment trajectory and not be postponed until the final phase of admis- sion in a (forensic) psychiatric hospital or ward. The reintegration process should be incorporated into every phase of a treatment trajectory. During this trajectory, PMIO should be able to acquire incremental liberties and gradually re-integrate into the community.

A gradual reintegration provides perspective, hope, and incremental progress. It should be supported and guided by professionals. One on one guidance by a professional is preferred over group activities in the community. If possible and if it is deemed to be desirable, along with the consent of PMIO, the family should be involved from the start of the reintegration process as they can play an important role in actual reintegration. 
Quality of life: daily activities, social network, housing and finances

It is important to focus on high-quality social contacts, meaningful daytime activities and work, and stable housing and income because these are often lacking in the lives of PMIO. Targeting these life domains enables reintegration into the community. It should be stressed that the quality of these factors is more important than simply their presence.

Employment and volunteer work have multiple functions: having an occupation and developing and extending a social network. In order to provide meaningful daily activities, consultation and discussion with PMIO are necessary.

Existing social contacts are often lost during (indefinite or lengthy) court-mandated treatment trajectories. Out of neces- sity, friendships are often only initiated with PMIO. Therefore, treatment providers should encourage and support the development and expansion of the social network of PMIO. Special attention should be paid to getting family members involved, and to including the neighborhood and the community in facilitating social acceptance.

\section{GG \\ A social network should not be restricted to contacts with 'companions by experience'} 95

Contact with 'companions by experience' should be encouraged within and across facilities. This companionship should be tailored to the needs and expectations of PMIO. 'Experiential knowledge' and the sense of 'being companions by experience' can emerge from different perspectives: some PMIO feel connected when they are able to exchange experiences about the criminal offences they have committed, others want advice and to discuss their legal status, and others feel connected because they have the same mental illness. However, a social network should not be restricted to contacts with 'companions by experience'.

(Future) housing and finances are also important. Stability, support, consultation, and discussion are as important in terms of these life domains.

Indefinite forensic psychiatric treatment as a mortgage?

An indefinite duration of court-mandated treatment weighs heavily on PMIO and their family members. Two recommendations can counterbalance this experience. First, a target date should be provid-

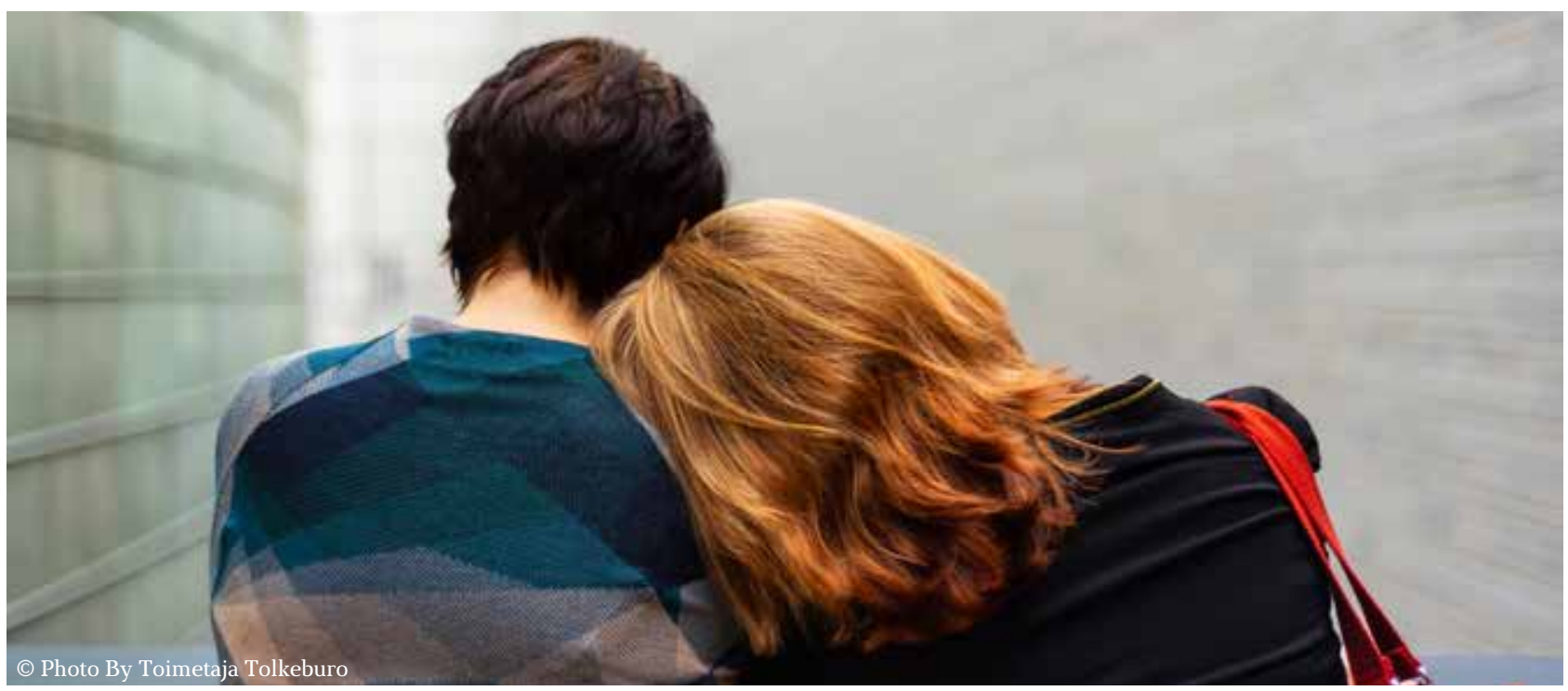


ed together with clear (sub) goals that should be attained by PMIO in order to be definitively released into the community. Second, transferring PMIO back to prison in case of non-crime related incidents should be avoided. If release conditions are violated, figure out why they are breached in discussion with PMIO. In doing so, the underlying causes of breaches can be dealt with.

\section{Doing research with persons} with mental illness who offended and their family members

A humane and high-quality approach towards PMIO and their family members is also a recommendation for researchers and academics. With this kind of approach, research participation can be experienced as pleasant, valuable and useful. It fosters the development of a trusting relationship between a (qualitative) researcher and a participant. Researchers should not be fearful of proximity. As well as being researchers they should also just be human beings, and have authentic interactions with participants. They should also have an informal chat after the interview.

Researchers should not only approach PMIO and their family members as human beings but also as 'knowledgeable' human beings. Researchers should inherently value their experiential knowledge. In this respect, researchers should also be reflexive regarding their preconceptions and attentive to participants' corrections.

Listening to and confronting the life stories of PMIO and their family members is not always easy. Their narratives were characterised by strength, resilience, combativeness, life wisdom, hope, perseverance, and love. Their life stories, however were also characterised by injustice, powerlessness and hopelessness. Specifically, the lack of informal and formal care and support as well as the excess of trauma and stigma was striking. Therefore, it is also important to provide formal and informal opportunities for researchers to debrief the participants.

\section{Conclusion}

The voices of PMIO and their families were centralized in this multidisciplinary study designed to develop multidisciplinary strengths-based strategies for PMIO and their families. Their knowledgeability is clearly reflected in the recommendations based on their experiential knowledge. Taking these recommendations into consideration can add a holistic and solution-focused approach towards PMIO and their families.

\section{The Authors}

Ciska Wittouck is a clinical psychologist and criminologist, and currently works as a postdoctoral staff member at the department of Criminology, Criminal Law and Social Law at Ghent University. Her research focuses on vulnerable groups in society and in criminal justice and mental health systems, strengths-based practices, procedural justice and legitimacy, and (innovative) qualitative research methods.

Freya Vander Laenen is an associate professor in Criminology at Ghent University. Her research focuses on vulnerable persons (because of substance use, mental illness, social exclusion) in contact with the criminal justice system, and she has long standing experience in research on drug policy, drug prevention, drug treatment, and harm reduction.

Stijn Vandevelde is an associate professor in Special Needs Education at Ghent University. His research interests include forensic special education; the support of mentally ill offenders (with an intellectual disability); persons with intellectual disabilities and co-occurring behaviour problems and/or psychiatric disorders; and rehabilitation of offenders (e.g. underpinned by the Good Lives Model). 
Sara Rowaert currently works as a postdoctoral staff member at the department of Special Needs Education at Ghent University. Her research focuses on family recovery and experiences as well as support of family within forensic mental health care.

Natalie Aga obtained a doctoral degree in Educational Sciences at Ghent University. Her research focuses on recovery needs and resources of persons labelled not criminally responsible and on lived experiences of persons with mental illness or intellectual disability who offended. She currently works as a lecturer and researcher at the Thomas More University College of Applied Sciences, Antwerp, Belgium.

Sofie Van Roeyen obtained a doctorate in criminological sciences at Ghent University. Her research interests include desistance, recovery, mentally ill offenders and forensic psychiatry with a particular focus on lived experiences.

Kurt Audenaert is a part-time senior full professor in Psychiatry and Criminology at Ghent University. His research focuses on aggression and transgressing behaviour, neurobiology and neuro-criminology.

Wouter Vanderplasschen is associate professor at the Department of Special Needs Education at Ghent University and is a senior researcher in the field of substance abuse treatment and recovery. His research interests include addiction recovery, case management, treatment methods, vulnerable groups, therapeutic communities, continuity of care and evaluation of treatment.

Tom Vander Beken is a senior full professor in Criminology at Ghent University. His research focuses on criminal justice related issues in an international and comparative perspective, and often has special focus on vulnerable persons (e.g. mentally ill offenders).

\section{References}

${ }^{1}$ This project was funded by Ghent University (BOF14/G0A/006). The research focused on family members who still have some sort of contact with their relative. However, we are well aware of the fact that some family members also have no or a troubled relationship with their relative. Therefore, when addressing family members of PMIO, it is important to take the heterogeneity of family members into account.

${ }^{2}$ Aga, N., Audenaert, K., Nollet, L., Rowaert, S., Schipaanboord, A.E., Vander Beken, T., Vander Laenen, F., Vanderplasschen, W., Vandevelde, S., Van Roeyen, S., \& Wittouck, C. (2019). Powerful narratives. The internment measure in a different light. GompelESvacina: Oud-Turnhout/'s-Hertogenbosch.

${ }^{3}$ Crocker, A. G., Livingston, J. D., \& Leclair, M. C. (2017). Forensic mental health systems internationally. In R. Roesch \& A. N. Cook (Eds.), Handbook of forensic mental health services (pp.
3-76). New York, NY, US: Routledge/ Taylor \& Francis Group.

${ }^{4}$ Landess, J., \& Holoyda, B. (2017). Mental health courts and forensic assertive community treatment teams as correctional diversion programs. Behavioral Sciences \& the Law, 35(6), 501-511.

${ }^{5}$ Barnao, M., Robertson, P., \& Ward, T. (2010). Good Lives Model Applied to a Forensic Population. Psychiatry Psychology and Law, 17(2), 202-217.

${ }^{6}$ Rapp, C. A., Saleebey, D., \& Sullivan, W. P. (2005). The future of strengthsbased social work. Advances in Social Work, 6(1), 79-90.

${ }^{7}$ Vandevelde, S., Vander Laenen, F., Van Damme, L., Vanderplasschen, W., Audenaert, K., Broekaert, E., \& Vander Beken, T. (2017). Dilemmas in applying strengths-based approaches in working with offenders with mental illness: A critical multidisciplinary review. Aggression and Violent Behavior, 32, 71-79.
${ }^{8}$ Coffey, M. (2006). Researching service user views in forensic mental health: A literature review. Journal of Forensic Psychiatry \& Psychology, 17(1), 73-107.

${ }^{9}$ Livingston, J. D. (2018). What Does Success Look Like in the Forensic Mental Health System? Perspectives of Service Users and Service Providers. International Journal of Offender Therapy and Comparative Criminology, 62(1), 208-228.

${ }^{10}$ Rycroft Malone, J., Seers, K., Titchen, A., Harvey, G., Kitson, A., \& McCormack, B. (2004). What counts as evidence in evidence based practice? Journal of Advanced Nursing, 47(1), 81-90.

${ }^{11}$ World Health Organization. (2018). European Health Report. Highlights. Geneva, Switzerland World Health Organization.

12 Gergen, K. J., Josselson, R., \& Freeman, M. (2015). The Promises of Qualitative Inquiry. American Psychologist, 70(1), 1-9. 
It is 6 october 2005. I step along in my new crocs. Over the next few years, they will carry many positive and negative things with them. Over the course of a seemingly endless way, I wear the same crocs. The final result is that I still have them, my crocs, and that I am still standing steady in them. I do not stand in the crocs now - I am standing in daily life. My crocs knew a lot of emotions. Metamorphoses. I have repeatedly pulled myself up by the crocs, because I started to do things with them during my long admission. I went with them everywhere. Haha, to give only a small example: I walked in my crocs even to the market. I went so far that the crocs have become an image of myself. Ouring my experience with moments of stress, my toes curled in them. I sweat inside them. You cannot imagine how strong my crocs were the day I went back to society. To give a new direction to my life, I stepped away from my old, worn-in crocs. I immediately bought a new pair. I wear these daily now. Since 4 August 2014, I walk with them in my home city. I live there in the privacy of my happy and wonderful family. It is certainly worth it to make the step and to see where you get in life. of course, it is with ups and downs, but you learn a lot from the downs. I can testify to that. My daily life has turned around 360 degrees. The crocs have endured the process of getting Clean very well. Now I am still clean. You have to be strong for that in daily life. These new crocs also carry this strength in my being. I am very happy to have bought this new pair. I alone have done this and no one did it for me. I have received advice and much support from my local environment. For that, I sincerely thank my wife and kids, my family, and the small group of friends that I have built up.

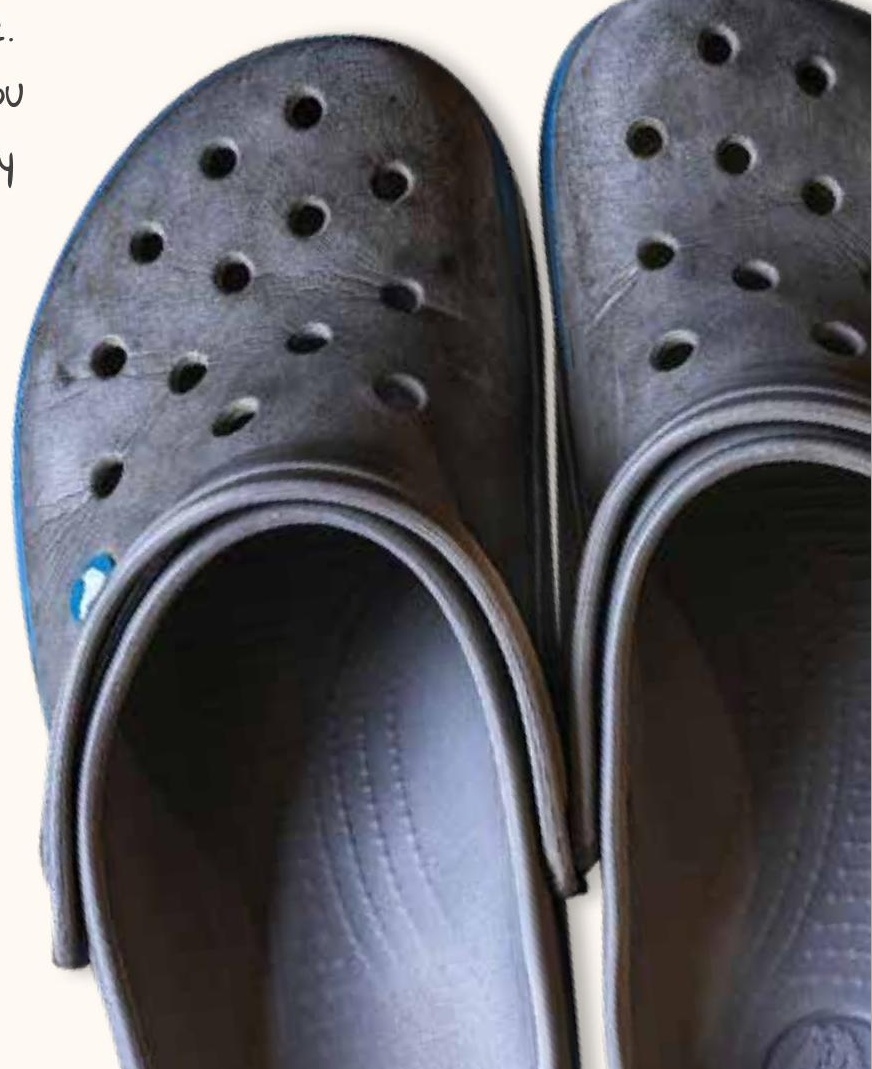



In addition to suffering caused, the meaning of the harm is also mediated by its wrongfulness. That it has no justification in law matters. For Shklar, injustice is often experienced through powerful, often distressing, emotions specific to the individual. ${ }^{2}$ It interrupts and disrupts lives, causing "shattered assumptions" about living in a world which can undermine the capacity to participate in society. ${ }^{3}$ The effects of experiencing injustice will often continue to dominate an individual's life long after physical wounds have healed, punishment has been inflicted, or compensation received.

Ǵ

$$
\begin{gathered}
\text { When a crime is } \\
\text { committed, criminal } \\
\text { justice agencies } \\
\text { focus mainly on the } \\
\text { perpetrator as the } \\
\text { problem }
\end{gathered}
$$

Consequently, many victims experience "secondary victimisation" by the criminal justice system which strives to engage with crime in an impersonal and rational manner. ${ }^{4}$ What are considered to be risk factors associated with offending, can be viewed from a humane perspective as harmful events or conditions which perpetrators of crime have experienced. ${ }^{5} \mathrm{~A}$ humane approach will understand that the reactions of society, the media, and the criminal justice system to crime play a significant part in adding to the harm endured by both victims and perpetrators. ${ }^{6}$ Social and criminal justice reactions often exclude victims and perpetrators from necessary resources, weaken significant relationships, and reduce personal responsibility, thus obstructing both recovery and reintegration. $^{7}$

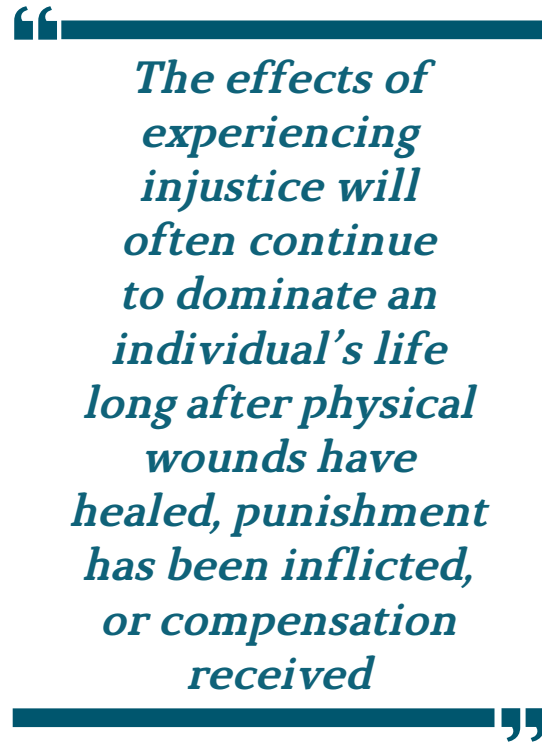

The UN 2030 Agenda for Sustainable Development and its goals are drafted to contribute to a safer world by reducing conflicts, crime rates and people's vulnerabilities and exposure to organized crime. Goal 16 of the 2030 Agenda is centered on promoting peaceful, just and inclusive societies, free from crime and violence, with justice for all. We will explain how focusing more on harm than on crime and using more humane or participatory reactions such as restorative justice approaches

2 Judith Shklar, The Faces of Injustice (Yale: Yale University Press, 1990.

3 Ronnie Janoff-Bulman, Shattered Assumptions: Towards a new Psychology of Trauma (New York: Free Press, 1992).

4 Maarten Kunst, Lieke Popelier, and Ellen Varekamp, "Victim Satisfaction with the Criminal Justice System and Emotional Recovery: A Systematic and Critical Review of the Literature," Trauma, Violence and Abuse 16, no. 3 (2014): 336-358;

Malini Laxminarayan, Mark, Bosmans, Robert, Porter, and Lorena Sosa, "Victim Satisfaction with Criminal Justice: A Systematic Review," Victims \& Offenders, 8, no. 2 (2013): 119-147.

5 Vittoria Ardino, "Post-Traumatic Stress in Antisocial Youth: A Multifaceted Reality," In Post-traumatic syndromes in children and adolescents, ed. Vittoria Ardino (Chichester: Wiley/Blackwell Publishers, 2011)

David Farrington, "Childhood Risk Factors and Risk-Focused Prevention," in The Oxford Handbook of Criminology, ed. Mike Maguire, Rod Morgan, and Robert Reiner (4th ed. Oxford: Oxford University Press, 2007);

Robin Weeks and Cathy Widom, "Self-Reports of Early Childhood Victimization among Incarcerated Adult Male Felons," Journal of Interpersonal Violence 13, no, 3 (1998): 346-361.

6 Howard Becker, Outsiders: Studies in the Sociology of Deviance (New York: The Free Press, 1963); Stanley Cohen, Folk Devils and Moral Panics: The Creation of the Mods and Rockers (London: Paladin, 1973); Edwin Lemert, Human Deviance, Social Problems and Social Control (Englewood Cliffs: Prentice-Hall, 1951).

7 Jeremy Travs and Michelle Waul, Prisoners Once Removed: The Impact of Incarceration and Reentry on Children, Families, and Communities (Washington: The Urban Institute Press, 2003). 


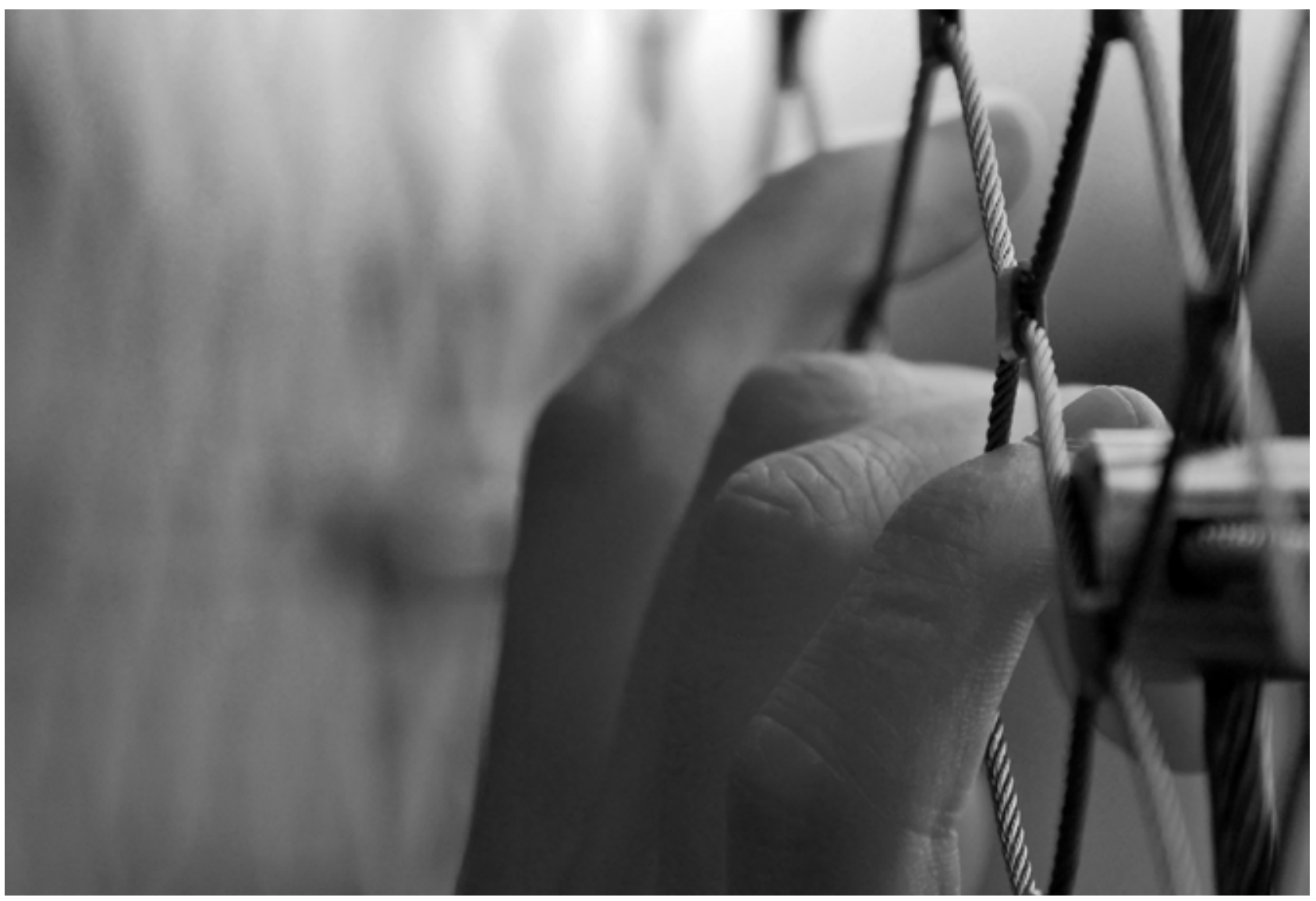

can contribute to this end. In the following sections we explain the values of more humane approaches, we address possibilities for change and the potential of restorative justice and we end with some conclusions.

\section{Humane approaches}

The harm of criminal behaviour extends beyond those immediately affected to society at large, causing fear of crime, reducing social cohesion, exacerbating intergroup prejudice and conflict, and demoralising whole commu- nities. ${ }^{8}$ People can lose a common belief in a just, stable and moral society. People's sense of control over their lives and their ability to participate actively in society are diminished by the harm of criminal behaviour.

Humane approaches to addressing the harm of criminal behaviour aim to restore the internal and external resources required to participate actively in society to people responsible for harm, people who have been harmed, and others who have been affected. Humane practices would have the purpose of preventing or undoing injustices, and restoring the individual, relational and social harms that have caused and been caused by criminal behaviour.

The values that shape more humane approaches relate to the value we place on the individual, the value we place on how individuals relate to each other, and the quality of the society we aspire to create. The concepts of "the common good", "dignity of the individual", "solidarity", and "social justice" can frame what a human response to crime looks like: a response

8 Chris Hale, "Fear of Crime: A review of the Literature," International Review of Victimology 4, no. 2 (1996): 79-150. 


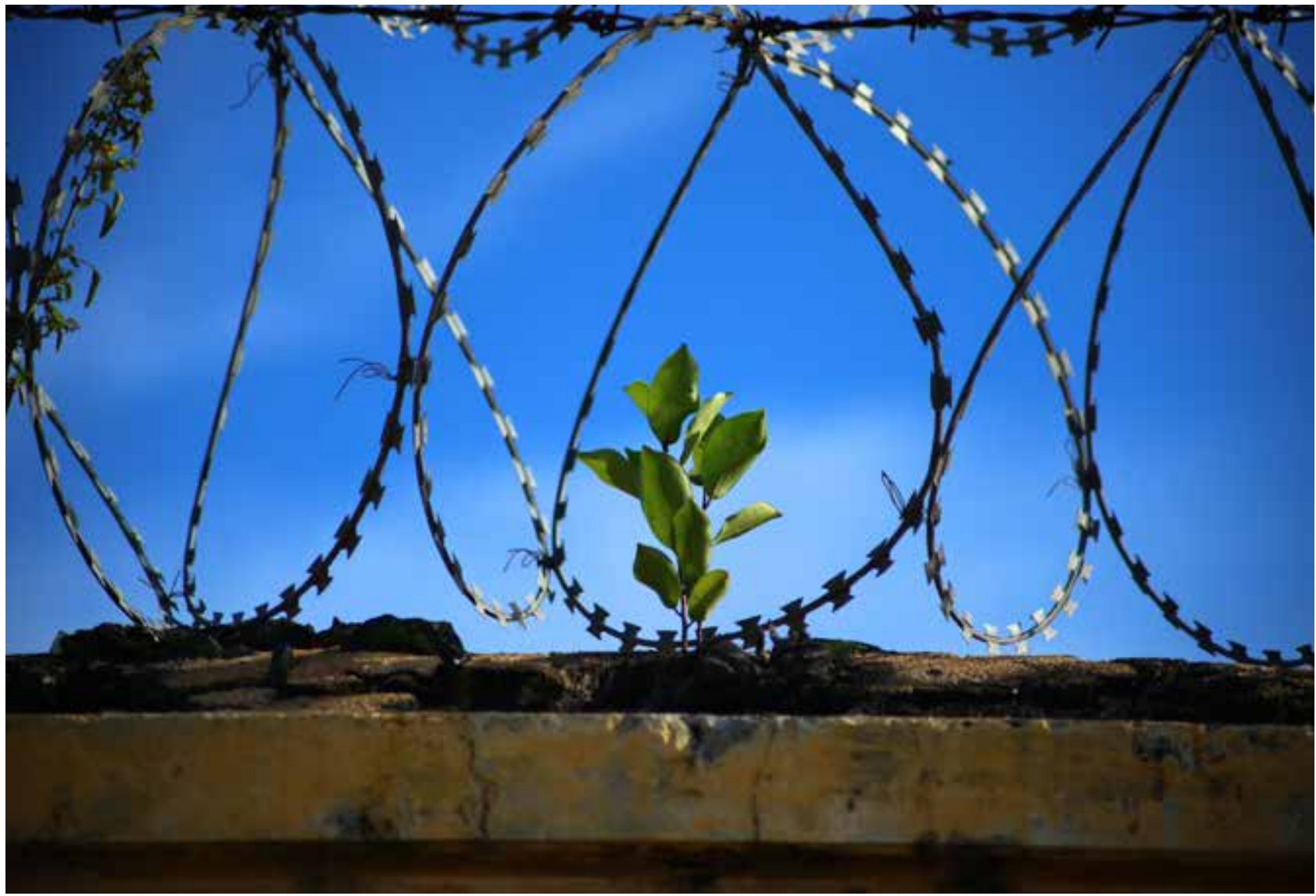

that respects, restores and sustains these values, as opposed to one that disregards, damages or violates them. From this viewpoint, a just society provides people with the opportunities and capacities to participate in their communities for the common good in a way that they choose.

\section{G4}

\section{Social justice can also address the neglect of victims and discrimination against offenders}

The dignity of human beings is derived from the value of human life and the potential of people's capacity to choose their actions and to be responsible for them. To be a victim of a crime is to be treated as a means to another's end or to be objectified. This is dehumanising and humiliating. Respect requires a refusal to stereotype, stigmatise, objectify or idealise individuals. Solidarity is derived from mutual responsibility and reciprocal support. Human beings can only live in relation to others. ${ }^{9}$ Both actions for the common good and harmful be- haviour have a "ripple effect" beyond those directly responsible and those directly affected by them. Families, friends, neighbours and communities have a stake in repairing harm and alleviating suffering. While other people may be a potential threat, they are also essential to our wellbeing.

Social justice refers to fair and right relations, to the redistribution of resources and to the removal of obstacles to equality of opportunity and full participation in society. This is the foundation of human rights and

9 Emmanuel Lévinas, Totality and Infinity: An Essay on Exteriority (Pittsburgh: Duquesne University Press, 1969). 
of many international statements on crime and criminal justice. More recently it has focused on the value of diversity. Social justice can also address the neglect of victims and discrimination against offenders.

\section{GG

The dignity of
human beings is
derived from the
value of human life
and the potential of
people's capacity to
choose their actions
and to be responsible
for them

These values inform key principles of humane practice. Rather than seeing individuals as simply products of their genes, their upbringing or their environment, a humane approach recognises their capacity to make meaning out of situations and events, to choose actions, to reflect upon those actions, to learn and to generate new understandings. More humane approaches offer opportunities for all parties to take active responsibility for the process of addressing the harm so that they may put it behind them.

\section{Possibilities for change and restorative justice}

A harmful act creates an obligation to make things right with the individual who has been harmed and with society. By fulfilling such an obligation, the individual earns the support of society with all its benefits and responsibilities. In this way, the offender is redeemed; this is what Bazemore refers to as "earned redemption."10 More humane approaches should offer individuals the opportunity and support to "signal" that they are in the process of transforming themselves.

\section{G4 \\ Both the processes of desistance (moving away from committing crime) and of recovery from trauma have relational elements}

Any humane approach should be designed to enable perpetrators to desist from crime or avoid harming other people, and should support victims to recover from the harm and suffering caused by crime. Both the processes of desistance (moving away from committing crime) and of recovery from trauma have relational elements. ${ }^{11}$

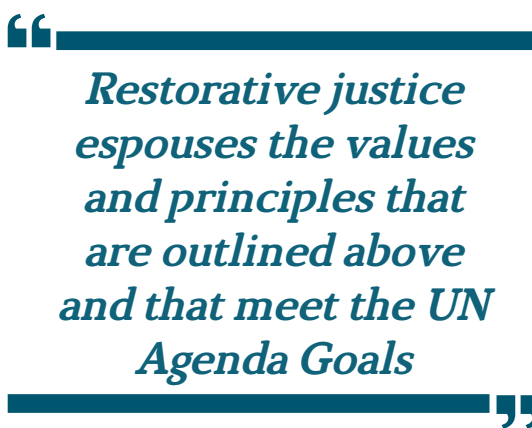

Restorative justice espouses the values and principles that are outlined above and that meet the UN Agenda Goals. It is an inclusive approach to addressing harm through engaging all those affected in coming to a common understanding and agreement on how the harm or wrongdoing can be repaired, relationships strengthened, and justice achieved. ${ }^{12}$

Restorative justice places harm at the core of the justice process and engages all those who have been affected by the act of harm, including the perpetrator. The counter-intuitive aspect of the restorative process is that each party needs the other to have what has been lost or violated restored. Victims usually want those responsible for the harm to make themselves accountable in a direct and practical way. By

10 Gordon Bazemore, "Restorative Justice and Earned Redemption: Communities, Victims, and Offender Reintegration", American Behavioral Scientist 41, no. 6 (1998): 768-813.

11 Shawn Bushway and Robert Apel, "A Perspective on Employment-Based Re-Entry Programming: Training Completion as a Desistance Signal," Criminology and Public Policy 11, no. 1 (2012): 73-86; Beth Weaver, Offending and Desistance: The importance of social relations (Abingdon: Routledge, 2016).

12 European Forum for Restorative Justice, "Forum 15 Strategy Paper" (Leuven: European Forum for Restorative Justice, 2016) 
doing so, perpetrators can earn respect by taking responsibility and making amends. Through such a process both parties may move on in their lives.

G4

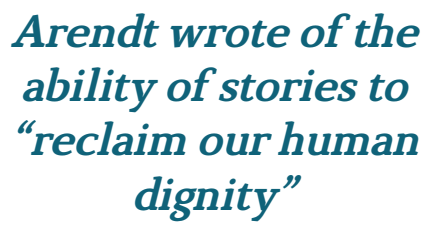

Arendt wrote of the ability of stories to "reclaim our human dignity"

narrative from one of "shame and humiliation to a portrayal of dignity and virtue." 15 Through a restorative process, dialogue has the capacity to "humanise what is going on in the world and in ourselves only by speaking of it [the harm], and in the course of speaking of it we learn to be human." 16

Meta studies show high satisfaction rates among victims, offenders and professionals that took part in a restorative justice process. The feeling of justice increases, participants feel that they are being taken seriously, the assumption of responsibility by offenders is appreciated and less recidivism is measured. $^{17}$

For many people it is a moment of change, a new beginning, and that often relates to being heard and sharing narratives.

\section{Conclusion}

Values such as the common good, human dignity, solidarity and social justice can reorientate our criminal justice system in transformative ways. Creating a more humane criminal justice system benefits everyone, in particular the person harmed and the person who has caused the harm. In these turbulent times, material self-interest, disrespect, division, inequality, and severe judgements and punishment can seem to flourish. It is critically important that alternative values continue to be applied in practical and effective ways. connections. ${ }^{14}$ The victim telling their story transforms the

\section{The Authors}

Tim Chapman is a visiting lecturer at the University of Ulster and current Chairperson of the European Forum for Restorative Justice.

tjchapman@ulster.ac.uk

Annemieke Wolthuis is an independent researcher, trainer and mediator working for Restorative Justice Nederland, and current Vice Chair of the European Forum for Restorative

\section{Justice.info@annemiekewolthuis.nl}

13 Hannah Arendt, Men in Dark Times (New York: Harcourt, 1968): 216.

14 Meredith Rossner. Just Emotions: Rituals of Restorative Justice (Oxford: Oxford University Press, 2013).

15 Martha Minow, Between Vengeance and Forgiveness: Facing history and Genocide and Mass Violence (London: Beacon Press, 2000).

16 Hannah Arendt, Men in Dark Times (New York: Harcourt, 1968): 25.

17 Joana Shapland, A. Atkinson, H. Atkinson, J. Dignan, L. Edwards, J. Hibbert, M. Howes, J. Johnstone, G. Robinson \& A. Sorsby. Does Restorative Justice affect reconviction? The fourth report from the evaluation of three schemes (Centre for Criminological Research University of Sheffield, 2008); Lawrence W. Sherman \& Heather Strang. Restorative Justice: The Evidence (London: The Smith Institute, 2007). 


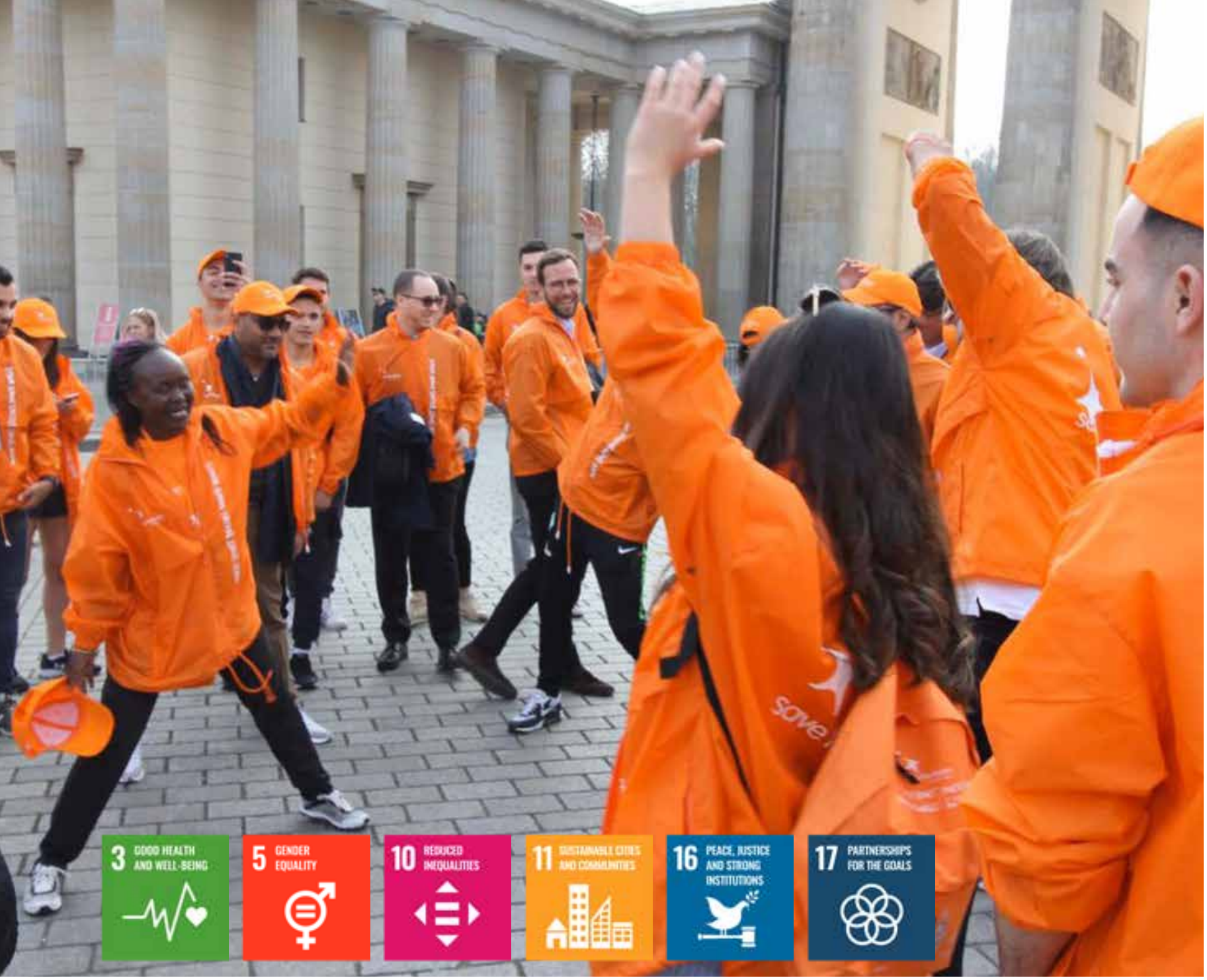

\section{When Sport Breaks Down Walls}

by Massimiliano Montanari

On the $9^{\text {th }}$ of November 2019, we celebrated the $30^{\text {th }}$ Anniversary of the Fall of the Berlin Wall, an event which has become a global icon for positive, disruptive change, a symbol of reunification and justice.

For Save the Dream, an organisation working to promote safe access to sport and its educational and social values, the temptation to associate the power of sport with the demolition of the Berlin Wall and any other barrier between or within nations was so strong that it resulted in the launch of the global campaign "When Sport Breaks Down Walls", in cooperation with the International Olympic Truce Center (IOTC) and the support of the United Nations Alliance of Civilizations (UNAOC). 
There have been many moments throughout history, when the universal language of sport has spoken to the world, promoting peace, reconciliation or simply showcasing that a different way of thinking is possible.

Berlin is the city which saw the Afro-American champion Jesse Owens challenging Hitler's myth of Aryan supremacy by winning four gold medals in the sprint and long jump during the 1936 Summer Olympics. Ironically Owens would never be invited to the White House to shake hands with the US President. Nonetheless, his victories remain one of the most powerful messages conveyed by sport in the course of history, along with the support and advice Owens received from his German competitor Luz Long. Long became a symbol of both sportsmanship and peace in a world which was entering into the II Second World War, during which he lost his life fighting as a German soldier.

GG

\section{There have been many moments throughout history, when the universal language of sport has spoken to the world}

Let us also be reminded about the German athletes who marched together at the Rome Summer
Olympics in 1960 as part of the United Team of Germany.

I had the opportunity last April, when we launched our campaign through the organisation in Berlin of a Youth Forum, to meet Hans Grodotzki, a German athlete who competed in the 1960 Rome Summer Olympic Games. His words allowed us to relive the moment the German team entered the stadium during the opening ceremony, wearing black and gold, with no sign of the German Federal Republic or the German Democratic Republic and marching to Beethoven's $9^{\text {th }}$ Symphony instead of the national anthem.

Nelson Mandela's quotes on the power of sport have inspired generations of "sport for peace activists". South Africa's victory of the 1995 Rugby World Cup played in South Africa remains one of most powerful examples of national reconciliation. A divided nation became one when South African President Nelson Mandela strode to the centre of the pitch in a Springbok jersey and shook hands with Francois Pienaar, captain of a team who represented for many years before one of the main symbols of apartheid.

The role of sport in breaking down walls is highlighted by the United Nations (UN) General Assembly resolution which, on the $23^{\text {rd }}$ of August 2013, proclaimed the $6^{\text {th }}$ of April as the
International Day of Sport for Development and Peace, a date which commemorates the inauguration in 1896 of the first Olympic games of the modern era in Athens.

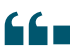

Through the resolution, the UN General Assembly invites States, international organizations, sports organizations and civil society to cooperate, observe and raise awareness of the International Day of Sport for Development and Peace.

The UN General Assembly started to adopt resolutions since 1993, urging its Member States to observe the Olympic Truce from the seventh day before the opening to the seventh day following the closing of each Olympic Games.

The 2018 Winter Olympics in PyeongChang, was dubbed the "Peace Olympics" due to athletes from North and South Korea marching together, for the first time under a unified flag. This step to rapprochement can be seen as one of the most recent examples of sport diplomacy. 


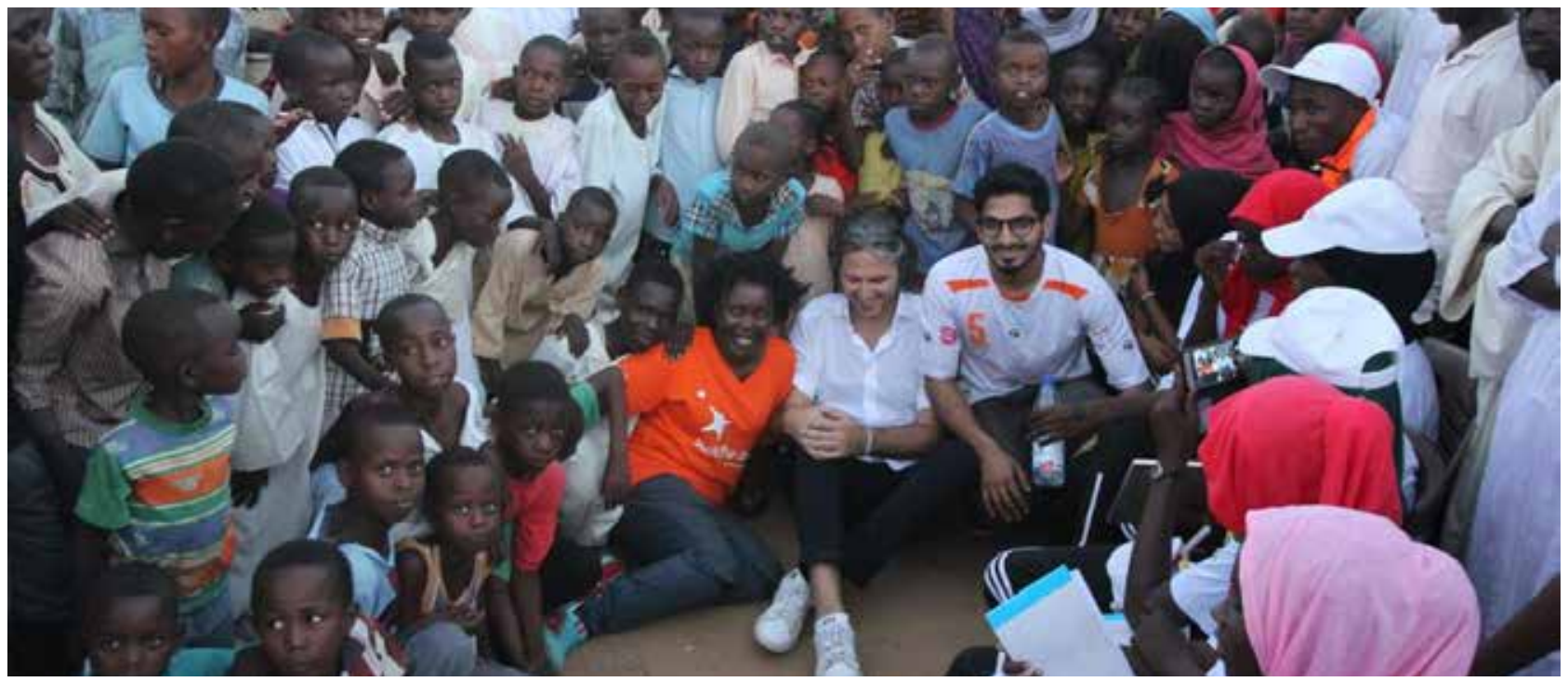

Regardless of these breakthroughs through the soft power of sport, walls continue to exist.

According to the report we issued on the $9^{\text {th }}$ of November 2019 jointly with the IOTC and with the support of UNAOC, at the end of World War II, there were seven border walls or fences in the world. By the time the Berlin wall fell in 1989, there were fifteen. Today, there are at least 77 walls or fences around the world.

An important question that continues to be asked is whether sport can do more to inspire, facilitate or catalyse political decisions or promote positive change across nations.

The answer is probably "yes" and it is supported by the growing attention paid to "sport for development and peace" or other issues affecting society such as violent extremism by inter- national organisations, sport bodies and, most importantly, by international, regional and national agencies for development and cooperation. Notwithstanding the closure of the UN Office on Sport for Development and Peace, there continues to be positive trends of coordinated actions and platforms where "sport for peace activists" have access to tools, information and interaction.

\section{GG}

By the time the
Berlin wall fell in
1989, there were
fifteen. Today,
there are at least
77 walls or fences
around the world

Many encouraging stories are coming from the world of sport, civil society and sport at the grass-roots level.
An inspiration to us all is the effort by Marathon Legend Tegla Loroupe, who organises the Peace Race in Kapenguria, Kenya every year. The aim is to promote unity between rival tribes in the West Pokot area. Since 2016 he also leads the Refugee Athletes Team which provides an opportunity to refugee athletes to compete in the Olympic Games under the flag of the International Olympic Committee.

Then there is the example of Nelsa Curbelo, human rights activist nominated twice for the Nobel Peace Prize, who has utilised sport and other soft powers to bring peace among gangs in Ecuador's city of Guayaquil. The city is home to over 200 gangs, of which some 60,000 disaffected youths are members.

The work of Suad Gallow, a former Somali National Women's Basketball Team Member is noteworthy. She is developing 
Women's basketball from grassroots to elite level in Somalia, while protecting girls willing to play from extremist groups trying to deny women the right to practice sport in the Country.

The story of Honey Thaljieh, today a FIFA official, remains inspiring. Thalijeh succeeded in establishing the National Women's Football Team of Palestine.

Katherina Salta, an IOTC official, founded in Greece the Country's first women's refugee team involving nationals from fourteen countries including Syria, Afghanistan, Iran, Iraq, Eritrea and Ethiopia.

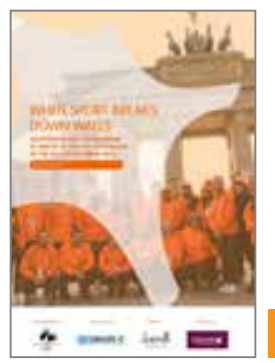

Please click here to download the Report When Sport Breaks Down Walls

\section{The Author}

Massimiliano Montanari has over eighteen years' experience in international affairs and innovation in pursuance of global objectives such as peace, inter-cultural dialogue and human development.

He serves as Chief Executive Officer at the global NGO "International Center for Sport Security" (ICSS) INSIGHT and leads ICSS' initiative Save the Dream as its Executive Director, established to promote inter-cultural dialogue and social innovation through the power of sport values. Montanari's previous position at the ICSS, which he joined in 2012, was as Chief of Cabinet to ICSS the President.

Before joining the ICSS, Massimiliano Montanari has worked for twelve years for different United Nations bodies, including the UN High-Commissioner for Refugees, the UN Office on Drugs and Crime and the UN Interregional Crime and Justice Research Institute, as well as taken part in Task Forces at the UN Secretariat in New York in different fields, such as addressing violent extremism, transitional justice, security in post-conflict zones and public-private partnerships.

Polyglot and creative thinker, Montanari has strong experience in international negotiations and in the development of multisectoral programmes, new ideas and global movements involving different sectors, from government to civil society. 

As a group of European organizations working in the fields of child and youth care, mentoring services and academic research, our work is highly connected with the targets of SDG 4. This includes eliminating disparities in education and ensuring equal access to all levels of education and vocational training for the most vulnerable, including persons with disabilities, and children in marginalized situations. $^{2}$

\section{GG}

\section{The United Nations with Goal 4 renewed its mission for better education of children and young people worldwide}

The Sapere Aude ${ }^{3}$ Improvement of the academic results of young people in care through mentoring pilot project was developed in 2016 and funded by the European Union Programme Erasmus+ Strategic Partnerships in the field of school education.
The initiative was motivated by recent academic research, as well as on-the-ground experiences from organizations spanning five European countries: Spain, France, Germany, Austria and Croatia. ${ }^{4}$

These international partner organizations share the core observation that children and young people who grow up in the public care system lack inclusive and equitable quality education opportunities. This is also reflected in a number of studies which demonstrate immense differences in the overall educational outcomes between children and young people living in residential care settings compared with their peers who live with their biological families. The 20082010 cross-national research project YiPPEE, which investigated the pathways to education of young people in public care, demonstrated inadequate educational situations within five European countries. The findings also showed that only $8 \%$ of young people who had been in care as children went on to access higher education, which was five times fewer than the overall number of young people accessing higher education. $^{5}$

One of the major factors in this situation is that we often see a structural division between the social care system and the education system as well as the failure of these systems to work adequately together. Moreover, it seems that the meaningful education of children and young people living in residential care is a low priority for professionals working with these segments of the population. This impression is reflected in the low expectations and little interest that social workers and responsible social institutions show towards the educational and professional development of their young clients. By neglecting the importance of education of these children and adolescents, we risk continuing and reinforcing the cycle of endemic poverty and unsatisfactory living conditions which many of them have already experienced.

2 United Nations: “Sustainable Development Goals. Quality Education”: https://www.un.org/sustainabledevelopment/education/

3 The popular Latin phrase and philosophic principal Sapere Aude has been used in different epochs and contexts to encourage and empower people to think for themselves and live a self-determined life. Without going any deeper into the theoretical concepts of Sapere Aude, it can be said that education continues to be a key element within almost every empowering process, especially when it comes to young people living in vulnerable situations. Therefore, we decided to name our project SAPERE AUDE.

4 The SAPERE AUDE project group consists of experts from the field of child and youth care: Fundació Privada Plataforma Educativa (Spain), BTG - Federal Association of Therapeutic Communities (Austria), S\&S gem. Gesellschaft für Soziales mbH (Germany), Parrains Par Mille (France) and the PLAY Association (Croatia), as well as research experts from the University of Girona.

5 Cameron, Claire; Jackson, Sonia (2011): "Final report of the YiPPEE project WP12 Young people from a public care background: pathways to further and higher education in five European countries". Thomas Coram Research Unit Institute of Education, University of London, UK. 


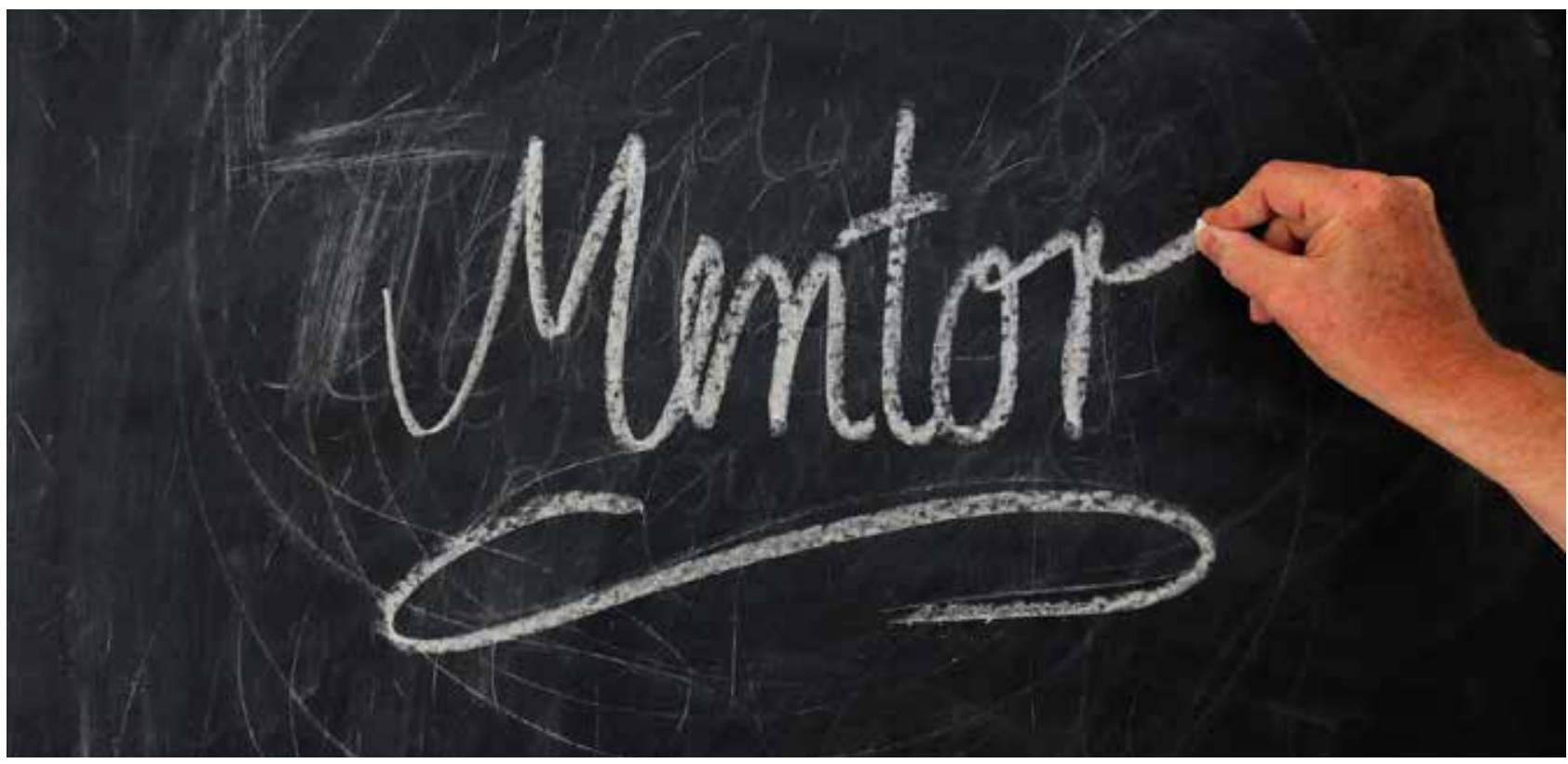

Social mentoring as a tool to break the cycle of social exclusion and the lack of education?

The Sapere Aude project aimed to make a positive contribution towards breaking this cycle of intergenerational lack of education and social exclusion, by empowering these children and young people through a specialized social mentoring project. Social mentoring, in the framework of the project, consists of a trusting and continuous relationship between a mentor and a mentee who lives in the social care system and lacks an individual support system through a partner or role model. ${ }^{6}$ Practical studies have shown that a close personal relationship, such as one with a mentor, can have a very important and positive impact on adolescents while they go through challenging life transitions. The Committee on Early Childhood, Adoption and Dependent Care also emphasized the importance of a mentor in the context of emotional health: "(...) having at least one adult who is devoted to and loves a child unconditionally, who is prepared to accept and value that child for a long time, is key to helping a child overcome the stress and trauma of abuse and neglect." Besides that, a social mentoring relationship provides young people with role models who may inspire them, while also giving them a more diverse picture of "real life" and its varying challenges.
GG

The eight percent of young people who had been in care as children went on to access higher education

\section{Results of the Sapere Aude social mentoring process}

Driven by the scientific and practical findings above, the main objective of the project was to implement a ninemonth social mentoring initiative and evaluate whether this mentorship had a positive impact on the educational results of young people between

6 Allen, B., \& Vacca, J.S (2010): "Frequent moving has a negative affect on the school achievement of foster children makes the case for reform, Children and Youth Services”. In: Children and Youth Services Review, vol. 32, no. 6, pp. 829-832.

7 The Committee on Early Childhood, Adoption and Dependent Care (2000): "Developmental Issues for Young Children in Foster Care". In: American Academy of Pediatrics, vol. 106, no. 5, pp. 1145-1146. 


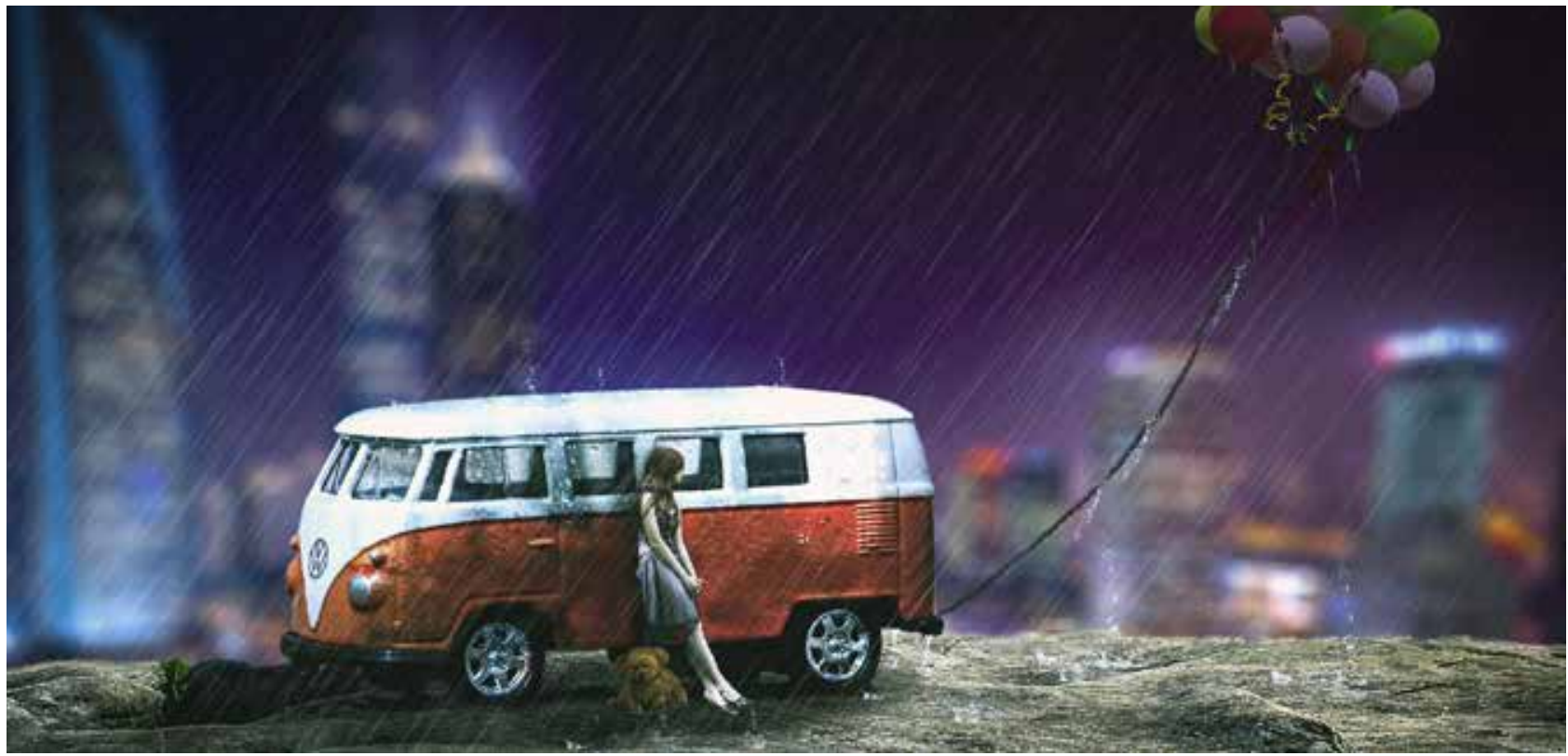

12 and 17 living in residential care. All social interactions and weekly meetings between the mentor and the mentee were monitored by care givers and the Research Team on Childhood, Adolescence, Children's rights and their Quality of Life (ERIDI) of the University of Girona. During the process, the ERIDI collected around 444 pre- and post-test surveys from mentees, mentors, care givers and teachers as well as 838 individual mentoring reports regarding all mentoring activities.

\section{G6}

A close personal relationship, such as one with a mentor, can have a very important and positive impact on adolescents
The data collected from these surveys and reports reflected the complexity and heterogeneity of every mentoring relationship and national setting. Nevertheless, we were happy to discover that the results confirmed the positive impact of the Sapere Aude mentorship project on the educational outcomes of children and adolescents who are currently living in our residential care centers. Besides the fact that the grades of the participants improved in the fields of natural science, social sciences, foreign languages and sports, it is particularly noteworthy that the mentees expressed a much higher self-confidence regarding their educational results and professional future. For example, many of the children and adolescents stated that they would like to start vocational training after completing school.
The data also showed that the mentees are less likely to look favourably at dropping out of school than they were before the mentoring project.

Asked about the school and learning settings, the mentees demonstrated a fear of stigmatization and exclusion from their familiar learning environment. The majority of the surveyed mentees spoke in favour of an inclusive learning approach and having the possibility to do individually tailored schoolwork that corresponds to their own level of learning. Overall, they expressed their gratitude for having a dedicated person in their life and for receiving the mentor's sole focus.

Even though we received a lot of positive feedback from them, their answers also brought up some very concerning topics. 


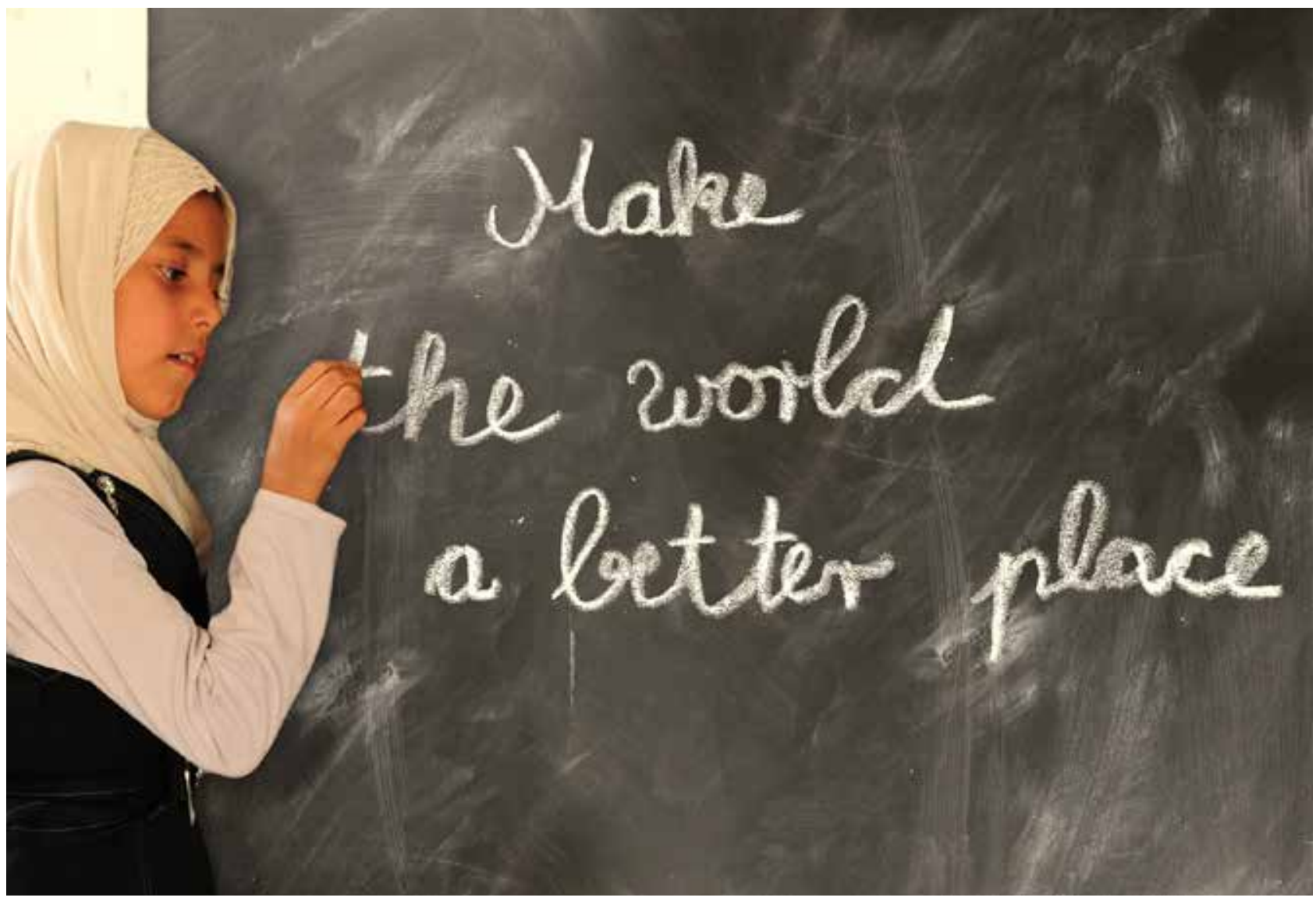

Mentees saw their educational future more positively than before the mentorship project, but they also stated in the posttests that they have less hope and less positivity towards their life and future in gener- al. This was raised in particular by participating children and young people with refugee status who suffer from traumatic experiences and constant uncertainty regarding their residency. The result of the social mentoring underscores the importance of Sustainable Development Goal 4, which urges us to focus on the social-emotional well-being of vulnerable people in order to achieve substantial learning outcomes. ${ }^{8}$

\section{The Author}

Milena Westermann holds an M.A. in Political Science from the University of Hamburg, with a specialization in International Political Theory. During her studies she completed an internship at the UNICRI Public Information Department. She graduated in 2018 with a thesis on Jihadist terrorism and the challenges for the European Union. She is currently working with the S\&S gemeinnützige Gesellschaft für Soziales mbH in Hamburg, in the area of communications and international cooperation.

8 For further details please take a look at our homepage: www.sapereaude-project.com/the-project/ 





\section{SDG 14: stepping up international efforts to tackle ocean plastic pollution}

by Jivan Dasgupta

Eight to twelve million tons of plastics end up in the oceans every year. One of the targets of Sustainable Development Goal (SDG), Goal 14 on life below water, calls upon states to prevent and significantly reduce marine pollution of all kinds, in particular from land-based activities, including marine debris, by 2025. Following China's ban of all imports of non-industrial plastic wastes in 2018, exports of plastic wastes by high-income countries have shifted to South East Asian countries putting unbearable stress on their waste management systems. Despite worldwide attention devoted to the ocean plastics crisis, these practices are likely to aggravate the problem. It shows that current efforts are not sufficient to achieve the SDG target 14 for marine plastic litter and microplastics. 
China and South East Asia are considered the largest plastic polluters of the oceans. ${ }^{1}$ Strong economic growth in this region has not gone hand in hand with a parallel development of waste management systems. Nevertheless, high-income countries are exporting significant amounts of plastic waste intended for recycling to this region. Weaker environmental regulations and law enforcement in these countries make treatment of plastic wastes more competitive. Discrepancies in environmental standards are driving forces for transboundary movements for all sorts of waste from industrialized countries to emerging and developing economies. ${ }^{2}$

\section{G6}

SDG 14 on life below water calls upon states to prevent and significantly reduce marine pollution of all kinds, in particular from land-based activities, including marine debris, by 2025
Half of all plastic waste intended for recycling (14 million tons/annum) is exported by high-income countries. These waste streams are often mixed or contaminated, rendering them more difficult (or impossible) to recycle. Before the 2018 import ban, China was importing half of their plastic scrap (7 million tons). ${ }^{3}$ High-income countries integrate these exports in their "recycling" statistics without monitoring the fate of this plastic scrap in the importing country.

\section{Surge in illegal practices}

The China import ban has sent shock waves into the global plastic waste trade. High-income countries have underinvested in domestic recycling capacity for years. As a result, the bulk of these plastic wastes has been relocated to countries within China's vicinity such as Malaysia, Thailand and Vietnam. These countries lack the infrastructures to manage their own waste, let alone an abrupt increase of low quality waste streams which should be treated under strict environmental control at special treatment facilities. This has resulted in a surge of illegal recycling facilities, illegal dumping in the (marine) environment and open, unregulated burning of materials. ${ }^{4}$ Substantial environmental and health risks are associated with these practices.

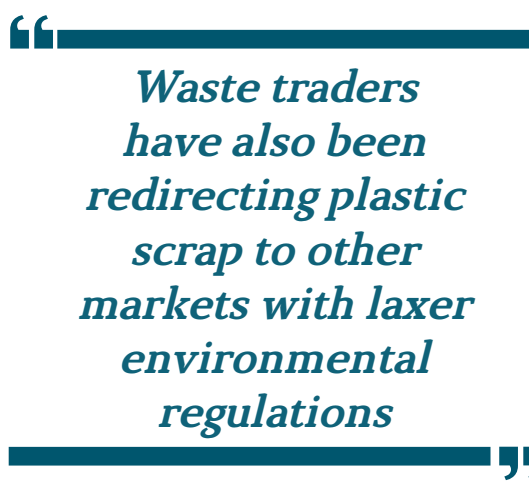

In recent months, these ASEAN countries have responded by imposing temporary import bans and restrictions. However, these restrictions are partially circumvented by illegal trafficking. These practices go from classifying waste as second hand goods or raw materials to mixing different types of waste and transporting waste on the black market. Waste traders have also been redirecting plastic scrap to other markets with laxer environmental regulations such as Indonesia and India. It shows

\footnotetext{
J. R. Jambeck et al., Marine pollution. Plastic waste inputs from land into the ocean, Science 347, 2015, p 768-771.

2 D. Kellenberg, Trading wastes, Journal of Environmental Economics and Management 64, 2012, p 68-87; J. R. Kitt, Waste Exports to the Developing World: a global response, The Georgetown International Environmental Law Review vol. 7, $1995, \mathrm{p} 485-514$.

3 A. L. Brooks et al., The Chinese import ban and its impact on global plastic waste trade, Science Advances Vol. 4, no. 6, 2018, DOI: 10.1126/sciadv.aat0131; C.A. Velis, Global recycling markets - plastic waste: A story for one player - China. Report prepared by FUELogy and formatted by D-waste on behalf of International Solid Waste Association - Globalisation and Waste Management Task Force. ISWA, Vienna, 2014.

4 Global Alliance for Incinerator Alternatives, Discarded - Communities on the Frontlines of the Global Plastic Crisis, 2019; Greenpeace Malaysia, The Recycling Myth - Malaysia and the Broken Global Recycling System, 2018; Shen Qu et al., Implications of China's foreign waste ban on the global circular economy? Resources, Conservation \& Recycling 144, 2019, p 252-255.
} 


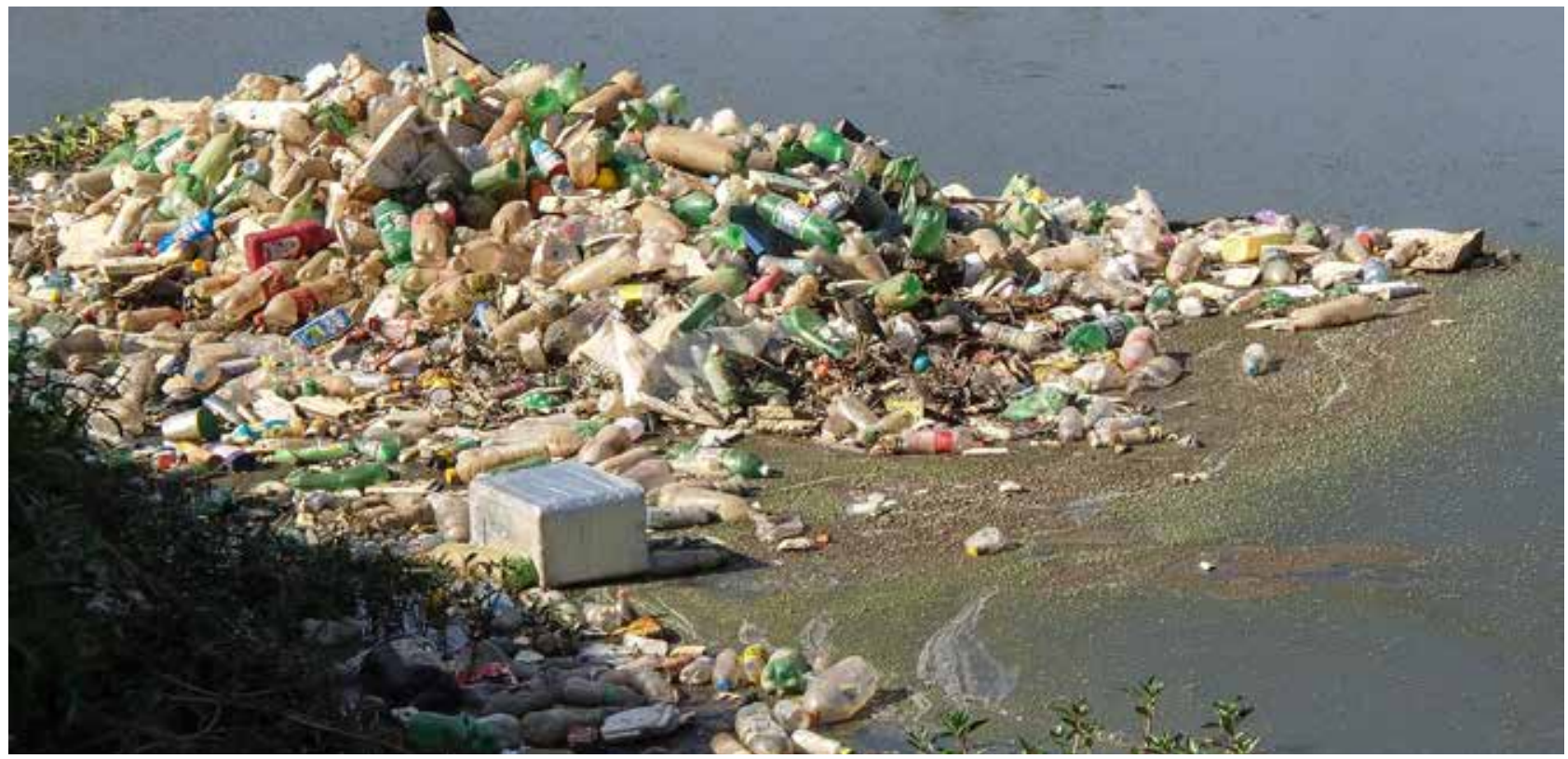

that waste follows the path of least resistance.

\section{Limitations of the Basel Convention and other treaties}

In May 2019, state parties decided to place plastic waste under the control mechanism of the Basel Convention on the Control of Transboundary Movements of Hazardous Wastes and Their Disposal. The underlying objective of the Convention is to improve the environmentally sound management of hazardous wastes and reduce their international trade through enhancement of trade controls. Once the amendment comes into force, an exporting country needs prior permission of the importing country to ship plas- tic wastes. In other words, the importing country is allowed to refuse the shipment, for example, if it does not have the capacity to manage it in an environmentally sound manner.

This amendment is a big step forward within the framework of the Basel Convention. However, policing and enforcement of the international waste trade (regulations) are inadequate in both exporting and importing countries. $^{5}$ Without rigorous enforcement capacities, illegal trafficking lurks right around the corner. Furthermore, the Basel Convention's contribution to enhancing the treatment and disposal of plastic wastes near the source of generation and limiting the export to countries with lower environmental standards has been limited.
There is a need to look at the broader picture. The overall weakness of the Basel Convention in addressing the ocean plastic pollution and the current chaos in global plastic waste trade lies in its core regulations, focused on the final (waste) phase in the lifecycle of plastics.

\section{4 \\ Without rigorous enforcement capacities, illegal trafficking lurks right around the corner}

"Upstream" processes in the lifecycle of plastics contribute largely to the current state of affairs. Strong population growth and unrestrained consumption

5 B. Appelqvist and J. Cooper, Waste Trafficking, Challenges And Actions To Be Taken, The International Solid Waste Association. 


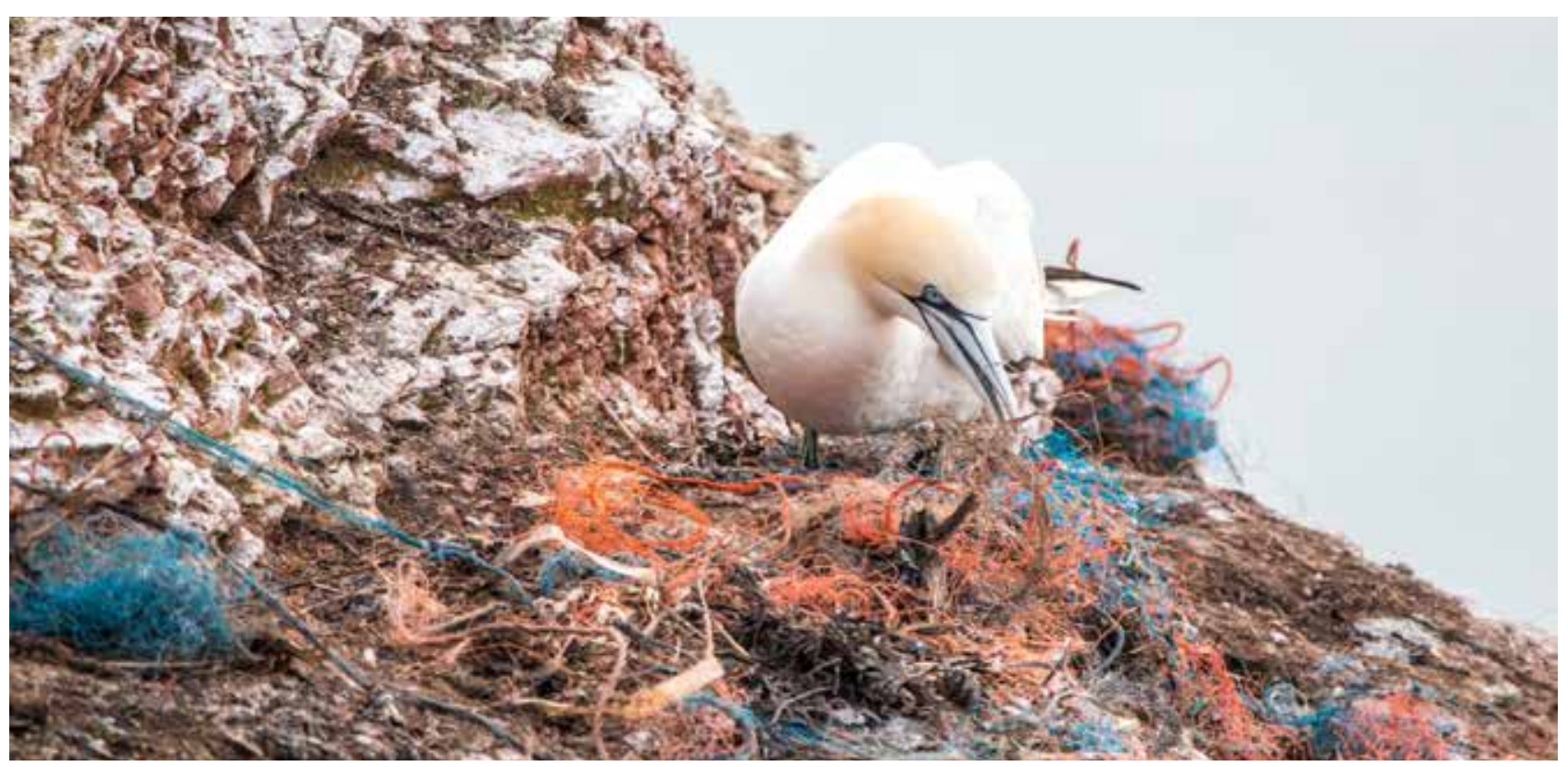

have caused the production of plastics to explode: from 1.5 million in 1950 to 348 million tons in $2018 .{ }^{6}$ In the $21^{\text {st }}$ century alone, more plastics were produced than in the whole $20^{\text {th }}$ century. In a business-as-usual scenario, global production is expected to quadruple by 2050 .

This exponential growth is exacerbated by poor recycling rates. The global recycling rate for all plastics ever produced is only $9 \%$ : $12 \%$ was sent for incineration and the remaining $79 \%$ was either landfilled or released into the (marine) environment. The problem is that the design of plastic materials does not take into account the after use needs of recycling. This is why high-income countries prefer to export their low value plastic wastes. Chemicals added to plastic products in order to enhance their functionality or aesthetic value hinder the recycling process. If plastic materials end up in the oceans, these toxic substances may leach into the marine environment, negatively affecting marine fauna.

There is no binding international convention with the primary objective to address landbased activities causing marine (plastic) pollution or the negative impacts of the globalized lifecycle of plastics. ${ }^{8}$ The Convention on the Law of the Sea (UNCLOS) is the only legally binding international treaty obligating states to take measures to prevent, reduce and control marine pollution from all sources on land and at sea. However, UNCLOS is a framework convention with general principles and does not prescribe specific measures nor environmental standards.

\section{A new international framework on prevention}

Besides the improvement of waste management, international efforts should focus primarily on the reduction and stricter regulation of primary plastics production as well as waste minimization. The way forward is to create a new legally binding international framework that encourages global actions across these pillars.

6 PlasticsEurope, Plastics - the Facts 2018 - An analysis of European plastics production, demand and waste data, 2019.

7 R. Geyer et al., Production, use, and fate of all plastics ever made, Science Advances 3, 2017, e1700782.

8 See also, UN Environment 2017, Combating marine plastic litter and microplastics: An assessment of the effectiveness of relevant international, regional and subregional governance strategies and approaches. 
The starting point for this framework would be to quantify the "significant reduction" target of SDG 14. Without quantification, this vague reduction target is merely adding up to the numerous general and vague provisions in the existing international legal framework.

States should have more ambition by setting binding global (or regional) reduction targets to achieve zero discharge of (plastic) litter and micro-plastics into the (marine) environment in the long term. Based on these targets for gradual reduction of marine plastics, states should establish national action plans consisting of national reduction targets and concrete measures.

The priority of these action plans should be to prevent (plastic) litter from entering the (marine) environment. ${ }^{9}$ The most direct way to do so is by committing to more waste prevention and improved waste management. In this regard, SDG 12 on sustainable consumption and production is of particular relevance. SDG 12 targets include achieving:

- sustainable management and efficient use of natural resources by 2030 (target 12.2);

- environmentally sound management of chemicals and all wastes throughout their life cycle, and significant reduction of their release to air, water and soil by 2020 (target 12.4);

- substantial reduction of waste generation through prevention, reduction, recycling and reuse by 2030 (target 12.5).

States should avoid unnecessary packaging and create a circular economy for plastics where design and format facilitates reuse and recycling and the waste management system is aligned with these recovery practices.

Considering that at least 2 billion people worldwide lack access to solid waste collection, in particular in developing countries, it goes without saying that the development of basic waste management facilities in these countries is a key component of prevention.

The Paris Climate Accord may serve as a model for a new international framework. Such an approach has the merit of creating a more level playing field between states and mobilizes international financing.

However, the flaws in the current international legal framework lie in the broad margin of discretion states have to regulate land-based sources of marine plastic pollution. This is enshrined in UNCLOS. The Convention provides that states shall "endeavor" to establish global rules on land-based sources of marine pollution, whilst for sea-based sources the wording "shall establish" is used. $^{10}$ States have been reluctant to give up national sovereignty on land-based sources as they are profoundly intertwined with national economic policy. International regulations on sea-based sources of marine pollution, on the other hand, are more advanced. The Marpol Treaty, which prohibits the discharge of plastic garbage by ships, and the London Protocol, which prohibits the dumping at sea of plastic waste from land, both illustrate this.

Therefore, a new international framework must demonstrate greater ambition by imposing specific additional measures at the international level.

The most straightforward "upstream" measure is to cap primary global plastics production from $100 \%$ fossil fuel sources. The political feasibility of such a measure is however unlikely.

A more acceptable solution may consist of banning or restricting (on a global scale) the production and use of the most harmful single use plastics, ${ }^{11}$ chemical additives and $\mathrm{mi}^{-}$

9 See also United Nations Environment Assembly, Resolution 3/7 “Marine litter and microplastics”, 4-6 December 2017.

10 Article 207, 4 and 211,1 UNCLOS.

11 See also, UN Environment, Legal Limits on Single-Use Plastics and Microplastics: A Global Review of National Laws and Regulations, 2018, https://www.unenvironment.org/news-and-stories/press-release/regulatory-landscape-single-use-plastics-shows-widespread-momentum 


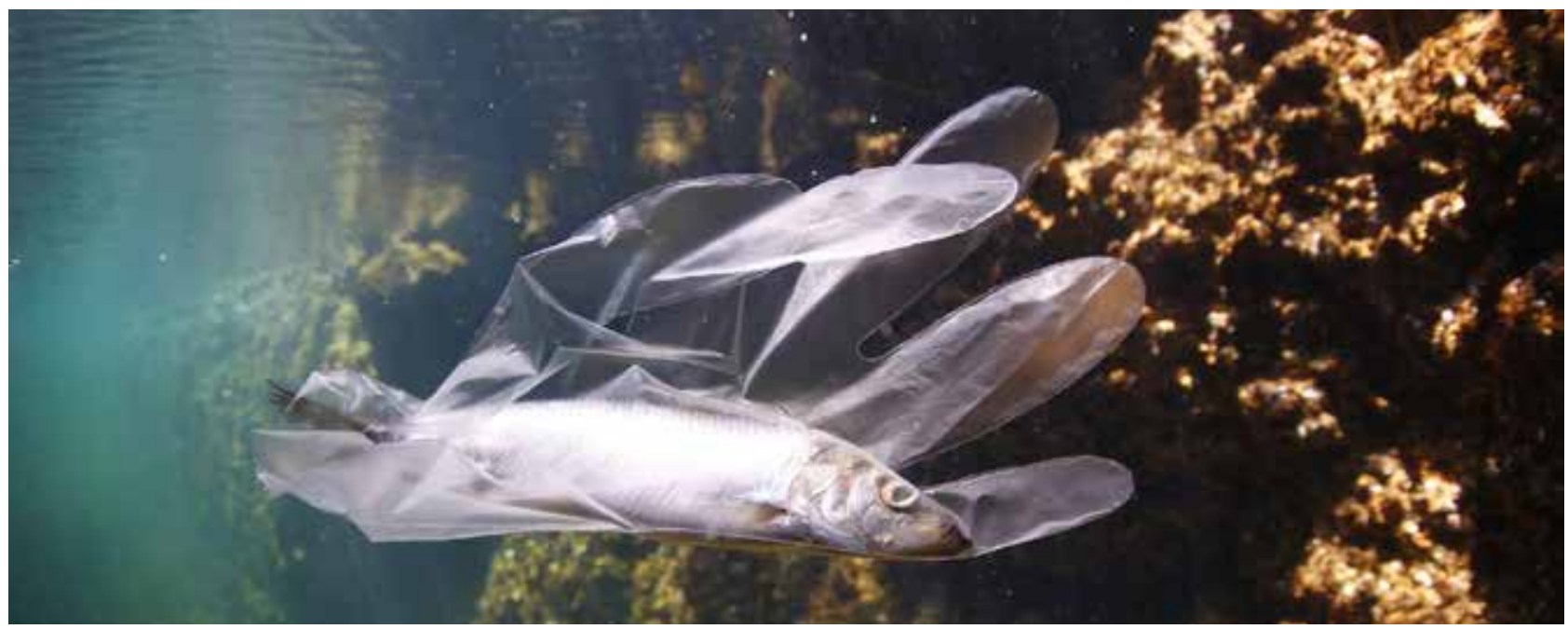

cro-plastics. This can certainly be done for plastic materials for which affordable and more environmentally sound alternatives exist or can be developed.

The mechanism of the Montreal Protocol, which successfully phased out substances depleting the ozone layer, may serve as a model for this option. Likewise, the European Union adopted in 2019 a directive to ban the single use plastics most found on $\mathrm{Eu}-$ ropean beaches, such as plastic cutlery, cotton buds and straws.

Furthermore, participating countries can be divided into two categories: countries with a high plastic waste generation per capita (developed countries) and countries with a high rate of mismanagement of plastic waste (emerging and developing countries). Dependent on the allocation to a certain category, states should set additional binding national reduction targets for the respective parameter.

A global fund may support the implementation of all these actions, in particular in the developing countries.

\section{Conclusion}

The current crisis in the global plastic waste trade results in illicit practices which further ex- acerbate environmental plastic pollution. It reveals the structural shortcomings in upstream and downstream processes in the globalized lifecycle of plastics. A new binding international agreement is recommended to address these shortcomings and eliminate discharge of plastics into the (marine) environment.

Worldwide attention to marine plastics has led to an unprecedented momentum to implement far-reaching measures. It is upon state leaders to grasp this opportunity and stop treating our oceans as a final dump for plastic wastes and to preserve the vital role the oceans play for our planet.

\section{The Author}

Jivan Dasgupta is a senior researcher at Ghent University (Belgium), Department of International, Public and European Law. His research primarily focuses on the development of a legal framework to tackle marine plastics and deep-sea mining in areas beyond national jurisdiction.

Prior to his academic activities, Jivan Dasgupta was a lawyer at the Brussels bar (Belgium) and served as advisor to a Belgian Deputy Prime Minister on energy and maritime transport policy. He also acted as in-house legal counsel for companies active in renewable energy, waste treatment and the development of maritime infrastructures and industrial zones. 


\section{Obligation to Investigate}

Minimum Investigative Standards under Article 2 of the ECHR, and Their Applicability to Post-conflict Situations

by Andrey Antonov

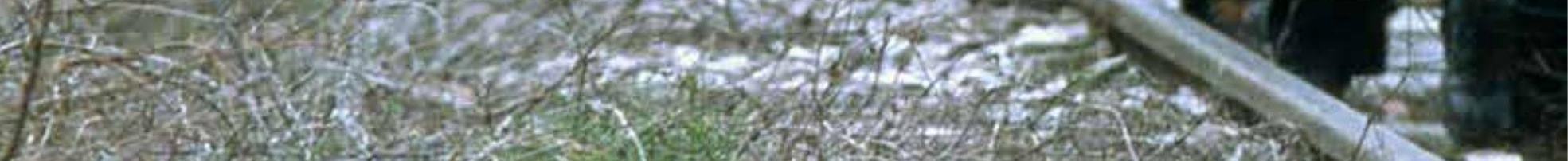




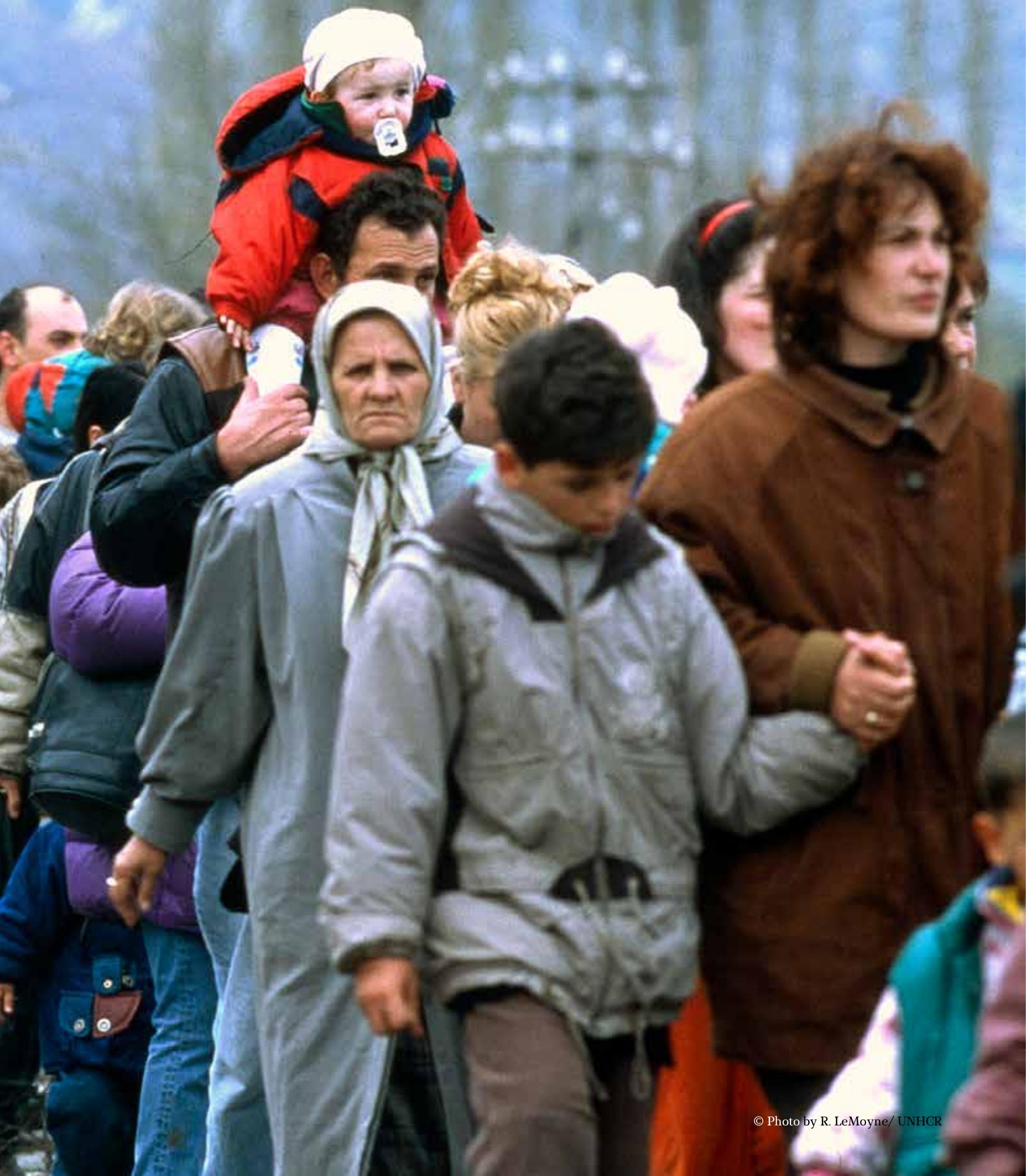


The Convention for the Protection of Human Rights and Fundamental Freedoms (or European Convention on Human Rights; hereinafter - ECHR, the Convention) is a Treaty aimed at the protection of human rights and political freedoms in Europe. The Convention was adopted in 1950 and entered into force on 3 September 1953. All Member States of the Council of Europe are party to the Convention. ECHR also establishes the European Court of Human Rights (hereinafter ECtHR, European Court), which receives, considers and delivers judgments over complaints of any person who feels his or her rights have been violated by a State party to the Convention. ECtHR's judgments find- ing violations are binding on the States in question, who are then obliged to execute them.

\section{GG}

\section{The Convention}

for the Protection of Human Rights and Fundamental

\section{Freedoms}

(or European

Convention on

Human Rights;

hereinafter - ECHR, the Convention) is

a treaty aimed at the protection of human rights and political freedoms in Europe
Article 2 of the Convention protect the most important right - right to life, of which no derogation is possible. ${ }^{1}$ Issues related to the right to life also arise from inter-state complaints, but the most of available case-law is stemming from the application and interpretation of the ECHR by the European Court.

While applying and deciding upon the relevant parts of the Convention, the ECtHR developed significant body of jurisprudence, which interpreted many provisions of the Convention, thus at times presenting new concepts, which have been then accepted and carried forward by other bodies and institutions. The concept of pro-

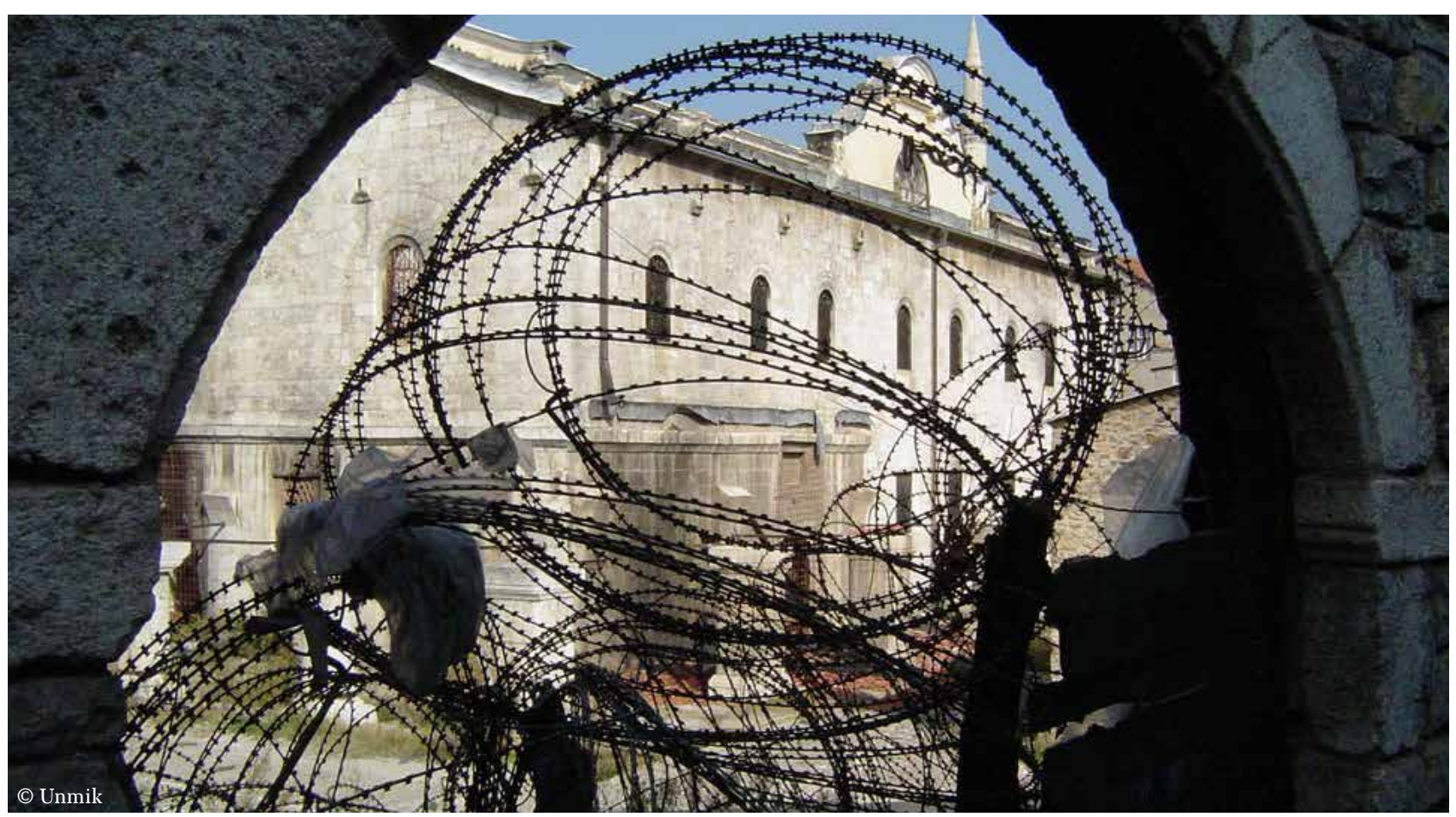

1 Article 15-2 of the ECHR. 
cedural obligation to investigate under Article 2 of the ECHR is one of those concepts.

This concept had largely emerged from the situations of obvious loss of life in life-threatening situations, where the investigative material presented to the reviewing experts at the European Commission and then ECtHR was so poor, that there were simply not sufficient grounds to assess whether the death was in violation of the obligation to protect life. This concept became a very effective tool to ensure that the authorities would not be able to avoid responsibility under Article 2 through intentional or negligent conduct of poor investigation. ${ }^{2}$ Subsequently, Article 2 provisions were also extended to cover cases of disappearances in life-threatening situations. ${ }^{3}$

In simple terms, this concept means that the State authorities are not only obliged to ensure that the right to life of no one under their jurisdiction is violated, neither by anyone acting on behalf of a State, or in their private capacity (which is the substantive obligation - under Article 2 para 1 ), but they also must conduct sufficient investigation into any suspicious death. In the first case of its kind, McCann and Others, the ECtHR said: "The obligation to protect the right to life under this provision, read in conjunction with the State's general duty under Article 1 of the Convention to 'secure everyone within their jurisdiction the rights and freedoms defined in Convention', required by implication that there should be some form of effective official investigation when individuals have been killed as a result of the use of force by, inter alios, agents of the State." ${ }^{4}$

\section{Criteria of Effective Investigation}

To be considered an effective investigation, an investigation should fulfil several basic requirements, formulated in the ECtHR's case-law: ${ }^{5}$

- it should be thorough;

- it should be expedient;

- it should be sufficiently independent and impartial;
- the materials and conclusions of the investigation should be sufficiently accessible for the relatives of the victims, to the extent it does not seriously undermine its efficiency;

- the investigation must also be capable of leading to a determination of whether the death was caused unlawfully and if so, to the identification and punishment of those responsible. ${ }^{6}$

Detailing more the criteria of independence, and particularly in relation to the alleged killings by "state agents", the ECtHR states that for an investigation to be effective, it may generally be regarded as necessary for the persons responsible for carrying out the investigation to be independent from those implicated in the events. This means not only a lack of hierarchical or institutional connection but also a practical independence. ${ }^{7}$ The fact that the investigation is to be performed "by an appropriate and impartial body" is also emphasised in the caselaw of the United Nations Human Rights Council (UN HRC),

2 See, among others: Tanrikulu v. Turkey [GC], no. 23763/94, judgment of 8 July 1999, §§ 69, 87, 96, 109-110, UCHR 1999-IV; Güleç v. Turkey, 27 July 1998, §§ 81-82, Reports of Judgments and Decisions 1998-IV; Finucane v. the United Kingdom, no. 29178/95, § 82-84, ECHR 2003-VIII.

3 See, among others: Palić v Bosnia and Herzegovina, no. 4704/04, 15 February 2011; Bazorkina v. Russia, no. 69481/01, 27 July 2006; Aslakhanova and Others v. Russia, nos. 2944/06, 8300/07, 50184/07, 332/08 and 42509/10, 18 December 2012.

4 ECtHR, McCann v. United Kingdon, no. 18984/91, judgment of 27 September 1995, § 161.

5 See: ECtHR [GC], Finogenov and Others v. Russia, nos 18299/03 and 27311/03, § 270-272

6 See: ECtHR [GC], Varnava and Others v. Turkey, nos 16064/90 and others, judgment of 18 September 2009, § 191; ECtHR, Palić $v$. Bosnia and Herzegovina, cited in footnote 11 above, at § 63.

7 See: ECtHR, Hugh Jordan v. the United Kingdom, judgment of 4 May 2001, § 105; ECtHR [GC], Giuliani and Gaggio v. Italy, [GC], no. 23458/02, judgment of 24 May 2011, § 300; ECtHR [GC], Ramsahai and Others $v$. the Netherlands, no. 52391/99, judgment of 15 May $2007, \S 325$. 


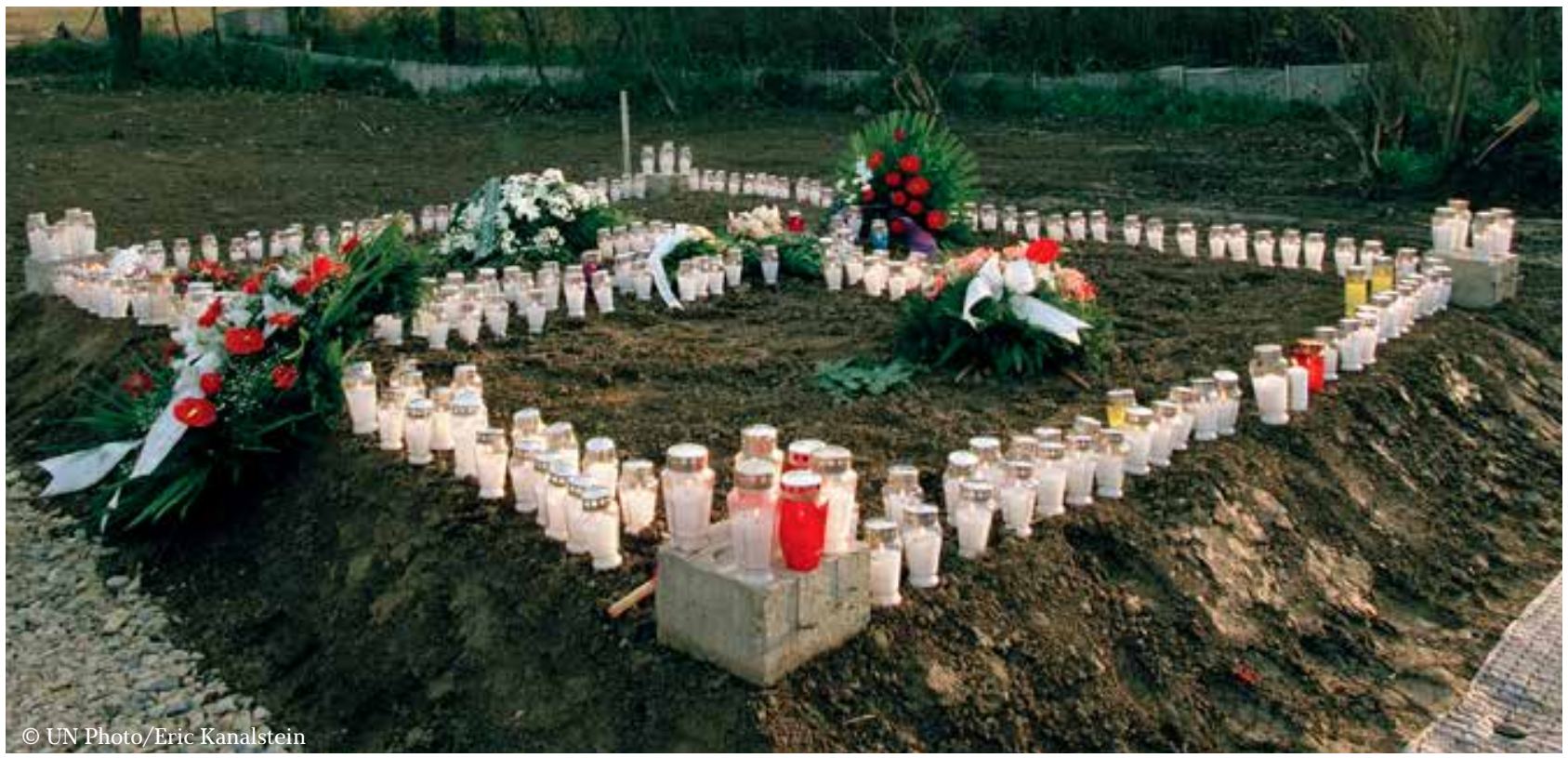

especially in cases of disappearances. ${ }^{8}$

G6

The fact that the
investigation is to
be performed "by
an appropriate and
impartial body" is
also emphasised
in the case-law of
the United Nations
Human Rights
Council

At the same time being realistic and acknowledging that in practice not every investigation should necessarily be successful nor come to a conclu- sion which coincides with the claimant's account of events, the ECtHR stresses that this procedural obligation "is not an obligation of results but of means." Therefore, the investigation will satisfy the requirement of "thorough investigation" if:

- the authorities take whatever reasonable steps they can to secure the evidence concerning the incident, including, inter alia, eye-witness testimony, forensic evidence and, where appropriate, an autopsy which provides a complete and accurate record of injury and an objective analysis of the clinical findings, including the cause of death;

- make a serious attempt to find out what happened and do not rely on hasty or ill-founded conclusions to close their investigation or as the basis of their decisions; ${ }^{9}$

- the investigation was capable of leading to the establishment of the facts of the case and, if the allegations prove to be true, to the identification and, possibly, the punishment of those responsible, ${ }^{10}$

- the investigation's conclusion are based on thorough, objective and impartial analysis of all relevant elements. Failing

8 See: HRC, Joaquín David Herrera Rubio et al. v. Colombia, § 10.3, Communication No. 161/1983, U.N. Doc. CCPR/C/OP/2 (1990); HRC, Basilio Laureano Atachahua v. Peru, § 8.3, Communication No. 540/1993, U.N. Doc. CCPR/C/56/D/540/1993 (1996).

9 See: ECtHR [GC], El-Masri v. "the former Yugoslav Republic of Macedonia”, no. 39630/09, judgment of 13 December 2012, § 183; ECtHR [GC], Mocanu and Others v. Romania, nos 10865/09, 45886/07 and 32431/08, judgment of 17 September 2014, § 322).

10 See: ECtHR, Mahmut Kaya v. Turkey, no. 22535/93, judgment of 28 March 2000, § 124; see also ECtHR, Paul and Audrey Edwards v. the United Kingdom, no. 46477/99, judgment of 14 March 2002, § 71. 


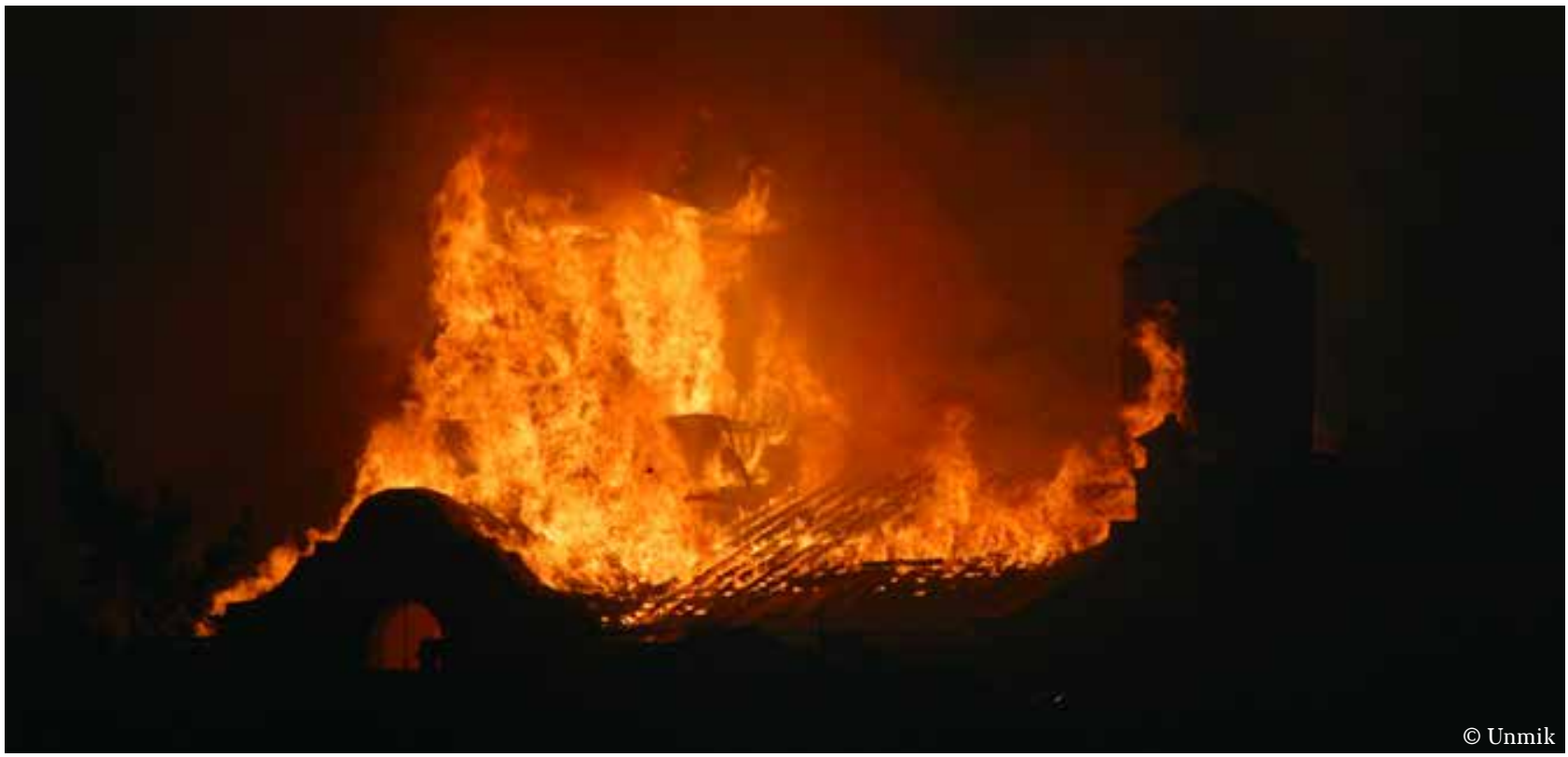

to follow an obvious line of enquiry undermines to a decisive extent the investigation's ability to establish the circumstances of the case and the identity of those responsible."

GG

\section{The investigation's conclusion are based on thorough, objective and impartial analysis of all relevant elements}

The European Court strongly states that any deficiency in the investigation which undermines its ability to establish the cause of death or the identity of the persons responsible will risk falling foul of these standards. ${ }^{12}$ Nevertheless, the same authority likewise clearly states that the nature and degree of scrutiny which satisfy the minimum threshold of the investigation's effectiveness depend on the circumstances of the particular case. Each of the cases must be assessed on the basis of all relevant facts and with regard to the practical realities of the investigative work. ${ }^{13}$

Concluding this, we can say that, following the logic and jurisprudence of the ECtHR if the above listed minimum standards are fulfilled (with a few exceptions), ${ }^{14}$ the investigation will most probably be considered effective, ${ }^{15}$ even if those responsible for the illegal loss of life were never held responsible through criminal proceedings. ${ }^{16}$

11 ECtHR, Kolevi v. Bulgaria, no. 1108/02, judgment of 5 November 2009, § 201.

12 See, among others: Mikheyev v. Russia, no. 77617/01, 26 January 2006, §§ 107 et seq.; Assenov and Others v. Bulgaria, 28 October 1998, §§ 102 et seq.).

13 See ECtHR, Velcea and Mazăre v. Romania, no. 64301/01, judgment of 1 December 2009, § 105.

14 See par example: ECtHR, Perevedentsevy v. Russia, no. 39583, judgement of 24/04/2014; see for detailed analysis of the judgement: Antonov A., Grigorjev V. Decision of the European Court of Human Rights in the case Perevedentsevy v. Russia: new trends in old position (in Russian) // Questions of Jurisprudence (ISSN: 2073-5022), № 6(28), 2014, P. 219-242.

15 See, e.g.: ECtHR, Grand Chamber (GC), Varnava and Others v. Turkey, nos 16064/90 and others, judgment of 18 September 2009 , § 191; ECtHR, Palić v. Bosnia and Herzegovina, cited in footnote 11 above, at § 63.

16 See, e.g: ECtHR, Palić v. Bosnia and Herzegovina, cited in footnote 11 above, at § 65; ECtHR [GC], Giuliani and Gaggio v. Italy, no 23458/02, judgment of 24 March 2011, § 301, 326. 


\section{Applicability of Investigative Standards to Criminal Investigations in Post- Conflict Situations}

The aim of this paper is not to reopen the ongoing discussion regarding the priority or complementary application of international human rights law or international humanitarian law on the territory of an armed conflict, and which norms establish obligation to investigate crimes committed there. ${ }^{17}$ The focus is on the applicability of the above procedural obligations equally to the investigations conducted in conflict/post-conflict time, and in peacetime conditions. Furthermore, this paper discusses if the standard minimum set (algorithm) of actions shall also be fully completed, and the standards complied with, or whether some requirements may be omitted, or deviated from during "turbulent times".
G6

The Court has held that "the obligation under Article 2 to safeguard life entails that, even in difficult security conditions, all reasonable steps must be taken to ensure that an effective, independent investigation is conducted into

alleged breaches of the right to life

In situations of conflict or generalised violence, the European Court on Human Rights has established the applicability of Article 2 to post-conflict situations, including in countries of the former Yugoslavia. ${ }^{18}$ The Court has further held that the procedural obligation under Article 2 continues to apply in "difficult security conditions, including in a context of armed conflict." 19 Similarly, the HRC has held that the right to life, including its procedural guarantees, shall be considered as the supreme right from which no derogation is permitted even in time of public emergency which threatens the life of the nation. ${ }^{20}$

The Court has acknowledged that "where the death (and disappearances) to be investigated under Article 2 occur in circumstances of generalised violence, armed conflict or insurgency, obstacles may be placed in the way of investigators and concrete constraints may compel the use of less effective measures of investigation or may cause an investigation to be delayed." ${ }^{21}$

Nonetheless, the Court has held that "the obligation under Article 2 to safeguard life entails that, even in difficult security conditions, all reasonable steps must be taken to ensure that an effective, independent investi-

17 See.: Dugard J. Bridging the gap between human rights and humanitarian law: The punishment of offenders // International Review of the Red Cross, 30-09-1998, № 324 [electronic source] - https://www.icrc.org/eng/resources/documents/article/other/57jpg6.htm (accessed on 20.05.2018); Русинова В.Н. Преследование нарушений международного гуманитарного права на основании принципа универсальности // Международное публичное и частное право, Москва, 2005, № 6б С. 21-26.

18 See, among other examples: ECtHR, Palić v. Bosnia and Herzegovina, cited in footnote 11 above, and ECtHR, Jularić v. Croatia, no. 20106/06, judgment of 20 January 2011.

19 See, e.g.: ECtHR [GC], Al-Skeini and Others v. the United Kingdom, judgment of 7 July 2011, no. 55721/07, § 164; ECtHR, Güleç v. Turkey, judgment of 27 July 1998, § 81, Reports 1998-IV; ECtHR, Ergi v. Turkey, judgment of 28 July 1998 , § 79 and 82, Reports 1998-IV; ECtHR, Ahmet Özkan and Others v. Turkey, cited above, § 85-90, 309-320 and 326-330; Isayeva v. Russia, cited above, § 180 and 210; ECtHR, Kanlibaş v. Turkey, no. 32444/96, judgment of 8 December 2005, § 39-51.

20 See.: HRC, General Comment No. 6, 30 April 1982, § 1; HRC, Abubakar Amirov and Aïzan Amirova v. Russian Federation, communication no. 1447/2006, views of 22 April 2009, § 11.2, CCPR/C/95/D/1447/2006

21 See, e.g.: ECtHR [GC], Al-Skeini and Others v. the United Kingdom, cited above, § 164; ECtHR, Bazorkina v. Russia, no. 69481/01, judgment of 27 July 2006, § 121. 
gation is conducted into alleged breaches of the right to life. ${ }^{22}$

Furthermore, while acknowledging that that Article 2 must not be interpreted in a way which imposes an impossible or disproportionate burden on the authorities, either in the context of policing activities or that of priorities and resources, the European Court stresses that what amounts to an impossible and/or disproportionate burden must be measured by the "very particular facts and contexts." 23

At the same time, the ECHR holds that even if the investigation could initially have en- countered certain objective difficulties due to war and postwar situation, the authorities' inactivity for long subsequent periods could no longer be justified. ${ }^{24}$ Similar requirements are established for the situations related to disappearances, torture and other kinds of inhumane and degrading treatment. ${ }^{25}$

\section{The Author}

Andrey Antonov is a Russian lawyer, a former police captain. After obtaining his PhD in Tactics of Criminal Investigation and Criminal Procedure, in 1999, he taught Theory of Criminal Investigation in the police university in Krasnodar, Russia, when he joined his first UN peacekeeping mission - UNMIK (Kosovo). Since that time, he worked for the UN in different capacities investigating war crimes and organized crime in Kosovo, providing legal support to UN missions (Sierra Leone), ensuring good conduct of UN personnel (Sudan and Kosovo), investigating serious misconduct (OIOS), and investigating serious violations of human rights by the UN Mission in Kosovo (Human Rights Advisory Panel) Currently he is the Head of Conduct and Discipline service at the UN Mission in Kosovo. This article presents some general findings from his UN sabbatical paper, completed in 2018, titled Criminal Investigation in Post-Conflict Environment by International Specialists (Organisational, Legal and Human Rights Aspects). Other, more practical and concrete findings and recommendations, will be presented in the articles to follow.

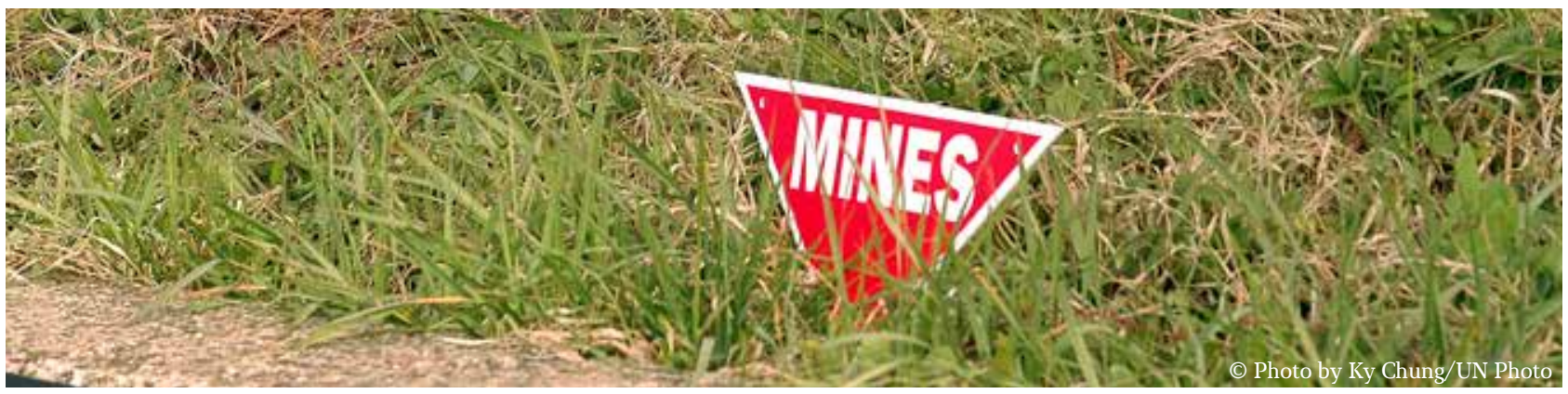

22 See, e.g.: ECtHR, Kaya v. Turkey, judgment of 19 February 1998, § 105, Reports of Judgments and Decisions 1998-I, at § 86-92; ECtHR, Ergi v. Turkey, no. 23818/94, judgment of 28 July 1998, Reports 1998-IV; cited above, at §§ 82-85; ECtHR [GC], Tanrıkulu v. Turkey, no. 23763/94, judgment of 8 July 1999, § 101-110, ECHR 1999-IV; ECtHR, Khashiyev and Akayeva v. Russia, nos $57942 / 00$ and 57945/00, judgment of 24 February 2005, § 156-166; ECtHR, Isayeva v. Russia, cited above, § 215-224; ECtHR, Musayev and Others v. Russia, nos 57941/00 and others, judgment of 26 July 2007, § 158-165; and many others.

23 See ECtHR, Palić v. Bosnia and Herzegovina, cited in footnote 11 above, at § 70; Brecknell v. The United Kingdom, no. 32457/04, judgment of 27 November 2007, § 62).

24 See e.g.: ECtHR, Jelić v. Croatia, no. 57856/11, judgment of 12 June 2014, § 92; ECtHR, Association “21 December 1989” and Others v. Romania, nos. 33810/07 and 18817/08, judgment of 24 May 2011, § 100.

25 See e.g.: Keller H., Chernishova O. Disappearance Cases before the European Court of Human Rights and the UN Human Rights Committee: Convergences and Divergences; Human Rights Law Journal 32 (2012), P. 237. 
Perhaps instead of jumping into the complexity of these questions, it is worth focusing on how our collective efforts can help us preventing technology from manipulating our senses. This consideration served as a guiding principal for the solution developed by the Open|DSE team in response to the UNICRI challenge at the Hackathon for Peace, Justice and Security (The Hague, June 2019). Before proceeding with the description of the solution, let's have a closer look at the AI technology behind the creation of this fake content.

\section{Deepfakes: how does it work}

Deepfakes is the result of years of advancement in the field of AI. The technology behind it is known as Deep Learning and it dates back to the early '40s, when scientists developed the first artificial neuron, called the Perceptron. ${ }^{1}$ The Perceptron, in its function, resembles a neuron, the basic unit of the human brains. Nevertheless, it took few decades before scientists proved that networks of Perceptrons can possibly behave like the human visual system. ${ }^{2}$ Nowadays, scientists with access to reason- ably powerful computers, have the created AI systems known, which, despite the term "neural", loosely resemble our brain. Nevertheless, these AI systems are capable to perceive the world in the same way we do. In fact, they can detect objects in pictures, recognize faces and understand human language.

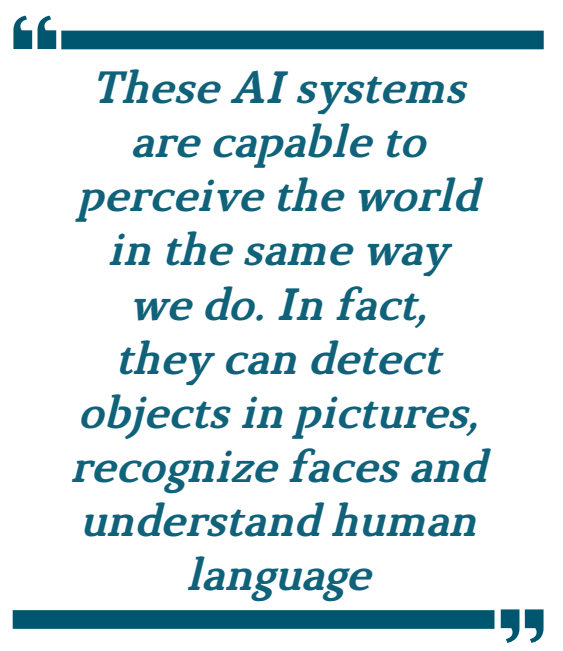

Imagine now we let two of this AI systems play against each other. One of them tries to create fake contents, e.g., fake faces. Its name is Generator. The opponent tries to understand if the content created by the Generator is real or fake. Its name is Discriminator. Which network wins the game? Up to now, the winner is the Generator. These systems, known as Generative Adversarial Networks (GANs), are capable to create any type of content, from images, to video, to news. The so-generated fake content is so plausible (see Figure 1) that we humans have only an average probability of $65 \%$ to recognize its falsehood. ${ }^{3}$

GANs are an open-source technology. It means that everyone with a good computer, such as those used for gaming, can use GANs to generate their own original content. Tech companies have promptly seen the benefits of using them for commercial purposes. For example, self-driving cars manufacturers are using them to let the cars learn how to drive autonomously using artificially generated content, e.g., weather and traffic conditions. Unfortunately, GANs have become widely known to the general public because of their usage to spread misinformation and discreditation. Deepfakes it's the most predominant example of this usage. ${ }^{4}$

\section{FakeSniff against Deepfakes}

The UNICRI Centre for Artificial Intelligence has promptly recognized the need to counteract the use of Deepfakes technology for discreditation and made

1 "A logical calculus of the ideas immanent in nervous activity". McCulloch, W. and Pitts, W., Bulletin of Mathematical Biophysics, 5:115-133, 1943.

2 “Neocognitron: A hierarchical neural network capable of visual pattern recognition." Fukushima, K., Neural Networks 1:119-130, 1988.

3 "A Style-Based Generator Architecture for Generative Adversarial Networks", Karras, T. Laine, S. and Aila, T. , International Conference of Computer Vision and Pattern Recognition (CVPR), 2019.

4 "The Best (And Scariest) Examples Of AI-Enabled Deepfakes" Marr, B. Forbes, July 2019. 


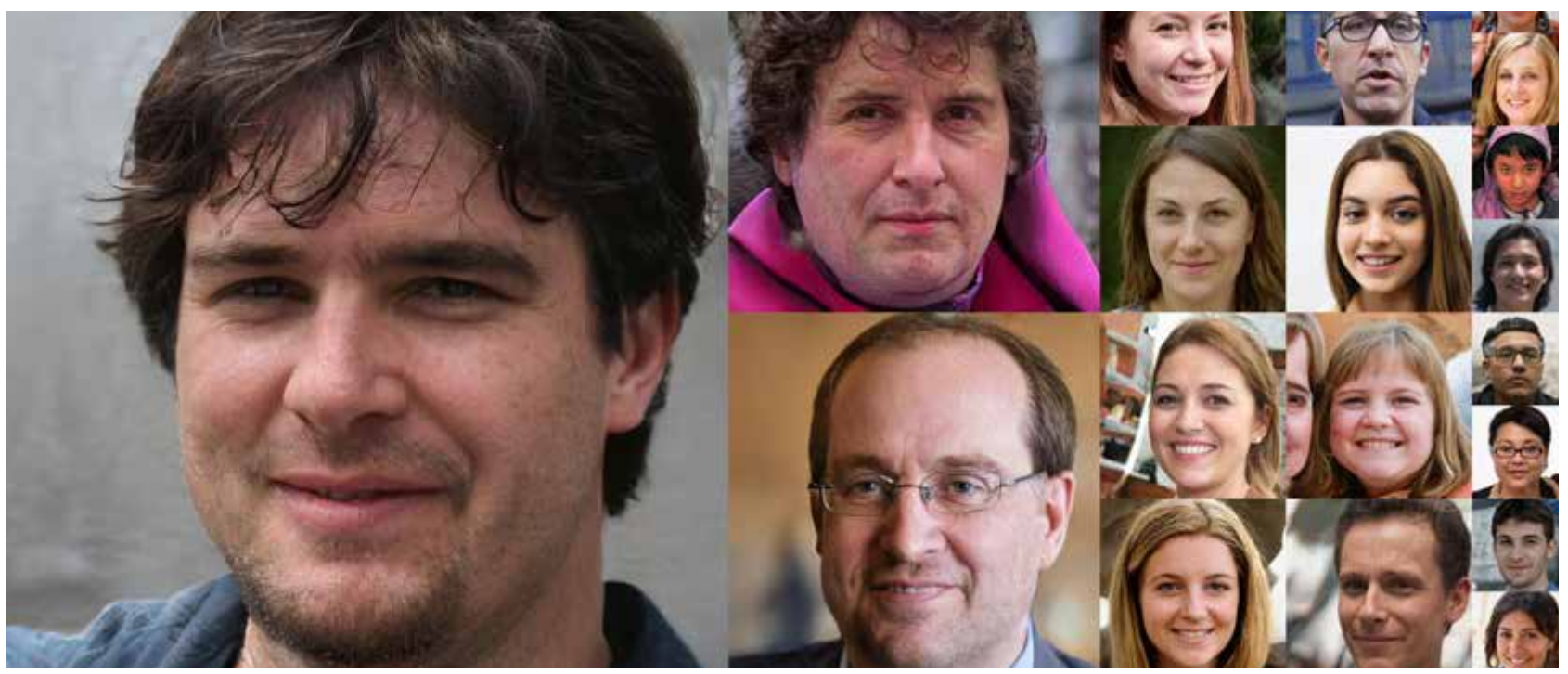

Figure 1: Faces generated by GAN. These people don't exist. Image courtesy (3)

a call for action. ${ }^{5}$ Data scientists, AI researchers and developers have been challenged to create innovative solutions to this rising problem. The Open|DSE team ultimately succeeded to come up with the winning solution, also gaining the grand prize of the overall hackathon. The developed solution is called FakeSniff.

FakeSniff is meant to primarily serve the general public. Single users can use FakeSniff on laptop or mobile phone to detect fake content and receive an instantaneous response in an easy and intuitive way. Nevertheless, FakeSniff contains technical possibilities to address more demanding needs of law enforcement, courts and security agencies. Recognizing these needs, we prepared the system to accommodate more complex and accurate frameworks to address the rapid change of manipulation techniques.

The beauty of the
solution is the
crowdsourcing
component which
allows the system
to be continuously
updated and being
able to upgrade the
modules

The formula of our solution relies on two major components. The first one is the detection module. It contains one of the most advanced Deep Neural Network available in the research community known as EfficientNet (EN). EN provides an immediate and accurate decision about fake contents, with the advantage to operate faster than other AI systems. EN has an accuracy to detect fake content of more than $97 \%$ in comparison to human judgement that stands at $65 \%$. A compan- ion module works alongside EN focusing on the explainability of the results. This explainability model is devoted to support law enforcement agencies in their decision-making process when using the system.

The FakeSniff interface (see Figure 2) is a web-based application with social media features. Anyone can connect to the FakeSniff website, tagging content as real or fake, providing comments about why they think a specific content is fake, signalizing and even upload new content. The beauty of the solution is the crowdsourcing component which allows the system to be continuously updated and being able to upgrade the modules. Conscious that people judgment can be influenced by cultural, political, religious and personal biases, FakeSniff keeps currently track of the feedback to have an 


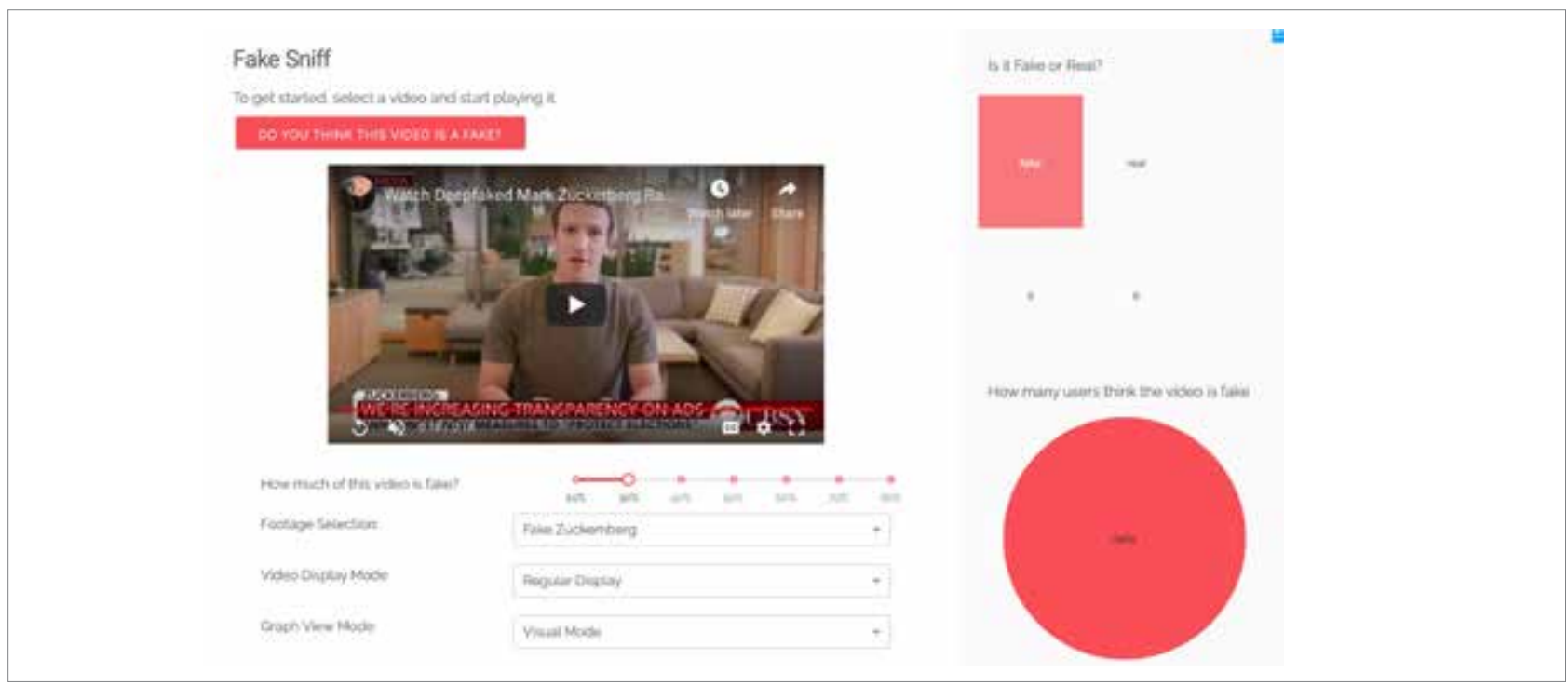

Figure 2: The FakeSniff interface. The AI core decides the probability of a certain content to be a fake.

The FakeSniff Community shares contributions to help the AI core to improve its operations.

understanding about the public perception of a certain content. We are currently investigating how to remove the human bias and use the feedback to improve its decisions. When succeeded, FakeSniff will be able to automatically update itself and to provide more accurate decisions even in case of more advanced manipulation algorithms. We designed FakeSniff to fit multiple purposes and to be incorporated in different tools. The knowledge acquired can be increased in the future in a very efficient way and can be able to adapt the system to different contents without losing the previous knowledge.
The power of collective human action

We believe that the human factor is fundamental in the development of future technologies. FakeSniff wants to be an example of this and, hopefully, a guidance. Our bet is that the human collective intelligence will be the truly differentiator in counterbalancing the spread of untrustworthy content. Nevertheless, we, as humans, need to increase our capability of recognizing fake content: nature didn't equip us for that! FakeSniff is aimed for that goal. In this seemingly unfair GAN competition between fake and real, humans are the necessary addendum to beat the Generators. Does it mean that the war between machines and humans has started? We don't think so. Technology is only a tool and, as such, we need to drive its use in the light of a collective benefit.

\section{G4 \\ We believe that the human factor is fundamental in the development of future technologies. FakeSniff wants to be an example of this}

\section{The Authors}

The Open|DSE team was composed by Pierluigi Casale, Vladimir Osin, Grazina Raguckaja and Giulia Violatto. The team members are a heterogeneous team of data scientists, AI researchers and project managers, working in both public and private sector organizations. Open|DSE is an open community that aims to spread knowledge and best practices in Data Science and Data Engineering. Members of Open|DSE regularly organize meetups and participate to hackathons to self-sustain the organization. For more information, visit https://open-dse.github.io. 
accounts at insane rates mining you. Since 2010, the advertising industry tripled in size all due to the bleeding-edge data mining practices. Considering the exponential advancements of Artifical Intelligence (AI) and Machine Learning, no one is really sure what the future holds.

Taking action to secure your data is all good; however, some misconceptions about online privacy could prove to be detrimental. Hopefully, clarifying some of the most common myths concerning online privacy will allow you to maintain your data security at all times.

\section{Private browsing mode ensure online privacy}

That's a biggie, to put it lightly. Every browser has a private-browsing setting whether it's called Incognito mode, Private Browsing, or InPrivate Browsing. Though the names are catchy, the reality of the matter is not what you might anticipate. ${ }^{1}$

In reality, private browsing sessions do very little to protect the data you share online. Yes, when using a private mode, browsing history, passwords, searches, cookies, and temporary files will not be saved or logged. While that is great, it does not ensure online privacy in any significant way.
You might get the impression that private browsing mode conceals your IP address and virtual location. Unfortunately, that's not true in any case. In fact, each site you visit, while using private mode, can identify your IP address even if it does not have cookies to provide all the specific information. In fact, your ISP (Internet Service Provider) and other third-parties can track pretty much all your online activities with ease.

At the end of the day, private browsing modes are an automatic way to delete your browsing history but not a legitimate measure to ensure online privacy.

\section{Public WiFi ensures online anonymity}

The importance of public WiFi can not be overstated. Having the ability to connect on the go is becoming an essential part of our daily lives, and with the increasing coverage of public WiFi, our lives are more interconnected than ever before. Unfortunately, people rarely think twice about such networks' security. What is even more concerning is the misconception that quite a few users hold - public networks to ensure online anonymity. The level of ignorance is alarming, as such claims couldn't be further from the truth.
Yes, it is true that your individual activities on the Internet are attributed to the public network when you are connected to one. However, that has nothing to do with actual online privacy as every unencrypted connection your device makes can be tracked and recorded by snoopers or bad actors.

Now think for a minute just how much information you share online. Yes, all that data is up for grabs, and that's a scary prospect. Highly-skilled snoopers can get their hands on your name, address, social security number, and other sensitive information by simply intercepting an unsecured public network.

\section{Virtual Private Networks guarantee online privacy}

Virtual private network, commonly known as VPN, is quickly becoming an essential part of everyone's online experience. That's mostly due to VPN's ability to establish a secure and private connection to the Internet. By rerouting all traffic that travels between your device and the web's servers, a VPN creates a secure tunnel that is virtually impenetrable.

However, not all VPNs can be trusted. You might have heard of a recent incident when it was

1 https://nordvpn.com/blog/incognito-mode-not-as-private-as-you-think/ 


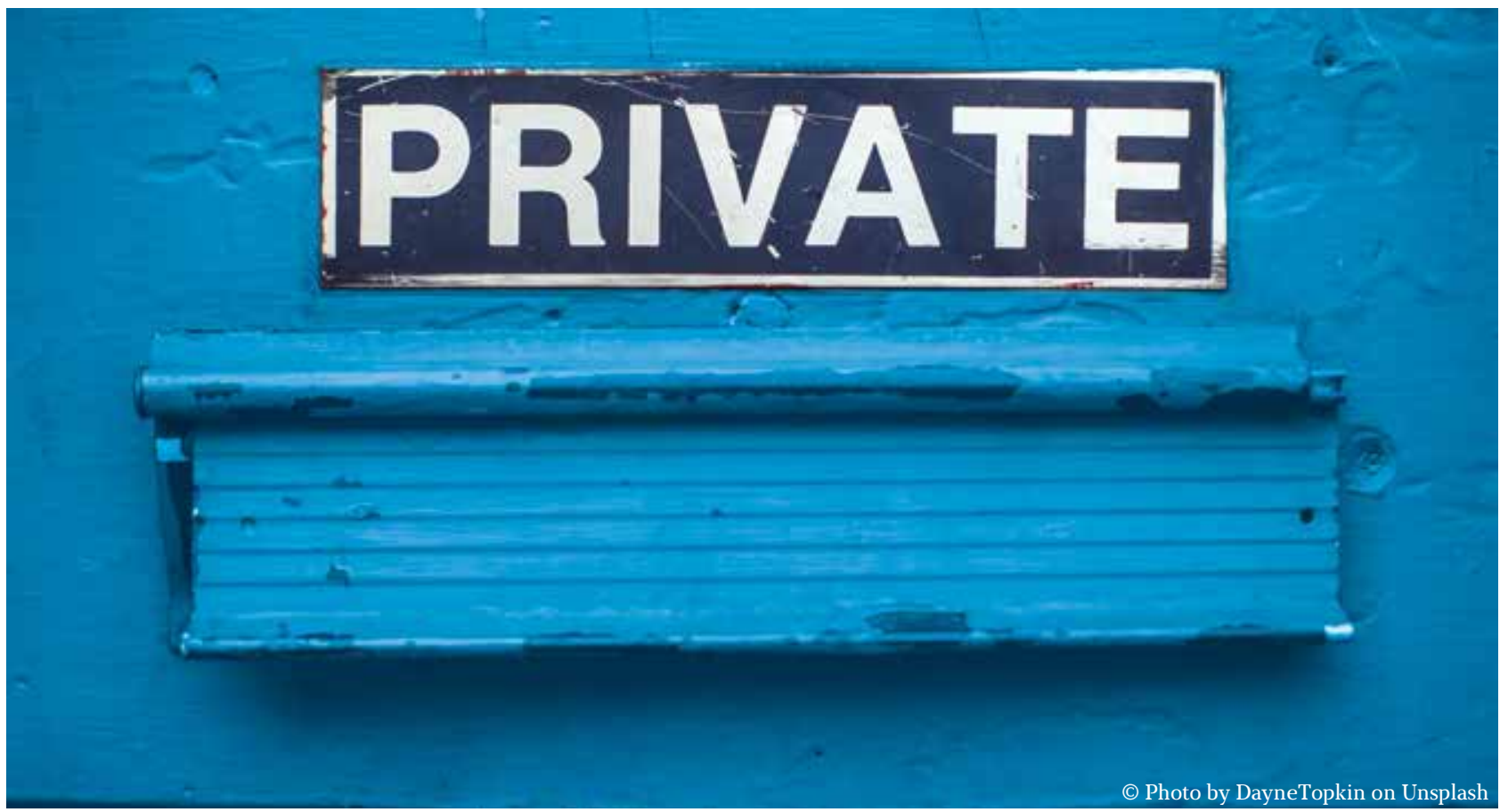

revealed that in spite of a highly promoted no logs policy, the service provider allowed a third party to track down one of their user's online activities. The issue in regard to logs is a prevalent one in the VPN industry; however, most casual users do not think twice about it before choosing a VPN service.

After all, using a VPN service that keeps a record of all your online activities defeats the purpose of using it in the first place. You should stay away from free VPNs, as such services are often related to data collection. If logs of user activity are kept, it is highly likely that the data might be transferred to third parties. In fact, there are not many VPNs on the market offering no logs policy, but you can find some - choose your VPN wisely.

\section{Internet of Things devices are not a security and privacy liability}

According to the Gartner forecast $^{2}$ the number of connected devices may reach 20 billion by 2020. The Internet of Things (IoT) market value is estimated to reach $\$ 1.4$ trillion by 2021, so apparently, the industry's growth pace is not going to slow down. Every day at least 150 million data points are generated mean- ing hackers are given a quite impressive number of entry points to reach sensitive information.

\section{G9 \\ Devices can be protected better, and that's a fact, but unfortunately, everything has its cost}

Devices can be protected better, and that's a fact, but unfortunately, everything has its cost. Apparently, a more prominent part of potential IoT users value low pricing more than better safety solutions. We all know what the main business princi-

2 https://www.gartner.com/newsroom/id/3869181 
ple is: give people what they ask for. This is what they are doing: companies offer low prices instead of ensuring the security of users' devices, which also saves them money. However, let's not be so pessimistic - probably it's just a matter of time as IoT is still in its infancy and needs time to develop the best solutions.

\section{You shouldn't worry about the privacy unless you hide something}

Forget this. Today hackers' best interest is not exposing illegal online activities: they have their nefarious goals. Successful spying provides hackers the control of your sensitive information that may be abused in different ways you have not even thought of.

Have you ever thought that your online information taken out of the context might be used against you? For example, you can even be associated with suspicious individuals who may be total strangers to you. Thus, it is a no-brainer for hackers to do that if they have all the data they need. So, forget saying that you are not a target. If you have a bank account (most probably you do), a social security number and other sensitive data, you are a target. Actually, all of us are.

\section{Cheap or free security tools provide the necessary protection}

Usually, while choosing a product or service, cheaper or free options are usually considered as the more attractive ones, and there is no blame in it. However, it's essential to continuously remind yourself that behind every free software or a product there is a business.

If you are not charged sufficiently or at all, most probably in this situation, you are treated as the product yourself by the service or product providers. Your data might be used for creating targeted ad campaigns and even sold to third parties. Is the product or service worth it? It's up to you to decide.

\section{GG \\ Your data might be used for creating targeted ad campaigns and even sold to third parties}

It is said that there's no such thing as a free lunch and this phrase can surely be applied here. You can find cheap or free solutions, but to ensure your online security you will need to buy some additional features for a proper piece of software. Otherwise, you may have a misleading sense of security.

\section{Hackers target only rich people}

Actually, it is the opposite. Usually, a hacker's goal is to hit as many users as possible. In such a situation, it is highly likely you could be a target. Hundreds of thousands of people may have their sensitive data leaked and, after that, a hacker only needs to go through it checking for any details that could lead to hacking into a victim's bank account with little or no trouble at all. Just imagine the consequence of that happening to you.

It is not only about the money though. Hackers may seek for copies of valuable documents, sensitive trade secrets and start blackmailing you afterwards. Your social media accounts may also be of great use.

Another argument why it is highly unlikely that wealthy people are the primary target for hackers is that they are wealthy enough to invest in hiring cybersecurity experts to protect themselves and their businesses from a severe harm that a hack could cause. It's simply easier 


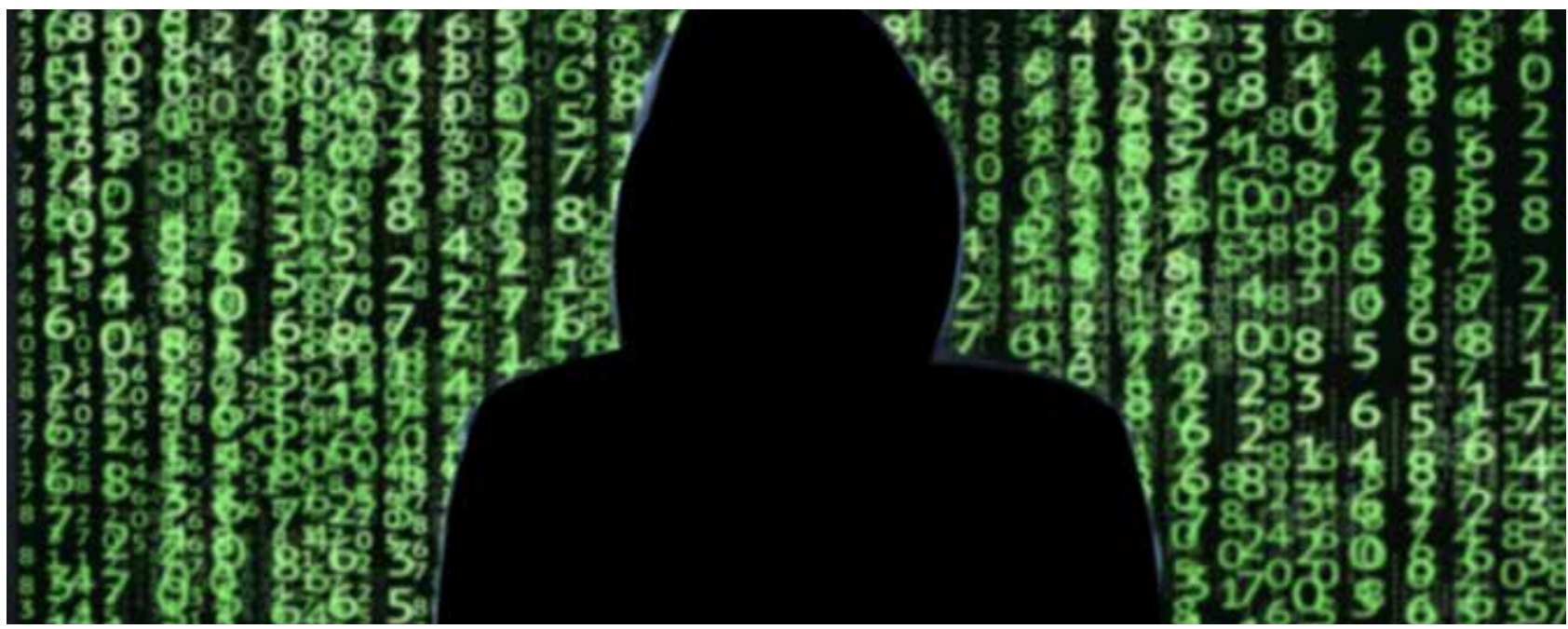

to spy on people who have poor security practices and know little about the subject.

\section{Private Facebook profile ensures that no one accesses your data despite your friends}

Even though Facebook "Settings" gives us loads of different privacy and security options, there is a bunch of information that is always shown publicly such as name, profile picture, cover photo, username, user id and gender. You should also keep in mind that the apps you add may acquire access to your friends' list. Even though Facebook allows you to adjust this setting, the transparency of it is highly doubted.

A scandal revealing the data of millions of users was allegedly used for political aims, put a red light on it and showed how manipulatively third parties might use our information. That is why it is critical to take your security and online privacy seriously. Carefully go through all the settings checking the information you provide about your activities as Facebook default settings $^{3}$ are highly open.

\section{Online anonymity is impossible to achieve}

Being precise, absolute 100\% anonymity most probably is hardly achievable, but there are ways to come pretty near to this percentage. Using a trusted VPN service that ensures no logs policy along with professional security software, can go a long way. It is also recommended to try changing your everyday browsing habits. This way the scope of data you share with others is going to decrease.

Additionally, it is important to note that there are loads of corporations, governments (they should ensure digital rights and appropriate safeguards), and cybercriminals working hard to get as much sensitive data from people as they can for different aims, and it's mainly up to us to decide what level of protection we want to use to ensure our online privacy and security.

\section{The Author}

Harold Kilpatrick is a cyber security consultant and a freelance blogger. He's currently working on a cyber security campaign to raise awareness around the threats that businesses can face online.

3 https://thehackernews.com/2018/06/facebook-privacy-setting.html 


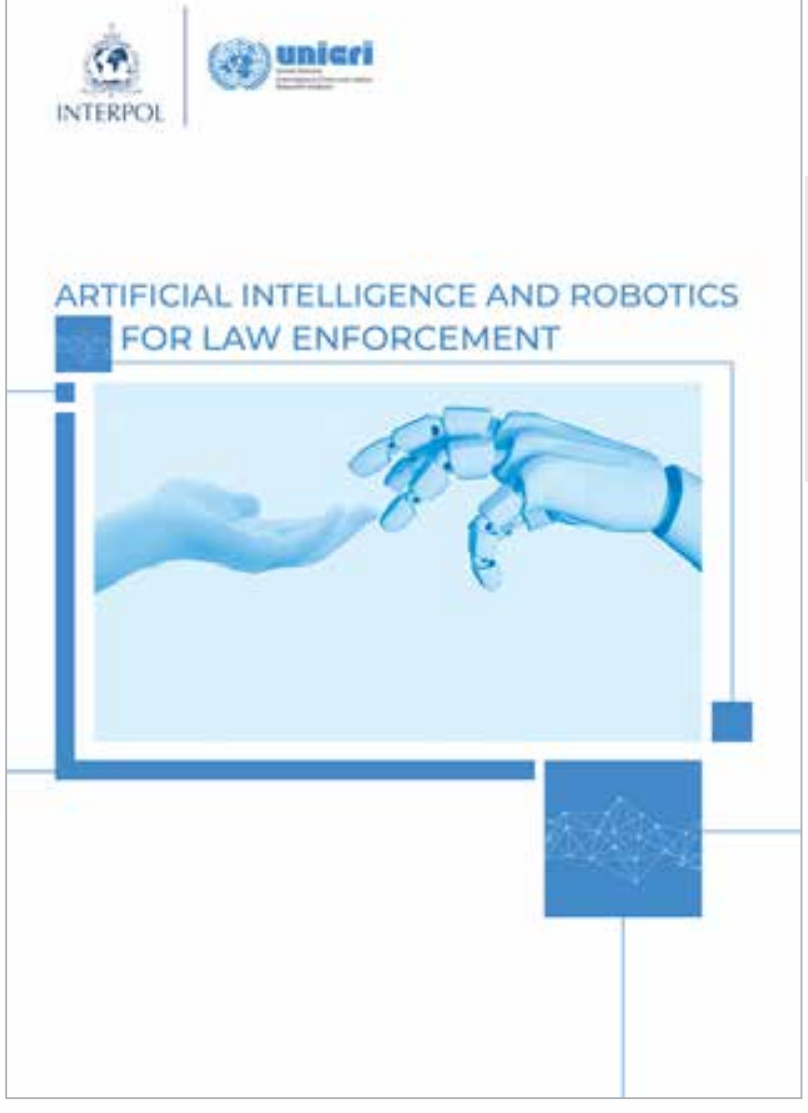

(6) unieri

PUBLICATIONS

\section{Artificial Intelligence and Robotics for Law Enforcement}

"Artificial Intelligence and Robotics for Law Enforcement" has been published by the United Nations Interregional Crime and Justice Research Institute's (UNICRI), Centre for Artificial Intelligence (AI) and Robotics, and Innovation Centre of the International Criminal Police Organization (INTERPOL).

The report summarizes key findings, challenges and recommendations presented and discussed during the first INTERPOL - UNICRI Global Meeting on the Opportunities and Risks of Artificial Intelligence and Robotics for Law Enforcement held in Singapore on 11-12 July 2018.

\section{ADDRESSING THE CHALLENGE OF DEEPFAKES}

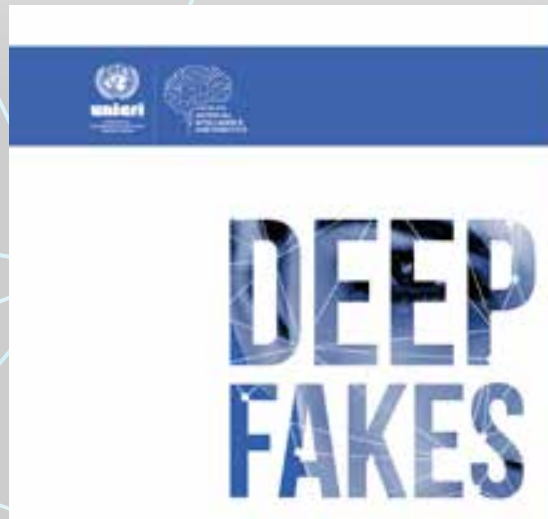

AND VILEO MANIPULATIONS WOPKSHOP HaCKaTHON FOR 600020 ig FOLLOW-UP

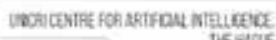

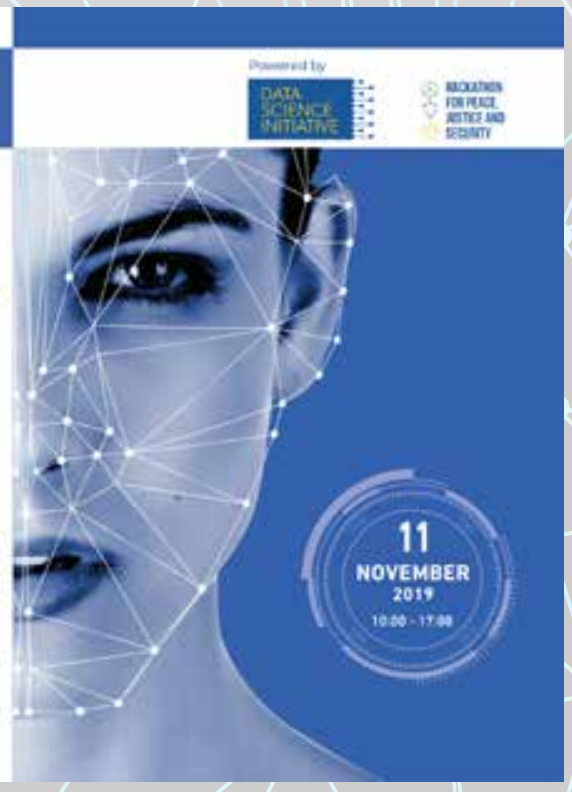

UNICRI, through its Centre for $\mathrm{Al}$ and Robotics, and the Data Science Initiative of the City of The Hague, hosted a workshop on Deepfakes and manipulated videos at The Hague Security Delta.

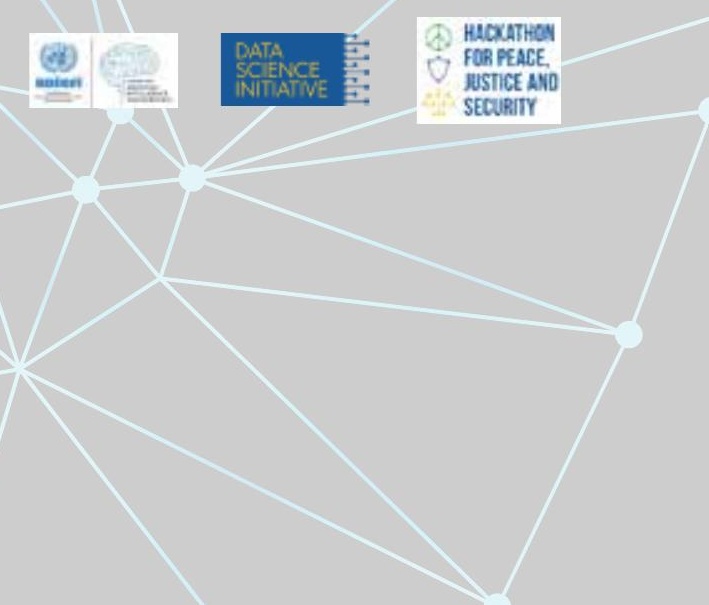


The Companion to International Humanitarian Law

A practical approach to the dissemination of International Humanitarian Law

- by Drazan Djukić and Niccolò Pons

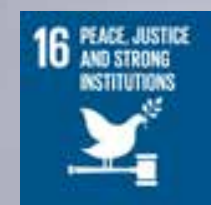




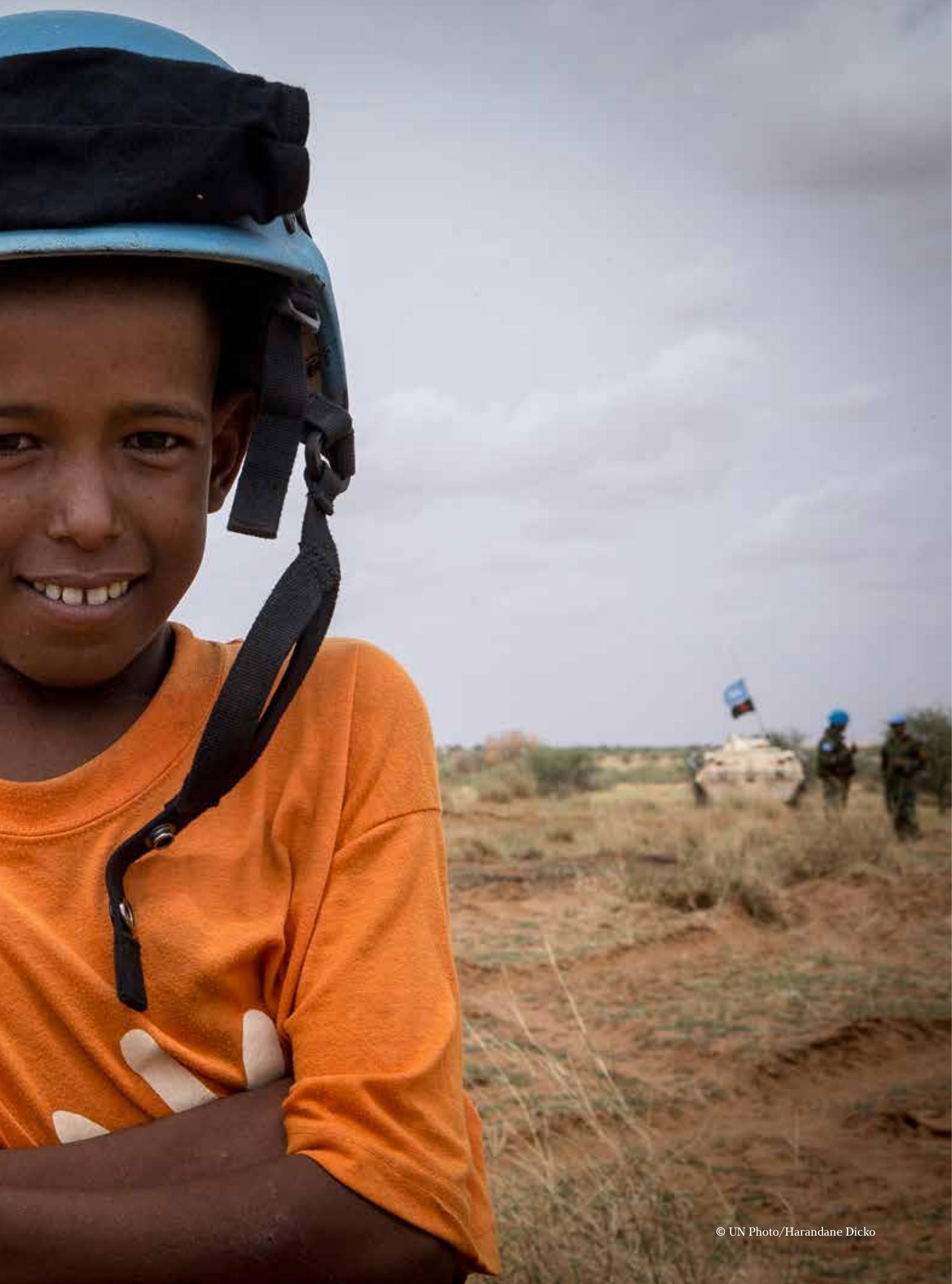




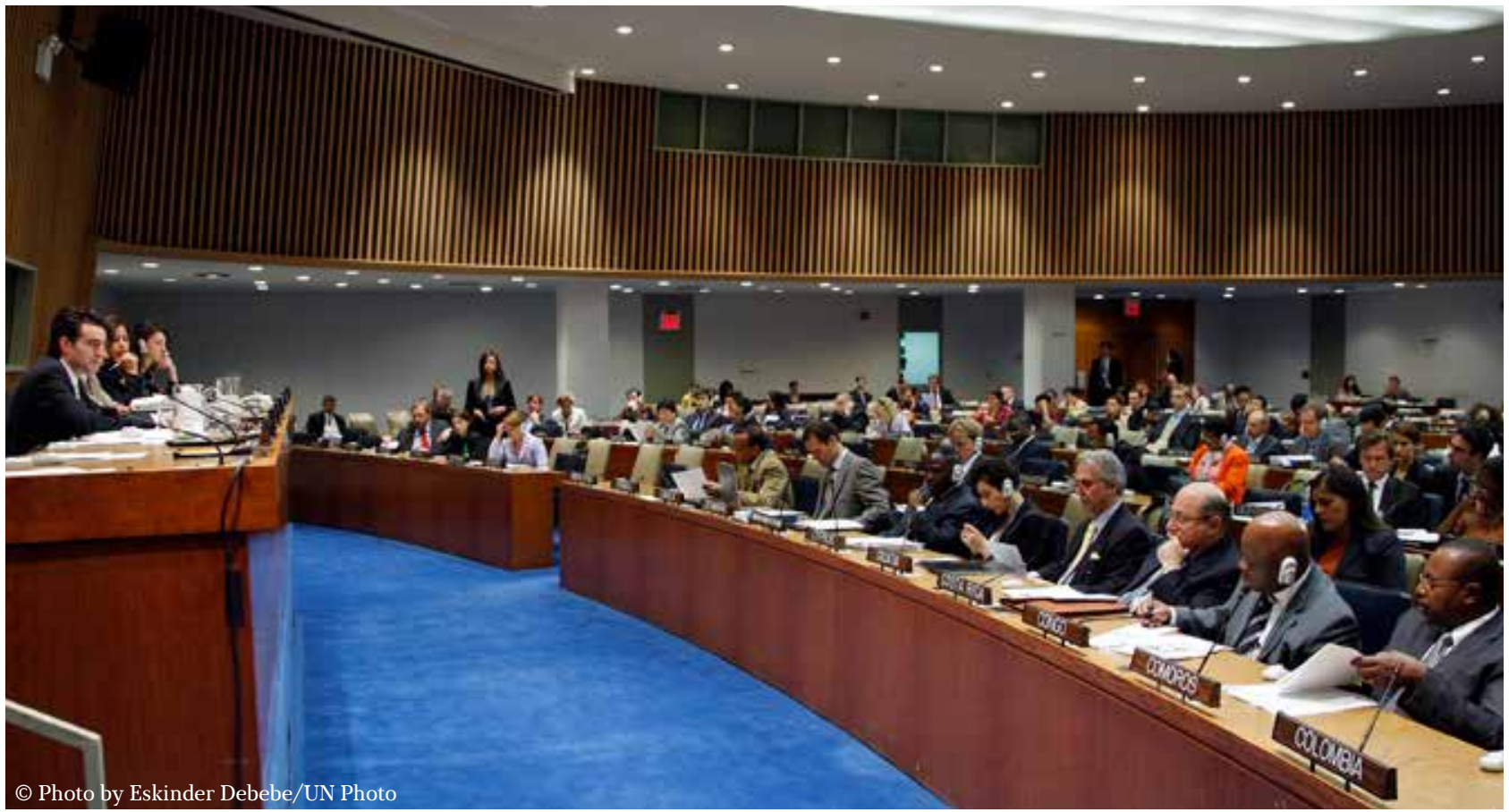

The Companion to International Humanitarian Law, edited by Drazan Djukić and Niccolò Pons, aims to contribute to the debate concerning the practical dissemination and the application of International Humanitarian Law (IHL). With its seven essays and 265 substantive entries written by 98 experts in the humanitarian field, the volume draws attention to the challenges and mechanisms enhancing IHL implementation by practitioners. This concept note explains the importance of the proper dissemination of IHL for the purpose of strengthening its implementation and contextualizes the edited volume in this framework, by briefly describing its contents.
Moving one-step backward, IHL is a set of international rules, which establish what is permissible and impermissible during international and non-international armed conflicts. According to the wellknown jurisdictional decision by the Appeals Chamber of the Yugoslavia Tribunal in the Tadić case, "an armed conflict exists whenever there is a resort to armed force between States or protracted armed violence between governmental authorities and organized armed groups or between such groups within a State." ${ }^{1}$ Armed conflicts are therefore extraordinary situations of violence that differ from internal disturbances and tensions, such as post-electoral violence or situ- ations of unrest, to which only human rights law and domestic law apply.

\section{GG \\ IHL is a set of international rules, which establish what is permissible and impermissible during international and non- international armed conflicts}

The main purpose of IHL is therefore to strike a balance between two competing forces. The military necessity of each belligerent party to weaken the opponent's military capabili-

1 Decision on the Defence Motion for Interlocutory Appeal on Jurisdiction, ICTY, Appeals Chamber, 2 October 1995, para. 70. 
ties, on the one hand, and the principle of humanity on the battlefield, on the other, whose aim is to limit the suffering of those who do not or no longer participate in the hostilities. Considering that armed conflicts are, by their very nature, exceptional situations that affect greatly the life of people, and that a discrete field of law was specifically developed to tackle such situations, it is all the more important to ensure that IHL norms be actionable. In other words, they must be put in practice in the most effective way to the benefit of those involved in or otherwise affected by hostilities.

64

The main purpose of IHL is therefore to strike a balance between two competing forces

When it comes to transforming IHL norms into action, one can make a distinction between the applicability of norms and their application. The former refers to the quality of being relevant or appropriate to a given situation, while the latter concerns the action of putting something into operation. To put it with an example, the drafting and adoption of rules and their inclusion into a treaty banning certain weapons or methods of warfare are certainly applicable to armed conflict. Their application, however, will be contingent upon two distinct but equally necessary processes. First, the treaty must undergo ratification by the respective States Party and incorporation into their own national legal system (legislative application process). Second, the norms contained in the treaty, together with its procedures and mechanisms, must be disseminated to armed forces, military and civilian decision-makers, other individuals involved in the process of applying such rules, armed groups, as well as to the civilian population more generally (practical application process). Likewise, when international tribunals, such as the International Criminal Court, the ICTY or the ICTR deliver a decision that develops a new interpretation of IHL, or strengthen or change an existing one, a similar process of dissemination and operationalization must take place. Decisions and judgments of courts of law on matters of IHL have an impact that goes well beyond the one in the criminal proceedings to which they belong. The legal advisers working with national armies, the legislators, academics, organizations involved in IHL will duly incorporate such findings in a variety of ways to disseminate them and ensure their application. In practice, a new interpretation on an IHL aspect can affect military manuals, rules of engagement for military personnel, national laws, and they may be taken into account to devise new legal training programmes for soldiers, military personnel and non-State actors.

The process of dissemination and application of IHL norms exemplified above is not just reflective of best practices or reasonable expectations when it comes to determining what is lawful and unlawful in times of war. It is most notably enshrined in the customary obligation of States to disseminate IHL as widely as possible. According to Articles 47, 48, 127 and 144 common to the four Geneva Conventions of 1949:

"The High Contracting Parties undertake in time of peace as in time of war, to disseminate the text of the present Convention[s] as widely as possible in their respective countries, and, in particular, to include the study thereof in their programmes of military and, if possible, civil instruction, so that the principles thereof may become known to the entire population."

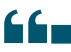

Decisions and judgments of courts of law on matters of IHL have an impact that goes well beyond the one in the criminal proceedings to which they belong 
The 1977 Additional Protocol I, applicable to international armed conflict, uses a similar wording in its Article 83, while Article 19 of Additional Protocol II, applicable to non-international armed conflict only, is less expansive yet clear: "[t]his Protocol shall be disseminated as widely as possible." The common denominator of these provisions is that they establish a legal obligation to disseminate IHL across all four Geneva Conventions and their Additional Protocols, both in time of war and in time of peace. Moreover, the implementation of such obligation lies with all States as it has crystallized a norm of customary law. ${ }^{2}$
Its rationale is that "knowledge of the law is an essential condition for its effective implementation." 3

Nevertheless, while IHL is a relatively simple, intuitive and dynamic field of law, it is not necessarily straightforward when it is brought into action. Certain concepts may appear clear on paper, but when applied to a concrete scenario, they might generate uncertainties, raise moral objections and draw blurred lines. ${ }^{4}$ This is why a more accessible, practical and interactive approach should be increasingly developed when bringing IHL from a normative level into action.
In this framework, the Companion to International Humanitarian Law discusses different mechanisms to foster the implementation of IHL. Etienne Kuster's opening essay explains the challenges and opportunities of disseminating IHL through academia. Academic circles are a powerful forum to implement the obligation to disseminate IHL as they can directly intervene on future generations of decision-makers, on the one hand, and can already interact with today's military and civilian personnel involved in armed conflict-related activities. In the second essay, Andrew Carswell and Jonathan Somer discuss ways of engaging

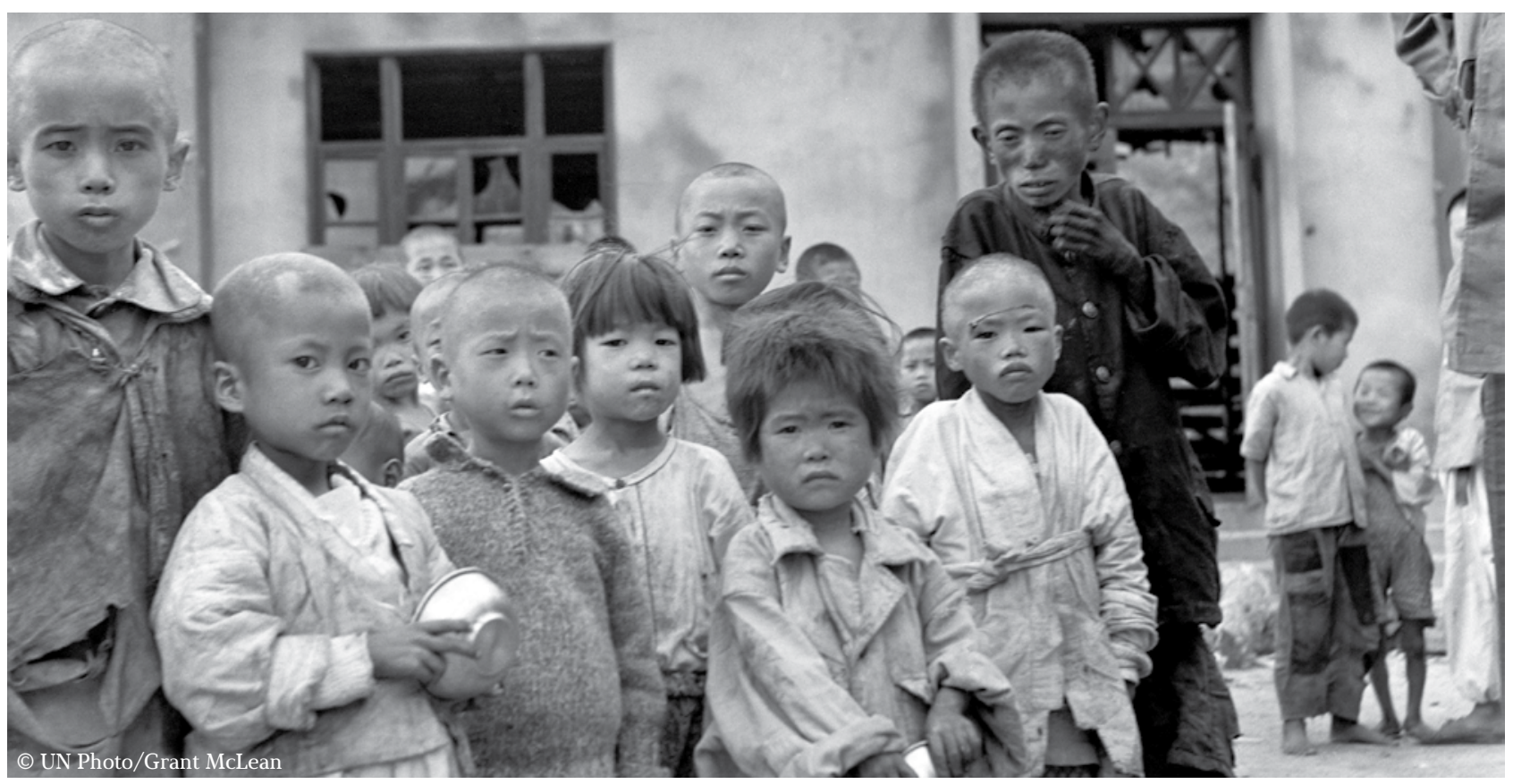

2 Rule 143 of the ICRC Customary IHL Study.

32016 ICRC Commentary to Article 47 Geneva Convention I, para. 2750.

4 Think for example of the rules governing conduct of hostilities, specifically the right to target combatants and civilians taking direct part in hostilities without all precautions normally applicable in time of peace under international human rights law. Or, the right to deprive combatants of their liberty without a due process of law and until the end of hostilities, on the sole basis that combatants may be interned as prisoners of war to avoid that they re-join their army and keep fighting. 


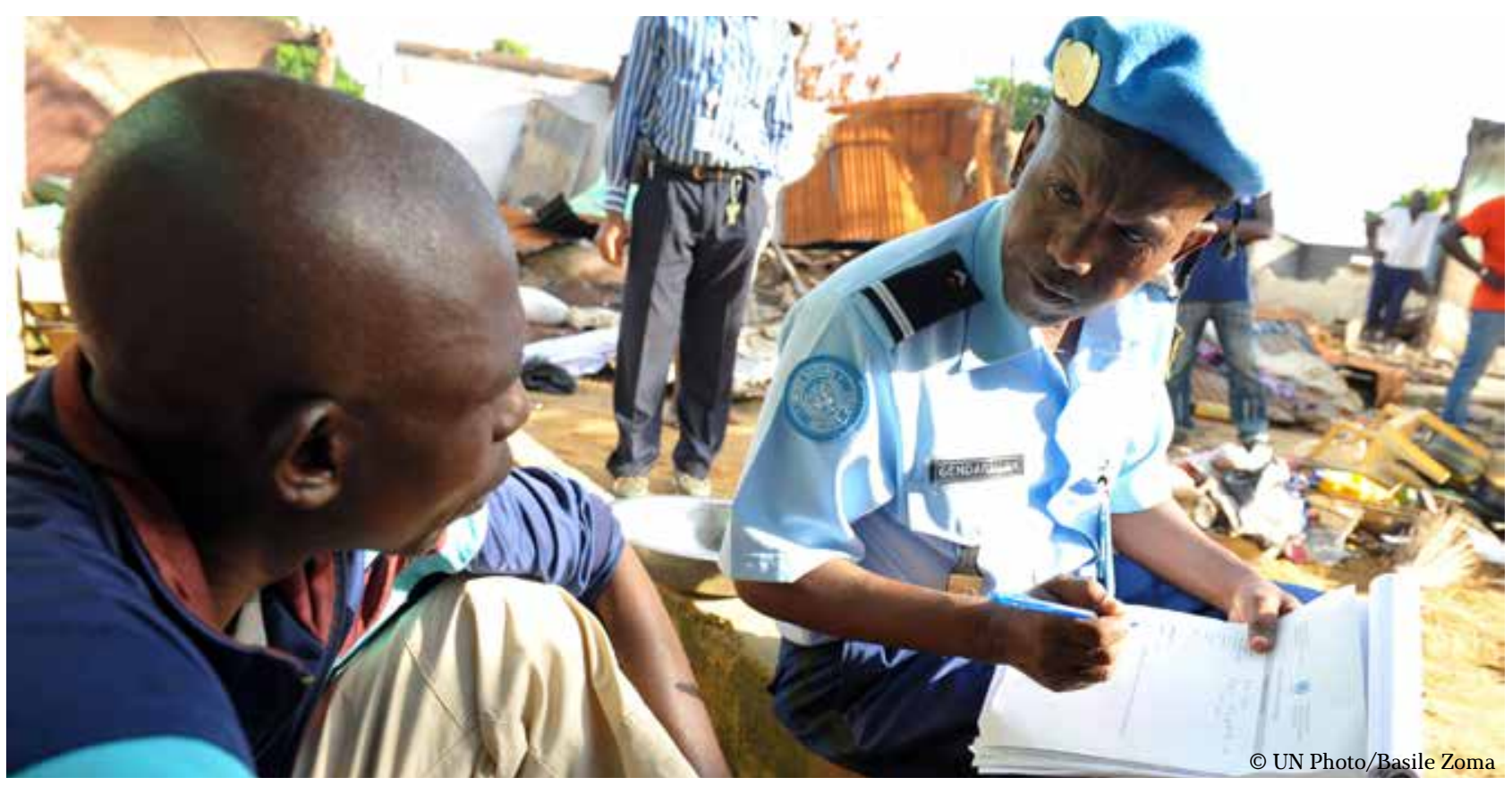

State armed forces and nonState armed groups to increase respect for humanitarian rules on the battlefield. In accordance with its Geneva Conventions-based mandate, the ICRC engages with all parties to an armed conflict, whether they are State armed forces or nonState armed groups, concerning their IHL obligations. In particular, in non-international armed conflict where IHL is necessarily more rudimentary, engaging with all parties whether State authorities or armed groups, can enhance the range of rules applicable to the conflict. In fact, both parties can agree to voluntarily apply more protective provisions (borrowed from the legal framework applicable to international armed conflict) on condition of reciprocity, that is to say that the opposing party does the same. This mutual agreement as to an enhanced application of IHL goes to the ultimate benefit of civilians who do not or no longer take part in hostilities. In the next contribution, Azra Kuci and Jelena Plamenac give an insight on an underexplored area, that of legislative measures at the national and international level in the field of IHL. Law making is the primary mechanism leading to the correct application of IHL. At the same time, however, the legislative power can become a distortive tool when States incorporate international provisions from treaties into their respective legislation by modifying the standards into a more favourable one for the State itself, for example by considering members of armed groups automatically as terrorists or by loosening the criteria to identify a military objective. This essay therefore highlights the dangerous distortions arising out of an opportunistic law-making process by States.

\section{GG \\ A more accessible, practical and interactive approach should be increasingly developed when bringing IHL from a normative level into action}

The subsequent set of pieces focus on how judicial and quasi-judicial bodies can affect IHL implementation. Robert Heinsch examines the advantages and challenges of the International Humanitarian Fact-Finding 


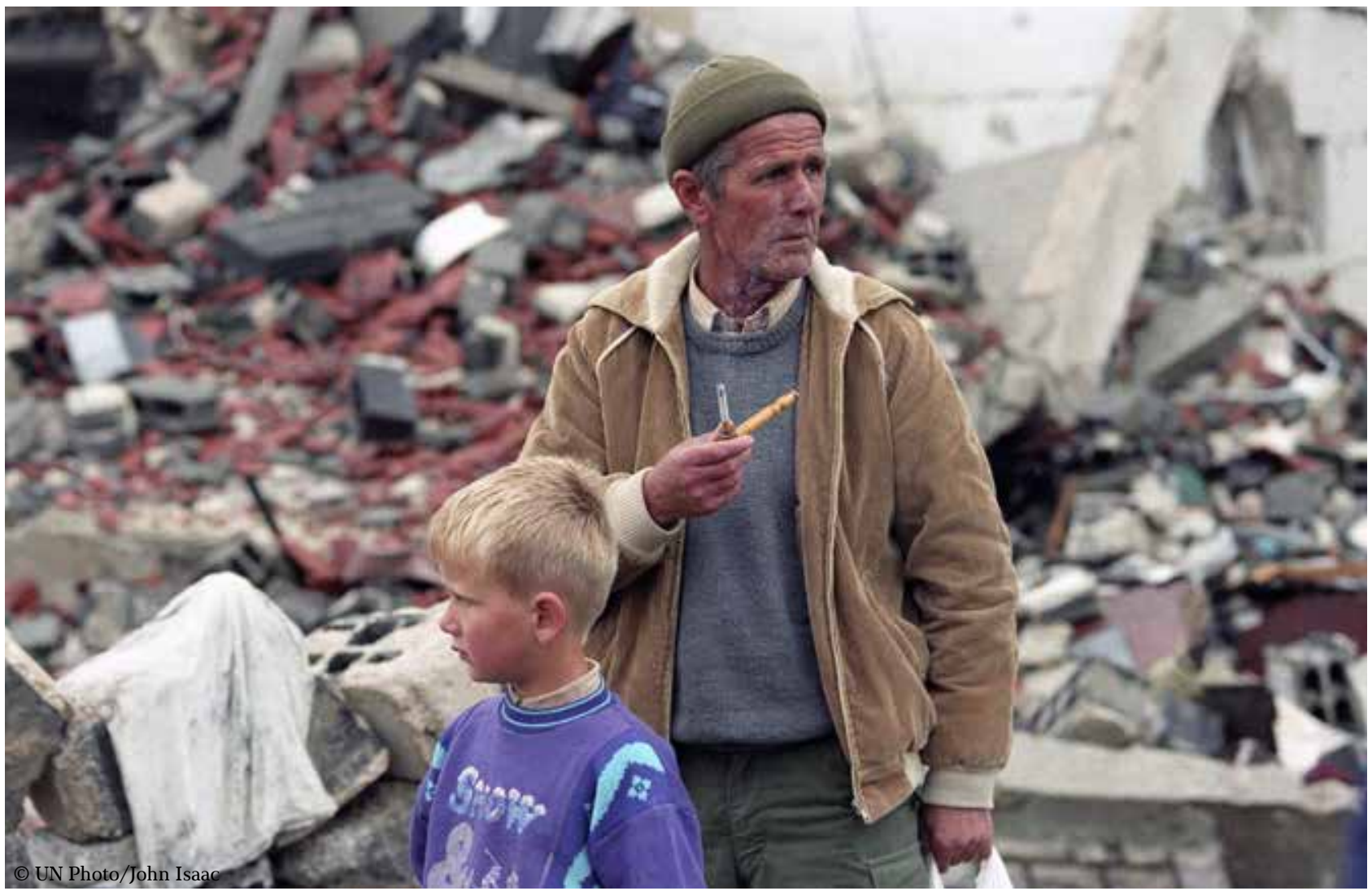

Commission envisaged in $\mathrm{Ar}-$ ticle 90 of the 1977 Additional Protocol I. This body, which activated its mandate in 1991, was relied upon only recently for the first time in the context of the armed conflict in Eastern Ukraine. The author reflects on the reasons of States' reluctance around this body as well as on the perspectives for the revival of a theoretically very relevant tool to implement IHL. Théo Boutruche discusses the contribution of the various United Nations Commissions of Inquiry to the implementation and clarification of IHL.
Nowadays, such commissions of inquiry or mechanisms are becoming increasingly popular ${ }^{5}$ in lieu of establishing special tribunals, for the simple reason that there are not the right conditions within the United Nations Security Council to set up institutions akin to the ICTY and ICTR, seen in the 90s. As such, it is important to understand how these new types of institutions, which are often mandated to apply IHL, can contribute to its interpretation and dissemination. Finally, Damien Scalia and Marie-Laurence Hebert-Dolbec, on the one hand, and Alessandra Spadaro, on the other, scrutinize the role of the European Court for Human Rights (ECtHR) and of international criminal tribunals and courts in interpreting, developing and applying IHL. The ECtHR has increasingly applied IHL in its decisions in order to interpret the human rights obligations of States. In so doing, it has embarked in complex inter-disciplinary analysis as to the interaction between international human rights law and IHL on very controversial issues, primarily deprivation of liberty and conduct of

5 Such bodies take different names, mandate and structure and nowadays deal or have dealt with situations of armed conflict in Yemen, Myanmar, Burundi, Syria, the Occupied Palestinian Territories, South Sudan, Eritrea, Libya, Democratic People’s Republic of Korea, the 2009 and 2014 Gaza conflict (see https://www.ohchr.org/en/hrbodies/hrc/iicisyria/pages/independentinternationalcommission.aspx) 
hostilities. As to international criminal tribunals, it is readily understandable how important their dissemination role is, given their binding power to enforce verdicts and sentences for war crimes, which therefore contributes immensely to shaping the details of IHL.

GS

$$
\begin{gathered}
\text { An enhanced } \\
\text { application of IHL } \\
\text { goes to the ultimate } \\
\text { benefit of civilians } \\
\text { who do not or no } \\
\text { longer take part in } \\
\text { hostilities }
\end{gathered}
$$

The second and most unique part of the volume collects 265 alphabetical entries, from 1 to
6 pages long, covering the vast majority of IHL concepts and notions. The entries explain all major IHL treaties; the fundamental principles of IHL; the types of armed conflicts; the categories of protected persons and objects; the various aspects governing situations of occupation; war crimes with corresponding jurisprudence; aspects of conduct of hostilities; types of weapons, methods of warfare, always with a primary focus on IHL. In addition, the editors have chosen to insert entries dealing with concepts that either do not find direct foundation in IHL or are under-regulated, among many: refugees, stateless persons, drones, terrorists, transitional justice, economic warfare, animals, and environment.
Accordingly, this second part of the Companion to International Humanitarian Law seeks to provide those who use IHL daily, in their professional or personal capacity, with an accessible resource to quickly familiarize themselves with IHL issues, while being sufficiently comprehensive and thorough to allow more demanding users to conduct further research. By creating a link between the academic knowledge of experts and researchers in IHL and the practical and direct experience of those working in war zones, the volume represents an effective instrument for achieving the functional implementation of IHL.

\section{The Authors}

Drazan Djukic (LL.M ADH Geneva and PhD Tilburg University) is Associate Legal Officer with the Pre-Trial Division of the International Criminal Court and previously worked for the Defence at the International Criminal Tribunal for the former Yugoslavia. He is also the author of the monography 'The Right To Appeal in International Criminal Law'.

Niccolò Pons (LL.M ADH Geneva) works in the field of refugee protection and detention monitoring. He worked as Associate Legal Officer at the Kosovo Specialist Chambers, the International Criminal Court and the Extraordinary Chambers in the Courts of Cambodia. 


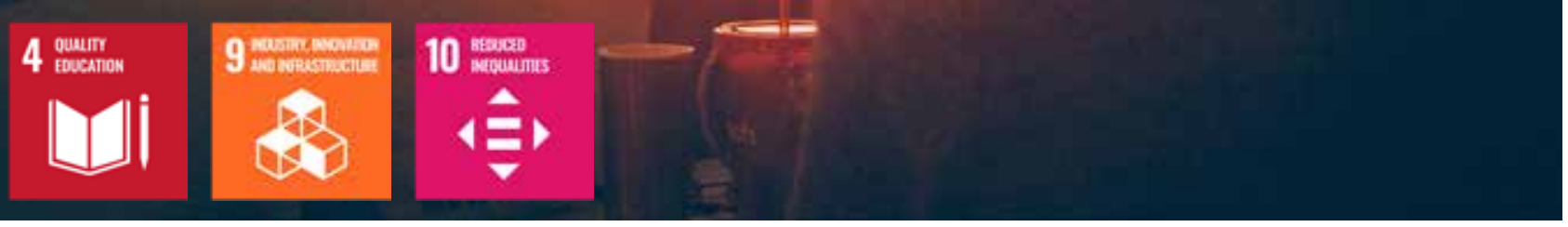

\section{Why collaborative communities are the future of youth empowerment and education}

by Rudradeb Mitra

\section{"You never change things by fighting the existing reality. To change something, build a new model that makes the existing model obsolete."}

Companies around the globe are finding it difficult to recruit the right talent, especially for emerging technologies like Artificial Intelligence (AI). A recent survey by EY and MIT Technology Review ${ }^{1}$ showed that $48 \%$ of current challenges comes in emerging technologies from a shortage of skilled talent while on the other hand, the number of data scientists and machine

1 Building a Better Working Europe[online], EY Survey December 2018, Available at: https://assets.ey.com/content/dam/eysites/ey-com/en gl/topics/attractiveness/EY-European-Attractive.pdf?download. 
learning engineers has increased tenfold in the last five years, primarily due to access to online education.

This shows a huge market failure. One of the reasons for this market failure is that corporations are stuck with the old form of hiring and managing people and overlook a large segment of the population who are well-trained and skilled, but through online education. This is the segment which is "invisible" to the corporations.

This segment of "invisibles" often come from remote parts of the world, are not educated in the top universities and do not come from affluent families, but many are highly motivated to learn and grow. This article presents a case showing that if you give them the right platform to prosper, they can prove to be equal if not better than the "best" in the world.

\section{The community- driven collaborative model}

I conducted an experiment with a group of 70 third and fourthyear undergraduate students from non-elite universities, living in remote parts of India. The goal was to see if they could build a sophisticated machine learning model. The selection criteria were simple: they all did an online course on machine learning, have implemented at least a couple of Machine learn- ing projects related to image analysis, and were intrinsically driven to learn and grow.

The problem which the group was given to solve was neither very simple nor very complex. The objective was to build a model to identify the shadow-free rooftop area on low-resolution satellite images. This was aimed at improving solar adoption as users, with a click of a button, will be able to analyze their solar rooftop potential. Such systems have been built in the West (for example, the Google Sunroof project) but they all work on high-resolution images. Our goal was to work on low-resolution images, as these are more likely to be the resources available in most areas of the developing world.

TALENT POOL

Global top tier universities

(MIT, Stanford, Cambridge, etc.)

Country top tier universities

(KTH, ETH, EPFL, etc.)

Mostly unknown universities

Online courses + no practical experience 
The challenges were huge: no tagged data, inexperienced developers with no prior work experience and not from top universities, a group of people who never met each other, and a small amount of money for product development.

G4

Corporations are stuck with the old form of hiring and managing people and overlook a large segment of the population who are well-trained and skilled, but through online education

What happened in the next six months was truly amazing. The students collaborated and were able to test multiple machine learning models and build a model with $80-85 \%$ accuracy in identifying areas of rooftops for solar adoption.

Looking back and connecting the dots, here are the things that made this happen:

\section{The selected candidates had huge intrinsic motivation:}

In recent years education has been democratized through online courses, open source code, and models, and emerging technologies like AI have become more accessible. Anyone in almost any corner on the planet can use AI to build products, and this opens up new opportunities which would have been not possible a few years ago. However, the work and hiring model has not changed. Companies still look for degrees, universities, and experience to hire people, so students not from the top of the pyramid (see below) don't have access to good work opportunities. When given an opportunity, they are highly motivated to prove and show their skills.

\section{The students collaborated, not competed:}

This group of students realized that if they competed with each other they wouldn't succeed. They think (rightly or wrongly) that they are not the best, so they tried to utilize the power of the group and learn from each other. It is doubtful that such an approach would be the case for people at the top of the pyramid, who are often greatly driven by competition.

The collaboration also helped in making the process of testing models faster and leaner. Multiple teams were formed, each of which was independently able to tag data and build models. Each of the teams started trying different models and sharing their learnings, thus utilizing the tactic of divide and conquer. Soon, one of the models came out as the winner, based on the accuracy of its results.

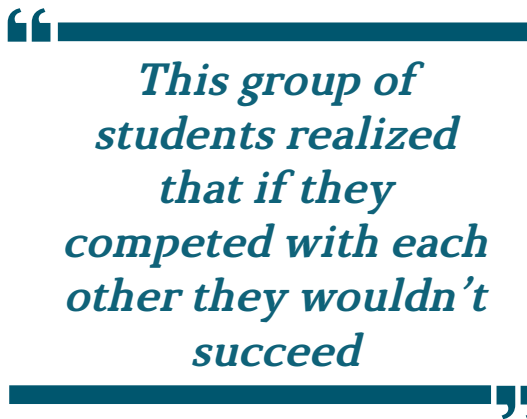

Extrinsic motivation was provided, but not "winner takes all":

In the community the mentor was at the top of the pyramid, followed by the community manager, then engineers working on building models and finally data taggers. Members from each team were striving to move up the ladder to reach the next level, which created an extrinsic motivation.

However, the monetary compensation for people on the same level was the same. This fostered collaboration.

\section{As a mentor, I listened and encouraged rather than taught:}

In a TED talk titled "School in the cloud" by Sugata Mitra, the speaker says that the best form of education is where the teacher just encourages the students and lets the students learn from each other. This is what I did also. In fact, in many cases, the students knew more than me and told me about machine learning models I did not know of. What I did in return was to offer incentives like: writing 

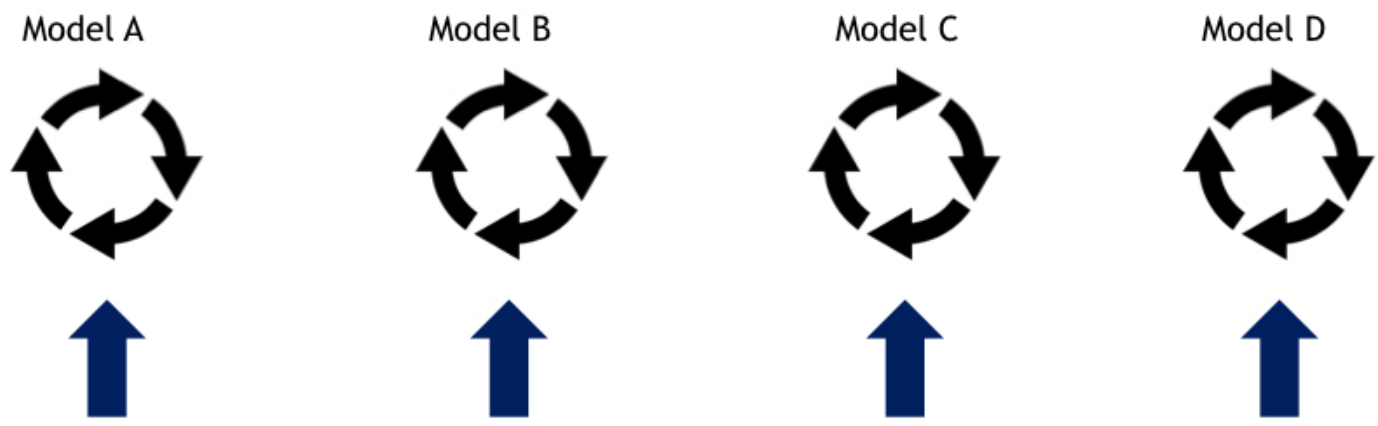

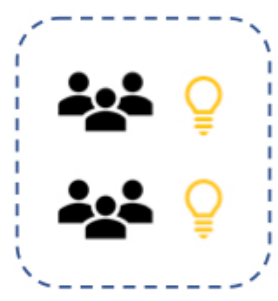

Subcommunity A

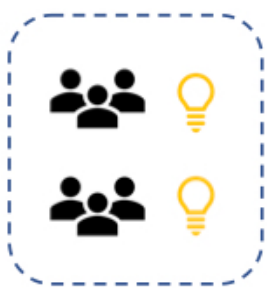

Subcommunity B

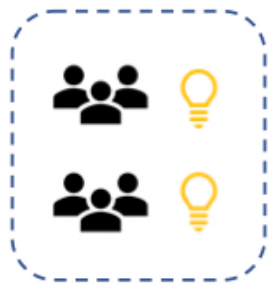

Subcommunity C

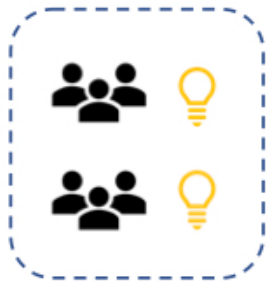

Subcommunity D

Equal compensation

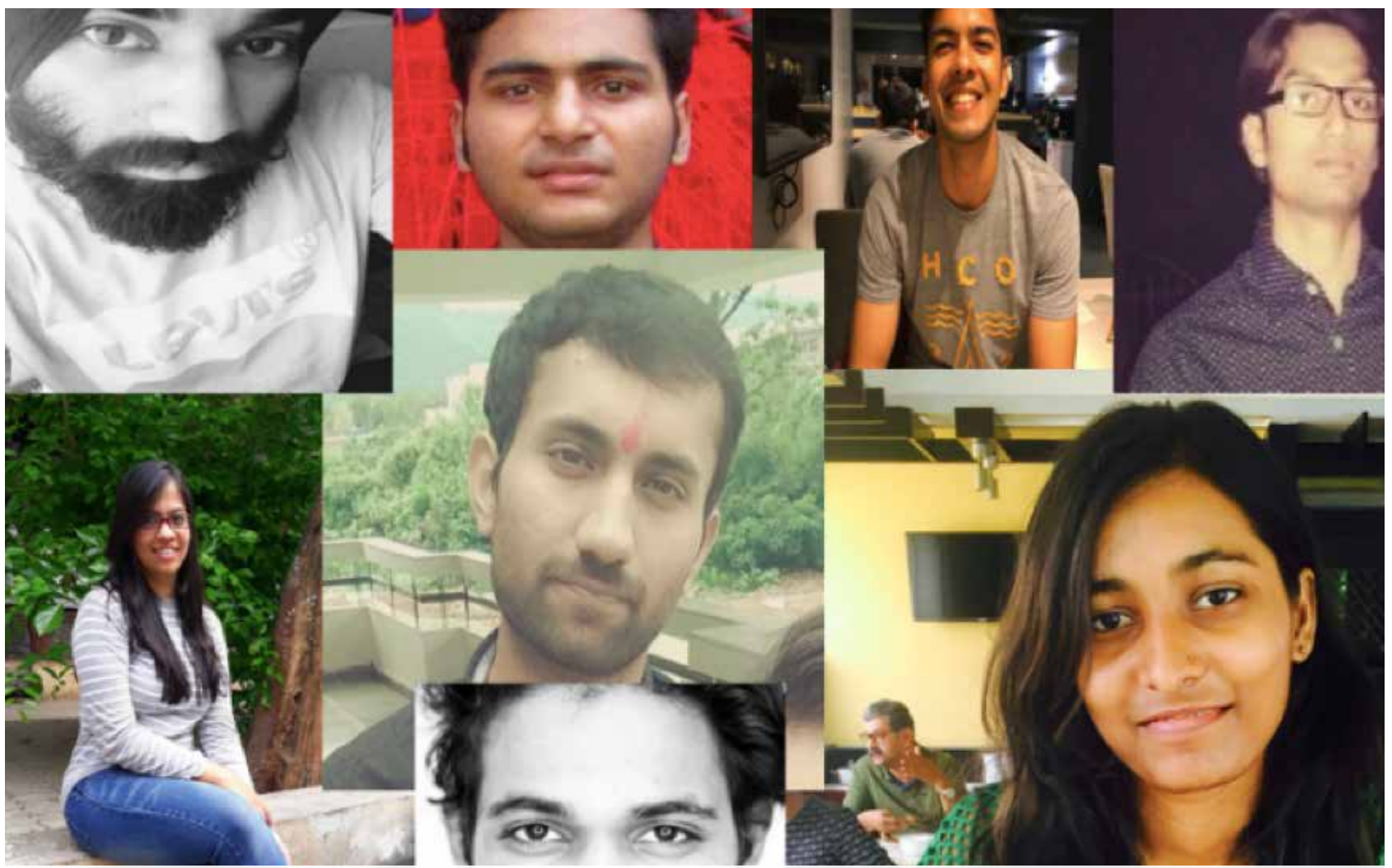

Students from all over India - who have never met each otherr - collaborated to build a community driven Machine Learning product for the clean energy sector. From top-left: Jitendra, Abhigyan, Raghav, Devendra, Raika, Iresh, Jerin, and Shivani. 


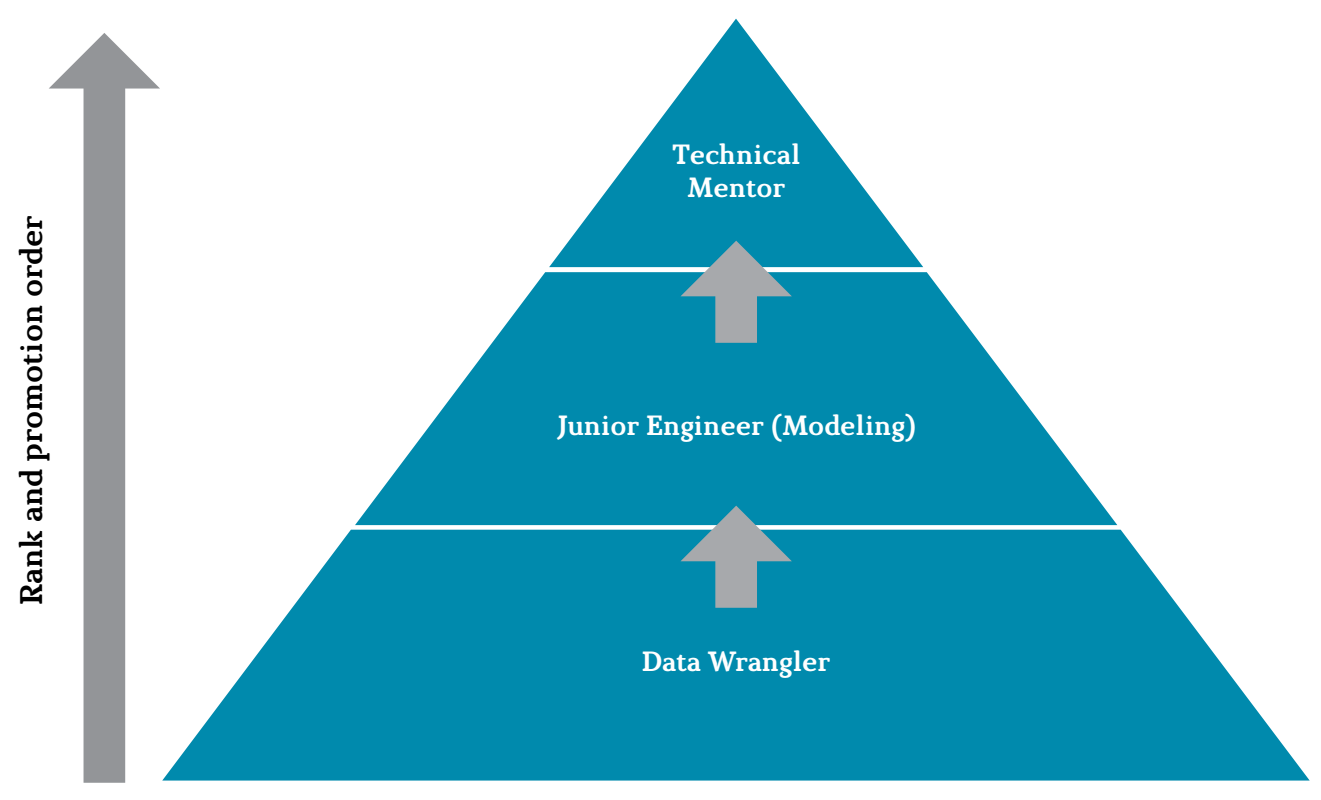

articles, giving credits to the students who were part of the community; providing certificates and recommendation letters. These incentives encouraged them to move up in rank and mentor other students. The above experiment demonstrated what I term as the Collaborative Model, where individuals driven by high intrinsic motivation form a community and the community members collaborate to build AI and Machine learning models. This makes the whole greater than the sum of its parts.

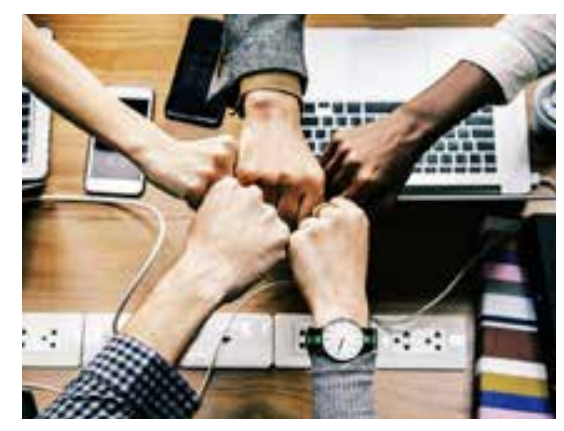

Creating inclusive and equitable learning opportunities for all

Goal 4 of the 2030 Agenda for Sustainable Development aims to "ensure inclusive and equitable quality education and promote lifelong learning opportunities for all." The Collaborative Model provides a groundwork to achieve this by offering the following advantages:

\section{Empowering youth and shar-} ing knowledge

Talent is not limited to certain areas (like the Bay area) but is available everywhere - be it in a small town like Novi Sad (Serbia) or Odessa (Ukraine) or in big cities like Ho Chi Minh (Vietnam). With today's technological advancement, online courses and available tools, tal- ent is everywhere and can be accessed easily.

Smriti Bahugana, a recent master's student from IIT Guwahati, adds: "It is also important to see that such impacting projects do not need a heavy setup; we are working on our laptops, at our homes, on something that we all are enthusiastic about."

\section{Building trust and respect for one another}

A community can also help to build trust. Companies that emerge from communities share common values, beliefs, and often a bigger vision that serves the long-term interests of those communities. This builds more trust and makes people more willing to use such systems and share their data, something which is receding in 
products built by large corporations.

\section{GG

Companies that
emerge from
communities share
common values,
beliefs, and often
a bigger vision that
serves the
long-term
interests of those
communities

According to Piyush Choudhury, a $4^{\text {th }}$ year student of IIT (ISM) Dhanbad, "Since we work remotely, we need to trust each other more. Everyone understands that a person cannot be free all the time, thus we adjust our time according to others and this builds respect for each other."

\section{Helping to build a truly communal product through diverse opinions}

Communities across the world with different values and perspectives are needed to build great products that strengthen human capabilities and solve pressing problems in today's and tomorrow's world. Products which are built from the incorporation of diverse opinions end up being more inclusive and appeal to a larger audience.

Raghav Saraf, a $4^{\text {th }}$ year student of Vellore Institute of Technology, says: "Everyone can share their opinions to help solve the problem and this is great as we get to look at the problem from many perspectives."

\section{Building a decentralized, equal-opportunity and peaceful world}

Through this model people no matter where they are born or live, if are equally talented, get equal access to work and opportunities. Additionally, people from diverse communities, who might dislike each other, can be brought together to collaborate and solve a common problem, thus creating an environment of mutual trust and understanding and leading to a more peaceful world. This is what the future world should be. A world where work is distributed, equal, transparent, and trustworthy and people collaborate to solve real problems.

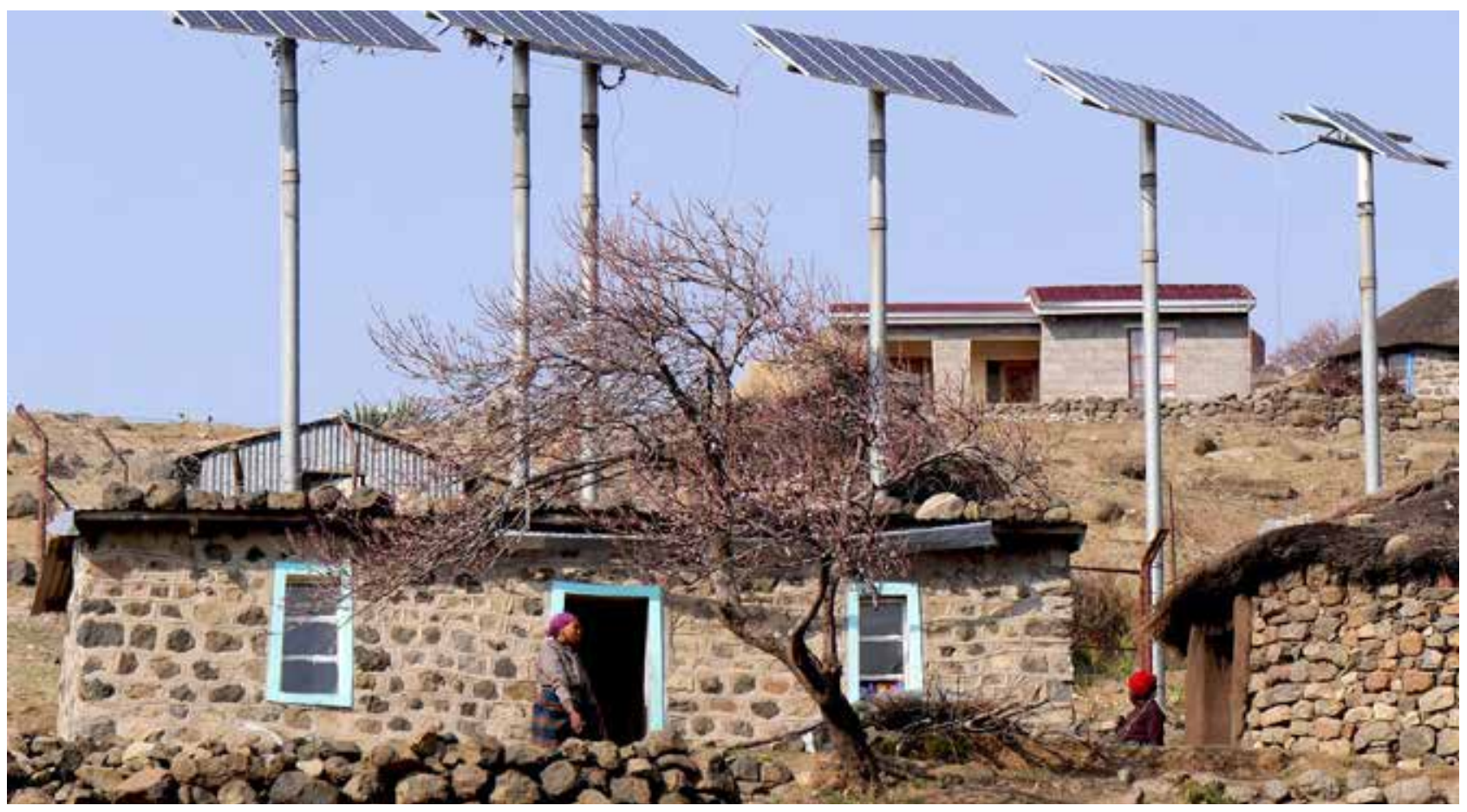




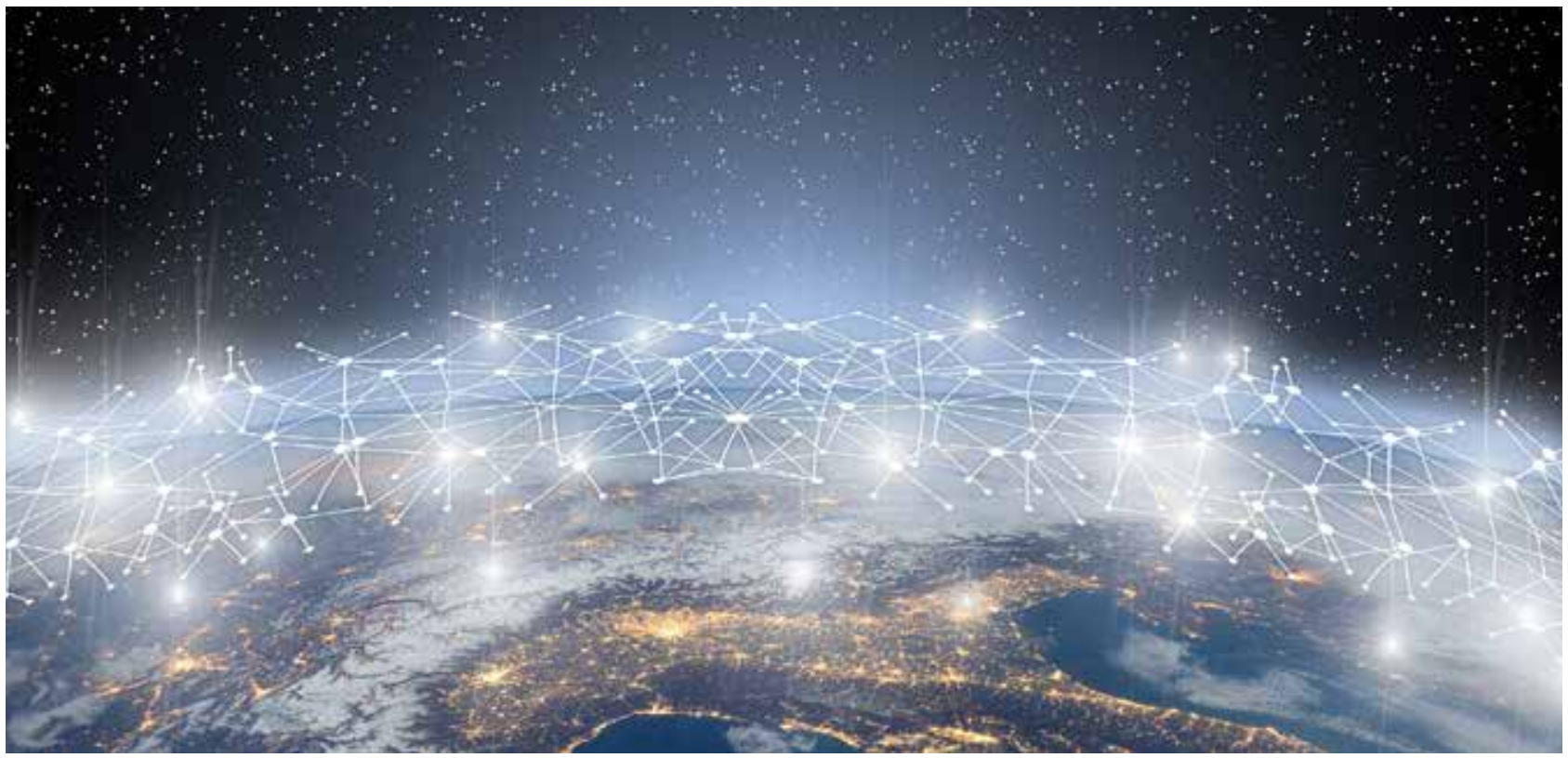

Is it possible to build such a future? Yes, according to Iresh Mishra, a $4^{\text {th}}$-year student of Shri Mata Vaishno Devi University: "Any real-world problem could be best solved if a group of people comes together to put in their dedicated efforts. When it comes to the collective efforts of dedicated individuals, Success is bound to occur!"

\section{A personal story}

Before ending this article, I must tell a personal story. Six months ago a girl named Shruti joined the solar project. At that time she worked as an Engineer in Oracle but was keen to become a $\mathrm{Ma}$ chine Learning (ML) Engineer. She did some online courses and also few projects online, however, she lacked real-world expe- rience and no one was willing to hire her as an ML Engineer. She joined the above-mentioned project, worked during weekends and evenings while keeping the full-time job and was instrumental in implementing the most accurate Machine Learning model. She is now ready to become a mentor. Stories like this make this collaborative approach such powerful.

\section{The Author}

Rudradeb Mitra started his career as an AI researcher in 2002 and worked with research labs, startups and banks to build AI products. During that period, he also published ten research papers on AI.

After graduating from the University of Cambridge, he built six tech startups. In the last two years, he is busy with sharing his knowledge and experiences. He is a mentor of Google Launchpad, MIT Enterprise, Impact Hub, and Founders Institute, an Entrepreneur in Residence at WeWork Labs, and a senior AI advisor of EFMA. He is also an invited speaker from 24 countries and has spoken at over 70 events. He is an avid writer and wrote his first book titled "Creating Value With Artificial Intelligence: Lessons learned from 10 years with building AI products." His current interest is creating collaborative AI learning environments and building products with social value. He sees that AI have the ability to solve the fundamental problems of human society and improve existing services in banking, insurance, energy and healthcare. 

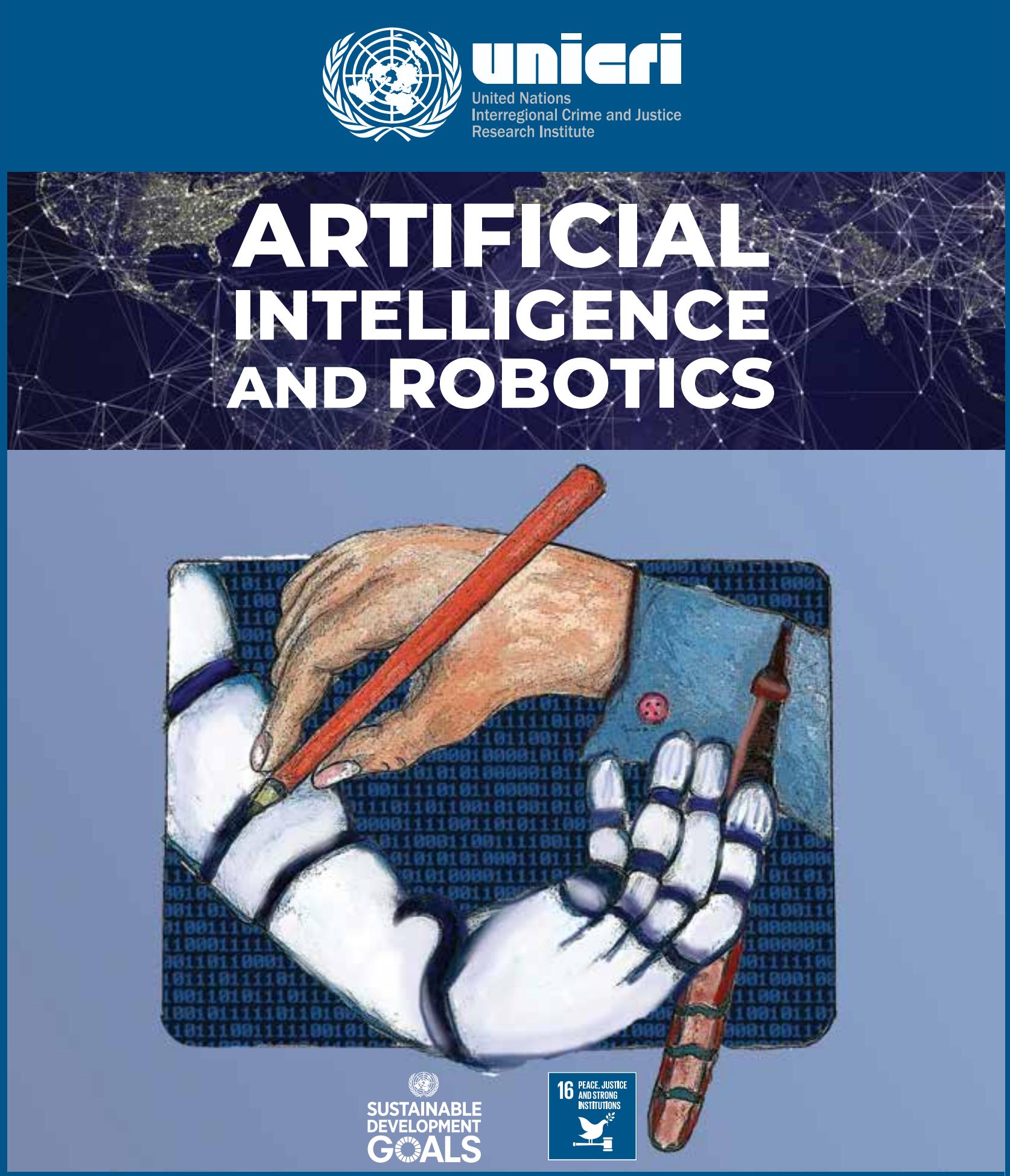

\section{CODING A PEACEFUL, JUST AND PROSPEROUS FUTURE TOCETHER}

UNICRI is advancing understanding of Artificial Intelligence (AI) and robotics from the perspective of crime prevention, justice, security and human rights.
Through its Centre for $\mathrm{Al}$ and Robotics, the Institute is sharing knowledge on the potential beneficial applications and harmful effects or malicious use of such technologies. 
ment of Children in Armed Conflict (OPAC), 2002. The international criminal law is established in the Rome Statute of $1998^{5}$ that regulates the jurisdiction of the International Criminal Court (ICC). Further, there is customary international law which is not written in a statute but is universally binding to everyone.

The GCs are silent on the issues of recruitment and the participation of children in hostilities because these were originally considered as domestic decisions for states to establish independently. According to the GCs, children are not participants in conflicts and are therefore protected as civilians. ${ }^{6}$ The two APs to the GCs aimed to voice the issue of children participating in the conflict. There are two APs because the Member States held that is was important to differentiate the rules of an international armed conflict from the rules of a non-international armed conflict. ${ }^{7}$ The First Additional Protocol (AP1), which is applicable for international armed conflicts only, allows the recruitment of children between the ages of 15 and 18 into the state armed forces. ${ }^{8}$ However, it prevents them from directly taking part in hostilities. This leaves open the question of what is meant by direct participation. According to the Second Additional Protocol (AP2), which applies to non-international armed conflicts, persons under the age of 15 shall not be recruited by either the state armed forces or nonstate armed groups and they shall not participate in conflicts in any way. ${ }^{9}$ This means that both APs consider 15 as the minimum age for recruitment and participation. However, this does not address the issue of children between the ages of 15 and 18. It should be noted that the APs do not include any measure of implementation or monitoring which makes them less effective. ${ }^{10}$

Article 77 of the AP1 orders states to give priority to the older children when recruiting persons between the ages of 15 and $18 .^{11}$ When it was drafted, it was commented that children between the ages of 16 and 18 were more physically fit to fight than their fathers and therefore would be more preferred for the armed forces. Further, due to the age structure in many countries, there are actually more children capable of fighting than people over the age of $18 .^{12}$ Under the APs children are eligible for two kinds of protection. First, children are considered to receive general protection as civilians and secondly, children under the age of 15 receive special protection if they fall into enemy hands. ${ }^{13}$ However, this protection is very narrow and reflects the fact that the APs are not designed to protect children as combatants. $^{14}$

The CRC is a universal treaty which provides a definition for a 'child': a person under the age of 18. According to article 38 of the CRC, states must ensure that persons under the age of 15 do not partake in conflicts

5 Rome Statute, 1998.

6 International Committee for the Red Cross 'Legal Protection of Children in Armed Conflict', (02-2003) https://www.icrc.org/en/document/legal-protection-children-armed-conflict-factsheet (accessed on 15-04-2018).

7 International Committee for the Red Cross: 'Protocols I and II additional to the Geneva Conventions'(01-01-2009) https://www.icrc.org/en/publication/0321-protocols-additional-geneva-conventions-12-august-1949 (accessed 14-04-2018).

8 Article 77 (2).

9 Article 4 (3) (c).

10 B Mezmur 'Child at both ends of the gun' (31-10-2005) University of Western Cape.

11 Article 77 (2).

12 G Van Bueren 'The International Legal Protection of Children in Armed Conflicts' (10-1994) Journal: International E Comparative Law Quarterly.

13 Additional Protocol, 1977, article 77.

14 Janet McKnight "Child Soldiers in Africa: a global approach to human rights protection, enforcement and post-conflict reintegration" (2010) 113 A.J.I.C.L. 


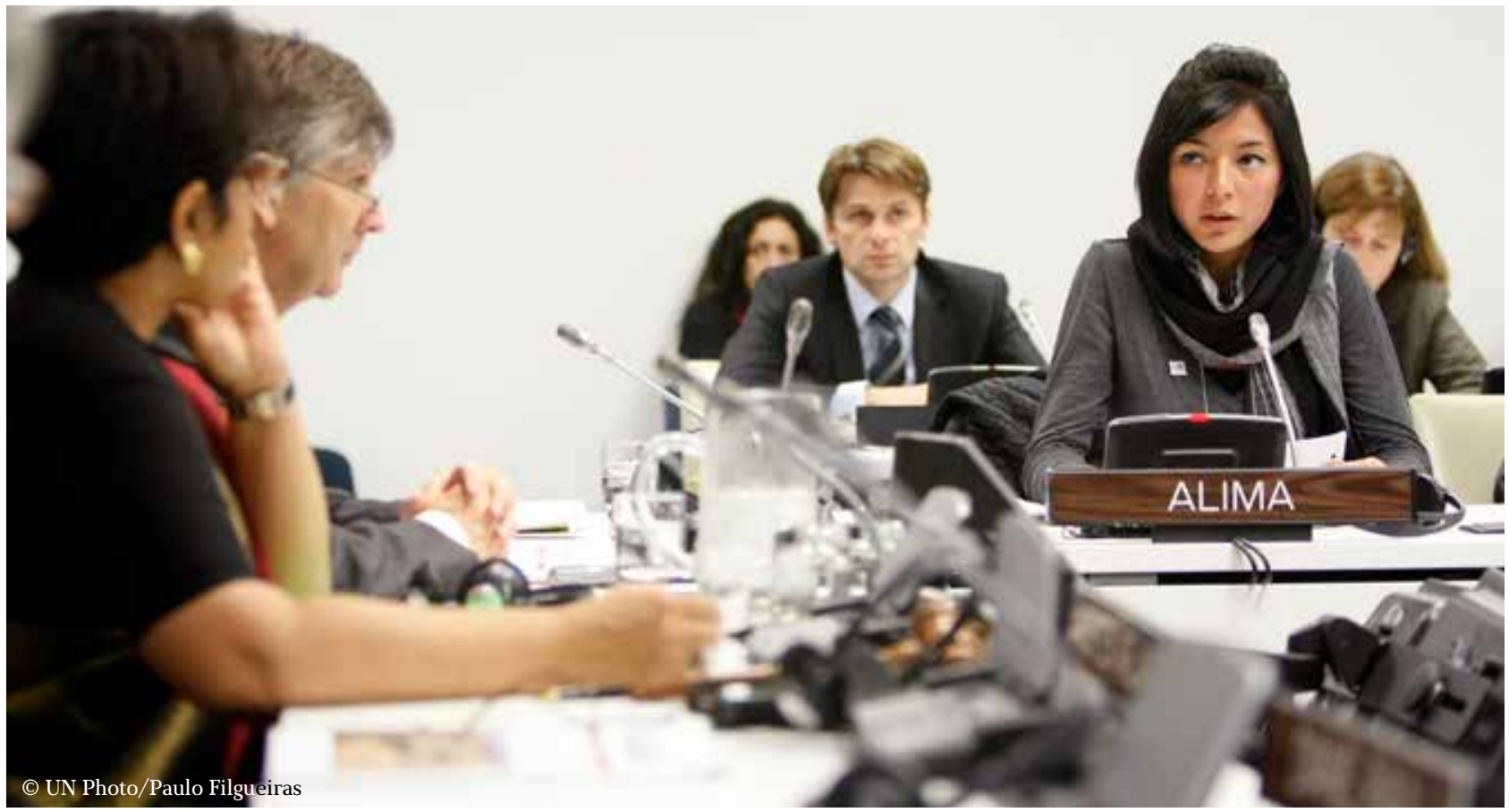

directly ${ }^{15}$ and shall take measurements to protect children affected by armed conflicts. ${ }^{16}$ The main international human rights law regulating children in conflicts is the OPAC. In 2018, 167 states had ratified the Protocol and 12 other states had signed it making the law nearly as universal as the CRC itself. The OPAC requires the State Parties to introduce the protocol into domestic legislation, inform the public of the regulations, demilitarise children from armed groups and aid them in reintegration to the communities. ${ }^{17}$
Article 1 of the OPAC imposes an obligation on the state to ensure that members of the state armed forces under the age of 18 do not take a direct part in the hostilities. ${ }^{18}$ According to article 2, the state is responsible for ensuring that children will not be forcibly recruited to their armed forces. ${ }^{19}$ However, article 3 permits a state to accept voluntary recruits without an age limit. ${ }^{20}$ Stricter terms are applied when determining the rules of other armed groups within a state under article 4. Non-state armed groups are prevented from recruiting and using children under the age of 18 in any situation. This was confirmed by the Special Court for Sierra Leone (SCSL) in the case of Issa Hassan Sesay which determined that non-state armed groups cannot recruit children under the age of 18 'under any circumstances'. ${ }^{21}$ Even though this case is not binding on states, it should be viewed as a good precedent on how the law should be interpreted.

The only protection the OPAC provides for voluntary recruits under the age of 18 is that the states recognise that they are under a special protection un-

5 Article 38 (2).

16 Article 38 (4).

17 Article 6.

18 Article 1.

19 Article 2.

20 Article 3 (3).

21 Prosecutor v. Issa Hassan Sesay, Morris Kallon and Augustine Gbao 25-2-2009 SCSL-04-15-T. 


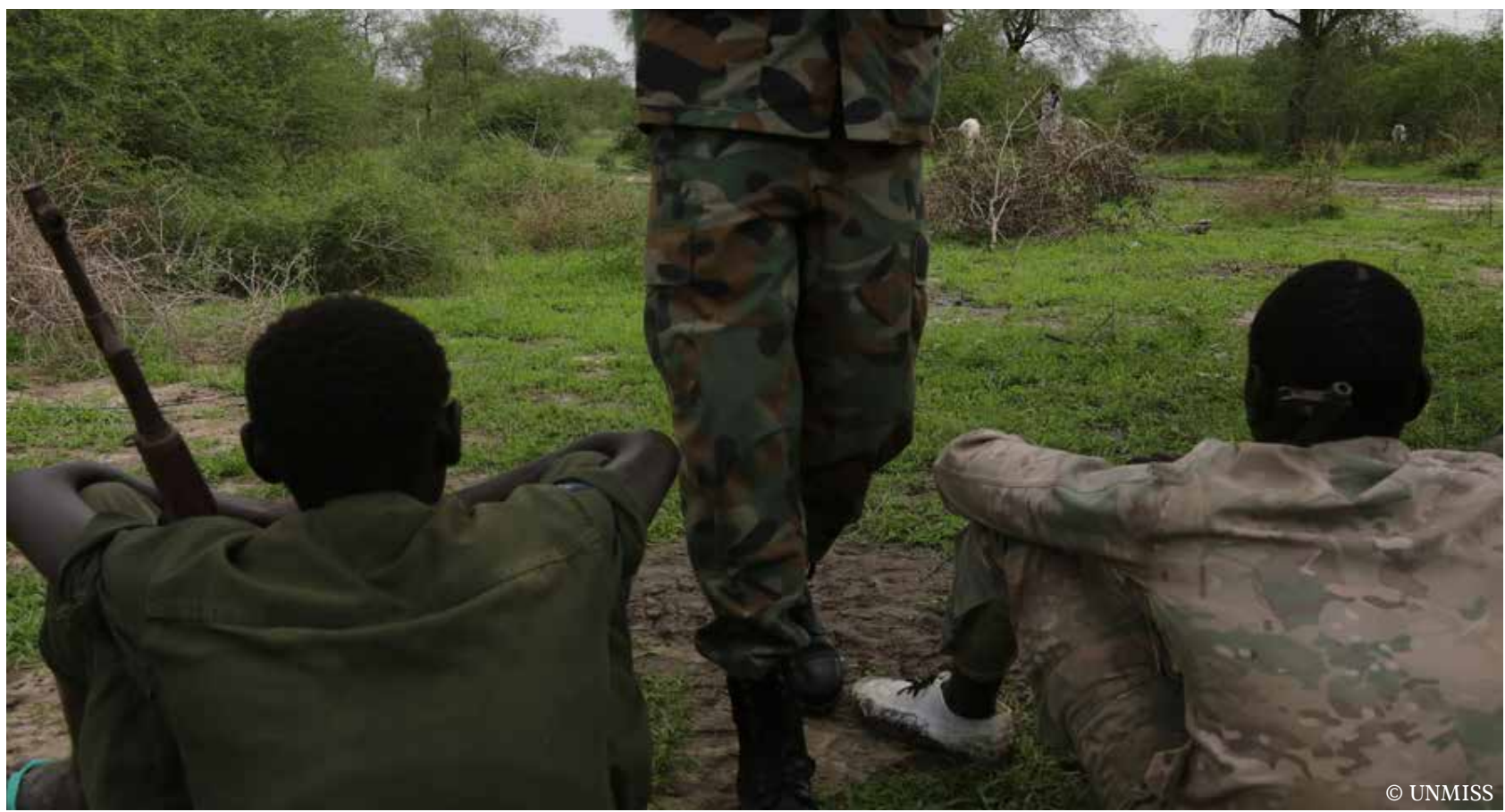

der the OPAC. ${ }^{22}$ Further, OPAC suggests that states set the minimum age of voluntary recruitment according to the CRC article $38^{23}$ which sets the limit of direct participation at $15 .{ }^{24}$ These two articles seem to be inconsistent with each other as article 1 sets a clear limit at 18 and article 3 provides a way around it. Further, the OPAC fails to distinguish what is meant by a direct or an indirect participation and brings a question whether it is ever possible for a person under the age of 18 to truly volunteer. The Cape Town Principles attempted to solve these issues by abolishing the concepts of direct and indi- rect participation as well as the idea of a voluntary recruitment of a person under the age of 18 . However, these principles are not enforceable law.

\section{G4}

Article 1 of the
OPAC imposes an
obligation on the
state to ensure that
members of the
state armed forces
under the age of
18 do not take a
direct part in the
hostilities.

gra
There are practical issues in the states guaranteeing that no person under the age of 18 is recruited to the armed forces. The OPAC states that a 'reliable proof of age' 25 must be shown upon recruitment but this is hard to fulfil in many States, where national birth registration systems are weak or unreliable. ${ }^{26}$ Various international human rights bodies argue against prosecuting children for the grave breaches because it harms their chances for rehabilitation and it is controversial to the state's responsibility to demilitarise children and to provide them with the necessary support for rehabilitation

26 D Helle "Optional Protocol on the involvement of children in armed conflict to the Convention on the Rights of the Child" (30-09-2000) 839 International Review of the Red Cross. 
is established in article 6(3) of the OPAC.

Article 8 of the Rome Statute also criminalises the enlistment of children under the age of 15 by the state armed forces ${ }^{27}$ and by non-state armed groups ${ }^{28}$ and allowing them to participate in conflicts, confirming the position that the APs have taken. The Statute does not address the issue of recruitment of children between the ages of 15 and 18 but article 26 limits criminal liability to $18 .{ }^{29}$ This means that the ICC does not prosecute anyone for crimes they have committed during conflicts while being under the age of 18. Further, it leaves children between the ages of 15 and 18 are without a status: they are neither victims nor perpetrators.

\section{G6

Various
international
human rights
bodies argue
against prosecuting
children for the
grave breaches
because it harms
their chances for
rehabilitation

Most countries have ratified or signed the Rome Statute establishing the recruitment of children under the age of 15 as a war crime. ${ }^{30}$ The International Labour Organisation (ILO) Convention on the Worst Forms of Child Labour which prohibits the compulsory recruitment of persons under 18 by an armed group have been ratified by 186 states. ${ }^{31}$ It seems that the international law is more lenient to allow government armed forces to recruit volunteers between the ages of 15 and 18 to take some part in hostilities whereas non-state armed groups are prevented from recruiting anyone under the age of $18 .^{32}$ The enforceability of this is difficult as the international law ratified by the State Parties is only binding on those states and no

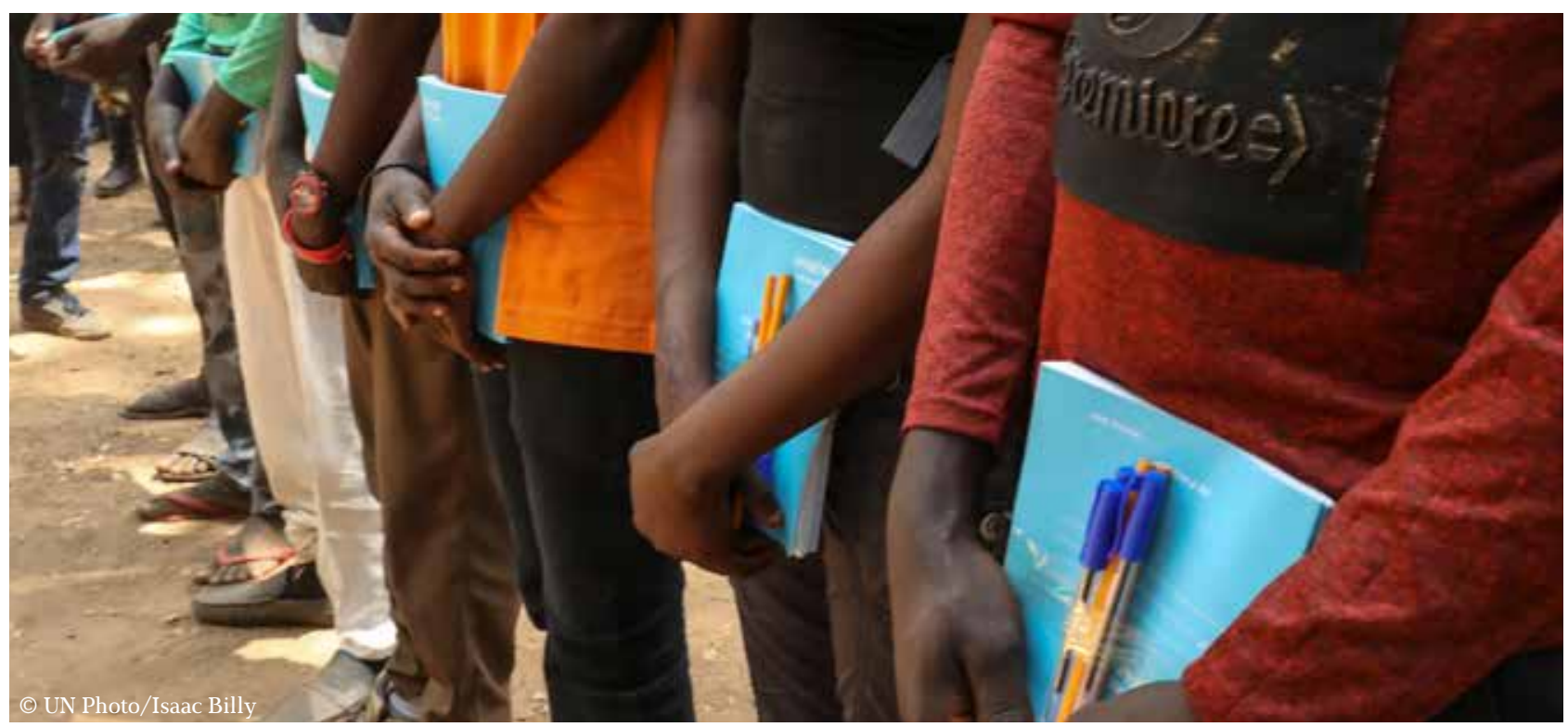

27 Article 8 (b) (26).

28 Article 8 (e) (7).

29 Article 26.

30 International Criminal Court 'The States Parties to Rome Statute' (2018) International Criminal Court https://asp.icc-cpi.int/en menus/asp/states\%20parties/pages/the\%20states\%20parties\%20to\%20the\%20rome\%20statute.aspx (accessed 15-04-2018).

31 International Labour Organisation Convention (adopted 17 June 1999, entered into force 19 November 2000): https://www.ilo.org/ dyn/normlex/en/f?p=NORMLEXPUB:11300:0::NO::P11300 INSTRUMENT ID:312327.

32 Prosecutor v. Issa Hassan Sesay, Morris Kallon and Augustine Gbao 25-2-2009 SCSL-04-15-T. 
other armed groups within the states. Further, it is likely that the armed groups within the state are fighting against the state. ${ }^{33}$ These discrepancies in international law of the definition of a child, the minimum age for recruitment and the age for criminal liability create loopholes which are exploited by Member State governments as well as non-state armed groups.

\section{The case of Uganda and the efficiency of the law}

The civil war in Uganda started in the early 1980s when rebellion groups moved against the Ugandan Government. Since the beginning of the conflict, hundreds of thousands of people have died. Further, more than a million people have been displaced from their homes which have caused pressure and unrest to the neighbouring countries as well. The conflict is particularly complex due to the many armed groups with different agendas in the region. One of the main rebel groups is the cult-like group called the Lord's Resistance Army (LRA). ${ }^{34}$
G6

\section{It has been estimated that child soldiers formed three-quarters of the LRA army}

The leader of the LRA is the notorious Joseph Kony. He originally established the group to protect the Acholi people in northern Uganda and later recruited and abducted many Acholi children to his ranks in order to make up for his diminishing army. ${ }^{35}$ It is hard to estimate how many children were partaking in the hostilities but some sources claim that the LRA may have abducted more than 60,000 children. ${ }^{36}$ It has been estimated that child soldiers formed three-quarters of the LRA army. ${ }^{37}$ The original agenda for the LRA was liberating north Uganda, however, the changes in the conflict forced them to abandon this goal. Since the LRA was forced out of Uganda, they have executed missions in South $\mathrm{Su}^{-}$ dan, Democratic Republic of the Congo (DRC) and the Central African Republic (CAR) contrary to their original goal. ${ }^{38}$
Uganda ratified the Rome Statute in 2002 and in 2004 referred the conflict in its territory to the ICC giving the ICC jurisdiction to prosecute for breaches of the Rome Statute in the Ugandan territory since 2002. ${ }^{39}$ The ICC executed arrest warrants against the five main leaders of the LRA for war crimes including the recruitment of children. Out of the five three, are now believed dead, Joseph Kony remains at large and Dominic Ongwen is facing trial at the ICC. ${ }^{40}$ If Kony is alive, bringing him to justice could help stabilise the situation in Uganda and enforce accountability for the recruitment of children.

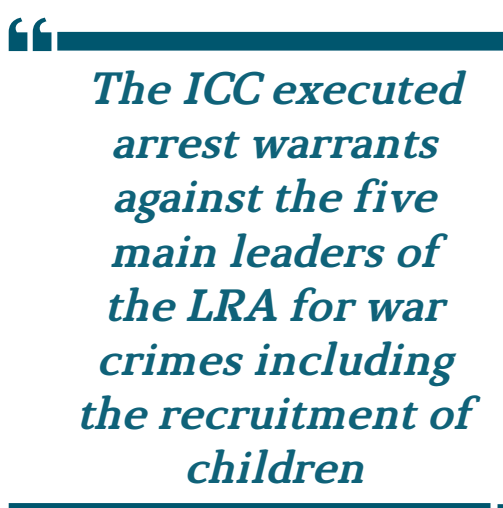

33 L Hill-Cawthorne 'Humanitarian law, human rights law and the bifurcation of armed conflict' 293 I.C.L.Q.

34 J R. Quinn 'The impact of internal conflict on customary institutions and law: the case of Uganda' (2015) 220 J.A.L.

$35 \mathrm{~J}$ McKnight 'Accountability in northern Uganda: understanding the conflict, the parties and the false dichotomies in international criminal law and transitional justice' (2015) 193 J.A.L.

36 Anonymous 'Uganda: Conflict Profile October' (10-2017) Peace Insight https://www.peaceinsight.org/conflicts/uganda/ (accessed 15-04-2018).

37 R N Souris 'Child soldiering on trial: an interdisciplinary analysis of responsibility in the Lord's Resistance Army' (2017) 316 Int. J.L.C.

38 Anonymous 'The rebel group. The LRA.' Invisible Children https://invisiblechildren.com/challenge/the-lra/?gclid=Cj0KCQiAiKrUBRD6ARIsADS2OLmzrDQSTvmyy97SSKbAA3MUNan3nAR2tmv PVDHOKdFNMGN18IObHcaAvN6EALw wcB (accessed 15-04-2018).

39 International Criminal Court 'Situation in Uganda' (02-2004) International Criminal Court https://www.icc-cpi.int/uganda (accessed 15-04-2018).

40 F Bensouda 'Opening Statement' (6-12-2016) International Criminal Court https://www.icc-cpi.int/Pages/item.aspx?name=2016-1206-otp-stat-ongwen (accessed 15-04-2018) 


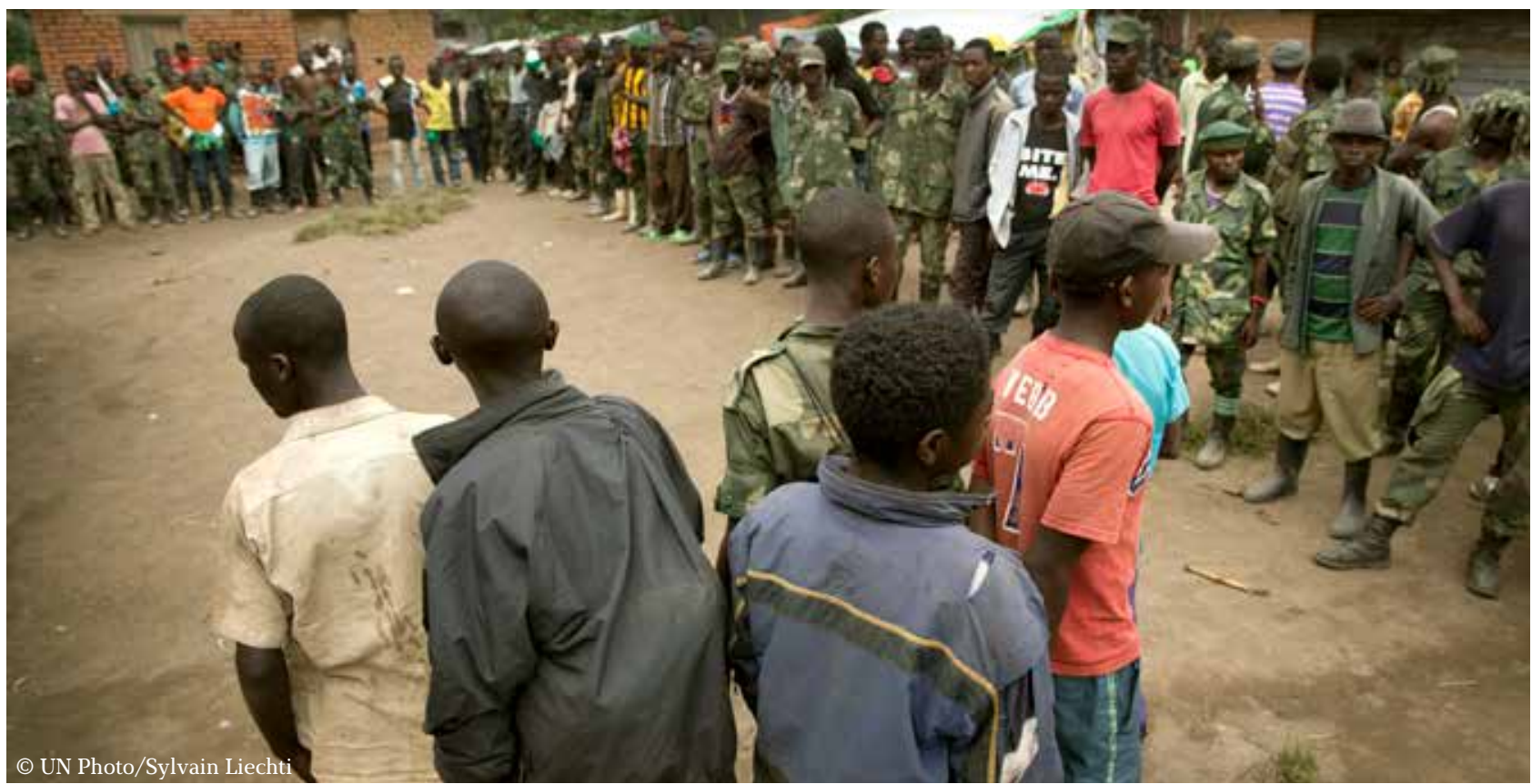

Uganda has also ratified the African Charter on the Rights and Welfare of the Child (ACRWC) of 1990, in 1994. Article 22 (2) specifically prevents the recruitment of children under the age of 18 and requires states to take measures to ensure that children do not partake in hostilities in any way. This law is providing children with a stronger protection than the international law does. It is important to notice that Uganda is Party to both the OPAC and the ACRWC, which both have a 'straight 18' standard. It is also a Party to the Rome Statute which holds the age of criminal liability at 18 . Contrary to the international law Uganda has ratified, the Ugandan Children Act holds minimum age for criminal responsibility $12 .{ }^{41}$ This law seems to be inconsistent not only with the international law but also with their own constitution which defines a child as a person under the age of $18 .^{42}$

\section{The reasons for the recruitment of child soldiers}

By 2010 children have been recruited to participate in conflicts in 85 countries and fought in at least 36 conflicts. ${ }^{43}$ The issue of child soldiers in Uganda is not unique and worldwide there are estimated 300,000 children in armed groups. ${ }^{44}$ Especially in the African conflicts, ethnic and cultural tensions, unemployment and lack of education put children at high risk for getting involved in conflicts. ${ }^{45}$ There are at least 20 states globally that have children between the ages of 10 and 18 participating in military training. ${ }^{46}$ This clearly shows the issue in the international law and its interpretation; there is a difference between training children which might even be considered a safety measure for

\footnotetext{
41 The Children Act part 10 (1).

42 The Constitution of Uganda, 1995 article 257 (c).

43 M. Happold 'Child Solders in International Law' (2005) Juris Publishing, Inc.

44 R N Souris 'Child soldiering on trial: an interdisciplinary analysis of responsibility in the Lord's Resistance Army' (2017) 316 Int. J.L.C.

45 Anonymous 'Child Soldiers Global Report 2008: Coalition to Stop the Use of Child Soldiers' (20 May 2008) Human Rights Watch https://www.hrw.org/legacy/pub/2008/children/Child Soldiers Global Report Summary.pdf (accessed 15-04-2018).

46 G Van Bueren 'The International Legal Protection of Children in Armed Conflicts' (10-1994) I.C.L.Q.
} 


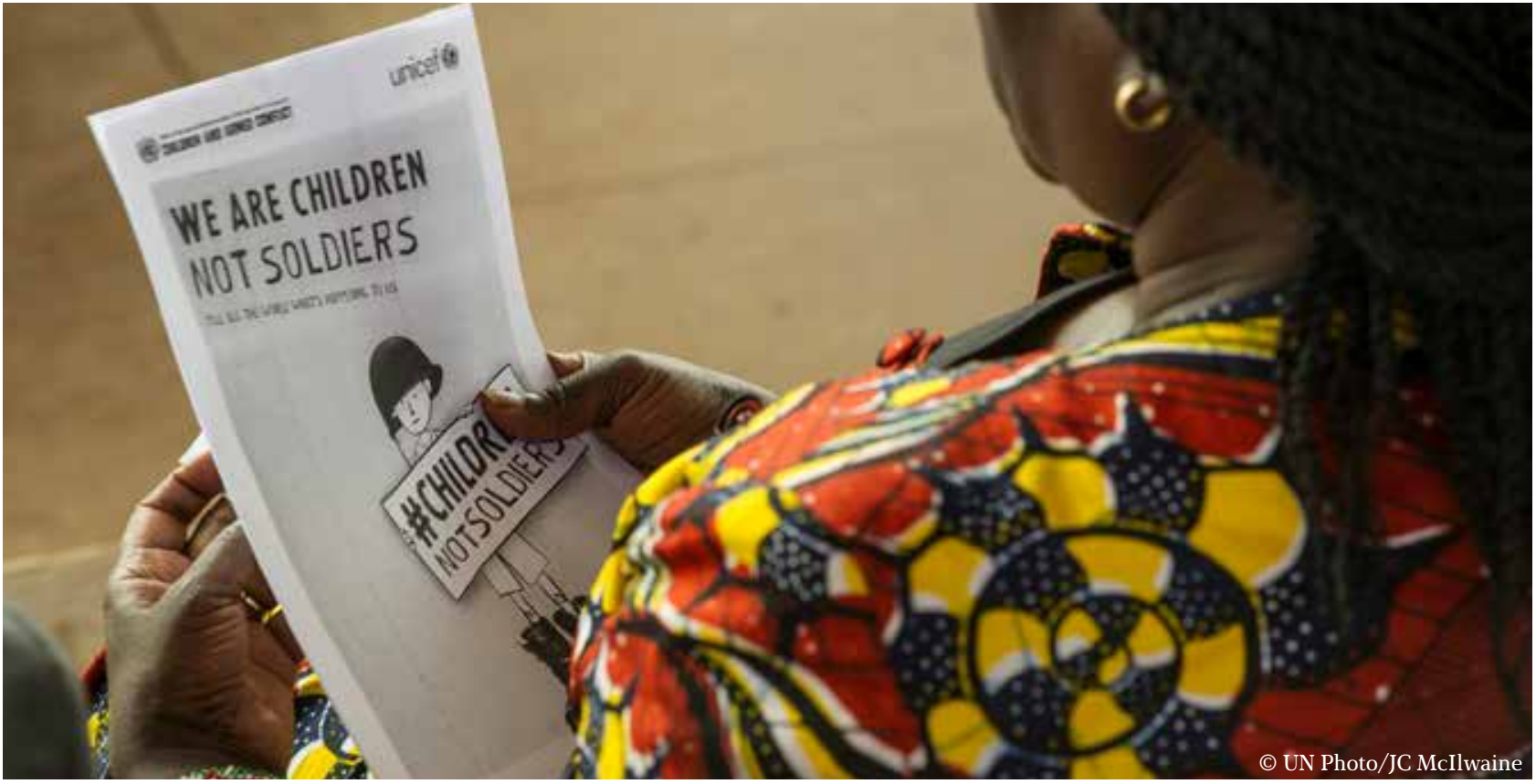

them and children actually partaking in hostilities.

Gq

\section{Surges in the recruitment and use of children often coincided with increasing levels of killing and maiming of children}

According to the Report of the Secretary-General of the United Nations "In 2017, changing conflict dynamics, including the intensification of armed clashes, directly affected children. Verified cases of the recruitment and use of children quadrupled in the Central African Republic (299) and doubled in the Democratic Republic of the Congo $(1,049)$ compared to 2016. The number of verified cases of the recruitment and use of children in Somalia $(2,127)$, South Sudan $(1,221)$, the Syrian Arab Republic (961) and Yemen (842) persisted at alarming levels. In addition, boys and girls recruited and used were often doubly victimized by subsequently being detained for their former association with armed forces or groups. Surges in the recruitment and use of children often coincided with increasing levels of killing and maiming of children. In addition, spikes in armed clashes and violence led to a substantial increase in the number of child casualties in Iraq (717) and Myanmar (296). Afghanistan, the Syrian Arab Republic and Yemen remained the country situations with the highest number of verified casualties. In Nigeria, BokoHaram continued to force civilians, including children, to perpetrate suicide attacks, which led to over half of all the verified child casualties in the country [...]. Additional developments included the abduction of over 1,600 children by Al-Shabaabin Somalia, pointing to a sustained reliance on children for combat and support duties." ${ }^{47}$

\section{GG \\ In Nigeria, BokoHaram continued to force civilians, including children, to perpetrate suicide attacks}

47 United Nations Children and armed conflict - Report of the Secretary-General https://undocs.org/s/2018/465 
It is beneficial for rebel groups to use child soldiers because other armed forces face a moral issue to kill children even if they are partaking in hostilities. Further, it is easier to manipulate what children think and they can be trained well for the group's purposes. The constant fear of punishment is an effective tool to divide the children against each other as well. ${ }^{48}$

It was much easier to make the children become good, integrated rebels

According to Cairns: "children are pliable in that they are flexible and easily manipulated and controlled. Young children are controllable through terror and brutality, a point not lost on older, stronger, and more cunning commanders. Through violence or threat of violence, young children can be trained to obey commands that many adults would contest or find ways around." ${ }^{49}$
One of the LRA commanders commented in an interview said: "It was easy to make the newly abducted children participate with us. We taught them to become loyal and do what we said. They listened. This was difficult with grown-ups; we could not change their minds easily. They were always thinking about going home to their families. It was much easier to make the children become good, integrated rebels." ${ }^{50}$

From the rebel group's perspective, children who do not become good fighters are easily disposed of since they can be sent to a raid against other groups. In this sense, they consider child soldiers very expendable. ${ }^{51}$

Technological advances have also enabled children to participate as weapons can be lighter in weight and certain weapons can be easier for children to manage than for adults. ${ }^{52}$ The trend of fighting conflicts in urban areas has spread and it can be argued that it might even be beneficial for children to learn how to fight and to defend themselves as they are increasingly more likely to be victims of conflicts whether they are bystanders or perpetrators. For this reason, it can be justified to teach children how to use weaponry. ${ }^{53}$ However, this view ignores the fundamental issue of whether children are actually mature enough to volunteer to fight. ${ }^{54}$

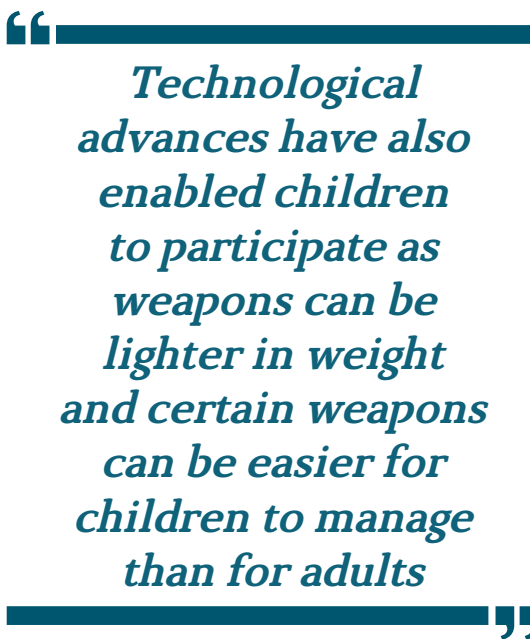

Especially in Northern Africa, the rebel groups take advantage of children's belief of manhood. Many of the tribal cultures, such as the Acholi, have rites for boys to achieve manhood. The armed groups copy these rituals and create their own versions that are used as initiations. Many of the initiation rituals include killing a family member or executing a prisoner, sometimes even drinking the blood of the victim after the act. ${ }^{55}$ The chil-

48 J McMahan 'Innocence, Self-Defence and Killing in War' (1994) Basil Blackwell Inc.

49 E Cairns 'Children and Political Violence' (1996). Cambridge, Blackwell Publishing.

50 L Vermeij 'Children of Rebellion. Socialisation of Child Soldiers within the Lord's Resistance Army'. MA Thesis, University of Oslo (2009).

51 UNICEF 'Report for the Children of Sierra Leone' (4/6-06-2001) Sierra Leone Truth and Reconciliation Commission https://www. unicef.org/emerg/files/SierraLeone-TRCReport.pdf (accessed 15-04-2018).

52 M Orkin 'Fighting for children but not letting them fight' (2002) UCL Juris. Rev.

53 M Kirollos, C Anning, G K Fylkesnes \& J Denselow ‘The war on children' (2018) Save the Children https://www.savethechildren. org/content/dam/usa/reports/advocacy/war-on-children-report-us.PDF (accessed 15-04-208).

54 M Orkin 'Fighting for children but not letting them fight' (2002) UCL Juris. Rev.

55 R N Souris 'Child soldiering on trial: an interdisciplinary analysis of responsibility in the Lord's Resistance Army' (2017) 316 Int. J.L.C. 
dren commit these acts in the fear for their lives; being a victim makes you a perpetrator.

\section{Methods of reintegrating children back into society}

Children are also in danger of being re-recruited if there are no mechanisms in place to support them and to reintegrate them into the society. Unaccompanied refugee children are exposed to the same risk.
Being a member of the rebel group is easier for many former child soldiers than seeking income elsewhere which is also why some children volunteer. ${ }^{56}$ Further, rebel groups, such as the LRA, are known to mutilate their soldiers' faces upon recruitment which makes it even harder for the children to be released from the stigma they carry. ${ }^{57}$ Article 39 of the CRC, imposes this duty to reintegrate and rehabilitate children to the states who are to take all appropriate measures to aid in the recovery of the child. ${ }^{58}$
G

Article 39 of the
CRC, imposes this
duty to reintegrate
and rehabilitate
children to the
states who are to
take all appropriate
measures to aid in
the recovery of the
child

The Truth and Reconciliation Commission (the Commission) was established in Sierra Le-

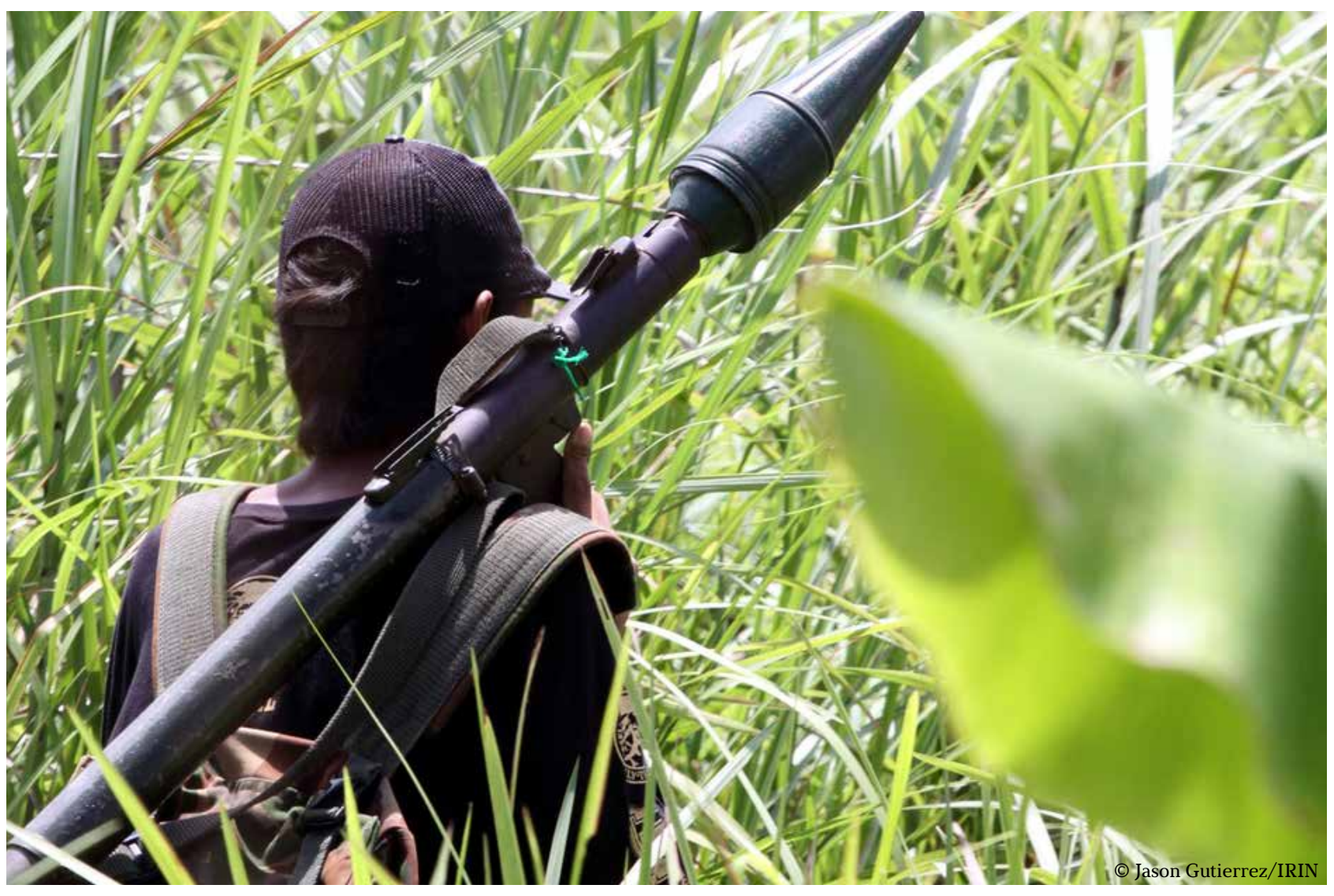

56 Anonymous 'Child Soldiers Global Report 2008: Coalition to Stop the Use of Child Soldiers' (20 May 2008) Human Rights Watch. https://www.hrw.org/legacy/pub/2008/children/Child Soldiers Global Report Summary.pdf (accessed 15-04-2018).

57 R N Souris 'Child soldiering on trial: an interdisciplinary analysis of responsibility in the Lord's Resistance Army' (2017) 316 Int. J.L.C.

58 Article 39. 
one in 2000 with the help of UNICEF and other international human rights organisations. Together they drafted a report of recommendations on what should be done in order to rehabilitate children in post-conflict. The SCSL decided that it would not hold children responsible for war crimes and established the Commission in order to break the cycle of violence and to re-establish the faith in the rule of law. The Commission, with the input from the children, recommended that the children should be placed in foster families where they could not be found; that the children should return to schools as soon as possible and receive both psychological and physical help as many of them were recovering from permanent damage and drug addiction. The Commission held it important that they gathered the facts of the conflict and the role of the children in order to assist the society to understand what the children had gone through and to raise awareness on the issue. The Commission provided the children with immunity for all their acts. This took away the shame the children were experiencing and allowed the community to help them in their recovery. ${ }^{59}$

\section{Actions to be taken to improve enforcement and prevent recruitment}

It seems more effective to try and solve the issue of recruitment at its root and prevent it from taking place. Instead of addressing the issues related to child soldiers individually, with several bodies of international law, it would be beneficial to combine the legal and the humanitarian efforts and create a body to govern over all four aspects of the issue: prevention of recruitment, enforcement of the law, rehabilitation and reintegration of child soldiers. The creation of the Cape Town Principles shows that states are aware of the issues related to the international legal framework governing the issues of child recruitment.

The first step towards decreasing the number of child soldiers and the rehabilitation of former child soldiers is to create consistency in the international law governing the issue. There needs to be a clear universal definition for child soldiers, for example, the definition from Cape Town Principles, and the international law rule that non-state armed groups cannot recruit persons under the age of 18 should be extended to apply to state armed groups as well. Further, the possibility of persons under the age of 18 to volunteer should be abolished due to the abuse of this rule.

\section{G \\ The creation of the Cape Town Principles shows that states are aware of the issues related to the international legal framework governing the issues of child recruitment}

At the moment, the threat of prosecution by the ICC is one of the most powerful tools that the international community has against the recruiters of children and it is vital that the ICC sets precedents that discourage armed groups from recruiting persons under the age of 18 . The international criminal tribunals, such as the International Criminal Tribunal for the Former Yugoslavia (ICTY), have taken the view that regulations applicable to international armed conflicts should also be applicable for non-international armed conflicts. ${ }^{60}$ As the non-state armed groups are unable to become treaty members, it is vital to establish customary international law rules that apply to everyone equally.

59 UNICEF 'Report for the Children of Sierra Leone' (4/6-06-2001) Sierra Leone Truth and Reconciliation Commission https://www. unicef.org/emerg/files/SierraLeone-TRCReport.pdf (accessed 15-04-2018).

60 Prosecutor v. Dusko Tadic 15 July 1999 International Criminal Tribunal for the former Yugoslavia (ICTY) IT-94-1-A 


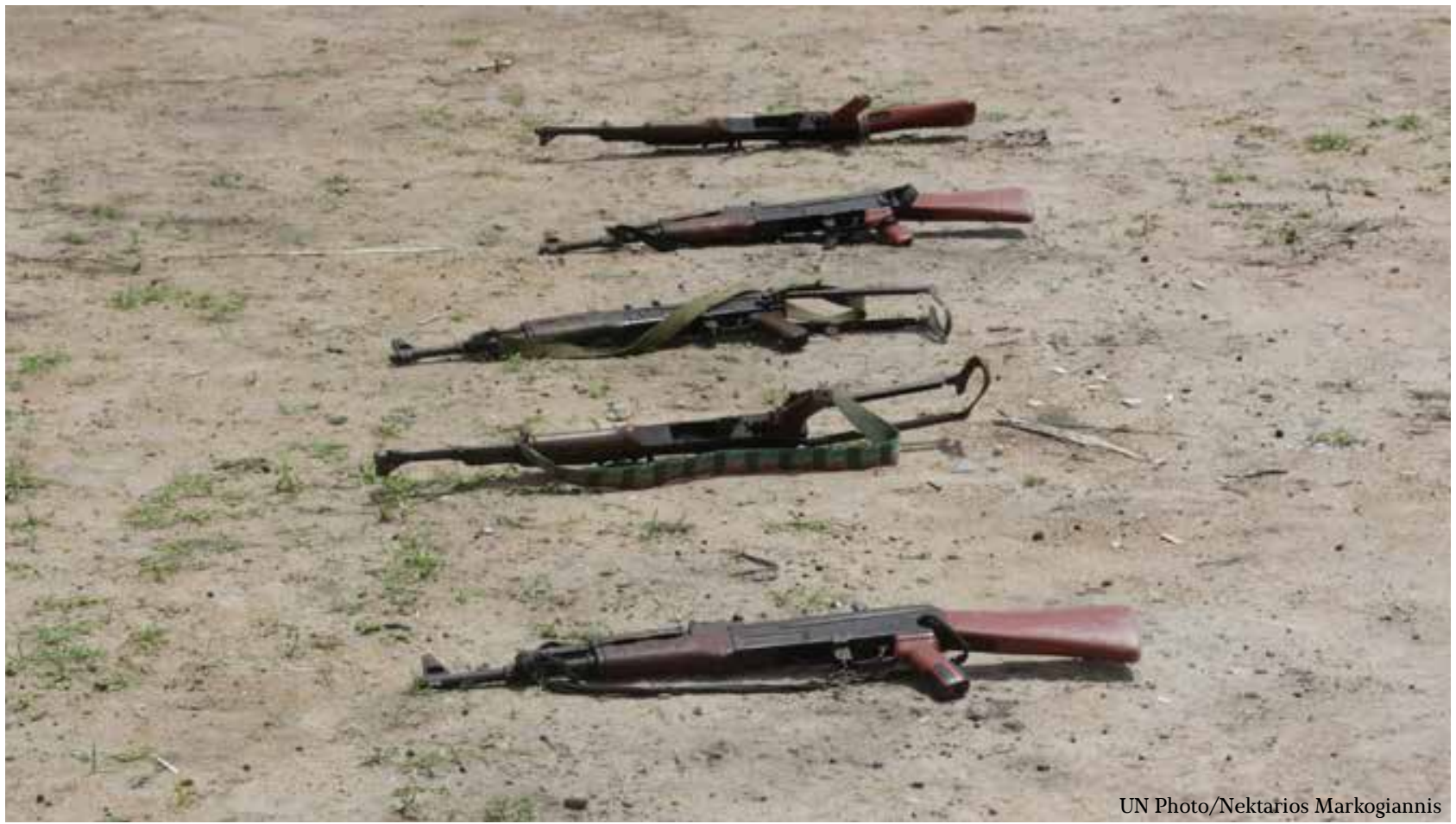

Once the international legal framework is consistent, it is important for the international community to put pressure on states to fully implement and enforce of the OPAC by abolishing contradicting domestic laws, strengthening domestic justice systems and holding the recruiters accountable. States must create mechanisms to prevent non-state armed groups from recruiting children. They must ratify and implement the Rome Statute and cooperate with the ICC in order to put pressure on the armed groups to abide the international humanitarian law.
The UN has reaffirmed the crucial role of child protection advisers in peacekeeping missions and is continuously ensuring that they are assessed and able to provide children with the best possible protection. The UN recognises that one of the main issues after the children have been demilitarised is reintegrating them in their families and has established programmes to assist through education, job training and family counselling. This work starts by securing adequate funding for child protection services combined with UN peacekeeping missions. ${ }^{61}$ In 2007, the UN Secretary-Gen- eral published a 'list of shame' which consisted of the names of persons responsible for recruiting and using children. This was a successful tool for demobilisation as it immediately led to the release of hundreds of children from several armed groups. ${ }^{62}$

Child soldier recruitment can be fought domestically by spreading awareness of the issue, lifting children from poverty and providing them with education. This would decrease voluntary recruitment and provide children with a safeguard from being coerced into armed forces. States should improve their

61 UN 'Issuing Presidential Statement, Security Council Expresses Deep Concern over Scale, Severity of Violations against Children in Armed Conflict' (31-10-2017). https://www.un.org/press/en/2017/sc13050.doc.htm (accessed 15-04-2018).

62 J McKnight 'Child soldiers in Africa: a global approach to human rights protection, enforcement and post-conflict reintegration' (2010) A.J.I.C.L. 
birth registration mechanisms in order to ensure that age limits are truly applied. It is important to establish peace talks with non-state armed groups and demobilise children from these groups. This would create a necessary customary international law practise to support the existing legal framework.

G6

\section{The UN recognises that one of the main issues after the children have been demilitarised is reintegrating them in their families}

The resources should be on the rehabilitation of child soldiers where possible and the community should work together towards ensuring that the children will receive the childhood they were taken from before. There are many strategies in place to rehabilitate and reintegrate children into society once they have been demobilised. These multi-national projects are called DDRs for disarmament, demobilisation and reintegration. DDR programmes have generally been reserved for children who have fought in conflicts but such programmes should be available for all children whether they have been directly or indirectly involved in the hostilities. Many of the children feel ashamed and impure for the acts that they have committed and have been shunned by their societies. This is why it is important to heal the children as both victims and as perpetrators. A successful way to address this has been religious and tribal purification rituals meant to provide the former child soldiers with a fresh start in society. ${ }^{63}$

There is an argument to be made that no law has managed to prevent wars, merely to change their nature and if effective measures are established to prevent armed groups from recruiting children, they will simply move onto another strategy such as autonomous weapons or robotic weapons which could cause even more destruction that the currently used arsenals.

\section{The Author}

Mira Luoma is information officer and humanitarian worker at the Finnish Refugee Council in Kampala, (Uganda).

Ms. Luoma participated in the UNICRI specialised training course in 2017 followed by an internship at the International Criminal Tribunal for the former Yugoslavia and the United Nations Mechanism for International Criminal Tribunals as a senior legal intern at the Registry.

Ms. Luoma completed her LL.M at Stellenbosch University in Cape Town (South Africa), with a cum laude and a thesis on the criminal responsibility of child soldiers.

63 M Denov 'Girl Soldiers and Human Rights: Lessons from Angola, Mozambique, Sierra Leone and Northern Uganda. The International Journal of Human Rights' (12-2008) 12 The International Journal of Human Rights 813-836. 


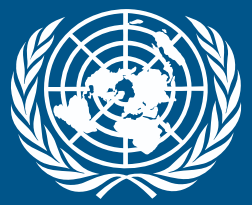

\section{THE CYCLE OF ENVIRONMENTAL CRIMES}
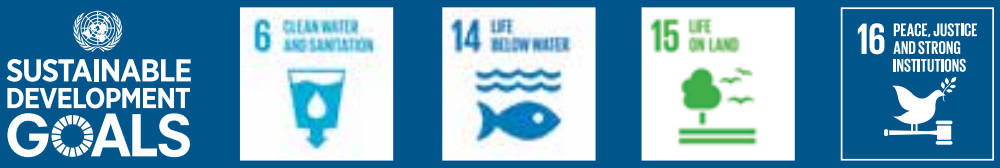

\begin{tabular}{|c|c|c|c|c|}
\hline $\begin{array}{l}\text { DEPOSIT THE } \\
\text { REVENUES IN AN } \\
\text { OFFSHORE BANK } \\
\text { ACCOUNT }\end{array}$ & $\begin{array}{l}\text { USE HIGH PROFITS TO } \\
\text { FUEL CONFLICTS }\end{array}$ & $\begin{array}{l}\text { YOU SELL YOUR } \\
\text { RESERVE OF } \\
\text { CHEMICALS TO } \\
\text { TERRORIST GROUPS } \\
\end{array}$ & $\begin{array}{l}\text { TERRORISTS BUILD } \\
\text { DIRTY BOMBS WITH } \\
\text { YOUR CHEMICALS AND } \\
\text { USE THEM AGAINST } \\
\text { POPULATION } \\
\end{array}$ & $\begin{array}{l}\text { BURN WASTE } \\
\text { BRINGING } \\
\text { POLLUTED AIR TO } \\
\text { BIG CITIES }\end{array}$ \\
\hline $\begin{array}{l}\approx \approx \widetilde{\approx} \\
\approx \\
\text { DUMPED } \\
\text { CHEMICALS } \\
\text { CONTAMINATE THE } \\
\text { MARINE ECOSYSTEM } \\
\text { AND REACH THE } \\
\text { COAST WHERE } \\
\text { CHILDREN SWIM }\end{array}$ & & & & $\underbrace{\text { d\% }}_{\substack{\text { DUMP WASTE IN } \\
\text { A CULTIIATED } \\
\text { AREA }}}$ \\
\hline $\begin{array}{l}\text { THE GROUP DUMPS } \\
\text { ILLEGAL } \\
\text { CHEMICALS, } \\
\text { POLLUES SEA AND } \\
\text { CONTAMINATES } \\
\text { WATER SUPPLY }\end{array}$ & & & & $\begin{array}{l}\text { FAMILIES EAT } \\
\text { CONTAMINATED } \\
\text { FOOD AND } \\
\text { BREATHE } \\
\text { POLLUTED AIR }\end{array}$ \\
\hline 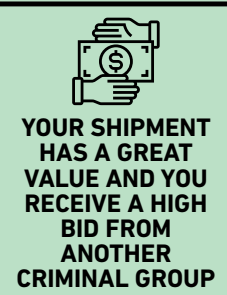 & & & & $\begin{array}{l}\text { TRADE ILLEGAL } \\
\text { PROFITS WITH } \\
\text { DRUGS, } \\
\text { COUNTERFEIT } \\
\text { GOODS AND } \\
\text { WEAPONS }\end{array}$ \\
\hline $\begin{array}{l}\text { 血圆 } \\
\text { YOU } \\
\text { SUCCESSFULLY } \\
\text { SMUGGLED } \\
\text { THROUGH BORDER } \\
\text { CONTROL! YOU } \\
\text { AVOID JAIL TIME }\end{array}$ & $\begin{array}{l}\text { BRIBE CUSTOMS } \\
\text { OFFCERS AND FORGE } \\
\text { TRANSPORTATION } \\
\text { DOCUMENTS }\end{array}$ & $\begin{array}{l}\text { ESTABLISH } \\
\text { ERANSNATIONAL } \\
\text { ORGANIIED CRAME } \\
\text { IETWORKS TO MANAGE } \\
\text { TRANSPORTATION }\end{array}$ & $\begin{array}{l}\text { FIX PUBLIC BIDDINGS TO } \\
\text { MANAGE THE DISPOSAL } \\
\text { OF CHEMICALS AND } \\
\text { WASTE }\end{array}$ & $\begin{array}{l}\text { COLLECT DIRTY } \\
\text { MONEY AS YOU } \\
\text { PASS GO }\end{array}$ \\
\hline
\end{tabular}

Environmental crime represents a growing danger for development, global stability and security.

Since 1991, UNICRI has contributed through research, awareness raising and capacity-building actions. Led by vast financial gains and facilitated by a low risk of detection and scarce conviction rates, criminal networks, acting across borders, have favoured the expansion of environmental crimes in recent years, affecting human rights and diverting resources that would otherwise be allocated to public services and development. 


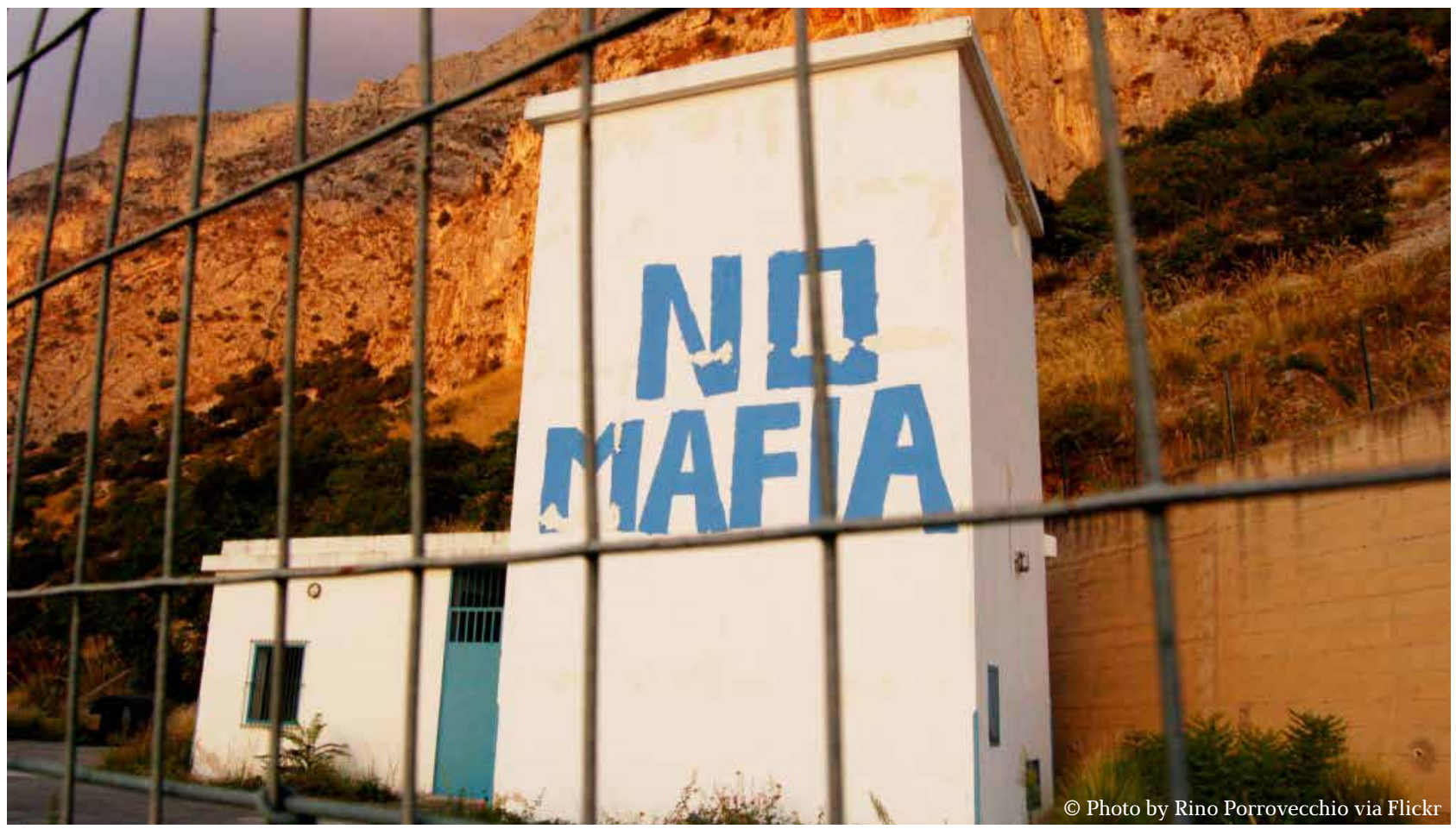

We must keep in mind that our family had always lived in Kalsa, an historic district of Palermo, in which, as Giovanni himself repeatedly said, many mobsters lived. It was precisely in such a context that Giovanni grew up, his character developed, and he began to meet other kids playing soccer in the parish camp. For example, during his adolescence and in that neighbourhood, he met Paolo Borsellino for the first time, as well as other kids destined to become famous Mafia personalities of the future, such as the boss Tommaso Spadaro, whom he met at a ping-pong tournament organized in an oratory. These circumstances allowed him to come into full contact with the minds of many of them and to fully understand their attitudes and characteristics. Only a person who grew up in such a context could have had the tools and the flexibility to understand the real dimensions of the Mafia phenomenon. Only a person gifted with his own intuition could have understood the fundamental role that could have been played by a broader judicial cooperation.

\section{GG \\ Only a person gifted with his own intuition could have understood the fundamental role that could have been played by a broader judicial cooperation}

What were the pillars of Giovanni Falcone's thinking on justice and international cooperation?

It all began when the prosecutor Costa was murdered at the beginning of the 80s. The judge Chinnici wanted to set up a working group with the collaboration of Giovanni, Paolo Borsellino, and Giuseppe Di Lello. This project was then developed and consolidated by Antonino Caponnetto, who in 1984 officially announced the establishment of a pool of magistrates, including Leonardo Guarnotta. The pool intended to coordinate the investigations and to provide an overview of the Mafia phenomenon with the aim of eradicating it and returning Sicily to its honest citizens. A de- 


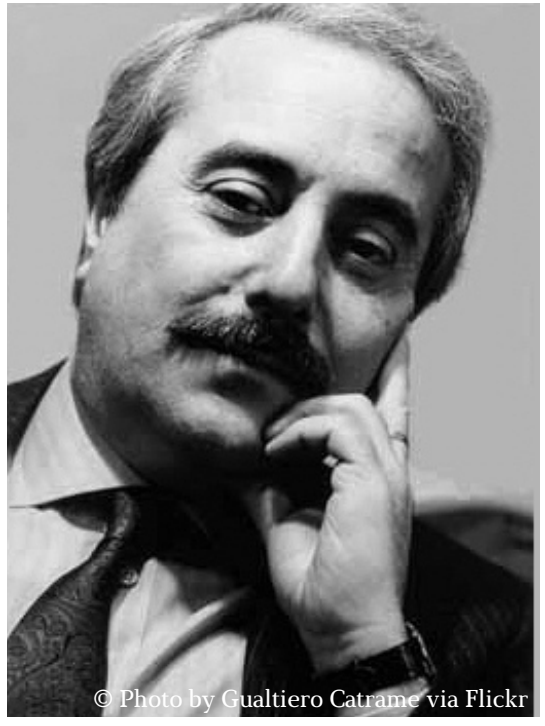

cisive moment in the creation of the c.d. "Falcone method" is embodied in the Spatola process, in which Giovanni, thanks to his investigations, succeeded in convicting 75 members of the Spatula/Gambino /Inzerillo gang. It was thanks to this success that the Falcone Method was universally recognized as an innovative and revolutionary investigative technique based on 3 pillars: observing the phenomenon from above and then analysing it in detail like in a magnifying glass; identifying, tracking and dismantling the economic relations between the criminal organizations; and making use of the collaboration of the "pentiti" (state'sevidence figures) as a key tool to understand the mafia dynamics. A collaboration was born with the US DEA and the FBI in those years precisely thanks to this investigative technique. This collaboration brought great results, allowing drug trafficking to be defeated even overseas.
Was there ever a moment in your brother's life in which he thought that the Mafia could never be defeated?

No, he never thought that. On the contrary, my brother Giovanni claimed that the Mafia would certainly be defeated. The Mafia has not always existed; it is a human phenomenon, and like all human phenomena it has had a beginning and it will have an end. If anything, it must be said that Giovanni, during his work against the Mafia as a magistrate, encountered numerous obstacles and enemies which tried to discredit him and put his work in a bad light, criticizing his innovative methods. These attacks made him realize that this phenomenon was extremely rooted, complex and intertwined. Achieving the final goal would have not been simple at all. But despite this, his profound sense of duty and loyalty and love for his city and for the institutions pushed him to never give up on his goal.

\section{4 \\ The Mafia has not always existed; it is a human phenomenon, and like all human phenomena it has had a beginning and it will have an end

You are the head of the Giovanni and Francesca Falcone
Foundation. How does the Foundation carry on the legacy of your brother?

This is a question that I am often asked and to which I always reply with a phrase from Giovanni which I consider his moral testament. "Everyone must do his or her duty to the end and play his or her part, big or small, at the cost of having to endure whatever sacrifice".

From this point of view, the Falcone Foundation carries out activities in the fields of education and cultural promotion. I would say that we are dealing with "counter-culture" and teaching young people what the Mafia is and how despicable its activities and methods of action are. Therefore, we have been working on projects for over 26 years together with thousands of Italian schools explaining to students who Giovanni was and why he died, but also providing them with the tools to take sides, support freedom and take a stand against the mafia, even when it offers attractive prospects.

We organize a competition every year, in collaboration with the Italian Ministry of Education, Universities and Research (MIUR), in which hundreds of schools from every corner of the country participate. Thanks to this initiative, we can raise awareness in the schools and tell stories that normally remain outside of 


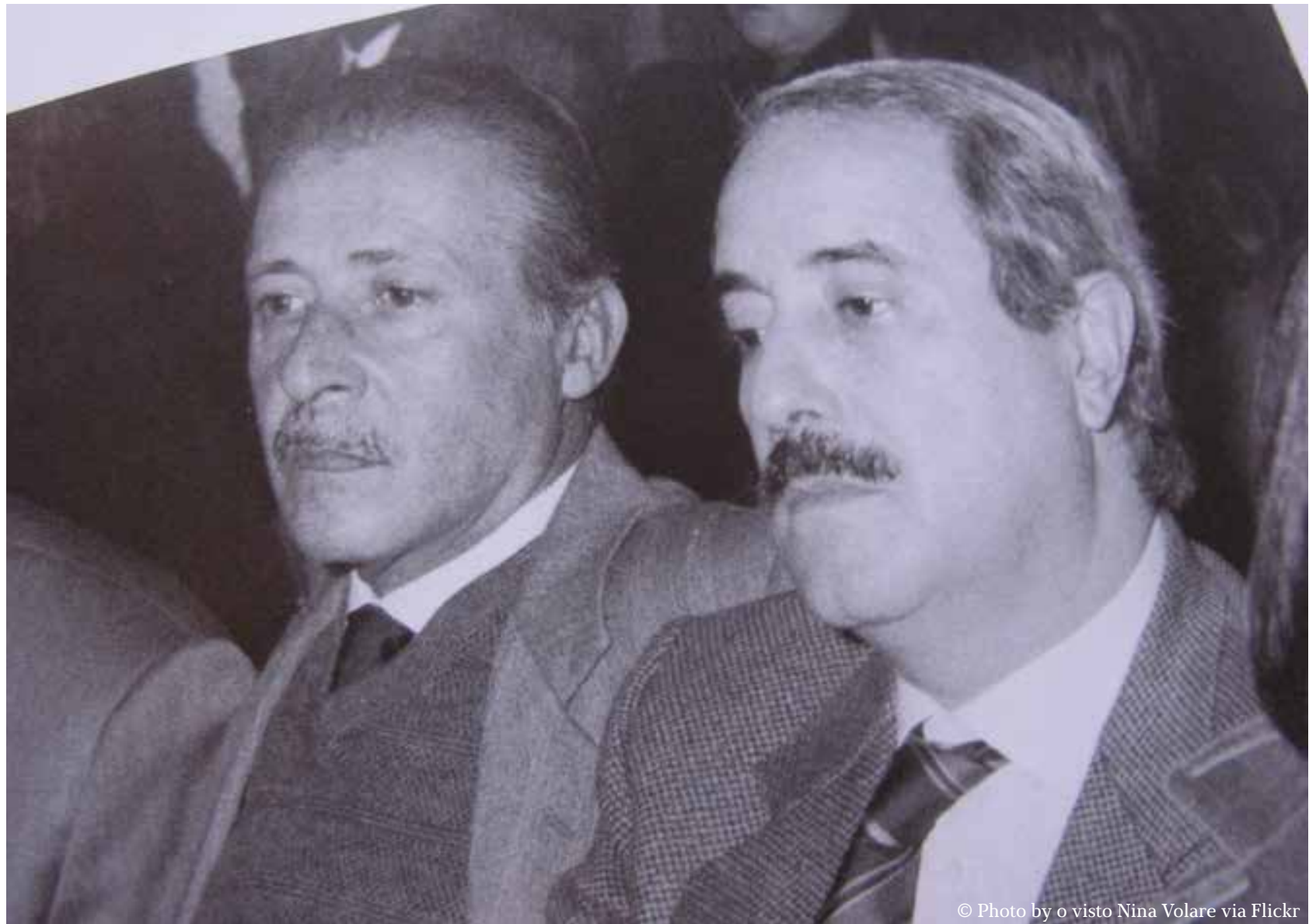

the classrooms. The event culminates in the so-called "Ship of Legality": about 1,500 Italian students travel to Palermo every 23 May to celebrate the memory of Giovanni and of the other great men and women who lost their lives fighting for the common good.

\section{GC}

Everyone must do his or her duty to the end and play his or her part, big or small, at the cost of having to endure whatever sacrifice
The new generations have not lived through the most violent years of the fight against organized crime, the bloody years of massacres of Capaci and via D'Amelio. Was that mafia more dangerous than the contemporary one? You have defined the present organized crime as a "silent" phenomenon.

Today the Mafia, a bit like the whole world due to globalization, is certainly changed; in a certain sense it has become more "bourgeois", infiltrating administrations, professions and economic and power centres in general. But we must not take the risk of believing that for these reasons it has become less dangerous and bloody. On the one hand, it is true that thanks to the strong suppressive measures carried out by the State with the means of law enforcement, the bloody seasons of mafia attacks have ended. On the other hand, some of the most horrible and offensive crimes for the whole community are committed today and are caused by organized crime. The Mafia and other organized crime networks are primary actors in the phenomena of the agromafias, the trafficking of human beings linked to the "caporalato" (illegal recruitment of workers), the trading 
of weapons and the patronage system which often influences the management of public resources.

Today, the Mafia makes less noise and you see it less, but this does not mitigate its danger and despicability. Kids must learn that they can find themselves dealing with the Mafia and its methods. They can be confronted by people without "coppola" and "lupara" (the traditional Sicilian hat and the sawn-off shotgun associated with the Mafia) and with degrees and ties, but they need to behave accordingly, rebelling against its dishonest logic.

What are the difficulties encountered by the Foundation in promoting legality?

Promoting the values of justice and legality is certainly not a simple activity; even today, after so many years, we encounter challenges, especially in the most neglected areas of the country and specifically in the city suburbs, where, at times, it is difficult to communicate the very concept of rule of law. However, I would like to stress that, little by little, thanks also to education and awareness activities, something is changing, and we have a greater perception of the importance of respecting fellow citizens and legality.

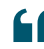

Today, the Mafia makes less noise and you see it less, but this does not mitigate its danger and despicability

\section{g}

You have decided to carry on a painful legacy, but yours is a mission that can change the future of many. What has been the most beautiful moment of the Foundation in which you have been able to witness the results of its work?

The moral legacy left by Giovanni is very painful and carrying on his ideas is a constant and tiring activity, but I must admit that it also brings many happy moments. During my frequent visits to Italian schools, I talked with young people and I heard their pertinent and interesting questions. For me, having the opportunity to help them in their personal growth and training is a reason for great pride and satisfaction. But the greatest joy is undoubtedly seeing thousands of children and young people with their eyes full of enthusiasm, promising to always carry the ideas of Giovanni Falcone with them. They are the hope and the future of Italy and seeing them so united every 23 May during the parade in the streets of Palermo, gathering beneath the Falcone Tree to show which side they have decided to join, is really an immense success for our land.

The Goal 16 of the United Nations 2030 Agenda for Sustainable Development focuses on promoting peaceful and inclusive societies, justice and strong institutions. Member States recognize that there can be no sustainable development without peace and no peace without sustainable development. What is the advantage that organized crime gains from the weakness of the judicial systems?

Violence and insecurity are general problems that are related to the general well-being and that all countries experience; for this reason, we should be confident about the achievement of Goal 16 of the Post2015 Development Agenda. The simple fact that we talk about it and that we have also reached an agreement on important issues such as justice, corruption, fundamental freedoms, and peace is a good step forward in my view. Moreover, it is exactly where institutions are absent that the seeds of mafias can germinate. If people are not offered the prospect of hope and personal development, it is easier for them to be seduced by the sirens of crime, which can offer them valuable and easy rewards in return for commit- 
ting terrible acts. Because of this, I believe that creating a mechanism to prevent violence by fighting crime and terrorism at all levels means making enormous progress towards the achievement of peace.

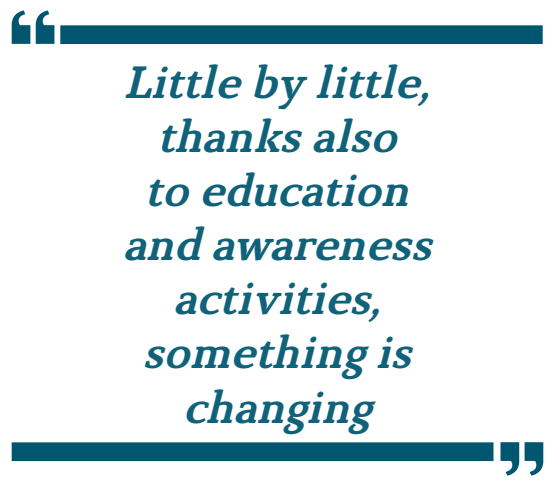

What is the relationship between the lack of development and growth opportunities, and crime?

Well, it is a closely connected relationship, as I said before. When a State is not able to offer the prospect of hope to its citizens it provides an "assist" to organized crime and therefore mafia. I would say that the lack of opportunities and economic development contribute to generating a feeling of aversion towards the institutions, in which they are considered guilty of not taking an interest in the wellbeing of citizens. The Mafia was born by taking advantage of a similar mechanism of hostility towards the State. The State did not care for its citizens, and the Mafia insert- ed itself in this "vulnus", offering, in its opinion, better living conditions. Yet, history teaches us that none of the people joining criminal organizations have seen their living conditions improved; on the contrary, all of them have only found themselves constantly having to execute orders, commit horrendous crimes, and worry about their own affiliates and the police.

But we must not make the mistake of thinking that the Mafia is exclusively linked to the poverty, or to Southern Italy. There are so many elements in such a complex phenomenon and it is impossible to find a single cause. In addition to economic hardship, in fact, there are other elements to consider, for example, familial affection, the desire to exercise power or even an inclination for violence and the desire for revenge.

What is the role of education in fighting the Mafia and other organized crime networks?

As Gesualdo Bufalino said, "The Mafia will be defeated by an army of elementary teachers". Crackdowns by law enforcement certainly will not be enough if they are not supported with educational and cultural activities. These activities will wipe out the fertile ground in which the Mafia thrives. In fact, school plays a decisive role and should aim to create a society that repudiates the Mafia's negative values, such as its "omertà" or indifference, until they are completely eradicated.

Education has a duty to promote the culture of legality and explain to young people that respecting others is beautiful and makes you feel good while worshipping false myths can lead to terrible consequences.

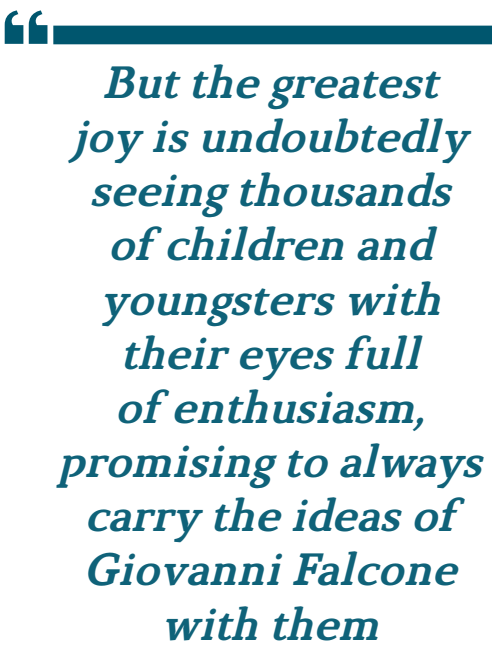

But the greatest joy is undoubtedly seeing thousands of children and youngsters with their eyes full of enthusiasm, promising to always carry the ideas of Giovanni Falcone with them

What is the message that the Foundation would like to send to young people all over the world?

The same thing that Giovanni taught us, and the same thing we tell the students we meet: never lower your head, be brave and always fulfil your commitments until the end. The future is all in their hands. 


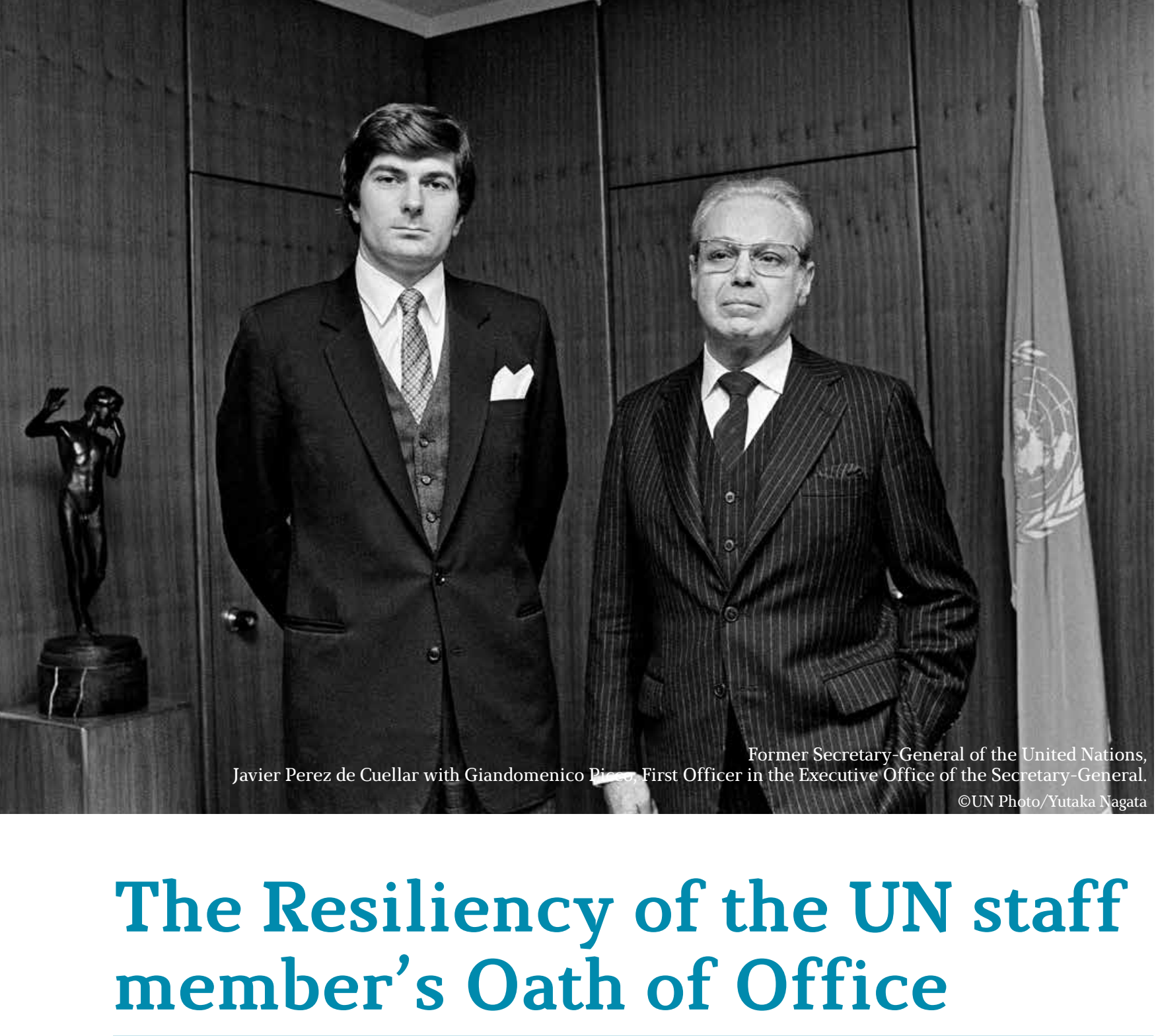

by Andrea Angeli

This is not the first time that I have been asked how we can succeed in advancing the values of the United Nations in the most critical situations. It is a good question. Even those who have served in peace missions for over thirty years cannot provide a single answer to this question.

In retrospect, the most striking example that implied the spirit of service and self-denial was recorded at the beginning of the 90s, during the grueling negotiations for the liberation of Western hostages in Lebanon.

The operation above required an extraordinary personal commitment from the "United Nations chief hostage negotiator" Giandomenico Picco, who conducted it in the utmost secrecy. For 18 long months he exposed himself to considerable risks as kidnapped persons were freed in a trickle. The envoy of the Archbishop of Canterbury, Terry Waite, prior to Picco, was kidnapped at that time. A mediation on thin ice and full of unknowns that for Giandomenico Picco involved numerous trips blindfolded and crouched in the trunk to reach secret locations in Beirut in the middle of the night. 


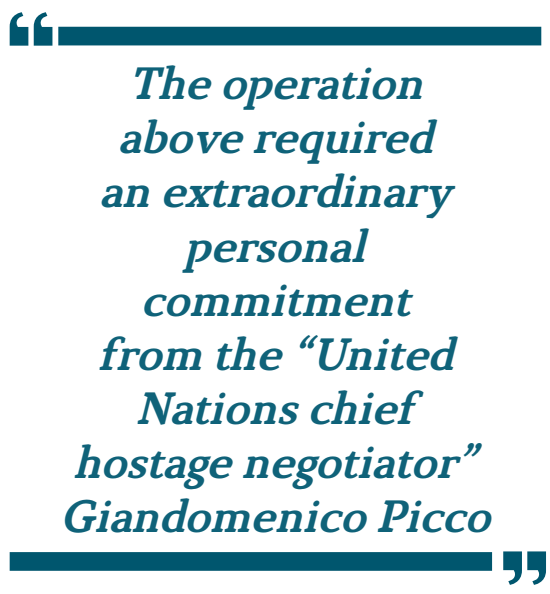

It has been said that Giandomenico Picco, being a protagonist of other annals of UN history - from the Iran-Iraq ceasefire to the Soviet withdrawal from Afghanistan - had a pact with the Secretary-General Pérez de Cuéllar. This alleged pact involved not informing the Secretary-General of high-risk situations, with an aim to avoid obliging him to ask Picco to abort mission.

An absolute trusting relationship between Pérez de Cuéllar and his right-hand man from Friuli (a region of Italy) - not always easy to develop - was key for these unthinkable operations. However, we are referring to facts that happened 30 years ago, when the undoubted respect for an international official, especially an official of the UN, was considerable. This brought greater freedom of movement and the power of initiative.

Many other lesser-known UN officials have made a difference in what are often called forgotten crises. Naming them and de- scribing their accomplishments would require a lot of time.

I joined the United Nations Protection Force (UNPROFOR) in the early 90s in Bosnia. UNPROFOR was initially an interim arrangement, aiming to create the conditions of peace and security for the negotiation of an overall settlement of the Yugoslav crisis.

During that time, I remembered how even a young official could decide to go and assist (and even save) people in difficulty at his/her own risk and guided only by conscience. In light of there being many needy people in Sarajevo under siege and in many other parts of the country, it is debatable if all the members of the mission have always given their best effort.

\section{G4}

Many other lesserknown UN officials have made a difference in what are often called forgotten crises

The case for me, however, has not always been akin to that of other UN members. How many times in retrospect did we recriminate idle, weak behaviors? The UN official, although often being imagined as a protector of vulnerable groups and associated to the blue hel- mets, is basically an employee, a bureaucrat, an international bureaucrat. In short, still a bureaucrat. $\mathrm{He} /$ she is the one who did not need to take his/her life at risk at every step. $\mathrm{He} / \mathrm{she}$ is the one who must respect the rules of the organization and its hierarchical structure.

\section{Ǵ⿴囗十 \\ How many times in retrospect did we recriminate idle, weak behaviors?}

A bold move, though heartfelt, can sometimes seriously embarrass the Organization and other relevant ongoing initiatives. Therefore, it is understandable that, in certain circumstances, a UN staff member must operate with caution, a behavior that may seem shy, if not apathetic. Hence, it could happen that a UN official may end up discontenting all. The journalist Andrea Nicastro rightly defined a UN staff member as "A peacekeeper: always between two fires" years ago.

Having said all this, which results from decades spent in crisis areas; a fundamental point remains for the UN staff member: the Oath of Office that reads as follows:

"I solemnly declare and promise to exercise in all loyalty, discretion and conscience the functions entrusted to me as 

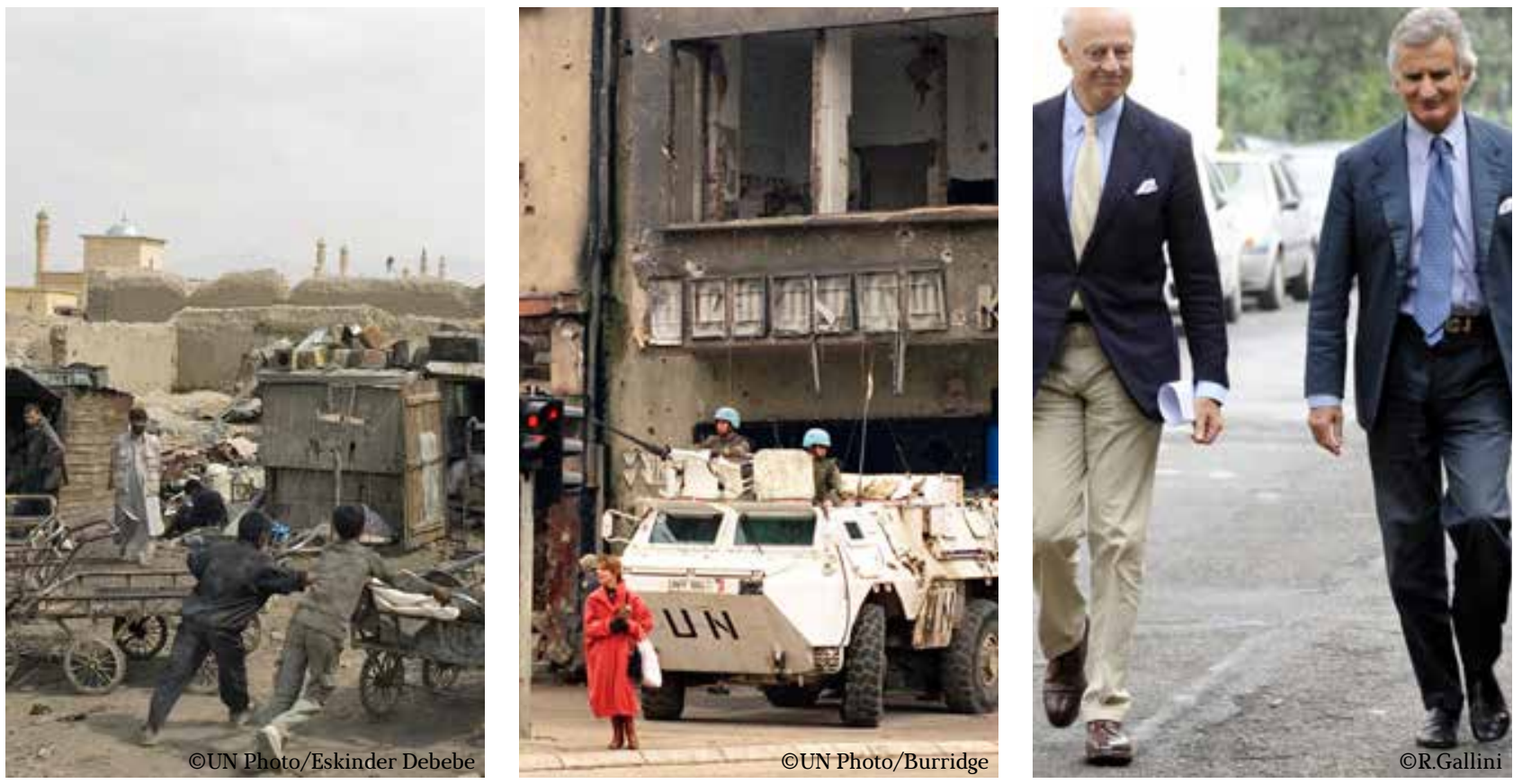

1) Two young boys push a cart full of scrap metal into a collection site in Kabul, Afghanistan. 2) A United Nations armoured personnel carrier on patrol in Sarajevo during the visit of Secretary-General Boutros Boutros-Ghali. 3) Rimini (Italy) 2012 - Andrea Angeli with Staffan de Mistura.

an international civil servant of the United Nations, to discharge these functions and regulate my conduct with the interests of the United Nations only in view, and not to seek or accept instructions in regard to the performance of my duties from any Government or other source external to the Organization". "This is the North Star that must always guide us through events and which does not allow for compromises.

I, like many others, probably did not always act as we should have or we could have, but certainly I never support any national strategies that are contrary to the UN guidelines and my conscience. The episodes of opposition with representatives of Member States (including representatives of my own country) were not lacking. I never regretted following the "UN Oath of Office" in conjunction with my judgment.

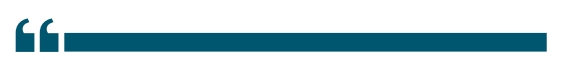

I solemnly declare and promise to exercise in all loyalty, discretion and conscience the functions entrusted to me as an international civil servant of the United Nations
In conclusion, I propose a few thoughts on the current reality. As what I have always said to young people leaving for a mission: "Be aware of the fact that everything is more difficult and even frustrating nowadays." The lack of respect for the United Nations flag along with the consequent risk of kidnappings or attacks have reduced room for maneuverability for those on the front lines. The UN, as well as other international organizations and many NGOs, has imposed very stringent measures regarding the movements of its operators. In addition, there are new technologies including mobile telephone, email, and social networks. All tools that un-

1 Status, basic rights and duties of United Nations staff members. ST/SGB/2016/9. 21 July 2016. 


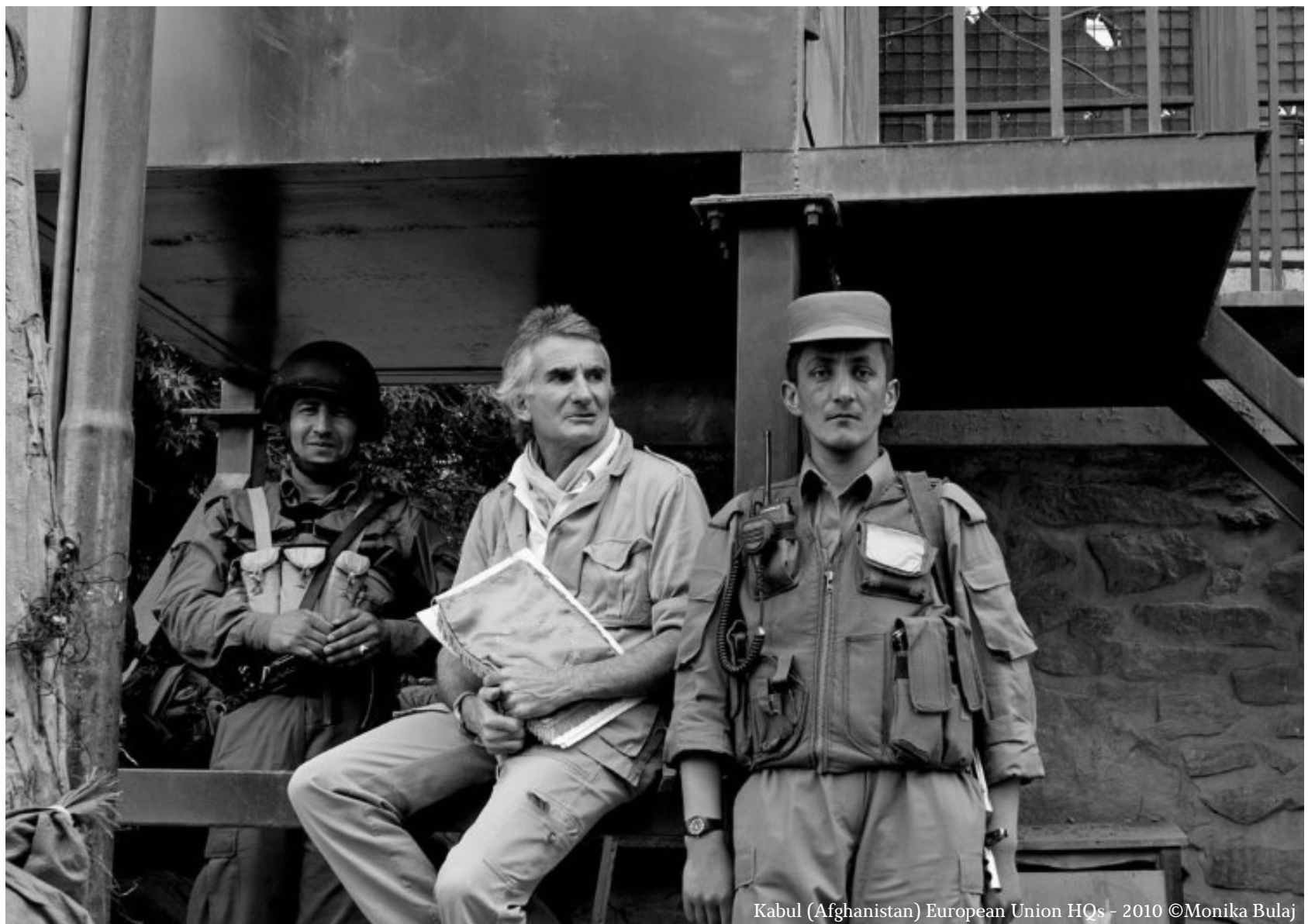

doubtedly increase the scope of a humanitarian operator. However, it is still a wishful thinking to believe that they can replace direct contacts with people in need. It happened to me in the last few years, too, and that's why I don't envy those who starts the profession now.

Can we therefore succeed today in advancing the values of the United Nations in the most difficult situations? It is possi- ble, although it will be substantially more difficult than before due to the aforementioned reasons. The universal values that has been fighting for over the centuries cannot fade.

\section{The Author}

Andrea Angeli joined the United Nations contingents in Namibia, Cambodia, East Timor and the Former Yugoslavia, where he served for fifteen years. He also worked for the United Nations in Santiago de Chile during the last phase of the military regime and served in Baghdad when Iraq was under Saddam Hussein. He worked in New York as Assistant to Bettino Craxi Special Envoy for the Foreign Debt. He was the spokesperson for the Organization for Security and Co-operation in Europe (OSCE) in Albania, for the Coalition Authority in Nassiriyah and for the European Union in Afghanistan. He was close associate of Staffan de Mistura, Undersecretary of State for Foreign Affairs in the Italian cabinet headed by Mario Monti. In 2014 he returned to Afghanistan as political adviser to the North Atlantic Treaty Organization (NATO) in Herat, a position which he later held in the Kfor mission of NATO in Pristina. He is currently working for the OSCE Office of the High Commissioner on National Minorities. 

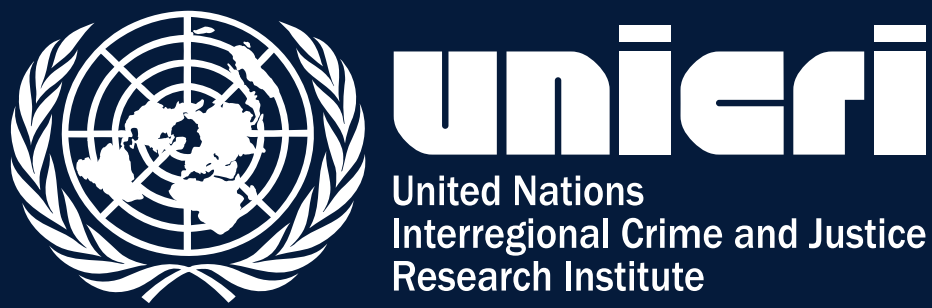

United Nations

Interregional Crime and Justice Research Institute

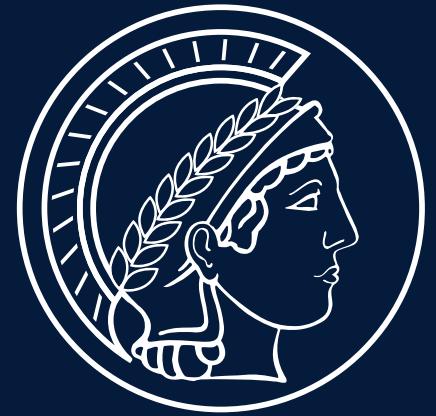

M AX - PLA NCK - GESELLSCHAFT

Max Planck Institute for Foreign and International Criminal Law

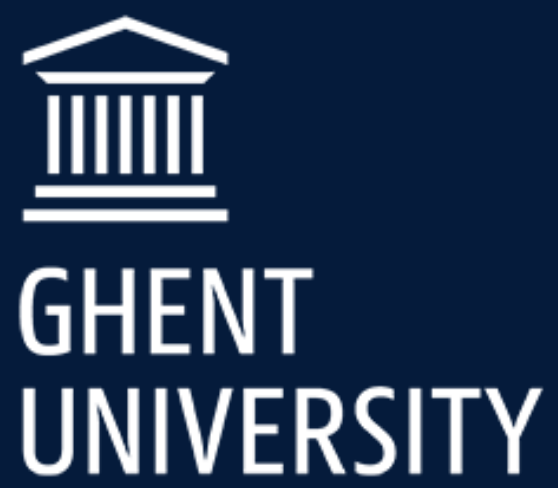

